NELSON CÁRDENAS OLIVIER

\title{
ANÁLISE DE FALHA DA CAMADA POLIMÉRICA EXTERNA DE CABOS UMBILICAIS
}

Exemplar Original: 2007

Exemplar Revisado: 2007

São Paulo 
NELSON CÁRDENAS OLIVIER

\title{
ANÁLISE DE FALHA DA CAMADA POLIMÉRICA EXTERNA DE CABOS UMBILICAIS
}

\author{
Tese apresentada à Escola \\ Politécnica da Universidade de São \\ Paulo para a obtenção do título de \\ Doutor em Engenharia
}

\author{
Área de concentração: \\ Engenharia Mecatrônica e Sistemas \\ Mecânicos \\ Orientador: \\ Prof. Titular Edison Gonçalves
}

Exemplar Original: 2007

Exemplar Revisado: 2007

São Paulo 
Este exemplar foi revisado e alterado em relação à versão original, sob responsabilidade única do autor e com a anuência de seu orientador.

São Paulo, de dezembro de 2007.

Assinatura do autor

Assinatura do orientador

FICHA CATALOGRÁFICA

Cárdenas Olivier, Nelson

Análise de falha da camada polimérica externa de cabos umbilicais / N. Cárdenas Olivier. -- ed.rev. -- São Paulo, 2007. $190 \mathrm{p}$.

Tese (Doutorado) - Escola Politécnica da Universidade de São Paulo. Departamento de Engenharia Mecatrônica e de Sistemas Mecânicos.

1.Imperfeições e falhas dos materiais 2.Polímeros (Materiais) 3.Cabos umbilicais 4.Fadiga dos materiais I.Universidade de São Paulo. Escola Politécnica. Departamento de Engenharia Mecatrônica e de Sistemas Mecânicos II.t. 


\section{AGRADECIMENTOS}

Ao professor Edison Gonçalves pela confiança depositada em mim desde o início, pela amizade, orientação e ajuda em todos os momentos.

Ao estimado amigo e professor Daniel Benitez Barrio pela amizade e ajuda, em grande medida por ele estou aqui.

À professora Izabel Fernanda Machado por suas críticas, sugestões e pelos ensinamentos.

Aos professores Miguel Angel Buelta Martinez, Carlos Alberto Nunes e Pedro Afonso de Oliveira Almeida por me permitirem participar nos seus projetos e tudo o ensinado.

Aos Doutores Wanderson Santana da Silva (Faculdade de Metalurgia EPUSP), Paula Ferreira Lépore (MFX), e Maria Cristina Farias More (Laboratório de Fenômenos Superficiais EPUSP). Ao Ing. IvanTessarolo e ao técnico Antonio "Juca" Coelho Jacomini (Laboratório de Estruturas e Materiais Estruturais EPUSP). Sem o auxilio deles tivera sido impossível todo o desenvolvimento experimental deste trabalho.

Aos colegas e ex-colegas do Centro de Estruturas Navais e Oceânicas da Universidade de São Paulo (CENO-USP), Dagne, Miguel Angel Garcia Dominguez, Valin, Miguel Angel Calle Gonzales, Gelson, Gomes, Miguel Jaimen Sandoval, Rodrigo, Anderson, Augusto, Gilberto, Laércio "o Tigrão", Antonio "Tonhão", Maria Luisa e Gustavo, pela amizade e a ajuda prestada.

Ao pessoal do Laboratório de Estruturas e Materiais Estruturais da USP (LEM-USP), Márcia, Zé, Ruy e Eduardo, pela colaboração na realização dos ensaios.

Aos amigos Liliane Magal, Andréa Martin e Elias Gomes pela ajuda prestada na revisão da redação e ortografia do texto da tese.

A todos meus amigos, em especial a aqueles que nos momentos mais difíceis sempre acreditaram e nos apoiaram Ariel Ruano, Oscar Mesa, Angel Gonzáles Rojas, Maria Aparecida Gonzáles, Mônica Arroyo, Vicente Eudes, Moustafa Hanzel Guillar, Regino, Flavia, Vilma Parmarola, Francisco Zaragoza, Patrícia Zineker, Julio C. Ceballo e Luis Buelta. Alguns nomes não estão aqui porque já foram mencionados anteriormente. 
A todos os funcionários da Universidade de São Paulo, especialmente ao pessoal do Coordenadoria de Assistência Social (COSEAS) destacando as assistentes sociais Maria de Fátima Moreira de Sá e lêda Reis que desde a chegada ao Brasil me atenderam com tanto carinho.

Ao Conselho Nacional de Pesquisa (CNPq) pela ajuda financeira.

Às instituições CENO-USP, LEM-USP, PETROBRAS e PROTENDE as quais fizeram possível a realização deste projeto.

A todas as pessoas e instituições que de uma forma ou outra tiveram a ver com o desenvolvimento deste trabalho.

\section{A TODOS MUITO OBRIGADO!}




\section{DEDICATÓRIA}

Ao bem mais prezado que me há dado a vida "MINHA FAMÍLIA" por tanto amor recebido durante todos estes anos:

Zenuna e Alfredo (meus pais)

A Jaque (minha esposa)

Mapy, Mirian, David e Alfred (meus irmãos)

Cosette, Sandrita, Alex, Davicito, Rances e Abelito (sobrinhos)

Tânia, Sandra e Raul (cunhados) 
Caminante, son tus huellas el camino y nada más. Caminante, no hay camino, se hace camino al andar. Al andar se hace camino y al volver la vista atrás. Se ve la senda que nunca se há de volver a pisar. Caminante, no hay camino sino estelas en la mar. Caminante no hay camino, se hace camino al andar. 


\section{SUMÁRIO}

$\begin{array}{lr}\text { LISTA DE FIGURAS } & 12 \\ \text { LISTA DE TABELAS } & 16 \\ \text { LISTA DE ABREVIATURAS } & 17 \\ \text { LISTA DE SÍMBOLOS } & 18 \\ \text { RESUMO } & 20 \\ \text { ABSTRACT } & 21 \\ 1 \text { INTRODUÇÃO } & 22\end{array}$

1.1 CARACTERÍSTICAS DOS CABOS UMBILICAIS E DE SUAS

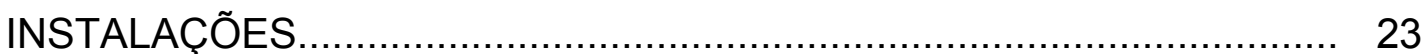

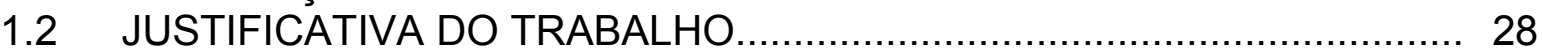

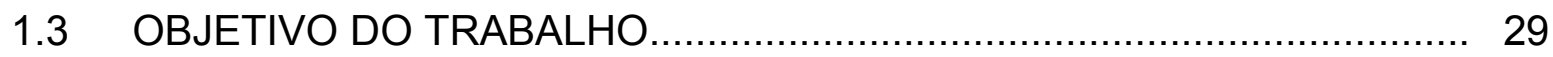

2 REVISÃO BIBLIOGRÁFICA ............................................... 31

2.1 MODOS DE FALHAS DOS CABOS UMBILICAIS.............................. 32

2.2 ENSAIOS MECÂNICOS EM CABOS UMBILICAIS E RISERS FLEXÍVEIS................................................................................. 33

2.3 POLÍMEROS COMO MATERIAIS USADOS NA ENGENHARIA.......... 43

2.3.1 Classificação dos polímeros........................................................... 44

2.3.2 Cristalinidade dos materiais poliméricos........................................ 44

2.3.3 Conformação das cadeias poliméricas............................................. 47

2.3.4 Relações tensão-deformação nos materiais poliméricos................. 49

2.3.5 Modelos físicos e equações constitutivas representativas do comportamento visco-elasto-plástico dos polímeros..................... 51

2.4 COMPORTAMENTO A FRATURA DOS MATERIAIS POLIMÉRICOS.. 55

2.4.1 Mecânica da fratura linear-elástica (MFEL)....................................... 55

2.4.2 Mecânica da fratura elasto-plástica (MFEP)................................... 62

2.5 COMPORTAMENTO À FADIGA DE MATERIAIS POLIMÉRICOS........ 64

2.5.1 Ensaios à fadiga em materiais poliméricos...................................... 65

2.5.2 Propagação da trinca em materiais poliméricos devido aos carregamentos cíclicos.................................................................. 68

2.5.3 Influência da temperatura sobre a vida a fadiga dos polímeros...... 70

2.6 DANO EM MATERIAIS POLIMÉRICOS........................................... 73

2.6.1 Manifestações do dano................................................................ 75

2.6.2 Estimativa do dano...................................................................... 76

2.6.3 Formas de medir o dano............................................................. 79

2.7 DEGRADAÇÃO DOS POLÍMEROS DEVIDO AO MEIO MARINHO...... 80

2.7.1 Influência dos agentes ambientais na degradação dos polímeros.. 82

2.7.1.1 Influência da radiação ultravioleta na degradação dos polímeros.......... 83

2.7.1.2 Influência da temperatura na degradação dos polímeros...................... 85

2.7.1.3 Influência do oxigênio na degradação dos polímeros............................ 86

2.7.1.4 Influência da umidade na degradação dos polímeros........................... 87

2.7.2 Ensaios de envelhecimento natural e artificial em polímeros.......... 87

2.7.3 Métodos para caracterizar a degradação nos polímeros devido ao 
envelhecimento....................................................................... 88

2.8 ENSAIOS DE TRAÇÃO EM MATERIAIS POLIMÉRICOS.................. 91

2.9 ESTADO DE TENSÕES MULTIAXIAIS E CRITÉRIOS DE

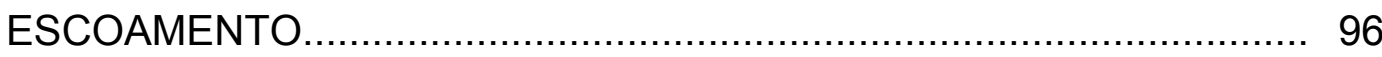

3 MÉTODO PARA ESTABELECER UM CRITÉRIO DE FALHA DA CAMADA POLIMÉRICA EXTERNA DO CABO UMBILICAL............... 99

3.1 HOMOLOGAÇÃO DE CABOS UMBILICAIS................................... 99

3.2 CRITÉRIO DE FALHA DA CAMADA POLIMÉRICA EXTERNA DE CABOS UMBILICAIS................................................................ 100

3.3 MÉTODO PROPOSTO............................................................ 101

3.3.1 Primeira etapa: Fadiga.................................................................... 101

3.3.1.1 Ensaio de fadiga no cabo umbilical segundo a norma API17E.......... 101

3.3.1.2 Deformações residuais............................................................. 104

3.3.1.3 Deformação na camada polimérica externa do cabo umbilical devido à tração inicial............................................................................ 107

3.3.1.4 Deformação na camada polimérica externa do cabo umbilical devido à flexão.

3.3.1.5 Ensaio de fadiga à tração uniaxial no material da camada polimérica externa do cabo

3.3.2 Segunda etapa: Envelhecimento.................................................. 114

3.3.3 Terceira etapa: Ensaios de tração................................................... 117

3.3.4 Quarta etapa: Microscopia.......................................................... 119

3.3.5 Quinta etapa: Absorção de água................................................ 120

3.3.6 Sexta etapa: Estimativa do dano................................................... 126

4 VALIDAÇÃO EXPERIMENTAL DO CRITÉRIO DE FALHA DA CAMADA POLIMÉRICA EXTERNA DO CABO UMBILICAL.............. 125

$4.1 \quad$ MATERIAIS E MÉTODOS......................................................... 125

4.2 ENSAIO DE FADIGA À TRAÇÃO UNIAXIAL NO HDPE DA CAMADA POLIMÉRICA EXTERNA DO CABO UMBILICAL............ 126

4.2.1 Determinação experimental da deformação residual a que está submetida a camada externa devido ao processo de fabricação.

4.2.2 Deformação no HDPE da camada externa do cabo umbilical devido à tração inicial.

4.2.3 Deformação devido à flexão.....................................................
4.2.4 tração uniaxial............................................................................... 134

4.2.5 Arranjo experimental usado no ensaio de fadiga à tração uniaxial do HDPE.

4.2.6 Execução do ensaio de fadiga à tração uniaxial do HDPE da camada externa do cabo. 
4.3 ENSAIO DE ENVELHECIMENTO ARTIFICIAL NO HDPE DA CAMADA POLIMÉRICA EXTERNA DO CABO UMBILICAL

4.3.1 Elaboração dos corpos de prova para ensaio de envelhecimento.

4.3.2 Execução do ensaio de envelhecimento artificial do HDPE da camada externa do cabo.

4.3.3 Execução dos ensaios de Dureza Tipo D................................... 140

4.3.3.1 Resultados dos ensaios de Dureza.............................................. 140

4.3.4 Microscopia eletrônica de varredura............................................ 141

4.4 ENSAIOS DE TRAÇÃO DO HDPE DA CAMADA POLIMÉRICA EXTERNA DO CABO

4.4.1 Preparação dos corpos de prova para o ensaio de tração.......... 144

4.4.2 Execução dos ensaios de tração instrumentado........................ 145

4.4.3 Execução dos ensaios de tração convencionais no HDPE da camada externa.

4.4.3.1 Resultados dos ensaios de tração no HDPE tirado da camada externa do cabo sem uso.

4.4.3.2 Resultados dos ensaios de tração no HDPE da camada externa do cabo ensaiada à fadiga segundo a norma API 17E.

Resultados dos ensaios de tração no HDPE da camada externa do cabo que foi submetida a fadiga à tração uniaxial...

4.4.3.4 Analise dos resultados dos ensaios de tração do HDPE que tinha sido submetido a fadiga à tração uniaxial.

4.4.3.5 Resultados dos ensaios de tração no HDPE da camada externa do cabo que foi envelhecido.

4.4.3.6 Analise dos resultados dos ensaios de tração do HDPE que tinha sido envelhecido artificialmente.

4.5 ENSAIO DE ABSORÇÃO DE ÁGUA NO HDPE DA CAMADA POLIMÉRICA EXTERNA DO CABO UMBILICAL.

4.5.1 Resultados do ensaio de absorção de água no HDPE................. 163

4.6 ESTIMATIVA DO DANO PROVOCADO PELOS CARREGAMENTOS CÍCLICOS NO HDPE DA CAMADA POLIMÉRICA EXTERNA DO CABO UMBILICAL.

5.1 Conclusões

5.2 Recomendações

REFERÊNCIAS BIBLIOGRÁFICAS

APÊNDICES

APÊNDICE A- BANCADA PARA ENSAIO DE FADIGA NO CABO 
APÊNDICE B- FOTOS DO ENSAIO DE TRAÇÃO DO CABO UMBILICAL...... 187 APÊNDICE C- DETERMINAÇÃO DAS TENSÕES RESIDUAIS A QUE ESTÁ SUBMETIDA A CAMADA EXTERNA DO CABO UMBILICAL $\quad 188$ APÊNDICE D- FOTOS DO ARRANJO PARA ENSAIOS DE ENVELHECIMENTO............................................................ 189 APÊNDICE E- FOTO DE ALGUNS DOS ESPÉCIMES APÓS DE ENSAIADOS À TRAÇÃO.. 


\section{LISTA DE FIGURAS}

Figura 1.1 - Cabos umbilicais usados nos SPF........................................ 24

Figura 1.2 - Configurações de linhas rígidas e flexíveis nos SPF.................. 25

Figura 1.3 - Estrutura típica de um cabo umbilical (seção transversal).......... 26

Figura 1.4 - Tipos de cabos umbilicais (seções transversais) utilizadas em operações offshore.

Figura 1.5 - Efeito da corrosão nas armaduras de tração de uma linha flexível devido a fissuras na camada polimérica externa............. 28

Figura 2.1 - Esquema de ensaio de flexão................................................. 34

Figura 2.2 - Configuração do ensaio de fadiga por flexão com rotação.......... 36

Figura 2.3 - $\quad$ Arranjo para ensaio de fadiga por flexão em forma de U............. 36

Figura 2.4 - Arranjo experimental para ensaio de fadiga por flexãorotação............................................................................... 38

Figura 2.5 - Arranjo experimental para ensaio de fadiga a traçãoflexão.

Figura 2.6 - Arranjo experimental para ensaio de flexão-tração simultâneas..

Figura 2.7 - Ensaio de flexão para estimar configuração deformada.............

Figura 2.8 - $\quad$ Arranjo experimental para ensaios de fadiga por flexão-tração... Figura 2.9 Modelo das cadeias dobradas.

Figura 2.10 - Micrografia óptica (obtida usando luz polarizada) da estrutura esferulítica do polietileno.

Figura 2.11 Cadeia polimérica com ligações covalentes simples. Conformação tipo Zig-Zag planar para uma seqüência etilênica.

Figura 2.13 Modelo da célula unitária do polietileno.

Figura 2.14 - Curvas tensão-deformação características para diferentes tipos de materiais poliméricos

Figura 2.15 - Efeitos da taxa de deformação e temperatura sob a curva tensão-deformação dos polímeros

Figura 2.16 - Modelos simples empregados para simular comportamento mecânico em polímeros estruturais e suas curvas tensãodeformação características.

Figura 2.17 - Trinca simulada por furo elíptico submetida à tensão numa chapa de grandes dimensões.

Figura 2.18 - Trinca aguda numa lâmina infinita tensionado uniformemente....

Figura 2.19 - Diferentes modos de carregamentos que originam as trincas nos sólidos.

Figura 2.20 - Curva de vida a fadiga para alguns tipos de polímeros estruturais.

Figura 2.21 - Curva comprimento da trinca - taxa de propagação da trinca devido á fadiga para HDPE.

Figura 2.22 - Representação física e matemática do Dano. 
Figura 2.23 - Elemento de volume representativo danificado submetido à tração uniaxial.

Figura 2.24 - Alongamento axial e contração lateral de duas barras carregadas à tração longitudinal.

Figura 2.25 - Representação gráfica do critério de escoamento baseado na máxima energia de distorção.

Figura 3.1 - Esquema típico para um ensaio de fadiga em cabos umbilicais segundo a norma API 17E.

Figura 3.2 - Arranjo de ensaio de fadiga mecânica no cabo umbilical segundo a API 17E

Figura 3.3 - Corpo-de-prova para ensaio de fadiga segundo norma API 17E

Figura 3.4 Arranjo para ensaio de desconfinamento...

Esquema da região do corpo-de-prova instrumentada antes e após do desconfinamento... 105

Figura 3.6 Esquema de viga submetida a flexão pura.

Figura 3.7 - Corpo-de-prova empregado nos ensaios de fadiga à tração uniaxial...

Figura 3.8 - $\quad$ Esquema do arranjo usado para o ensaio de fadiga à tração uniaxial.

Figura 3.9 - Gráfico dos ciclos de fadiga a serem impostos ao polímero no ensaio de fadiga à tração uniaxial.

Figura 3.10 - Condições ambientais a que está submetido o cabo durante sua vida de serviço nos SFP.

Figura 3.11 - Esquema do arranjo de ensaio de envelhecimento

Figura 3.12 - Esquema guia para elaboração dos espécimes, do material submetido à fadiga convencional uniaxial, usados no ensaio de absorção.

Figura 3.13 - Arranjo experimental usado no ensaio de absorção de água.

Figura 4.1 Seção transversal do cabo umbilical. Foto do corpo-de-prova usado no ensaio de desconfinamento...

Figura 4.3 - Foto do extensômetro empregado no ensaio de desconfinamento.

Figura 4.4 - Foto da região do corpo-de-prova instrumentada antes e após de retirada a seção da camada externa do cabo.

Figura 4.5 Curvas deformação-tempo obtidas durante o desconfinamento

Figura 4.6 Fotos do arranjo experimental usado para o ensaio de fadiga uniaxial convencional do HDPE.

Figura 4.7- Gráfico dos ciclos de fadiga impostos ao HDPE no ensaio de fadiga uniaxial convencional.............................................. 136

Figura 4.8 - Fotos dos três ambientes para ensaio de envelhecimento........... 139 Figura 4.9 - Micrografias eletrônicas de varredura das superfícies do HDPE 
não envelhecido.

Figura 4.10 - Micrografias eletrônicas de varredura das superfícies do HDPE que fora submetido a carregamentos cíclicos e envelhecido...... 143

Figura 4.11 - Foto do corpo-de-prova de tração instrumentado...................... 145

Figura 4.12 - Arranjo de ensaio de tração instrumentado............................... 146

Figura 4.13 - Curvas deformação-força e tensão-deformação para o corpode-prova instrumentado de prova ensaiado a tração.................. 147

Figura 4.14 - Curva tensão-deformação do HDPE retirado do cabo sem uso..

Figura 4.15 - Curva tensão-deformação do HDPE submetido a

Figura 4.16 - Curvas tensão-deformação do HDPE que tinha sido submetido

Figura 4.16 - Curvas tensão-deformação do HDPE que tinha sido submetido a fadiga à tração uniaxial.

Figura 4.17 - Curvas tensão-deformação para o HDPE retirado do cabo sem 151 uso, submetido a fadiga à tração uniaxial e segundo a norma API 17E

Figura 4.18 - Curva tensão-deformação para o HDPE retirado do cabo sem uso e envelhecidos.

Figura 4.19 - Curva tensão-deformação para o HDPE que foi submetido a carregamentos cíclicos e envelhecimento.

Figura 4.20 - Sobreposição das curvas tensão-deformação para o HDPE retirado do cabo sem uso e envelhecido.

Figura 4.21 - Sobreposição das curvas tensão-deformação para o HDPE que foi submetido à fadiga e envelhecido.

Figura 4.22 - Fotos do arranjo usado no ensaio de absorção de água...............

Figura 4.23 - Gráfico de colunas, número de carregamentos cíclicos aplicados versus incremento da massa do HDPE

Figura 4.24 - Representação esquemática dos estados tensionais a que é submetida a camada polimérica externa do cabo umbilical nos ensaios de fadiga...

Figura 4.25 - Representação gráfica dos valores de dano provocados pelos carregamentos cíclicos nos ensaios de fadiga realizados

Figura A1 - Foto da bancada de ensaio à fadiga do cabo segundo API17E

Figura A2 -

Foto da bancada de ensaio com corpo-de-prova montado.

Figura A3 Ensaio á fadiga do cabo segundo a norma API 17E em andamento.

Figura A4 -

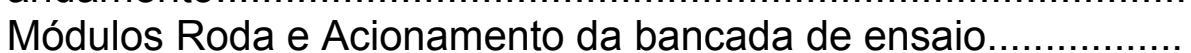

Figura B1 - Foto do corpo-de-prova instrumentado para ensaio de tração 


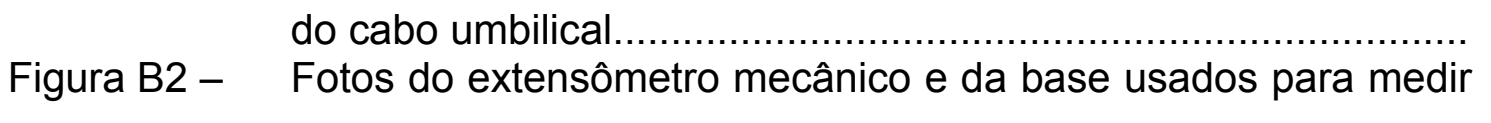
a deformação durante o ensaio de tração do cabo umbilical...... 187

Figura D1 Arranjo para ensaios de envelhecimento................................. 189

Figura E1 - Foto de alguns dos espécimes feitos de HDPE após de 


\section{LISTA DE TABELAS}

Tabela 4.1- Valores das deformações obtidas durante o desconfinamento.... 130

Tabela 4.2- Valores de alongamento e a deformação correspondente aplicados durante o ensaio de fadiga à tração uniaxial................ 136

Tabela 4.3 - $\quad$ Resultados dos ensaios de Dureza Tipo D no HDPE................. 140

Tabela 4.4 - Valores $\varepsilon, \sigma, v$ e E obtidos no ensaio de tração instrumentado... 148

Tabela 4.5 - Valores de tensão e deformação significativos obtidos no ensaio do HDPE retirado do cabo sem uso............................... 149

Tabela 4.6 - Valores de tensão e deformação significativos do ensaio de tração feito ao HDPE que foi submetido à fadiga segundo a norma API 17E.

Tabela 4.7 - Valores das tensões e deformações significativas obtidos nos ensaio de tração do HDPE que foi submetido a fadiga à tração uniaxial.

Tabela 4.8 - Valores das tensões e deformações significativas obtidos nos ensaios de tração dos corpos-de-prova feitos de HDPE retirado do cabo sem uso e submetidos a carregamentos cíclicos.

Tabela 4.9 - Valores das tensões e deformações significativas obtidas nos ensaios de tração para o HDPE envelhecido e não envelhecido, que não foi submetido a carregamentos cíclicos.

Tabela 4.10 - Valores das tensões e deformações significativas obtidas nos ensaios para os corpos-de-prova feitos de HDPE que foram submetidos à fadiga mecânica segundo a API 17E e envelhecimento..................................................................... 157

Tabela 4.11 - Resultados dos ensaios de absorção de água no HDPE............. 164

Tabela 4.12- Valores de dano provocado pelos carregamentos cíclicos no HDPE da camada externa do cabo umbilical.

Tabela A1 - Tabela A1 - Características técnicas da bancada de ensaio de fadiga fabricada segundo a norma API 17E 


\section{LISTA DE ABREVIATURAS}

\begin{tabular}{|c|c|}
\hline $\begin{array}{l}\text { API } \\
\text { ASTM }\end{array}$ & $\begin{array}{l}\text { Instituto Americano do Petróleo, American Petroleum Institute } \\
\text { Sociedade americana para ensaios e materiais, American Society for }\end{array}$ \\
\hline CTOD & $\begin{array}{l}\text { Testing and Materials } \\
\text { deslocamento da abertura na ponta da trinca, crack tip opening } \\
\text { displacement }\end{array}$ \\
\hline EP & resina epóxi, epoxy resin \\
\hline EPR & elastômero de propileno-etileno, ethylene propylene rubber \\
\hline FCP & propagação da trinca por fadiga, fatigue crack propagation \\
\hline HDPE & polietileno de alta densidade, high density polyethylene \\
\hline IFP & Instituto Francês do Petróleo \\
\hline iPP & polipropileno isotático; isotatic polypropylene \\
\hline LDPE & polietileno de baixa densidade, low density polyethylene \\
\hline MEF & Método dos Elementos Finitos \\
\hline MEV & microscópio eletrônico de varredura \\
\hline MFEL & Mecânica da Fratura Linear Elástica \\
\hline MFEP & Mecânica da Fratura Elasto - Plástica \\
\hline PA & poliamida, polyamide \\
\hline PE & polietileno, polyethylene \\
\hline PET & poli(tereftalato de etileno), poly(ethylene terephthalate) \\
\hline PP & polipropileno, polypropylene \\
\hline PPO & poli(óxido de propileno), poly(propylene oxide) \\
\hline PS & poliestireno, polystyrene \\
\hline PTFE & poli(tetraflúor-etileno), polytetrafluorethylene \\
\hline $\mathrm{RCP}$ & propagação rápida da trinca, rapid crack propagation \\
\hline SAD & Sistema de aquisição de dados \\
\hline SPF & sistema de produção flutuante \\
\hline UHMWPE & polietileno de altíssimo peso molecular, ultra-high molecular weight \\
\hline VER & $\begin{array}{l}\text { polyethylene } \\
\text { elemento representativo de volume }\end{array}$ \\
\hline
\end{tabular}




\section{LISTA DE SÍMBOLOS}

\begin{tabular}{|c|c|}
\hline A & alongamento total \\
\hline a & semicomprimento da trinca \\
\hline $\mathrm{C}_{\mathrm{p}}$ & calor específico \\
\hline $\mathrm{D}$ & dano acumulado \\
\hline Im & incremento da massa \\
\hline $\mathrm{Im}_{\mathrm{su}}$ & incremento da massa do material retirado do cabo sem uso \\
\hline $\mathrm{Im}_{\mathrm{D}}$ & incremento da massa do material danificado \\
\hline$d z$ & comprimento do segmento de viga analisada \\
\hline$d \theta$ & ângulo formados durante a flexão do segmento de viga \\
\hline $\mathrm{E}$ & módulo de elasticidade \\
\hline$E_{\text {ef }}$ & módulo de elasticidade efetivo \\
\hline$E_{r}(t)$ & módulo de relaxação \\
\hline$\Delta \mathrm{E}$ & energia de ativação \\
\hline $\mathrm{F}$ & carga aplicada \\
\hline $\mathrm{F}_{\mathrm{e}}$ & carga de escoamento \\
\hline $\mathrm{F}_{\mathrm{n}}$ & carga em que se observa uma deformação de n\% \\
\hline $\mathrm{F}_{\mathrm{r}}$ & carga de ruptura \\
\hline$f$ & freqüência \\
\hline$f_{i j}$ & função conhecida de $\theta$ \\
\hline $\mathrm{G}_{\mathrm{c}}$ & energia de fratura \\
\hline K & fator de intensidade concentração de tensões \\
\hline $\mathrm{K}_{\mathrm{l}}$ & intensidade do campo de tensões na ponta da trinca \\
\hline $\mathrm{K}_{\mathrm{lc}}$ & fator de intensificação de tensões para o modo I \\
\hline $\mathrm{K}_{\max }$ & valor máximo da intensidade de tensões durante o ciclo de carga \\
\hline $\mathrm{K}_{(\mathrm{T})}$ & fator de intensificação de tensões em função da temperatura \\
\hline L & comprimento da base de referência \\
\hline$L_{0}$ & comprimento da base de referência inicial \\
\hline$L_{f}$ & comprimento da base de referência final \\
\hline$\Delta \mathrm{L}$ & incremento do comprimento de referência \\
\hline M" & perda da rigidez \\
\hline $\mathrm{m}_{\mathrm{s}}$ & massa do material antes da absorção \\
\hline $\mathrm{m}_{\mathrm{u}}$ & massa do material após da absorção \\
\hline $\mathrm{N}$ & vida a fadiga em número de ciclos \\
\hline$p_{s}$ & peso do material antes da absorção \\
\hline $\begin{array}{l}\mathrm{p}_{\mathrm{u}} \\
\mathrm{R}\end{array}$ & $\begin{array}{l}\text { peso do material após da absorção } \\
\text { taxa de deformação }\end{array}$ \\
\hline r & raio de curvatura na ponta do furo \\
\hline S & área da seção transversal final \\
\hline $\mathrm{S}_{\mathrm{o}}$ & área da seção transversal inicial \\
\hline$S_{D}$ & áreas superficiais das microtrincas e microdefeitos \\
\hline $\mathrm{T}$ & temperatura \\
\hline$T_{f}$ & temperatura de fusão \\
\hline $\mathrm{T}_{\mathrm{g}}$ & temperatura de transição vítrea \\
\hline $\mathrm{t}$ & tempo \\
\hline$U_{R}$ & resiliência \\
\hline $\mathrm{U}_{\mathrm{T}}$ & tenacidade \\
\hline $\mathrm{y}$ & distância do ponto analisado à camada neutra \\
\hline
\end{tabular}




$\begin{array}{ll}\gamma & \text { energia superficial liberada } \\ \gamma & \text { taxa de deformação ao cisalhamento } \\ \delta_{\mathrm{c}} & \text { deslocamento crítico da trinca } \\ \delta S & \text { área da interseção do plano com EVR } \\ \delta S_{\mathrm{D}} & \text { área da interseção de todos os defeitos com } \delta S \\ \delta_{\mathrm{t}} & \text { incremento no comprimento da trinca } \\ \varepsilon, \varepsilon_{\mathrm{o}} & \text { deformação convencional ou de engenharia } \\ \varepsilon_{\mathrm{f}} & \text { deformação até a fratura } \\ \varepsilon_{\mathrm{p}} & \text { deformação no limite de proporcionalidade } \\ \varepsilon_{\llcorner} & \text {deformação longitudinal } \\ \varepsilon_{T} & \text { deformação transversal } \\ \eta & \text { viscosidade } \\ \psi & \text { continuidade } \\ \theta, r & \text { coordenadas polares do ponto } \\ \nu & \text { coeficiente de Poisson } \\ \xi_{\mathrm{d}} & \text { energia dissipada } \\ \rho & \text { densidade, raio de curvatura } \\ \sigma, \sigma_{\circ} & \text { tensão aplicada } \\ \sigma_{11,} \sigma_{22,} \sigma_{33} & \text { tensões principais } \\ \sigma_{\mathrm{c}} & \text { tensão crítica para o início do crescimento da trinca } \\ \sigma_{\mathrm{e}} & \text { limite de escoamento } \\ \sigma_{\mathrm{ef}} & \text { tensão efetiva } \\ \sigma_{\mathrm{f}} & \text { tensão de fratura } \\ \sigma_{\mathrm{ij}} & \text { componente do tensor de tensões no ponto } \\ \sigma_{\mathrm{n}} & \text { limite convencional n } \\ \sigma_{\mathrm{p}} & \text { limite de proporcionalidade } \\ \sigma_{\mathrm{r}} & \text { limite de resistência do material } \\ \sigma_{\mathrm{t}} & \text { tensão nos extremos do furo } \\ \sigma_{(t)} & \text { tensão dependente do tempo } \\ \sigma_{\mathrm{y}} & \text { limite de escoamento na ponta da trinca } \\ \tau & \text { tempo de relaxação } \\ \varphi & \text { estriç̧ão } \\ & \\ & \end{array}$




\section{RESUMO}

No presente trabalho é proposto um método para estabelecer um critério de falha da camada polimérica externa dos cabos umbilicais usados em operações offshore. $\mathrm{O}$ método proposta baseia-se na determinação do incremento da quantidade de água absorvida pela camada polimérica externa do cabo devido à deterioração provocada pelos carregamentos ć́clicos e o envelhecimento originados pelo meio marinho. Este método propõe a realização de um ensaio de fadiga à tração uniaxial no polímero que compõe a camada externa do cabo. $O$ teste é feito simulando as solicitações a que é submetida a camada externa do umbilical durante os ensaios de fadiga feitos, segundo a norma API 17E, durante o processo de homologação do cabo. Além disso, se propõe fazer um ensaio de envelhecimento artificial no polímero da camada externa simulando as condições de serviço do cabo no meio marinho. Com o fim de avaliar a influência dos carregamentos cíclicos e o os agentes do meio marinho nas propriedades do polímero, são feitos ensaios de absorção de água segundo a norma ASTM D 570, ensaios de tração segundo a norma ASTM D 638, ensaios de dureza segundo a norma ASTM D 2240 e observações num microscópio eletrônico de varredura. Finalmente a partir do incremento de massa sofrido pelo polímero no ensaio de absorção de água foi estimado o dano no material da camada externa do cabo. Os resultados obtidos no trabalho mostraram que os carregamentos cíclicos e o meio marinho aceleraram o processo de degradação da camada polimérica externa do umbilical demonstrando assim a eficiência do método proposto.

Palavras-chave: Falha. HDPE. Cabos Umbilicais. Fadiga. Envelhecimento. Absorção de água. Dano. 


\begin{abstract}
In the present work is proposed a method to establish a failure criterion of the polymeric external layer of umbilical cables used in offshore operations. The proposed method is based on the determination of the increment of the quantity of absorbed water by the polymeric external layer of the cable due to deterioration caused by cyclic loads and the aging process originated by the marine environment. The method proposes to carry out a uniaxial fatigue test on the polymer that composes the external layer of the cable. This test is made simulating the cyclical deformation that the external layer is submitted in the umbilical during the fatigue test done, according to the API 17E standard, during the process of cable homologation. It is also intended to make an artificial aging test in the polymeric external layer simulating the service conditions of the cable in the marine environment. In order to evaluate of the cyclical loads and the sea set aging influence on the properties of the polymer, carry out water absorption test according to the ASTM D 570 standard, traction test according to the ASTM D 638 standard, hardness test according to the ASTM D 2240 standard and observations in an scanning electron microscopy. Finally starting from the mass increment suffered by the polymer in the water absorption test it was estimated the damage in the external layer material of the cable. The results obtained in this work showed that the cyclical loads and marine environment accelerated the degradation process of polymeric external layer of umbilical cable demonstrating the efficiency of the proposed method.
\end{abstract}

Keywords: Failure. HDPE. Umbilical cable. Fatigue. Aging. Water absortion. Damage. 


\section{INTRODUÇÃO}

A indústria petrolífera brasileira tem apresentado significativos progressos nas ultimas décadas. As descobertas de grandes bacias de petróleo e gás natural associado aos esforços da Petrobras e de instituições de pesquisa têm propiciado ao País o aumento da produção de petróleo e gás natural, ao mesmo tempo em que têm ampliado suas reservas provadas (SCHIOZER, 2005).

No ano de 2006, a produção de petróleo no País atingiu 1,9 milhões de barris/dia. Deste volume, $10 \%$ foram provenientes da exploração em terra e $90 \%$ em mar. Do extraído do mar, 20 \% são de águas rasas ou seja, até $400 \mathrm{~m}$ de profundidade e 70 $\%$ de águas profundas e ultra profundas, acima de $400 \mathrm{~m}$ de profundidade. Atualmente, as reservas de petróleo brasileiras aprovadas são de 13,2 bilhões de barris, desta, a maior parte encontra-se situada em águas profundas e ultraprofundas (PETROBRAS, 2006).

Estima-se que para o ano 2010 a produção da PETROBRAS deva chegar a 2,3 milhões de barris por dia (SCHIOZER, 2005; PETROBRAS, 2006), mas para garantir isto será necessário vencer as dificuldades tecnológicas, tendo em vista que as jazidas de petróleo e gás encontradas mais recentemente estão localizadas em águas cada vez mais profundas. Este desafio tem obrigado a um grande esforço da Petrobras e instituições de pesquisas no sentido de desenvolver novas tecnologias e equipamentos que garantam um aumento eficiente e seguro da produção de petróleo e gás natural em águas profundas e ultraprofundas.

Hoje, a Petrobras é líder mundial na produção e exploração de óleo e gás em águas profundas e ultraprofundas, No campo de Roncador, na Bacia de Campos, a profundidade de produção atinge $1.886 \mathrm{~m}$ e a de exploração atinge $3.000 \mathrm{~m}$ (PETROBRAS, 2006).

Novas e revolucionarias técnicas envolvendo o uso de sistemas de produção flutuantes (SPF), constituídos estes por plataformas de produção, navios convertidos e subsistemas que os compõem, tais como, cabos submarinhos eletro-ópticos e eletro-hidráulicos (cabos umbilicais), risers de produção flexíveis e não flexíveis, linhas de ancoragem, etc. Estes, são os elementos fundamentais que têm ajudado a superar os obstáculos impostos pelas grandes profundidades oceânicas. 
Os cabos umbilicais, usados nas operações offshore, têm a importantíssima função de transmitir sinais de controle e alimentar com energia as árvores de natal (conjuntos de conectores e válvulas instalados acima da cabeça do poço e que têm como função controlar o fluxo dos fluidos produzidos e/ou injetados no poço) e manifold (equipamento instalado no fundo do mar cuja função é a passagem e manobra da produção, no qual o óleo é agrupado em um mesmo coletor) ajudando a controlar, assim, os fluxos de entrada e saída de óleo, gás e água (ISO 10423; ISO 13705).

Os cabos umbilicais, são estruturas compostas por materiais metálicos e poliméricos, que lhe conferem sustentabilidade e flexibilidade, possibilitando a utilização de longos segmentos de cabos. A principal vantagem é que eles apresentam maior tolerância aos movimentos dos SPF, ocasionados pelas ondas e correntes marinhas. A facilidade de transporte, instalação, e possibilidade de remanejamento para outros SPF são outros aspetos vantajosos dos cabos umbilicais. Como desvantagem, verifica-se a dificuldade de fabricação dos mesmos, uma vez que envolvem diferentes materiais e geometrias internas complexas.

O aumento da utilização de cabos umbilicais e das solicitações de carregamento tem conduzido ao desenvolvimento de estudos voltados à melhor compreensão do comportamento mecânico destes. Além disso, a perspectiva de explorar petróleo a profundidades cada vez maiores faz com que o custo de fabricação dos cabos aumente substancialmente, hoje podendo chegar $\mathrm{R} \$ 2.000,00 / \mathrm{m}$, faz com que haja uma tendência de um esforço crescente voltado ao desenvolvimento cientifico tecnológico desses cabos umbilicais.

\subsection{CARACTERÍSTICAS DOS CABOS UMBILICAIS E DE SUAS INSTALAÇÕES}

Para a exploração de reservas petrolíferas situadas em grandes profundidades marinhas, mais de $1.500 \mathrm{~m}$, é necessária a utilização de sistemas e equipamentos controlados a partir da superfície. Nas cabeças dos poços, no fundo marinho, são instaladas árvores de natal e manifolds os quais são remotamente controlados e monitorados. 
Estes dispositivos têm como função regular a entrada e saída dos fluxos de óleo, gás e água nos poços. Os cabos umbilicais são os encarregados de fornecer energia elétrica, acionamento eletro-hidráulico e transmitir sinais de controle as árvores de natal e manifolds instalados nas cabeças dos poços petrolíferos no fundo marinho. A Figura 1.1 (TORRES, 1996) ilustra duas aplicações das linhas flexíveis (cabos umbilicais e risers flexíveis) nos SPF.
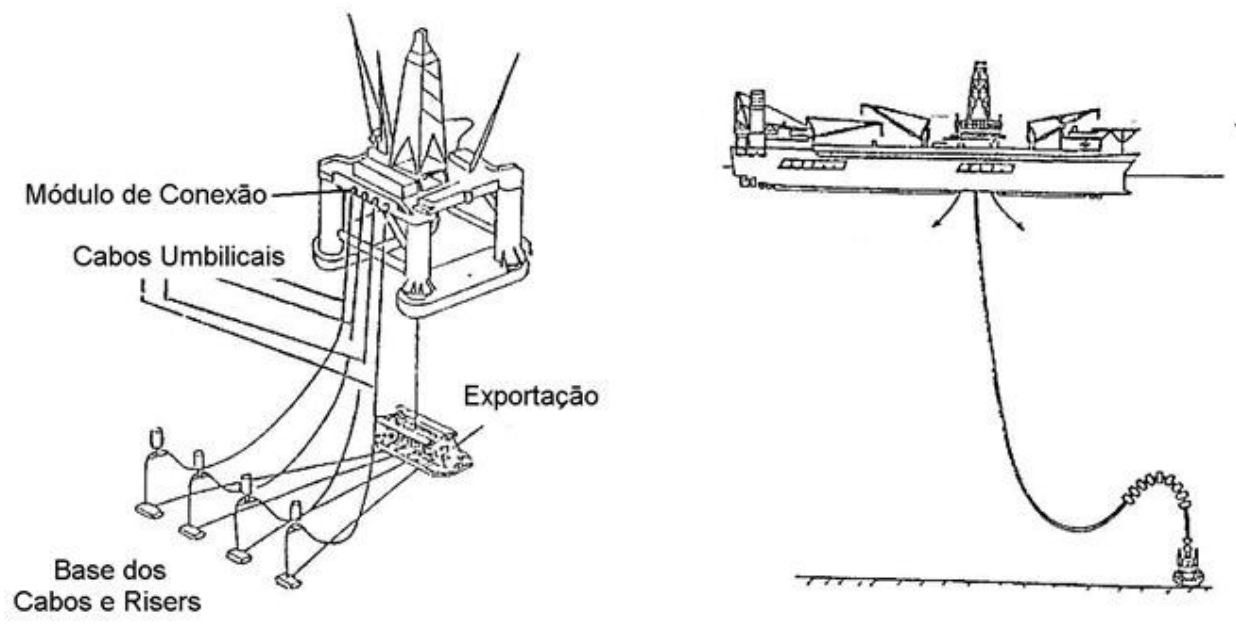

Figura 1.1 - Cabos umbilicais usados nos SPF (TORRES, 1996)

Os cabos umbilicais depois de serem instalados nos SPF têm duas zonas que ficam sob solicitações muito diferentes. Uma é a parte do cabo que fica assentada no fundo marinho, e a outra, a que fica suspensa desde a unidade de produção até o fundo, caracterizada por apresentar um longo vão suspenso (catenária). Na primeira zona as cargas atuantes são, em sua maioria, estáticas, já na segunda as cargas são dinâmicas, originadas pela correnteza oceânica e pelas movimentações do SPF, onde são evidenciadas a diversidade e complexidade dos carregamentos a que estão submetidos os cabos umbilicais durante sua vida em serviço. Na Figura 1.2 (PATEL; SEYED, 1995) ilustram-se varias configurações de instalação de linhas rígidas e flexíveis no meio marinho. 


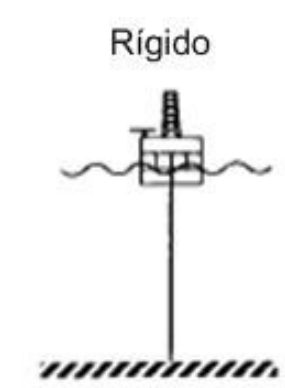

"Steep-wave"

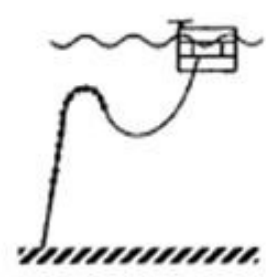

Catenária Simples

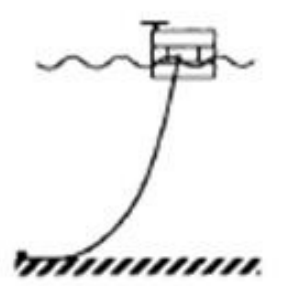

"Lazy-S"

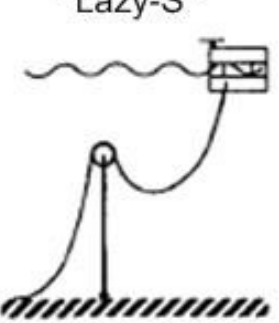

"Steep-S"

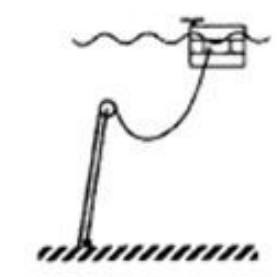

"Lazy-wave"

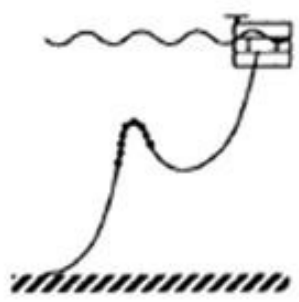

Figura 1.2 - Configurações de linhas rígidas e flexíveis nos SPF (PATEL; SEYED, 1995)

A estrutura dos cabos umbilicais varia de acordo com a utilização que lhe será dada e a tecnologia do fabricante. Geralmente, os umbilicais estão compostos por uma superposição de camadas homogêneas feitas de materiais poliméricos, camadas não homogêneas elaboradas de aço e um núcleo funcional que pode ser formados por cabos ópticos e/ou cabos elétricos e/ou mangueiras hidráulicas.

Num projeto considerado adequado, os cabos umbilicais devem ser capazes de atender a certos requisitos básicos, tais como: suportar grandes cargas de tração, resistir à pressão externa e resistir à flexão e à torção.

A estrutura típica de um cabo umbilical, mostrada na Figura 1.3 (CÁRDENAS; MACHADO; GONÇALVES, 2007) é composta basicamente de uma superposição de camadas plásticas e metálicas de caráter estrutural, cabos de cobre, que têm como função conduzir energia elétrica e um cabo de fibra óptica responsável pela transmissão de sinais. 


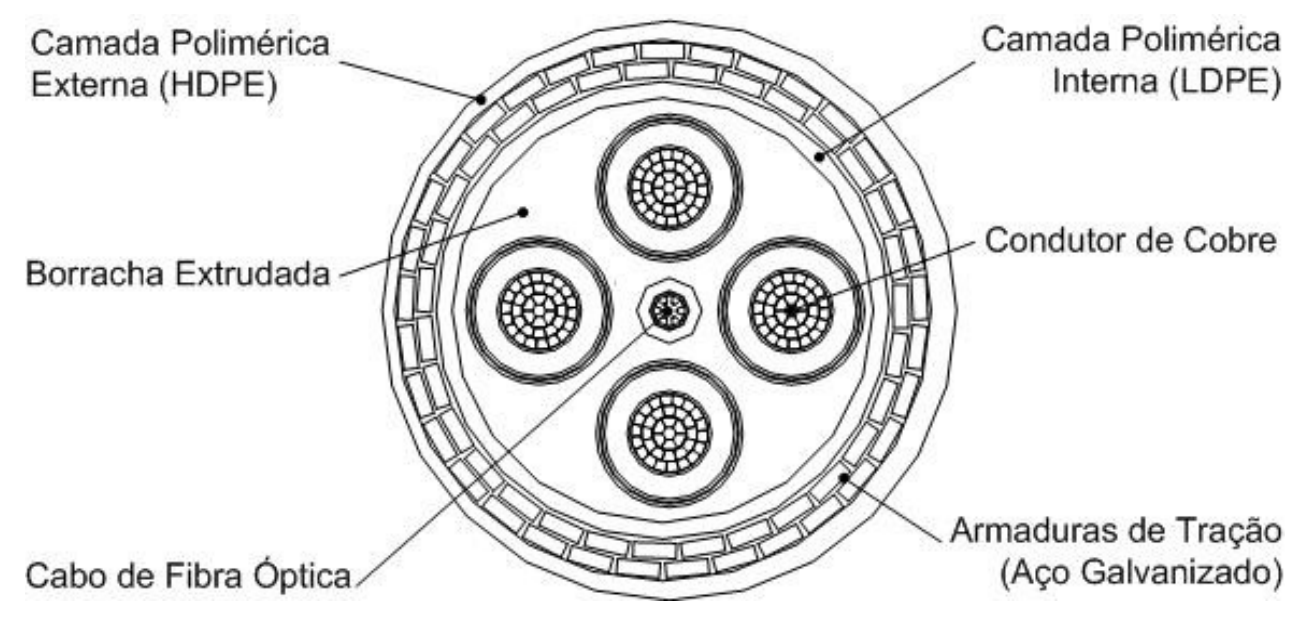

Figura 1.3 - Estrutura típica de um cabo umbilical (seção transversal) (CÁRDENAS; MACHADO; GONÇALVES, 2007)

As camadas homogêneas são constituídas normalmente por materiais poliméricos extrudados. No caso das camadas externas sua função fundamental é manter a estanqueidade do cabo, protegendo a estrutura interna deste contra a corrosão provocada pelo meio marinho (água marinha, radiação ultravioleta do sol e oxigênio), a abrasão e o impacto com outras linhas, além de ajudar a manter os demais componentes do cabo na sua posição, assegurando a forma cilíndrica deste e ajustando a rigidez à flexão do mesmo. Já as camadas poliméricas internas servem como lubrificantes, pois elas diminuem o atrito entre as partes metálicas do cabo.

As camadas não homogêneas elaboradas de aço são compostas por duas ou mais camadas, formadas por tendões (arames) de secção transversal retangular ou circular enrolados helicoidalmente. Tais camadas são responsáveis por suportar quase toda a carga de tração axial a que está submetido o cabo e ao mesmo tempo permite que este mantenha uma boa rigidez flexional.

O núcleo funcional é o encarregado de fornecer energia elétrica, sinais ópticos e comandos hidráulicos as árvores de natal e manifold situados no fundo do mar. $\mathrm{Na}$ Figura 1.4 (LÉPORE, 2003; PIRELLI CABOS, 2004) mostram-se diferentes estruturas de umbilicais (seção transversal) usados em SPF. 


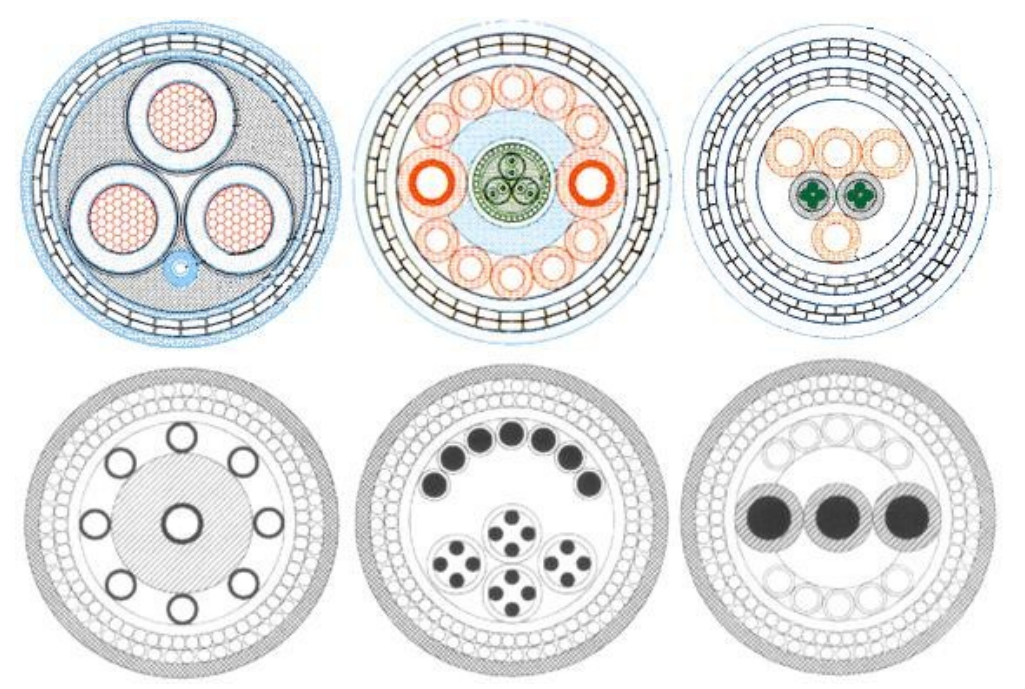

Figura 1.4 - Tipos de cabos umbilicais (seções transversais) utilizadas em operações offshore (LÉPORE, 2003; PIRELLI CABOS, 2004)

O arranjo adequado dos diferentes componentes do cabo é de vital importância para obter uma boa distribuição das tensões originadas pelas cargas externas. Recomenda-se, sempre que possível, a simetria dos componentes e ter em conta, principalmente, os esforços de tração, flexão e compressão a que vai estar submetido o cabo durante a instalação e sua vida em serviço. Para elaborar um projeto de cabo umbilical apropriado o fator econômico é um dos principais fatores a ter-se em conta para que este seja adequado.

Os materiais mais utilizados na elaboração da camada polimérica externa são polietileno de alta densidade (HDPE), poliamida 11, poliamida 12 e poliuretano. Esta camada deve ter boas propriedades em relação ao envelhecimento, resistência ao desgaste, grande alongamento antes de atingir à ruptura, resistência à abrasão, corrosão, impacto e boa flexibilidade, devido o prolongado efeito dinâmico a que está submetido o cabo durante sua vida útil. Além disso, deve ter boa resistência ao ataque dos agentes ambientais do meio marinho tais como a água do mar, radiação ultravioleta, oxigênio e altas temperaturas. Todos estes fatores combinados podem provocar fissuras e ruptura por fadiga, desgaste, envelhecimento e degradação dos materiais poliméricos que o compõem. 
Na Figura 1.5 (ALVES, COSTA, 2001; QUINTELA, ALVES, 2002) pode-se observar os efeitos catastróficos da corrosão nas armaduras de tração de uma linha flexível originado pela fissura ou ruptura da camada polimérica externa.
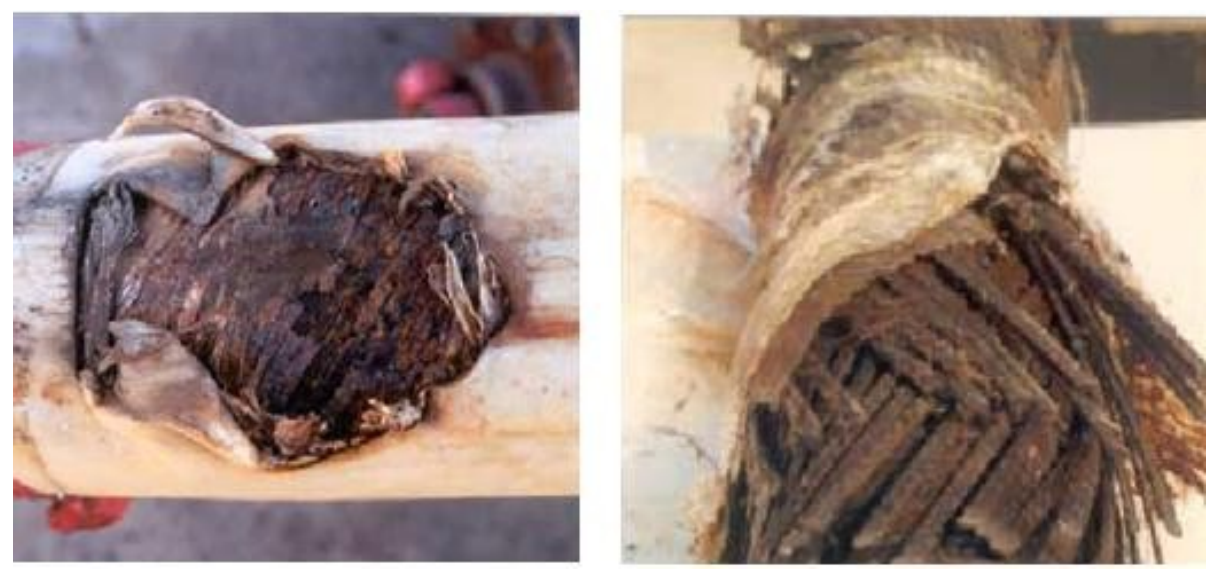

Figura 1.5 - Efeito da corrosão nas armaduras de tração de uma linha flexível devido a fissuras na camada polimérica externa (ALVES; COSTA, 2001),

(QUINTELA; ALVES, 2002)

\subsection{JUSTIFICATIVA DO TRABALHO}

Os cabos umbilicais usados nos SPF encontram-se submetidos a severas condições do ambiente marinho, ou seja, ondas e correntes marítimas que originam deslocamentos laterais das plataformas e movimentação das linhas ao longo do comprimento dos cabos, ocasionando sobre os mesmos uma combinação de esforços de tração, flexão, torção e pressão externa. Todos estes fatores unidos aos elementos ambientais do meio marinho tais como radiações ultravioleta, oxigênio, temperaturas e a água do mar podem ocasionar diferentes falhas estruturais como, por exemplo: fissuras das partes poliméricas e metálicas, assim como o envelhecimento precoce das partes poliméricas.

No intuito de minimizar falhas estruturais têm-se feito muitos estudos e ensaios experimentais sobre o comportamento mecânico global dos cabos umbilicais, de suas armaduras de tração e outras partes metálicas. No entanto, pouco se há estudado sobre a camada polimérica externa do cabo que tem a importantíssima 
função de evitar a penetração da água do mar no cabo, protegendo assim a sua estrutura da corrosão do meio marinho, além de ajudar a manter os tendões das armaduras de tração na sua posição. Segundo estudos feitos a falha da camada polimérica externa de uma linha flexível pode originar a diminuição da vida útil da linha de 25 para 2 anos ou menos, devido à fadiga sob corrosão das armaduras de tração em um ambiente marinho (UKOOA, 2001; TAYLOR, JOOSTEN, SMITH, 2002).

Deve-se ressaltar que a falha do cabo umbilical resulta numa conseqüência desastrosa tanto sob o ponto de vista ecológico como econômico, já que a perda do controle e monitoramento dos processos de produção pode provocar vazamento de petróleo com os conseqüentes transtornos ecológicos e grandes riscos para todos os seres vivos. Além disso, a paralisação dos sistemas provoca a interrupção nas operações de produção e perfuração o que traz grandes perdas econômicas.

\subsection{OBJETIVO DO TRABALHO}

O objetivo geral deste trabalho é validar um método que permita estabelecer um critério de falha da camada polimérica externa dos cabos umbilicais.

Além deste, podem-se estabelecer os seguintes objetivos específicos:

- Simular as condições de carregamento a que está submetida a camada polimérica externa do cabo umbilical durante um ensaio feito segundo a API 17E, através de ensaio de fadiga uniaxial à tração.

- Avaliar os danos causados pelos carregamentos cíclicos e meio marinho (água salgada, radiação ultravioleta, temperaturas e oxigênio) sobre o comportamento mecânico e a microestrutura da camada polimérica externa do cabo umbilical.

- Estimar a relação existente entre os carregamentos cíclicos e a quantidade de água absorvida pela camada polimérica externa do cabo umbilical.

Tendo em vista estes objetivos, o texto do presente trabalho ficou distribuído em cinco partes, da seguinte forma. 
$\mathrm{Na}$ primeira parte do trabalho, é feita uma introdução ao tema do trabalho, explicando o que é um cabo umbilical, quais são suas características estruturais e funcionais, diferentes tipos de configurações na instalação dos cabos no meio marinho, diferentes tipos de construções dos umbilicais, materiais empregados na elaboração da camada polimérica externa, justificativa e objetivo do trabalho.

Na segunda parte, é feita uma revisão bibliográfica sobre os modos de falhas dos cabos umbilicais e tipos de ensaios mecânicos já realizados com linhas flexíveis usadas em operações offshore. Também é feita uma análise sobre a estrutura e o comportamento mecânico dos materiais poliméricos centrando a atenção na viscoelasto-platicidade, comportamento à fratura, comportamento à fadiga, dano acumulado, grandes deformações e envelhecimento provocado pelos diferentes agentes do meio marinho nos termoplásticos e especificamente do HDPE.

Na terceira parte, é proposto um método para estabelecer um critério de falha da camada polimérica externa do cabo umbilical.

Na quarta parte, é desenvolvido um exemplo real de análise de falha na camada polimérica externa de um cabo umbilical com o fim de validar o método proposto no capítulo anterior. São explicados pormenorizadamente todos os ensaios feitos durante a realização do trabalho.

Por último, na quinta parte do estudo, são expostas as conclusões e feitas sugestões para próximos trabalhos. 


\section{REVISÃO BIBLIOGRÁFICA}

Durante as últimas décadas no Brasil a engenharia Offshore tem mostrado-se como uma área em desenvolvimento acelerado. A descoberta de volumosas bacias petrolíferas em grandes profundidades marinhas, tem levado ao desenvolvimento de novos equipamentos e tecnologias para produção e prospecção de hidrocarbonetos do fundo marinho.

Novos conceitos de posicionamento e fundeio foram desenvolvidos e outros tantos estão em pleno desenvolvimento como alternativa segura aos sistemas convencionais de posicionamento dinâmico, empregados com especial ênfase nas atividades de prospecção, perfuração e produção. Das plataformas fixas de produção, técnica e economicamente viáveis até profundidades de cerca de $500 \mathrm{~m}$, passou-se às plataformas semi-submersíveis e mais recentemente ao emprego de Sistemas de Produção Flutuantes (SPF). Estes sistemas são constituídos por plataformas de produção, navios convertidos para o mesmo fim e subsistemas, tais como, cabos umbilicais, risers de produção rígidos e flexíveis, linhas de ancoragem etc.

Os cabos umbilicais constituem uns dos elementos fundamentais na produção de petróleo e gás em águas profundas. Sua função é enviar sinais de controle e fornecer energia elétrica ao conjunto de válvulas, instalado na cabeça do poço, no fundo do mar. Eles fornecem energia elétrica e transmitem comandos ópticos e hidráulicos, controlando e monitorando assim os fluxos de entrada e saída de óleo, gás e água nos poços submarinhos.

As linhas flexíveis para uso offshore estão constituídas pela superposição de camadas poliméricas e metálicas. Este tipo de estrutura foi proposta pela primeira vez no ano 1960 pelo Instituto Francês do Petróleo (IFP). Em 1972 foram disponibilizados para a indústria petrolífera (SOUZA et. al., 1998). Aqui no Brasil, foram usadas pela primeira vez em 1979, no Campo de Enchova, na Bacia de Campos (TORRES; 1996). Rapidamente seu uso expandiu-se pelo mundo, sendo que no princípio dos anos 90 , já terem sido instalados mais de $50.000 \mathrm{~km}$ de cabos umbilicais (LEGALLAIS, 1993; LEPORE, 2003). Já a Petrobras entre os anos 1977 e 
2000 instalou mais de $3.600 \mathrm{~km}$ de linhas flexíveis (cabos umbilicais e risers flexíveis) nas costas brasileiras (UNICAMP-DPE, 2004).

\subsection{MODOS DE FALHAS DOS CABOS UMBILICAIS}

Cabos umbilicais são produtos multicamadas complexos que utilizam uma ampla gama de materiais poliméricos, metálicos, fibras têxteis etc. A contribuição de cada um destes produtos ao comportamento mecânico do conjunto dá uma complexa combinação de propriedades e interações. Estas interações são as causas de vários tipos de falhas tais como: fratura, fadiga, desgaste e degradação dos materiais devido à diferentes solicitações mecânicas e aos agentes agressivos do meio marinho (radiação ultravioleta, água salgada, oxigênio, temperaturas, etc) a que estes materiais estão submetidos.

As falhas dos cabos umbilicais podem ser originadas devido a vários fatores tais como: sobrecargas, fadiga mecânica, dano localizado (impacto), corrosão, envelhecimento dos materiais poliméricos, desgaste por atrito entre as diferentes camadas ou abrasão externa, entre outros (FUKU et al., 1992). Além disso, grandes mudanças de curvatura podem provocar fadiga e fluência nas camadas poliméricas e ao mesmo tempo comprometer a estanqueidade e o bom comportamento dos cabos. Seguem abaixo alguns dos motivos que podem provocar o colapso dos cabos umbilicais e risers flexíveis (UKOOA, 2001; LEPORE, 2003).

- Ruptura dos tendões que compõe as armaduras de tração seja por tração, fadiga ou desgaste;

- Ruptura da camada polimérica externa que permite a penetração da água do mar originando corrosão na estrutura metálica interna do cabo;

- Ruptura da camada polimérica externa devido ao efeito degradante do meio marinho (água salgada, oxigênio e a radiação ultravioleta da luz solar);

- Ruptura por fadiga dos condutores elétricos;

- Curvatura extrema que pode originar instabilidade flexo-torcional (laços e nó), durante a operação de lançamento do cabo; 
- Ruptura de tendões das armaduras de tração devido ao desenrolamento causado pela torção excessiva do cabo;

- Ruptura das camadas poliméricas por envelhecimento devido ao uso prolongado ou efeito dinâmico;

- Ruptura das armaduras de tração crushing devido ao esforço de compressão provocado pelas sapatas durante a instalação;

- Flambagem lateral das armaduras de tração devido esforços combinados de compressão axial e flexão cíclica.

A falha do cabo também pode ocorrer em suas terminações e conexões. Variações bruscas de sua rigidez flexional em zonas de grande curvatura normalmente nos extremos da linha e expansão térmica diferencial originam fadiga mecânica e perda da estanqueidade. A fluência das camadas poliméricas podem comprometer a selagem dos cabos.

Ainda hoje, requisitos de projeto não são geralmente diferenciados no que diz respeito às possíveis falhas que podem ocorrer. Devido a isto, grandes esforços de pesquisa têm-se desenvolvido, onde se busca conseguir uma maior correlação entre critérios de projeto e realidade de serviço. Para atingir este objetivo após o projeto e fabricação e antes do lançamento e instalação, os cabos são testados nas condições mais próximas possíveis das condições reais de serviço.

\subsection{ENSAIOS MECÂNICOS EM CABOS UMBILICAIS E RISERS FLEXIVEIS}

Vários tipos de ensaios mecânicos têm sido desenvolvidos no que diz respeito às linhas flexíveis (cabos umbilicais e riser flexíveis), Witz e Tan (1992a, 1992b, 1995), Fuku et al. (1992), Spark et al. (1992), Ishi et al. (1995), Saevik e Berge (1995), Feld et al. (1995), Cárdenas e Gonçalves (2002a), Lépore (2003), Troina et al (2003), Lépore e Buelta (2007) entre outros. No entanto, poucos reproduzem as condições reais de serviço a que cabos e risers ficam submetidos após de sua instalação nos SPF no meio marinho.

Witz e Tan (1992a), fizeram ensaios de flexão com três tipos de estruturas flexíveis diferentes (cabo submarino, cabo umbilical e riser flexível) usadas em operações 
offshore. O objetivo dos ensaios foi comparar os resultados experimentais com os resultados obtidos em um modelo analítico elaborado pelos autores para predizer o comportamento mecânico à flexão de estruturas flexíveis multicamadas (linhas flexíveis). Eles usaram espécimes de $4 \mathrm{~m}$ de comprimento. Para a realização dos ensaios os corpos-de-prova foram colocados no chão, seus extremos foram conectados com uma talha como mostra a Figura 2.1 (WITZ; TAN,1992a). Ao arranjo foi incorporada uma célula de carga para medir os carregamentos que seriam aplicados, a célula de carga estava acoplada em um computador para aquisição dos valores das cargas aplicadas. Os espécimes foram submetidos à flexão por incrementos e as distâncias entre os extremos do corpo-de-prova $(X)$ e da horizontal ao ponto de máxima deflexão $(\mathrm{Y})$ foram medidas. Com os valores de $\mathrm{X} e$ Y e usando a função parabólica foram estimadas as curvaturas do ponto de máxima deflexão para os diferentes carregamentos aplicados, também foram determinados os momentos flexores no ponto de maior deflexão.

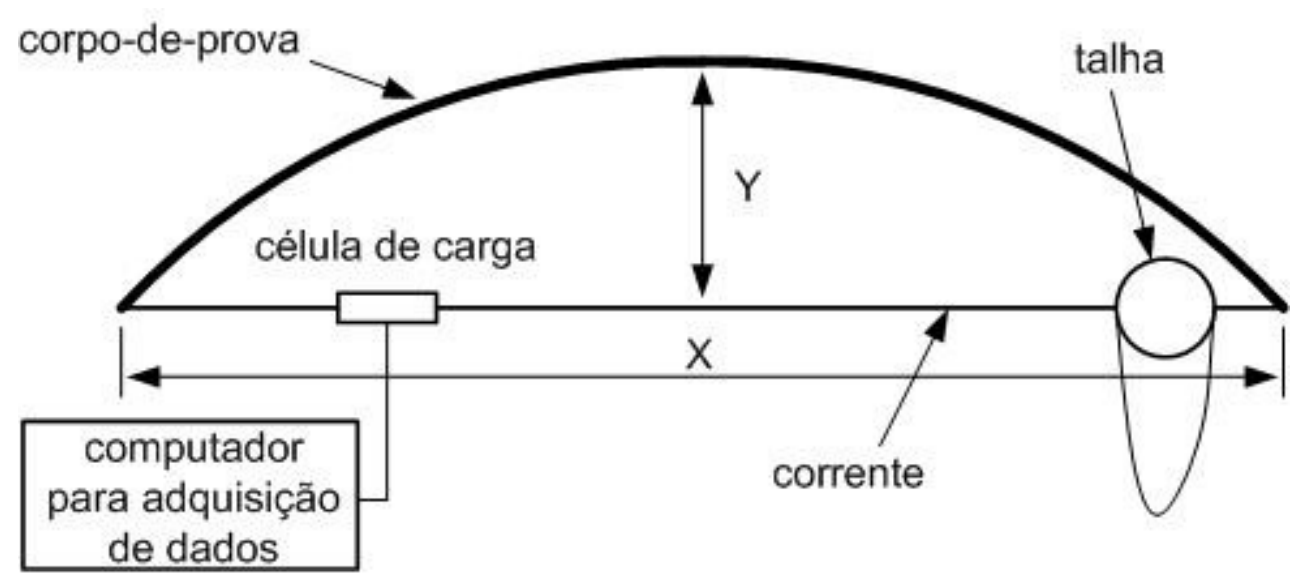

Figura 2.1 - Esquema de ensaio de flexão (WITZ; TAN,1992a)

Para todas as estruturas ensaiadas a correspondência entre os resultados experimentais e analíticos (curvaturas do ponto de máxima deflexão e momento flexor nesse ponto) foi satisfatória, apesar de nos ensaios as medidas de curvatura tomadas não terem sido diretas, e que no modelo analítico não se terem levado em conta o atrito existente entre os corpos-de-prova e o chão. 
Witz e Tan (1992b), também fizeram ensaios de tração com dois tipos de cabos submarinhos. O objetivo dos ensaios foi comparar os resultados experimentais com resultados obtidos de um modelo analítico, elaborado por eles, para predizer o comportamento mecânico de linhas flexíveis quando submetidas à tração. Como corpos-de-prova utilizaram-se seções de cabos com 7,5 m de comprimento, estas foram submetidas a cargas de tração axial. Em alguns espécimes foi restringinda a rotação nos extremos e em outros não. Os carregamentos foram aplicados por meio das armaduras de tração dos cabos. Eles mostraram experimental e analiticamente que as condições de contorno nos extremos dos corpos-de-prova têm um notável efeito sobre a rigidez axial. Nos casos que a rotação nos extremos foi restringida a rigidez axial aumentou.

Nos modelos analíticos a rigidez axial do núcleo funcional foi desprezada, também antes de executar os ensaios as camadas poliméricas externas dos cabos foram removidas. A concordância entre os resultados obtidos, curvas carga aplicadadeformação, experimental e analiticamente foi boa.

Fuku et al. (1992), estudaram a vida a fadiga em tubulações flexíveis, eles simularam as complexas solicitações originadas pelo carregamento externo atuante no riser provocado pelo movimento da plataforma flutuante e as variações das condições ambientais. Fizeram dois tipos de ensaios usando como corpos-de-provas seções de riser flexíveis com diâmetros exteriores de 101,6 mm e 203,2 mm. Durante os testes foram impostas mudanças de curvatura na tubulação originando carregamentos cíclicos nas suas diferentes camadas. No primeiro ensaio mostrado na Figura 2.2 (FUKU et al., 1992), o cabo foi submetido a solicitações de flexão e rotação combinadas. Neste teste usaram-se corpos-de-prova de 5 a $8 \mathrm{~m}$ de comprimento. Com uma curvatura prescrita e aplicou-se uma rotação ao redor do eixo do corpo-de-prova, impondo a mudança de curvatura especificada. Além disso, também foi imposta uma pressão interna. Os números totais de ciclos aplicados até a falha do riser foram registrados. 


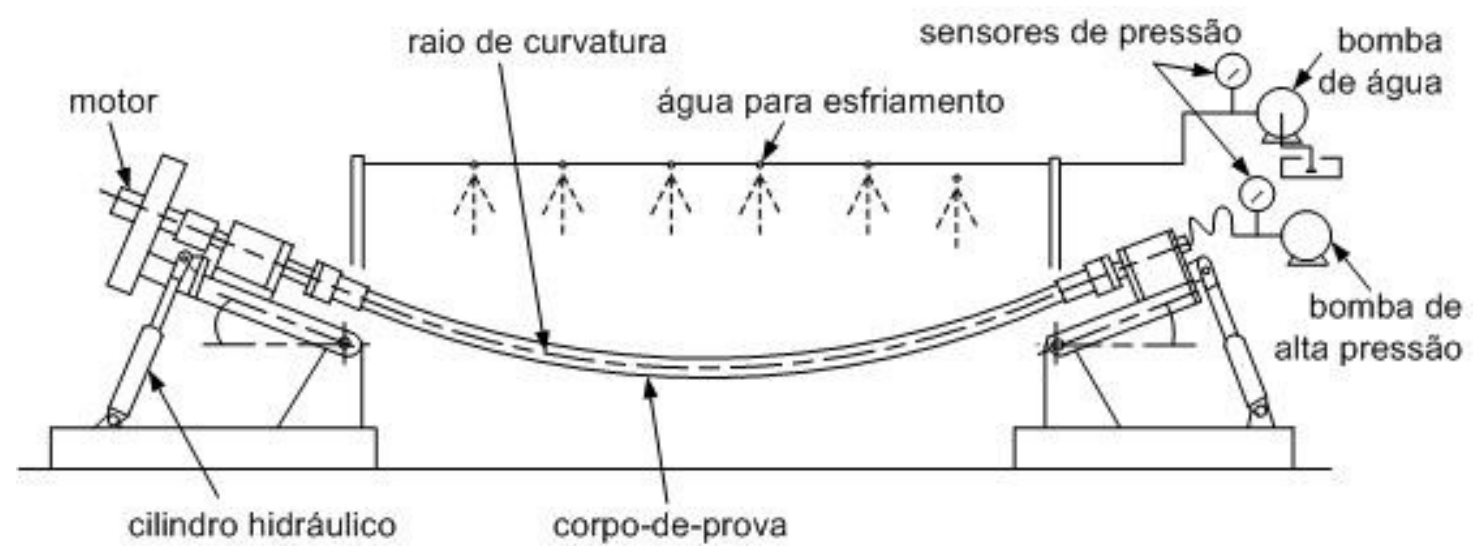

Figura 2.2 - Configuração do ensaio de fadiga por flexão com rotação

(FUKU et al., 1992)

O segundo ensaio feito foi de fadiga por flexão (forma de U). A Figura 2.3 (FUKU et al., 1992) mostra a configuração do ensaio. Neste ensaio os corpos-de-prova, com comprimento de 12 a $14 \mathrm{~m}$, foram suspensos em forma de $\mathrm{U}$, e foram impostas mudanças na curvatura mediante deslizamento de um de seus extremos para cima e para baixo. Além da tração de suspensão foi imposta uma pressão interna e registrou-se o número de ciclos até a falha.

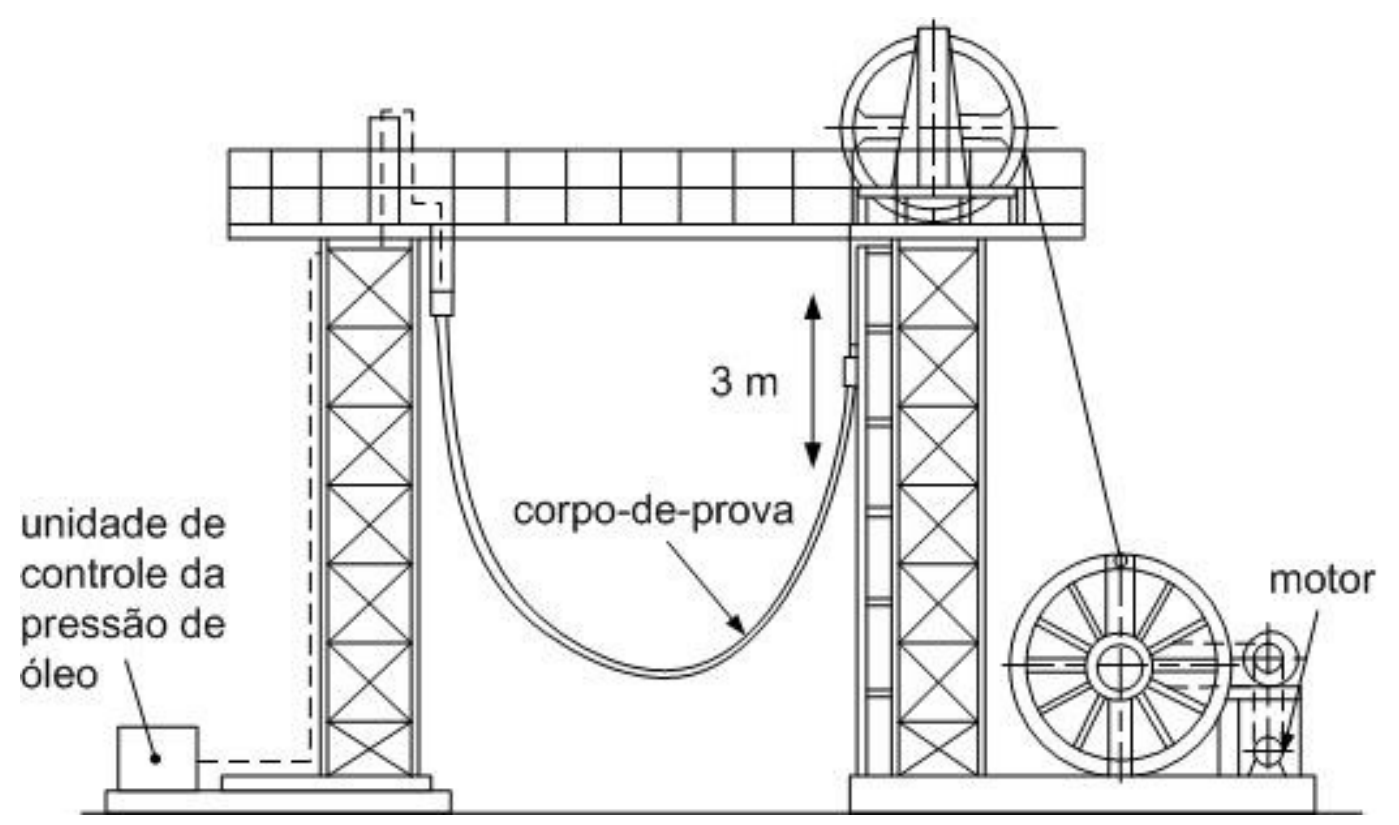

Figura 2.3 - Arranjo para ensaio de fadiga por flexão em forma de $U$ (FUKU et al., 1992) 
Observando os dois arranjos experimentais utilizados por Fuku et al. (1992), percebe-se que no ensaio de fadiga por flexão em forma de $U$ as condições do experimento se aproximam das condições reais de uso das linhas flexíveis no ambiente marinho, já no arranjo de flexão com rotação difere bastante das condições reais. Depois da análise e comparação dos resultados obtidos em ambos os ensaios, os autores concluíram que existe uma grande influência da taxa de mudança de curvatura e do tamanho do corpo-de-prova na vida a fadiga dos riser, e que para uma mesma mudança de curvatura no ensaio de fadiga por flexão (forma de u), o tempo de vida foi quatro vezes maior que no ensaio de fadiga por flexão com rotação. O modo de falha foi o mesmo para ambos os ensaios: ruptura por fadiga na armadura de tração interna. Finalmente, o trabalho estabelece procedimentos analíticos estatísticos para a predição do tempo de vida dos risers sob condições irregulares do meio.

Ishi et al. (1995), avaliaram experimentalmente protótipos de riser elaborados com novos materiais para ver seu desempenho a profundidades maiores de $1.000 \mathrm{~m}$. Nestes novos tipos de tubulações flexíveis com o fim de diminuir seu peso as armaduras de tração de aço foram trocados por materiais compósitos, polímeros reforçados com fibras. Eles fizeram testes para determinar a rigidez à flexão e a rigidez axial dos riser com e sem pressão de trabalho interna. Também foram feitos ensaios de fadiga à flexão com rotação usando um arranjo similar ao usado por (FUKU et al., 1992). Após feitos o ensaios os autores concluíram que as tubulações flexíveis testadas poderiam trabalhar a profundidades de mais de $1.000 \mathrm{~m}$.

Witz e Tan (1995), fizeram ensaios de fadiga por flexão com rotação em cabos submarinhos eletro ópticos com o objetivo de validar um modelo analítico elaborado por eles mesmos. O cabo utilizado como corpo-de-prova tinha $34 \mathrm{~mm}$ de diâmetro. Os ensaios foram feitos no arranjo apresentado na Figura 2.4 (WITZ; TAN, 1995), usaram-se três tipos de configurações, mudando os comprimentos dos espécimes (dois de 3,695 $\mathrm{m}$ e um de $1,626 \mathrm{~m}$ ) e os raios de curvaturas a que estes foram submetidos (2,8 m; 0,64 m; 0,49 m). Após concluídos os ensaios eles perceberam que o comprimento dos corpo-de-prova e o tipo de fixação nos extremos tiveram grande influência sobre os resultados obtidos. 


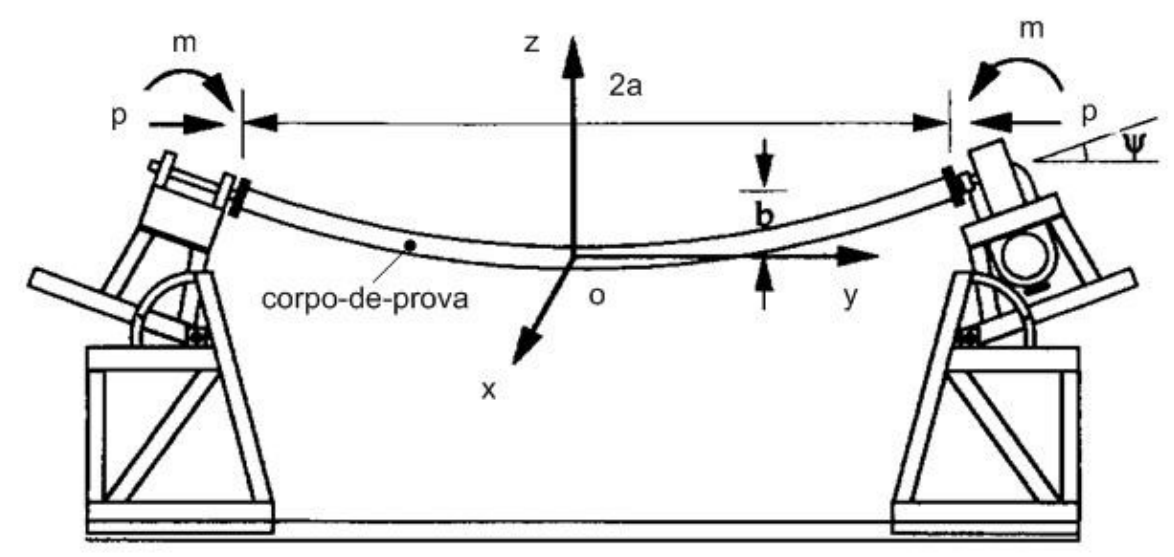

Figura 2.4 - Arranjo experimental para ensaio de fadiga por flexão-rotação (WITZ; TAN, 1995)

O trabalho mostrou que durante a flexão com rotação a maior contribuição às tensões cíclicas atuantes sobre o corpo-de-prova foi a flexão local. A falha nos corpos-de-prova sempre foi encontrada na região média destes, local onde ocorre a máxima flexão devido à curvatura. Este padrão de falha demonstrou que o efeito das condições de contorno dos extremos do espécime se expande uniformemente ao longo de todo seu comprimento. Além disso, mostrou-se que os defeitos na superfície das armaduras de tração diminuem significativamente a vida a fadiga do cabo umbilical. Neste ensaio igual aquele realizado no teste de fadiga de flexão com rotação feito por Fuku et al. (1992), as condições do experimento diferem bastante das condições reais de serviço dos cabos no meio marinho.

Saevik e Berge (1995), levaram a cabo ensaios de fadiga em risers flexíveis para uso dinâmico. Eles ensaiaram dois riser de 101,6 mm de diâmetro e $8 \mathrm{~m}$ de comprimento cada um com seu bend stiffener como mostra a Figura 2.5 (SAEVIK; BERGE, 1995). O objetivo dos ensaios foi determinar experimentalmente a vida dos riser testados quando submetidos a carregamentos ciclicos e calibrar um modelo de fadiga. Os corpos-de-prova foram submetidos a carregamentos cíclicos de tração e flexão combinados até que ocorreu a falha. O extremo do corpo-de-prova onde se encontrava o bend stiffener foi engastado na estrutura do arranjo experimental com inclinações diferentes para cada um dos dois casos de estudo, $10^{\circ}$ no primeiro caso 
e $5^{\circ}$ no segundo. O carregamento foi aplicado no lado oposto no extremo do riser com um atuador servo hidráulico.

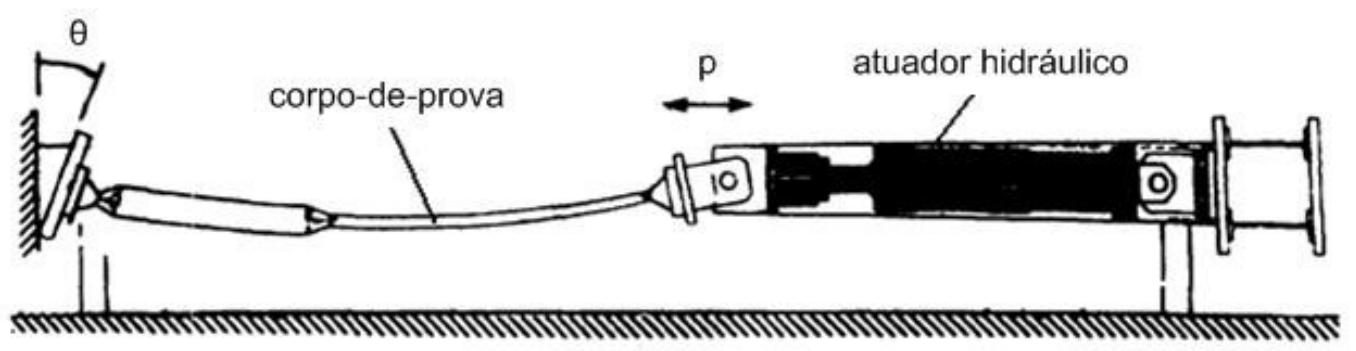

Figura 2.5 - Arranjo experimental para ensaio de fadiga a tração-flexão

(SAEVIK; BERGE, 1995)

Ambos os corpos-de-prova falharam devido à fadiga na armadura de tração, mas em diferentes lugares, o modo de falha do primeiro corpo foi fadiga num ponto de contacto entre as armaduras de tração, no segundo corpo a falha primaria foi fadiga na região da ancoragem das armaduras de tração com a resina epóxi do bend stiffener. Estudos teóricos foram realizados para correlacionar o modo de falha experimental e as predições feitas com o modelo de fadiga. A correlação entre os modos de falha dos modelos teórico e dos experimentos foi boa.

Feld et al. (1995), realizaram ensaios usando como corpos-de-prova cabos submarinhos eletro ópticos. Eles realizaram dois tipos de ensaios, primeiramente com amostras dos componentes metálicos dos cabos (tendões de aço das armaduras de tração e condutores de cobre) com o fim de levantar as curvas de tensão-deformação para logo usar estas como dados de entrada em modelos analíticos. Adicionalmente foram feitos ensaios com o material de isolamento dos condutores de cobre (Elastômero de propileno etileno - EPR) para determinar seu módulo de cisalhamento, módulo de compressão e o cisalhamento interfacial máximo admissível.

O segundo tipo de ensaio foi realizado com os cabos na integra. Os corpos-de-prova utilizados tinham $7 \mathrm{~m}$ de comprimento. Dois tipos de cabos foram testados com seção transversal de condutores de cobre medindo 70 e $80 \mathrm{~mm}^{2}$, respectivamente. Ambos os cabos tinham seção transversal muito similar, sendo esta formada por três condutores de cobre enrolados helicoidalmente ao redor do eixo do cabo, uma armadura de tração no sentido da hélice e outra no sentido contrário dos condutores de cobre e um cabo de fibra óptica. Foram ensaiados quatro corpos-de-prova, dois 
de cada tipo de cabo. Durante os ensaios os espécimes foram submetidos à tração com a rotação dos extremos livre e restringida, a flexão e a tração-flexão combinada com a rotação nos extremos restringida. Os ensaios de tração-flexão simultâneos foram feitos no arranjo mostrado na Figura 2.6 (FELD et al., 1995).

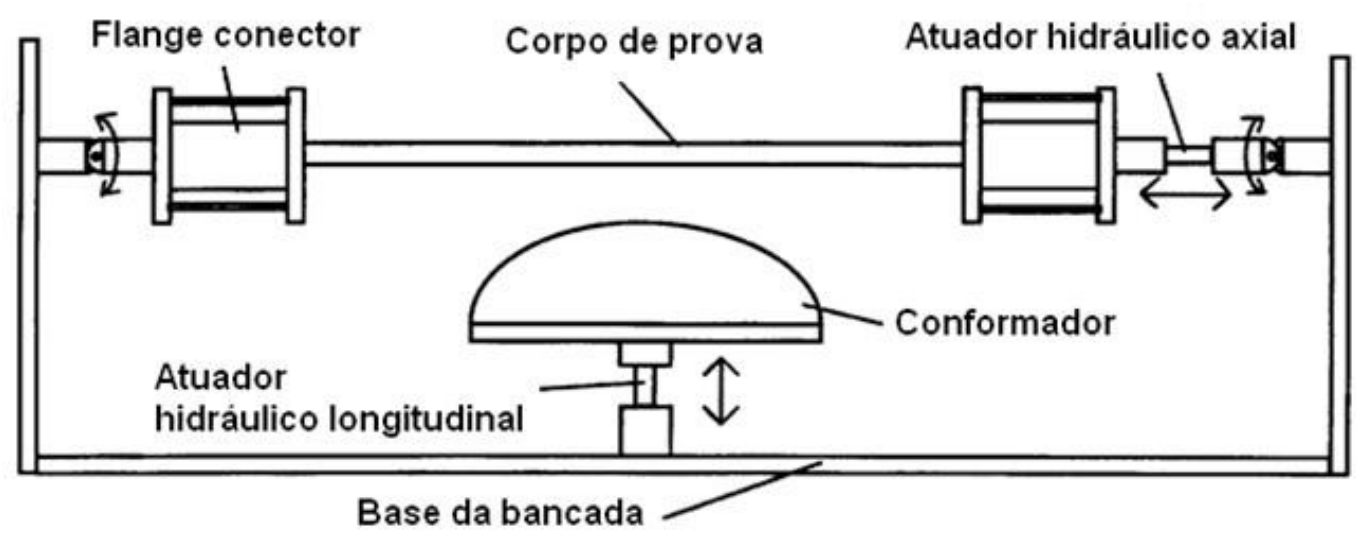

Figura 2.6 - Arranjo experimental para ensaio de flexão-tração simultâneas (FELD et al., 1995)

Durante os ensaios dos cabos foram obtidos os valores de deformação longitudinal devido aos carregamentos aplicados. Estes resultados foram usados em modelos analíticos elaborado pelos autores, incorporando aos modelos as não linearidades associadas à plasticidade dos elementos metálicos e poliméricos.

Troina et al. (2003), fizeram ensaios de flexão em tubulações flexíveis usadas em operações offshore. O corpo-de-prova testado foi uma seção de riser de 101,6 mm de diâmetro interno e $4 \mathrm{~m}$ de comprimento. O corpo-de-prova foi instrumentado com extensômetros de resistência elétrica nos tendões da armadura de tração, além disso, também empregou-se um transdutor de posição. Durante o ensaio um extremo do corpo-de-prova ficou fixo e ou outro foi deslocado originando o dobramento do espécime. Na Figura 2.7 (TROINA et al., 2003) mostra-se um esquema do arranjo usado para os ensaios. 


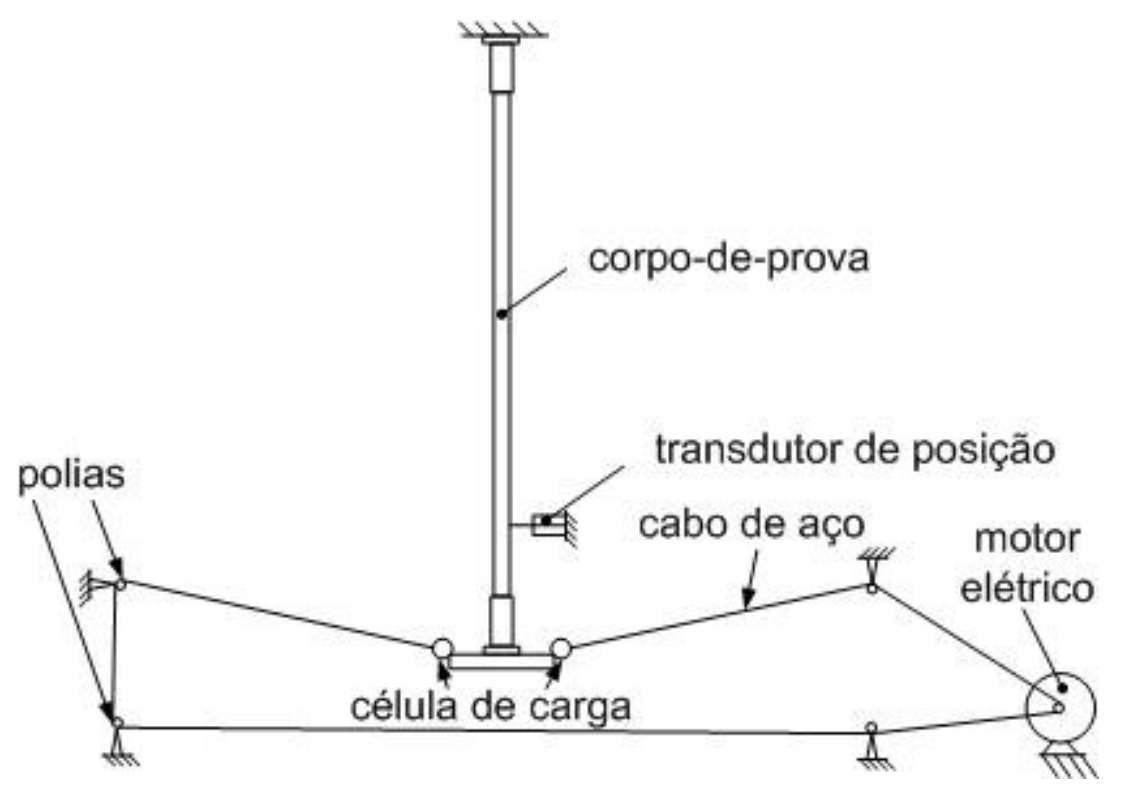

Figura 2.7 - Ensaio de flexão para estimar configuração deformada (TROINA et al., 2003)

Foram feitos três tipos de ensaios. O primeiro consistiu na variação da pressão interna até 20,68 MPa (3.000 psi) para ver como se comportava a estrutura do corpo-de-prova. No segundo ensaio foram impostos deslocamentos laterais de $+0,5$ e -0,5 m em torno de um ponto de equilíbrio da extremidade livre do corpo-de-prova.

Durante os deslocamentos todos os dados dos sensores foram registrados para estimar a configuração deformada do riser. No último ensaio feito, o extremo livre do riser foi submetido a um deslocamento continuo a baixa velocidade com o fim de determinar sua rigidez à flexão.

Durante os ensaios os valores de deformação nas armaduras de tração e dos deslocamentos foram adquiridos pelos sensores para assim conhecer as resposta deste tipo de estruturas às solicitações impostas. Após concluído o estudo os autores concluíram que quando o riser foi pressurizado sua rigidez a flexão aumentou.

Cárdenas e Gonçalves (2002a, 2004), estudaram a influência dos carregamentos cíclicos sobre as propriedades mecânicas da camada polimérica externa (HDPE) e interna (LDPE) de um cabo submarino eletro-óptico. Eles fizeram um ensaio de fadiga numa bancada projetada e fabricada segundo a norma API 17E (Apêndice A). Como corpo-de-prova foi usada uma seção de cabo com 108,5 mm de diâmetro 
externo e 13,5 $\mathrm{m}$ de comprimento. O espécime foi submetido a 30.000 carregamentos cíclicos de $60.000 \mathrm{kN}$. Após aplicar os carregamentos foram retiradas as camadas poliméricas externa (HDPE) e interna (LDPE), com estas foram elaborados corpos-de-prova para ensaios de tração.

Os resultados do ensaio de tração mostraram que os carregamentos cíclicos a que foi submetido o cabo umbilical tiveram uma significativa influência nas propriedades mecânicas da camada externa do cabo, HDPE, provocando uma grande diminuição de sua tenacidade, não acontecendo o mesmo com a camada interna elaborada de LDPE a que não sofreu uma variação perceptível nas suas propriedades mecânicas (CÁRDENAS; GONÇALVES, 2004).

Lépore e Buelta $(2003,2007)$, fizeram ensaios de fadiga em cabos umbilicais. O objetivo dos ensaios foi simular o tempo de vida útil dos cabos em condições as mais próximas possíveis à aquelas de serviço no meio marinho. Para executar os ensaios utilizaram duas bancadas projetadas e fabricadas segundo a norma API 17E. Nas Figuras 2.8 e no Apêndice A, apresentam-se os dois arranjos experimentais empregados.

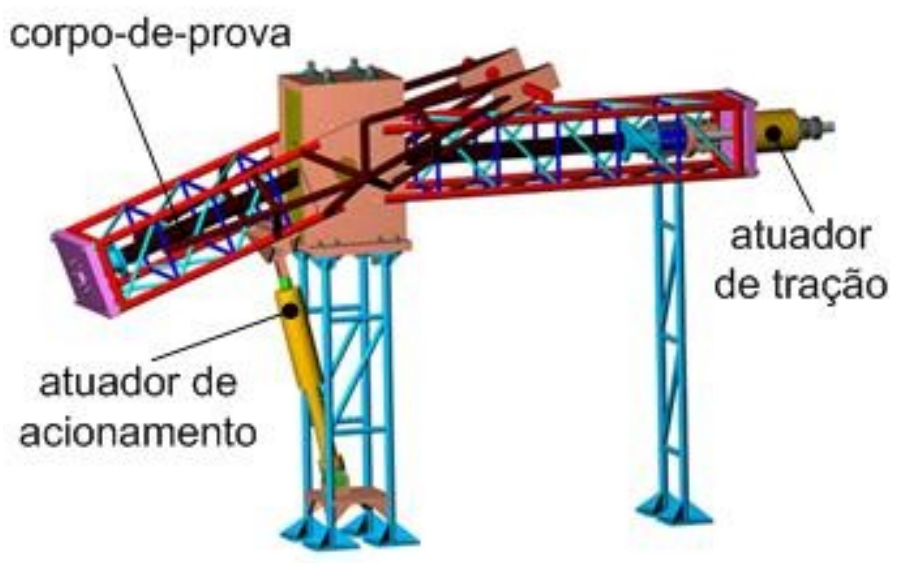

Figura 2.8 - Arranjo experimental para ensaios de fadiga por flexão-tração (LÉPORE, 2003)

Eles usaram como corpos-de-prova seções de umbilicais com 108,5 mm de diâmetro externo e com 7 e 13,5 m de comprimento. Os cabos foram instrumentados com extensômetros de resistência elétrica em vários pontos de sua armadura de 
tração externa. Durante a realização dos ensaios foram efetuadas medições da passagem da corrente elétrica ao longo dos condutores de cobre, além disso, antes e depois de concluído os ensaios foram medidas a atenuação do sinal nas fibras ópticas.

Eles observaram, que com o aumento do número de ciclos de cargas aplicadas, cresceram as deformações residuais nas armaduras de tração externas dos cabos e aumentou ligeiramente a resistência elétrica dos condutores de cobre. Nas fibras ópticas não se notou nenhum efeito na atenuação do sinal (LÉPORE, 2003).

\subsection{POLÍMEROS COMO MATERIAIS USADOS EM ESTRUTURAS}

O termo polímeros é formado por duas palavras de origem grega, a primeira poli cujo significado é muitas e a segunda meros a qual se traduz como unidades repetidas. Assim entende-se como polímeros, materiais constituídos por muitas unidades químicas repetidas. Eles estão formados por moléculas muito grandes e de elevado peso molecular (macromoléculas) nas quais os átomos das cadeias são unidos por ligações covalentes. Os meros são arranjados formando longas cadeias moleculares (VAN VLACK, 1984; MASCIA, 1989; RAYMOND, 1991; CALLISTER, 1997; CANEVAROLO, 2002).

Os polímeros estruturais têm uma ampla aplicação na vida moderna e a sua utilização tem-se estendido em larga escala na indústria. Suas principais vantagens, que os têm tornado materiais de grande interesse para a engenharia, são: módulos de elasticidade considerados adequados para uso estrutural, quando em temperatura ambiente; baixa densidade em comparação com outros materiais de uso estrutural como os metais; alta razão de resistência mecânica por unidade de massa em comparação com outros materiais; boa resistência ao impacto; facilidades de fabricação e processamento; menor consumo de energia para fabricação e transformação; não susceptível ao fenômeno de corrosão, já que a ausência de insaturações olefínicas favorece as características de resistência à oxidação e às intempéries; bom isolamento elétrico e térmico; baixo custo de acabamento (BLASS, 1988; MANO, 1991; ANDERSON, 1995). 


\subsubsection{Classificação dos polímeros}

De acordo com sua estrutura molecular os polímeros podem ser divididos em dois grandes grupos: Termoplásticos e Termorrígidos (FLORY, 1953; HARPER, 1992), dentro deste último grupo incluem-se os elastômeros.

Os termoplásticos, grupo no qual se encaixam o polietileno de alta densidade (HDPE), são formados por cadeias moleculares bidimensionais unidas por forças secundárias fracas, forças de Van der Waals, que permitem os movimentos individuais das cadeias. Eles são muito sensíveis às mudanças de temperatura, amolecendo quando aquecidos (eventualmente se liquefazendo) e endurecendo quando resfriados. Este processo é totalmente reversível e pode ser repetido, eles são solúveis e recicláveis (VAN VLACK, 1984; SUH, TURNER, 1985; CALLISTER, 1997).

Em nível molecular, as forças das ligações secundárias são diminuídas à medida que se elevam as temperaturas e pressões, devido ao aumento do movimento molecular, de tal forma que o movimento relativo das cadeias adjacentes é facilitado quando uma solicitação mecânica é aplicada. Uma degradação irreversível acontece quando a temperatura de um termoplástico fundido é elevada até o ponto no qual a vibração molecular torna-se forte o bastante para quebrar ligações covalentes primárias, (VAN VLACK, 1984; SUH, TURNER, 1985; CALLISTER, 1997).

\subsubsection{Cristalinidade dos materiais poliméricos}

A estrutura dos polímeros em estado sólido depende do modo com que as cadeias moleculares são empacotadas. A fase amorfa è devido a desordem das cadeias, já a fase cristalina esta definida por cadeias que tem uma ordem regular e repetitiva. Daí que a cristalinidade nos polímeros depende do alinhamento dos segmentos das cadeias poliméricas em um arranjo tridimensional quase perfeito.

As fases cristalinas estão interconectadas com as fases amorfas não existindo uma divisão clara entre elas. Uma completa transformação para o estado cristalino é 
impossível já que apenas uma parte das moléculas adota uma conformação ordenada necessária.

Existem varios modelos que explicam a morfologia dos materiais poliméricos. Um dos mais antigos é o "Modelo da Micela Franjada". Segundo este modelo, os polímeros cristalinos são constituídos por duas fases, uma de cristalitos pequenos (100 $\AA$ ), dispersos numa matriz amorfa. Os cristalitos são formados por segmentos moleculares de diferentes cadeias, alinhados uns aos outros paralelamente em ordem tridimensional. Com o aprofundamento do estudo das estruturas poliméricas este modelo foi caducando, pois não explicava a existência de monocristais poliméricos nem de agregados cristalinos maiores, os esferulitos (CALLISTER, 1997; CANEVAROLO, 2002).

Atualmente a teoria mais aceita é o "Modelo das cadeias dobradas". Este modelo apresenta os polímeros formados por cristais e estes constituídos por placas finas, chamadas de lamelas, de espessura entre 100 e $200 \AA$. Nos cristais as cadeias são orientadas na direção normal à superfície das lamelas. Devido que o comprimento das cadeias moleculares é muito maior, $10^{3}$ a $10^{5} \AA$, que a espessura das lamelas $10^{2} \AA$. Conclui-se que as cadeias devem estar dobradas sobre si mesmas dentro do cristal. Cada molécula dobra-se de maneira regular, estabelecendo um plano de dobramento de espessura I. A espessura do cristal é chamada período de dobramento e coincide com a altura do plano de dobramento (CALLISTER, 1997; CANEVAROLO, 2002).

Uma das principais características da morfologia dos polímeros cristalizados a partir do estado fundido é a existência de esferulitos. Ao ser resfriado um polímero fundido cristalizável, o processo de cristalização inicia-se em núcleos individuais que se desenvolvem radialmente, formando os esferulitos (CALLISTER, 1997; CANEVAROLO, 2002).

Os esferulitos são caracterizados por ter uma estrutura fina a qual é composta por lamelas na forma de feixes que crescem radialmente a partir de um núcleo central. Inicialmente as lamelas são paralelas umas a outras, mas ao crescer divergem, torcem-se e ramificam-se, chegando a formar estruturas esferulíticas radialmente simétricas. Eles são considerados agregados esféricos de milhares de monocristais lamelares os que se orientam em direção radial a partir de um núcleo, e são 
interligados por materiais amorfos (LIN, ARGON, 1994; CALLISTER, 1997; CANEVAROLO, 2002). Na Figura 2.9 mostra-se esquematicamente o modelo das cadeias dobradas: a, morfologia de um esferulito (LIN; ARGON, 1994) e b, lamelas que compõe o esferulito (CALLISTER, 1997).

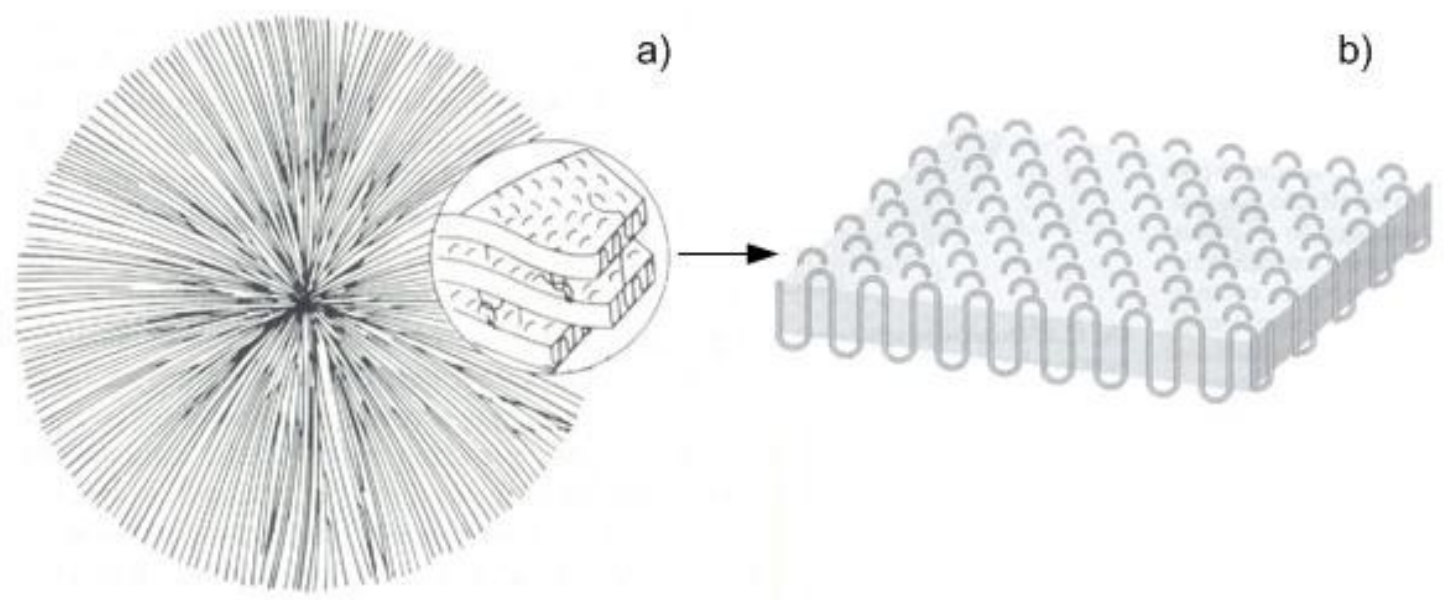

Figura 2.9 - Modelo das cadeias dobradas: a, morfologia de um esferulito; $b$, lamelas que compõe o esferulito (LIN, ARGON, 1994; CALLISTER, 1997)

A cristalinidade nos polímeros depende de vários fatores tais como a estrutura química, presença de impurezas e as condições de cristalização. Os polímeros formados por cadeias lineares têm maior cristalinidade, quando existem ramificações na cadeia principal ou grupos laterais a cristalinidade diminui. A cristalização pode ser favorecida quando estas ramificações ou grupos laterais são pequenos, regulares e arranjados simetricamente (CANEVAROLO, 2002).

Nos polímeros semicristalinos, o caso do HDPE, o grau de cristalinidade tem uma forte influência nas suas propriedades físicas e mecânicas. O aumento da cristalinidade no material polimérico leva a um aumento em várias propriedades do material tais como: rigidez, resistência mecânica, resistência à abrasão, temperatura de transição vítrea $\left(T_{g}\right)$, temperatura de fusão $\left(T_{f}\right)$, por outro lado reduzem-se a resistência ao impacto e ao alongamento na ruptura (CANEVAROLO, 2002). 
Na Figura 2.10 (CALLISTER, 1997), mostra-se uma micrografia de transmissão (usando luz polarizada) do polietileno onde pode-se apreciar os esferulitos de sua estrutura. Entre os esferulitos se formam contornos lineares adjacentes e dentro de cada um de eles aparece uma cruz de malta (CALLISTER, 1997).

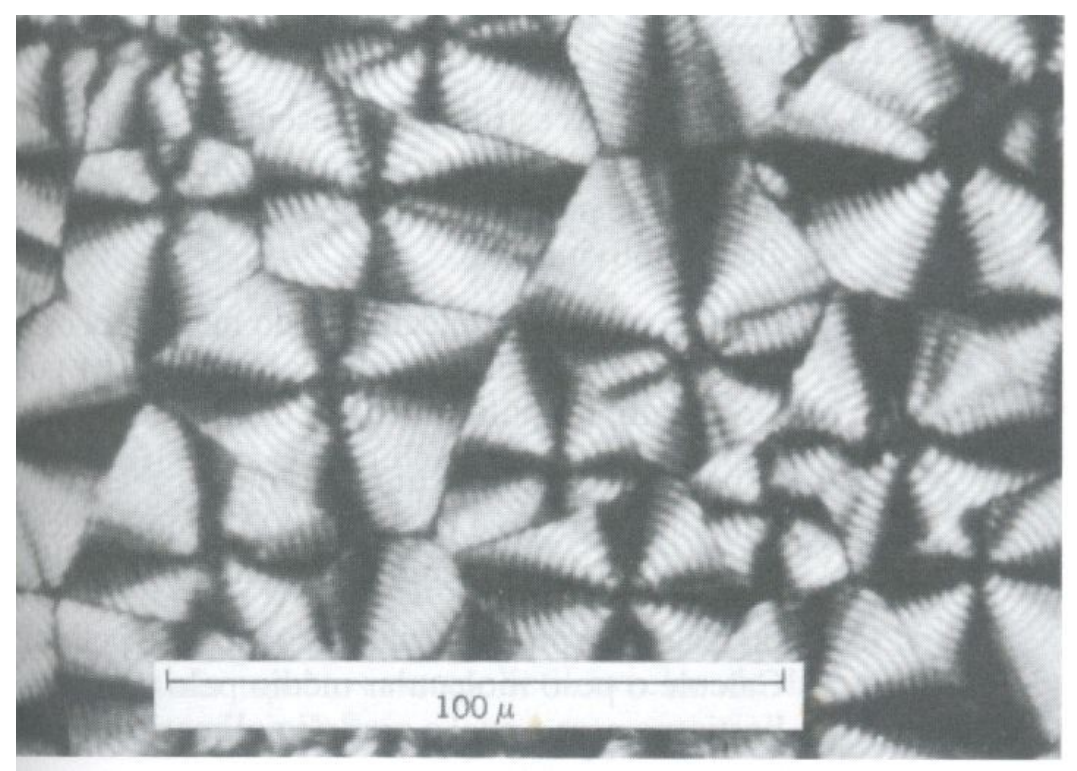

Figura 2.10 - Micrografia óptica (obtida usando luz polarizada) da estrutura esferulítica do polietileno (CALLISTER, 1997)

\subsubsection{Conformação das cadeias poliméricas}

Chamamos de conformação da cadeia polimérica ao arranjo geométrico espacial que esta tem. Este pode ser mudado por meio de simples rotações das ligações covalentes C-C. Estas rotações são livres mais devem respeitar a geometria tetraédrica do carbono. O ângulo da ligação C-C sempre é de $109^{\circ} 28^{`}$ e a distância entre dois átomos ligados é de 1,54 $\AA$ (CANEVAROLO, 2002). Na Figura 2.11 (CANEVAROLO, 2002) mostra-se esquematicamente a conformação de um segmento da cadeia polimérica, formada por quatro átomos de carbono ligados por ligações covalentes simples. 


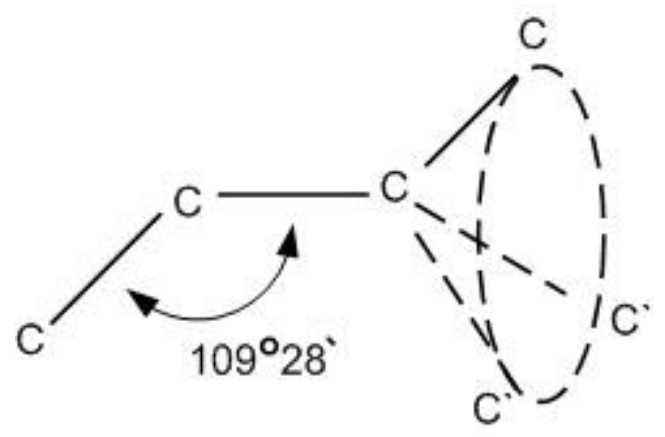

Figura 2.11 - Cadeia polimérica com ligações covalentes simples (CANEVAROLO, 2002)

Uma cadeia olefínica saturada possui no mínimo 2000 ligações covalentes simples, sendo que todas as ligações poderão se posicionar com esse mesmo grau de liberdade. Isto leva a uma grande mobilidade das cadeias poliméricas (CANEVAROLO, 2002).

A forma de empacotamento das cadeias poliméricas vai depender de sua estrutura química e do meio em que esta inserida. Existem três tipos de conformações, Enrodilhada ou em novelo, Helicoidal e Zig-Zag planar (CANEVAROLO, 2002).

A conformação tipo Zig-Zag planar, é característica do estado sólido. Cadeias lineares sem grupos laterais podem se empacotar de maneira regular, conformandose em tipo Zig-Zag. Os átomos de carbono da cadeia principal se arranjam espacialmente em um plano único, mantendo constante os ângulos e as distâncias entre ligações. O HDPE apresenta este tipo de conformação. A Figura 2.12 (CANEVAROLO, 2002) mostra este tipo de conformação para uma seqüência etilênica.

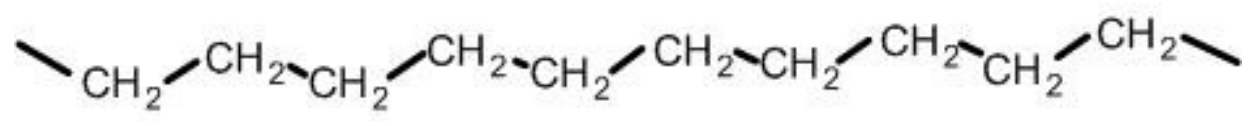

Figura 2.12 - Conformação tipo Zig-Zag planar para uma seqüência etilênica (CANEVAROLO, 2002) 
Na Figura 2.13 (LIN, ARGON, 1994; WARD, SWEENEY, 2004), mostra-se esquematicamente a célula unitária do polietileno, a qual tem uma estrutura ortorrômbica.

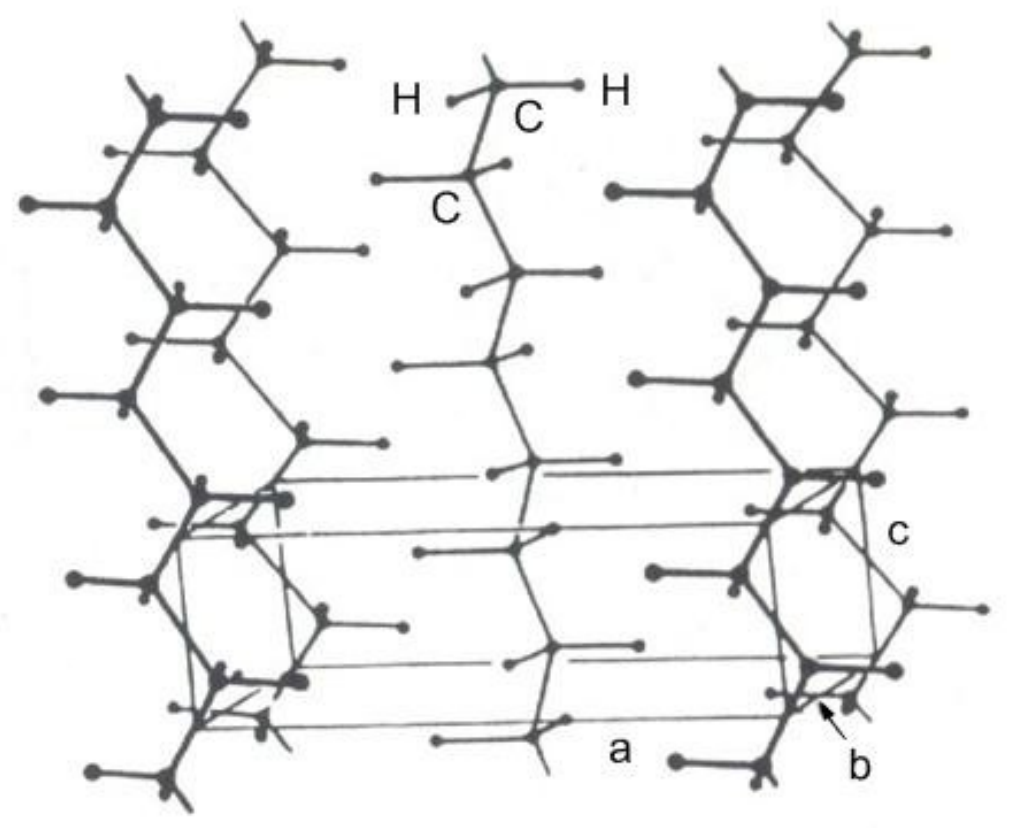

Figura 2.13 - Modelo da célula unitária do polietileno: $a=0,74 \mathrm{~nm}, b=0,493 \mathrm{~nm}$, c=0,254 nm (LIN, ARGON, 1994; WARD, SWEENEY, 2004)

\subsubsection{Relações tensão-deformação nos materiais poliméricos}

Os materiais poliméricos são muito sensíveis à taxa de deformação e à temperatura. Daí a grande influência destes fatores nas curvas tensão-deformação destes materiais. Na Figura 2.14 (NIELSEN; LANDEL, 1994), mostram-se as curvas tensãodeformação características para os diferentes comportamento dos materiais poliméricos.

A Figura 2.14a, apresenta as curvas tensão-deformação típicas dos materiais termorrígidos os quais são duros e frágeis, pelo que sua deformação máxima é somente um pequeno percentual. Este tipo de polímero é muito pouco sensível à taxa de deformação e à variação da temperatura (NIELSEN; LANDEL, 1994). 

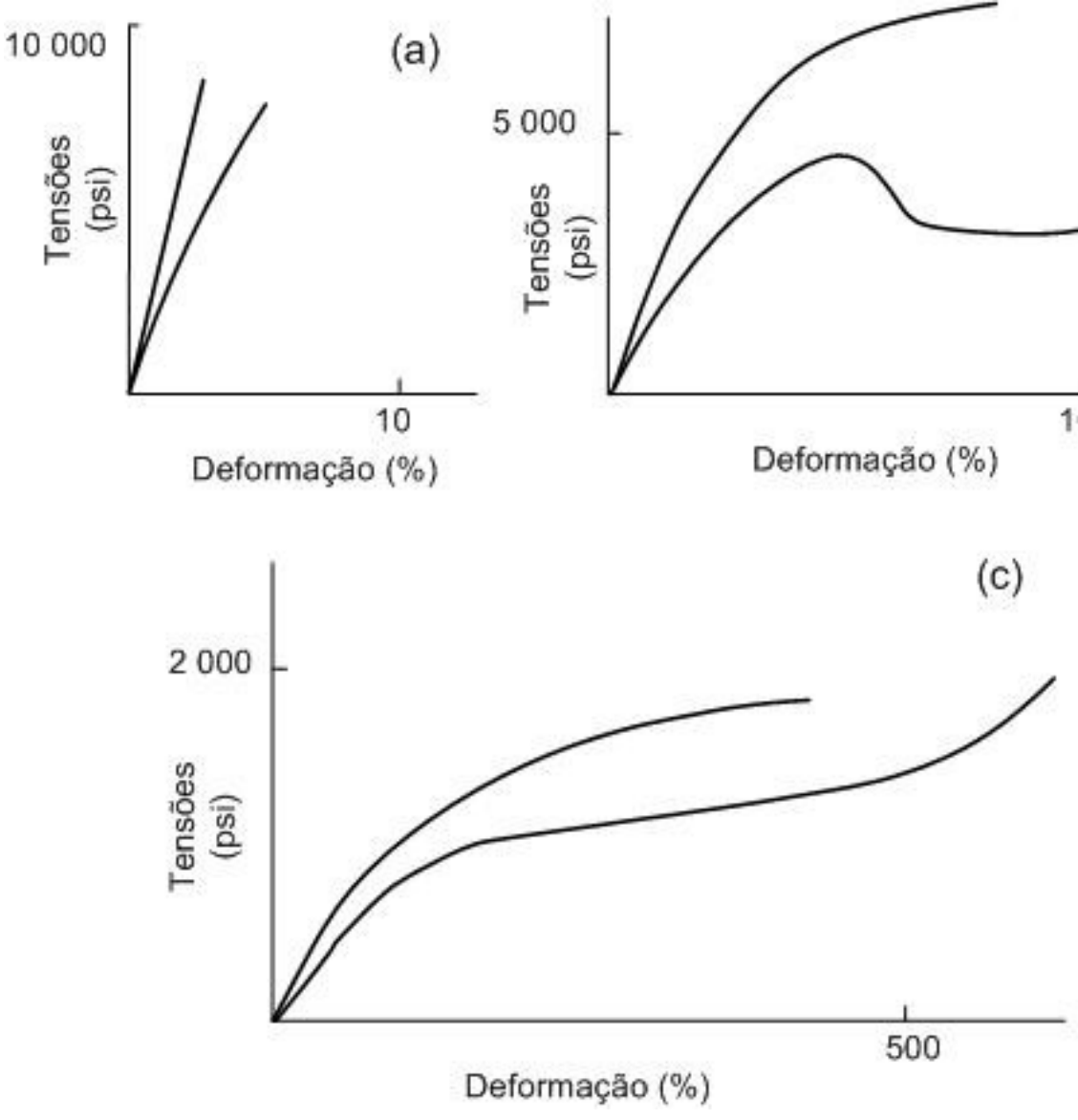

Figura 2.14 - Curvas tensão-deformação características para diferentes tipos de materiais poliméricos: a, termorrígidos; b, termoplásticos; c, elastômeros (NIELSEN; LANDEL, 1994)

Para os polímeros termoplásticos cristalinos e semicristalinos a forma típica das curvas tensão versus deformação é mostrada na Figura 2.14b, estes são muito sensíveis a variações de temperatura e a taxas de deformação. Geralmente o estrangulamento e arrastamento destes começa nas seções mais frágeis. A deformação final neste tipo de materiais pode atingir até $700 \%$. A zona onde surge o pescoço não sofre ruptura imediatamente quando o fluxo de tensões aumenta devido à orientação das cadeias moleculares. Antes da fratura, a seção transversal do corpo-de-prova diminui uniformemente (NIELSEN; LANDEL, 1994).

Para elastômeros e termoplásticos muito dúcteis que não fazem pescoço a curva de tensão-deformação características é mostrada na Figura 2.14c (NIELSEN; LANDEL, 1994). 
Na Figura 2.15 (SUH; TURNER, 1985) podem-se apreciar as variações que acontecem no comportamento dos polímeros de uso estrutural devido as mudanças na taxa de deformação e na temperatura.

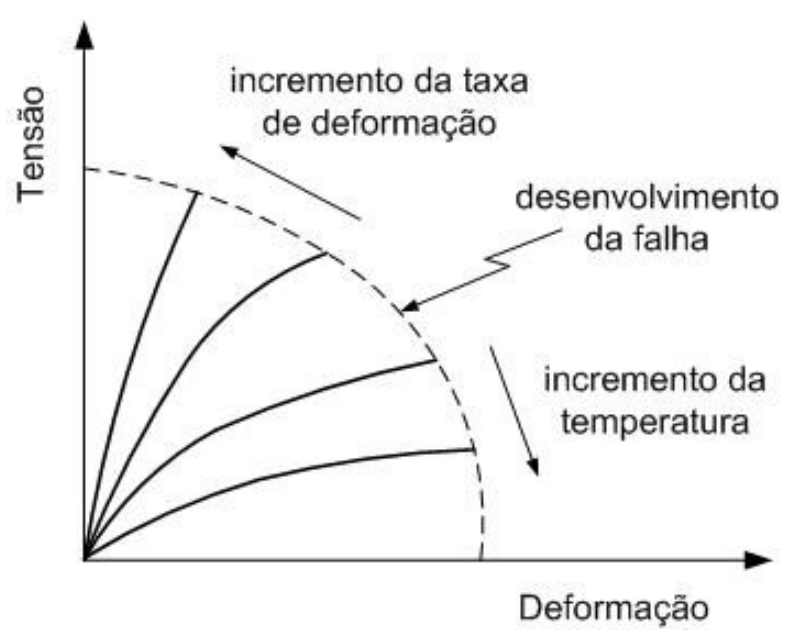

Figura 2.15 - Efeitos da taxa de deformação e da temperatura sob a curva tensãodeformação dos polímeros (SUH; TURNER, 1985)

As linhas contínuas mostram as curvas tensão-deformação para taxa de deformação constante e diferentes temperaturas ou para temperatura constante e diferentes taxas de deformação. Pode-se observar que para grandes taxas de deformação e para baixas temperaturas os materiais poliméricos apresentam um comportamento vítreo (Suh; Turner, 1985).

\subsubsection{Modelos físicos e equações constitutivas representativas do comportamento visco-elasto-plástico dos polímeros}

O comportamento mecânico dos polímeros tem uma dependência, marcada da temperatura e da taxa de deformação, devido a sua natureza visco-elasto-plástica destes tipos de materiais. Isto implica que tenham um comportamento similar aos sólidos puramente elásticos e aos líquidos viscosos (NIELSEN; LANDEL, 1994).

Para simular este comportamento geralmente usam-se dois modelos físicos muito simples ou a combinação destes, os quais são tratados matematicamente usando 
varias equações constitutivas, estes modelos são o sólido elástico e o líquido viscoso.

O sólido elástico é representado por uma mola ideal, com forma definida, sob a ação de uma carga que se deforma linearmente e ao ser removida a carga, o corpo volta a sua forma original, ou seja, recupera-se a deformação. Neste sistema, todo o trabalho é armazenado como energia potencial, tal qual uma mola deformada.

O liquido viscoso é representado por um amortecedor (pistão com fluido), no qual um líquido flui irreversivelmente sob a ação de cargas externas. Neste sistema todo o trabalho feito sobre ele é dissipado em forma de calor.

Na Figura 2.16 (NIELSEN; LANDEL, 1994), pode-se apreciar os modelos simples mais empregados para simular o comportamento mecânico dos polímeros estruturais, e as curvas tensão-deformação características destes.
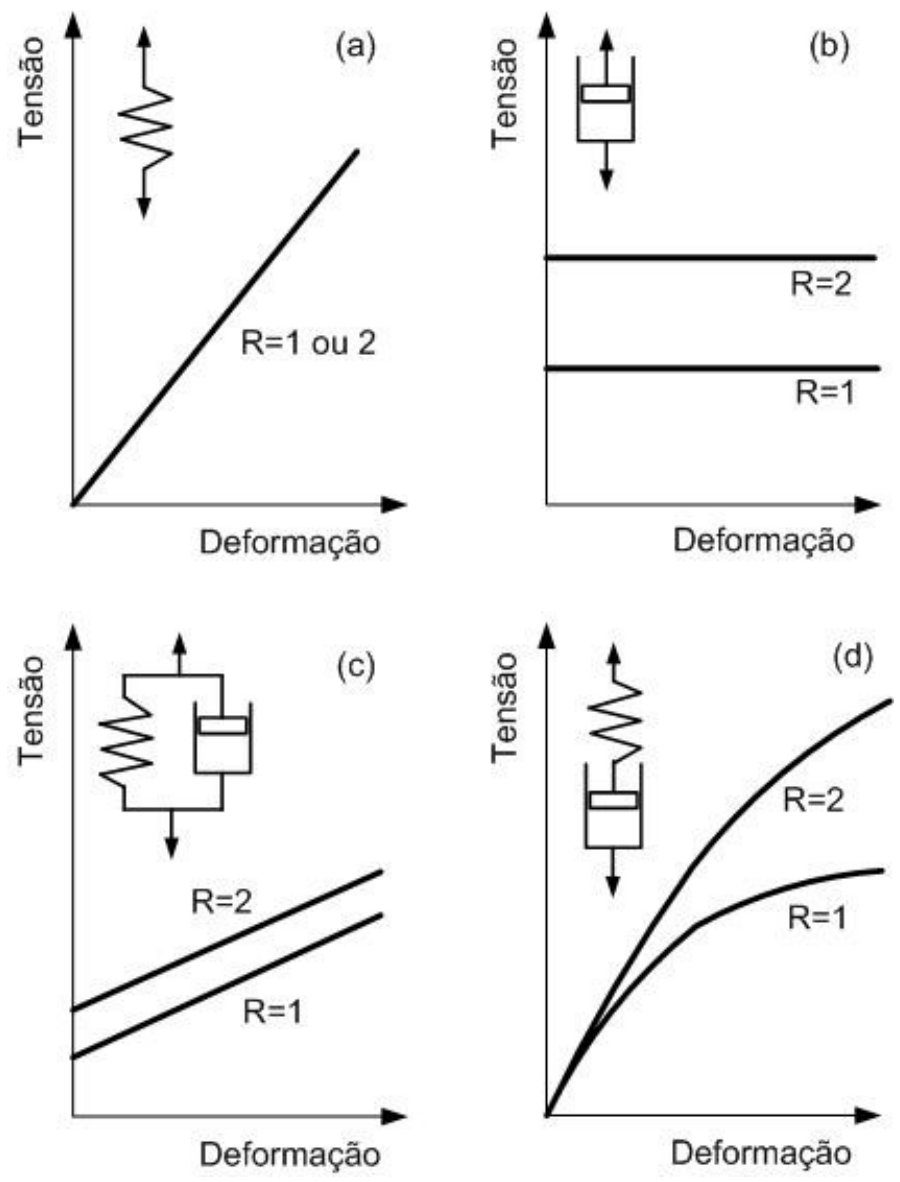

Figura 2.16 - Modelos simples empregados para simular comportamento mecânico em polímeros estruturais e suas curvas tensão-deformação características

$\left(\mathrm{R}=\mathrm{d} \varepsilon / \mathrm{dt}\right.$ - taxa de deformação, $\left.\mathrm{R}_{2}=2 \mathrm{R}_{1}\right)$, (NIELSEN; LANDEL, 1994) 
A Figura 2.16a, representa a curva tensão-deformação de uma mola a qual tem módulo elástico constante não dependendo da velocidade do ensaio. Ela obedece a Lei de Hooke eq.(2.1).

$$
\sigma=E \cdot \varepsilon
$$

onde:

E- módulo de elasticidade (Pa);

$\varepsilon$ - deformação.

A deformação é diretamente proporcional à tensão originada pela carga aplicada. $O$ módulo de elasticidade è o coeficiente de proporcionalidade, este representa a energia necessária para deformar o ângulo e a distância das ligações entre os átomos das cadeias poliméricas (CANEVAROLO, 2002).

Na Figura 2.16b, mostra-se um amortecedor onde a força resistiva ao movimento é proporcional à taxa de deformação do ensaio eq.(2.2), (NIELSEN; LANDEL, 1994).

$$
\sigma=R \cdot \eta
$$

onde:

R- taxa de deformação (1/s);

$\eta$ - viscosidade do amortecedor (poise).

A viscosidade $\eta$ representa o atrito entre os segmentos das cadeias poliméricas que são originados durante a deformação. $\mathrm{O}$ valor de $\mathrm{R}=\mathrm{d} \varepsilon / \mathrm{dt}$ representa a dependência do tempo na resposta dos materiais poliméricos a uma solicitação determinada.

A Figura 2.16c, mostra o modelo de Voigt-Kelvin, composto por uma mola e um amortecedor ligados em paralelo. Neste modelo a tensão total $\left(\sigma_{T}\right)$ é compartilhada entre a mola e o amortecedor $\left(\sigma_{T}=\sigma_{m}+\sigma_{a}\right)$, mas a deformação em cada componente é igual à deformação total $\left(\varepsilon_{T}=\varepsilon_{m}=\varepsilon_{\mathrm{a}}\right)$, (WARD; SWEENEY, 2004). A curva tensãodeformação é dada pela eq.(2.3), (NIELSEN; LANDEL, 1994).

$$
\sigma=R \cdot \eta+E \cdot \varepsilon
$$


A tensão inicial do amortecedor tem um valor maior que zero, e na mola esticada incrementa-se a tensão, a declividade da linha é o módulo de elasticidade da mola.

A Figura 2.16d (NIELSEN; LANDEL, 1994), corresponde ao modelo de Maxwell, composto este por uma mola e um amortecedor ligados em serie. Neste modelo a tensão na mola $\left(\sigma_{\mathrm{m}}\right)$ e no amortecedor $\left(\sigma_{\mathrm{a}}\right)$ são idênticas $\left(\sigma_{\mathrm{T}}=\sigma_{\mathrm{m}}=\sigma_{\mathrm{a}}\right)$. Já a deformação total $\left(\varepsilon_{\mathrm{T}}\right)$ é a somatória da deformação na mola $\left(\varepsilon_{\mathrm{m}}\right)$ e a deformação no amortecedor $\left(\varepsilon_{\mathrm{a}}\right),\left(\varepsilon_{\mathrm{T}}=\varepsilon_{\mathrm{m}}+\varepsilon_{\mathrm{a}}\right)$, (WARD; SWEENEY, 2004). O comportamento da curva tensão-deformação é dado pelas eq.(2.4) ou (2.5), (NIELSEN; LANDEL, 1994).

$$
\begin{aligned}
& \sigma=R \cdot \eta\left[1-\exp \left(-\frac{E \cdot \varepsilon}{R \cdot \eta}\right)\right] \\
& \text { ou } \\
& \sigma=R \cdot \eta\left[1-\exp \left(-\frac{t}{\tau}\right)\right]
\end{aligned}
$$

onde:

t- tempo (s);

$\tau$ - tempo de relaxação (s).

A declividade inicial corresponde ao estiramento da mola e é dado por seu módulo de elasticidade, o qual é independente da taxa de deformação. Ao aumentar a deformação, a declividade da curva decresce e sua magnitude depende da velocidade do ensaio quando o amortecedor começa a relaxar parte das tensões. Eventualmente a mola pára de esticar-se e todo o deslocamento decorre do movimento do amortecedor. A curva tende a ficar plana e comportar-se como na Figura 2.16b.

$\mathrm{Na}$ realidade os materiais poliméricos apresentam um comportamento mais complexo que os modelos apresentados na Figura 2.16. Não obstante, os polímeros muito frágeis tem curvas semelhantes às da Figura 2.16a, abaixo do ponto da falha, e os muito dúcteis tem curvas similares às da Figura 2.16d. Nenhum destes modelos mostram o ponto de escoamento característico dos polímeros semicristalinos como o HDPE. 


\subsection{COMPORTAMENTO A FRATURA DOS MATERIAIS POLIMÉRICOS}

Fratura e falha do material têm sido associadas com os testes de tensãodeformação ou à ruptura por fluência (NIELSEN; LANDEL, 1994). Entende-se por fratura a separação de um corpo ou peça em duas ou mais partes como resposta da aplicação de uma carga sobre o mesmo. Esta tem dois modos de acontecer: fratura dúctil ou fratura frágil (CALLISTER, 1997).

A fratura dúctil é caracterizada por uma deformação plástica extensiva na vizinhança da propagação da trinca com grande absorção de energia antes que aconteça a falha. Este processo é lento e a sua extensão não aumenta, a não ser que aconteça um incremento das tensões aplicadas. O segundo modo, a fratura frágil, acontece com uma deformação plástica pequena e muito pouca absorção de energia. Durante esta, a propagação da trinca é extremamente rápida, contínua, propagando-se espontaneamente sem um incremento na magnitude da carga aplicada (CALLISTER, 1997).

A fratura dúctil é menos perigosa do que a frágil, já que a presença de uma deformação plástica maior dá um aviso da iminência da falha, ao contrário da segunda que acontece repentina e catastroficamente sem prévio aviso como conseqüência da espontânea e rápida propagação da trinca. Além disso, precisa-se de maior quantidade de energia de deformação para induzir a fratura dúctil. Todo processo de fratura envolve duas etapas, primeiro a formação e depois a propagação da trinca, (CALLISTER, 1997).

\subsubsection{Mecânica da fratura linear-elástica (MFEL)}

Os diversos estudos de comportamento a fratura de polímeros abordam o assunto através de três diferentes enfoques, estes são: a mecânica dos meios contínuos; o comportamento da estrutura molecular; e aproximação estatística. A aproximação estatística permite apreciar o início do processo de fratura devido a uma série de eventos que podem ser previstos através de considerações determinísticas. A situação é mais simples para materiais que são deformados de uma forma elástico- 
linear, devido à não dependência do tempo, a visco-elasticidade e a deformação plástica não são consideradas (KINLOCH; YOUNG, 1983).

O principal problema dos polímeros dúcteis é sua tendência a sofrer uma transição para um comportamento frágil devido a modificações nas condições de ensaio, por exemplo diminuição da temperatura ou incremento da taxa de deformação.

$\mathrm{Na}$ maioria das situações práticas, as fraturas são originadas por concentrações locais de tensões, tais como as imperfeições e os entalhes. Portanto, é extremamente importante $\mathrm{o}$ conhecimento do estado local de tensões $\mathrm{e}$ deformações (KINLOCH; YOUNG, 1983).

Para materiais com comportamento elástico, a análise do fenômeno de fratura é mais simples, já que independe do tempo. A dependência do tempo e a deformação plástica nos materiais que se comportam visco-elasticamente tornam mais complexa esta análise.

Um destes casos simples é a análise das tensões ao redor de um furo elíptico numa chapa fina submetida a uma tensão $\sigma_{\circ}$, como é mostrado na Figura 2.17 (KINLOCH; YOUNG, 1983).

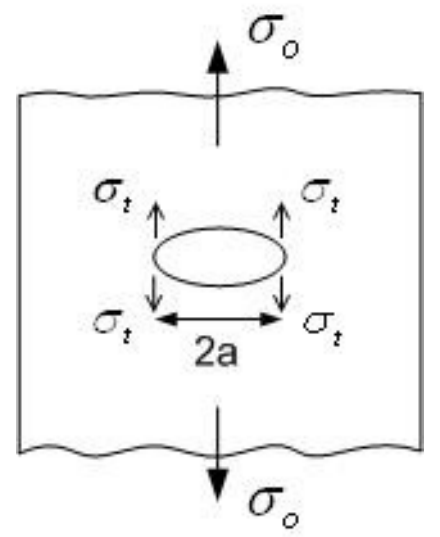

Figura 2.17 - Trinca simulada por furo elíptico submetida à tensão numa chapa de grandes dimensões (KINLOCH; YOUNG, 1983) 
Neste caso as tensões $\sigma_{\mathrm{t}}$, nos extremos do eixo maior do furo são dadas pela eq. (2.6).

$$
\sigma_{t}=\sigma_{0}\left(1+2 \sqrt{\frac{a}{r}}\right)
$$

onde:

$\sigma_{t}-$ tensão nos extremos do furo $(\mathrm{Pa})$;

$\sigma_{\circ}$ - tensão aplicada $(\mathrm{Pa})$;

a- semi-comprimento do furo no eixo maior $(\mathrm{m})$;

r- raio de curvatura na ponta do furo $(m)$.

Neste caso, a falha acontece onde a concentração de tensões é maior e $\left(\sigma_{t} / \sigma_{0}\right)$ aumenta com incremento de a e o decréscimo de $\mathbf{r}$, ainda que, como $\mathbf{r}$ tende a zero o furo elíptico converte-se numa trinca, a concentração de tensão passa a ser infinita e só uma aproximação modificada é necessária. Uma forma de superar este problema é usando a análise clássica de Griffith.

Griffith (1920), resolveu o problema da singularidade matemática da concentração de tensões infinitas na ponta da trinca realizando um balanço energético para o modelo de fratura. Ele relacionou a energia liberada pela propagação da trinca com a energia requerida para criar uma superfície nova. Desta forma, relacionou a tensão de fratura $\sigma_{f}$, com o semicomprimento da trinca no seu eixo maior e obteve a eq.(2.7).

$$
\sigma_{f}=\sqrt{\frac{2 \cdot E \cdot \gamma}{\pi \cdot a}}
$$

onde:

$\sigma_{f}$ - tensão de fratura $(\mathrm{Pa})$;

E- módulo de Elasticidade (Pa);

$\gamma$ - energia superficial liberada $\left(\mathrm{J} \mathrm{m}^{-2}\right)$. 
Medindo-se a tensão de fratura como uma função de a, obtém-se a equação de Griffith para os materiais frágeis, como é o caso dos polímeros cristalinos (KINLOCH, YOUNG, 1983; NIELSEN, 1962; NIELSEN, LANDEL, 1994). No entanto, o valor de $\gamma$, derivado das medições, é maior que a energia superficial liberada, devido a um elevado grau de deformações plásticas locais na ponta da trinca. A energia dissipada por este processo, o termo $2 \gamma$ da equação de Griffith é substituído pela energia de fratura $\left(G_{c}\right)$ eq.(2.8) e (2.9).

$$
\begin{aligned}
& \sigma_{f}=\sqrt{\frac{E \cdot G_{c}}{\pi \cdot a}} \quad \text { ou } \\
& \sigma_{f}=\sqrt{\frac{E \cdot G_{c}}{\pi\left(1-v^{2}\right) a}} \quad \text { (estado plano de tensões) (2.8) }
\end{aligned}
$$

onde:

$\mathrm{G}_{\mathrm{c}}$ - energia de fratura $\left(\mathrm{J} \mathrm{m}^{-2}\right)$;

$v$ - coeficiente de Poisson.

Ainda que a resistência à fratura seja um parâmetro fácil de definir, não acontece o mesmo com a energia de fratura $\mathbf{G}_{c}$. Kinloch e Young (1983) a definem como a energia requerida para formar uma unidade de trinca.

Um aspecto útil da aproximação de Griffith é que o efeito dos defeitos presentes no corpo-de-prova pode ser observado rapidamente. O módulo de elasticidade e a energia de fratura podem ser tratados como constantes do material para certas condições de ensaio. A resistência à fratura poderá ser controlada principalmente pela dimensão do comprimento da trinca ou defeitos na estrutura. Daí, se as dimensões do defeito são conhecidas, a resistência a fratura pode-se predizer.

Uma outra forma de abordar a análise de fratura é através da utilização do Fator de Intensificação de Tensões definido através dos desenvolvimentos teóricos de Westergaard (1939), que apresenta soluções para certas funções de tensão 
considerando a presença de uma trinca numa lâmina infinita, como a representada na Figura 2.18 (KINLOCH; YOUNG, 1983).

Para regiões fechadas na ponta da trinca a solução é dada pela eq.(2.10)

$$
\sigma_{i j}=\sigma_{0} \sqrt{\frac{a}{2 \cdot r}} f_{i j}(\theta)
$$

onde:

$\sigma_{\mathrm{ij}}$ - componente do tensor de tensões no ponto $(\mathrm{Pa})$;

r e $\theta$ - coordenadas polares do ponto;

$\mathrm{f}_{\mathrm{ij}}$ - função conhecida de $\theta$.

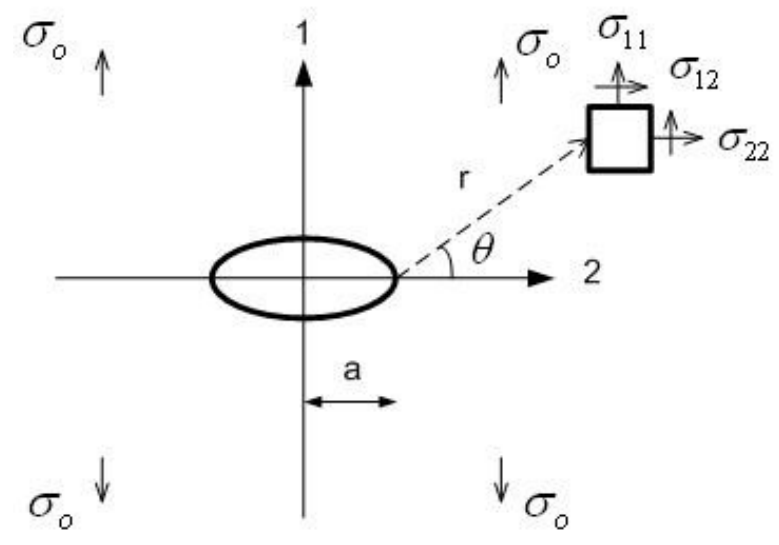

Figura 2.18 - Trinca aguda numa lâmina infinita tensionado uniformemente (KINLOCH; YOUNG, 1983)

Irwin (1964) modificou esta solução como se mostra na eq.(2.11).

$$
\sigma_{i j}=\frac{K}{\sqrt{2 \cdot \pi \cdot r}} f_{i j}(\theta)
$$

onde $\mathrm{K}$ foi definido como o Fator de Intensificação de Tensões, sendo estabelecido para a lâmina infinita como sendo igual a $K=\sigma_{\circ}(\pi a)^{1 / 2}$. 
$\mathrm{O}$ fator de intensidade de tensões $\mathrm{K}$, refere-se à magnitude das intensidades de tensões locais na trinca em termos de carregamento aplicado e geometria da estrutura onde é localizada a trinca.

Uma trinca num sólido pode ser feita de três modos diferentes os quais são mostrados na Figura 2.19 (KINLOCH; YOUNG, 1983): a) Modo I, abertura; b) Modo II, deslizamento ou cisalhamento no plano; c) Modo III, corte ou cisalhamento fora do plano.

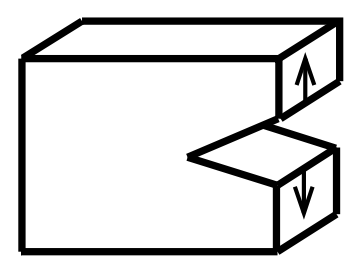

(a)

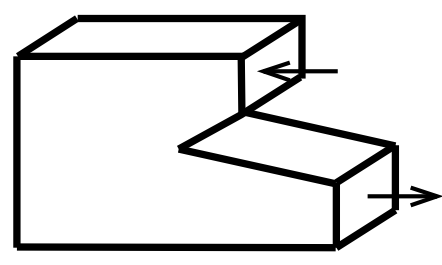

(b)

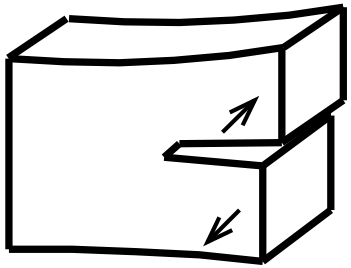

(c)

Figura 2.19 - Diferentes modos de carregamentos que originam as trincas nos sólidos: a, abertura; b, deslizamento; c, corte (KINLOCH; YOUNG, 1983)

A superposição destes três diferentes modos constitui o caso geral de carregamento da trinca. O Modo I, abertura à tração, tecnicamente, é o mais importante (KINLOCH; YOUNG, 1983) já que é o que mais comumente ocorre originando a falha. Para este modo as tensões na ponta da trinca podem-se desenvolver a partir das eq.(2.12); (2.13); (2.14) e (2.15) (KINLOCH; YOUNG, 1983).

$$
\begin{aligned}
& {\left[\begin{array}{l}
\sigma_{11} \\
\sigma_{12} \\
\sigma_{22}
\end{array}\right]=\frac{K_{I}}{\sqrt{2 \cdot \pi \cdot r}} \cos \frac{\theta}{2}\left[\begin{array}{l}
1+\operatorname{sen} \frac{\theta}{2} \cdot \operatorname{sen} \frac{3 \theta}{2} \\
\operatorname{sen} \frac{\theta}{2} \cdot \cos \frac{3 \theta}{2} \\
1-\operatorname{sen} \frac{\theta}{2} \cdot \operatorname{sen} \frac{3 \theta}{2}
\end{array}\right]} \\
& \sigma_{33}=0 \quad \text { (para estado plano de tensões) }
\end{aligned}
$$




$$
\begin{aligned}
& \sigma_{33}=v \cdot\left(\sigma_{11}+\sigma_{22}\right) \quad \text { (para estado plano de deformações) } \\
& \mathrm{e} \\
& \sigma_{23}=\sigma_{13}=0
\end{aligned}
$$

onde:

$\sigma_{11}, \sigma_{22}$ e $\sigma_{33}$ - tensões principais $(\mathrm{Pa})$;

$\mathrm{K}_{1}$ - fator de intensificação de tensões para o modo I $\left(\mathrm{Pa} \mathrm{m}^{1 / 2}\right)$;

re $\theta$ - coordenadas polares do ponto;

$v$ - coeficiente de Poisson.

Para o plano onde $\theta=0^{\circ}$ a tensão de cisalhamento é zero, e que para $\theta=0^{\circ}$ as tensões $\sigma_{11}, \sigma_{22}$ e $\sigma_{33}$ são tensões principais.

Analisando a eq.(2.16) é evidente que como o raio tende a zero, então a tensão $\sigma_{\mathrm{ij}}$ tende a infinito, portanto a tensão não é suficiente para o estabelecimento de um critério local de fratura. Devido a isso, Irwin (1964), postulou a critério de fratura baseado no Fator de Intensificação de Tensões da seguinte forma, unicamente define o campo de tensões ao redor da trinca eq.(2.16) (KINLOCH; YOUNG, 1983).

$$
K_{I} \geq K_{I c}
$$

onde:

$\mathrm{K}_{1}$ - intensidade do campo de tensões na ponta da trinca $\left(\mathrm{Pa} \mathrm{m}^{1 / 2}\right)$;

$\mathrm{K}_{\mathrm{lc}}$ - tenacidade à fratura ou valor crítico do fator de intensificação de tensões para o modo I $\left(\mathrm{Pa} \mathrm{m}^{1 / 2}\right)$.

$\mathrm{O}$ valor de $\mathbf{K}_{\mathrm{lc}}$ é uma propriedade do material, e $\mathbf{K}_{\mathrm{l}}$ é um valor que caracteriza a intensidade do campo de tensões na ponta da trinca. 


\subsubsection{Mecânica da fratura elasto-plástica (MFEP)}

No desenvolvimento do estudo da mecânica da fratura, observou-se que os valores obtidos para o Fator de Intensificação de Tensões Crítico $\left(\mathrm{K}_{\mathrm{IC}}\right)$ para alguns materiais eram muito elevados, fazendo com que as tensões atingissem valores muito superiores aos limites de escoamento. Portanto, tornava-se inviável a representação do fenômeno de fratura através da Mecânica da Fratura Linear Elástico (MFEL). Esses materiais desenvolvem a fratura no regime plástico. Devido ao emprego industrial, houve grande motivação para se pesquisar o fenômeno do fraturamento elasto-plástico, e, conseqüentemente, métodos de cálculo que permitissem o projeto da estrutura sob essa condição de serviço (RICETTI; BITTENCOURT, 1998).

A mecânica da fratura elasto-plástica procura simular o comportamento de trincas em materiais com comportamento não linear e independentemente do tempo. Os dois parâmetros mais utilizados para a representação da elasto-plasticidade no fraturamento são: a Integral $\mathrm{J}$ e o deslocamento da abertura da ponta da trinca $\delta$ (CTOD). Seus valores críticos são praticamente independentes do Fator de Intensificação de Tensões Crítico $\left(\mathrm{K}_{\mathrm{IC}}\right)$ do material, quando se consideram grandes deformações plásticas. A integral J e o CTOD podem ser utilizados como critérios para dimensionamento no regime elasto-plástico. Embora possuam limitações, esses parâmetros são mais abrangentes que a MFEL (RICETTI; BITTENCOURT, 1998).

O Método da Integral J é bastante eficiente, principalmente para materiais dúcteis, e de fácil implementação computacional. $O$ desenvolvimento de modelos que combinam dano e fraturamento tem ganhado ênfase por representarem mais fielmente o fenômeno físico, sendo validados para os casos de pequenas e grandes deformações. Apesar disso, ainda existem grandes dificuldades em acoplar de forma satisfatória estes modelos, pois a transição entre a predominância de efeitos microscópicos para os macroscópicos não é trivial (CASTELEIN, COULON, G'SELL, 1997; RICETTI, BITTENCOURT, 1998).

Muitos trabalhos estão sendo feitos com a finalidade de avaliar a integridade estrutural de componentes de engenharia. Massa; Piques e Laurent, (1997), pesquisaram o critério da propagação rápida da trinca $(\mathrm{RCP})$ no polietileno de média 
densidade utilizado em tubulações para gás. O primeiro corpo-de-prova analisado foi um anel com trinca (cracked ring) e depois um corpo-de-prova Charpy, onde foram levantados o fator de intensificação de tensões em função da temperatura $K_{(T)}$ e a taxa de deformação, obtendo-se no limite inferior da temperatura o valor crítico $\left(\mathrm{K}_{\mathrm{IC}}\right)$. Isto dá um critério para se prever a RCP.

Por outro lado Bureau, Dickson e Denault (1998a) realizaram testes de propagação da trinca por fadiga (FCP) em misturas poliméricas de poliestireno (PS) e polietileno de alta densidade (HDPE) em diferentes proporções. Os corpos-de-prova empregados foram do tipo compact test especimen (CT) obtidos por processos de injeção, submetidos a cargas cíclicas com freqüências entre 2 a $20 \mathrm{~Hz}$. Constatou-se que o incremento da freqüência de carga leva a uma diminuição do crescimento da trinca por fadiga. Além disso, foi constatado também que os corpos-de-prova carregados paralelamente ao sentido do fluxo de injeção, mostraram menor crescimento da trinca por fadiga em relação aos carregados perpendicularmente, comprovando as boas propriedades mostradas por estes materiais quando são submetidos a tensões paralelas no sentido do fluxo fundido, (BUREAU, DICKSON, DENAULT, 1998a; BUREAU, DICKSON, DENAULT, 1998b; LIU; PIGGOTT,1998; PEGORETTI, MARCHI, RICCO, 1997).

Mills (1974), propôs uma forma de estimar o tamanho da região plastificada, que, em comparação com os resultados obtidos em ensaios, apresentou boa concordância para chapas de policarbonato, polisulfatos e policlorovinil. O modelo proposto é baseado na análise de escoamento, ou coesivo, para chapas finas trincadas. É um tipo de modelo de trincas que apresenta escoamento localizado, baseado em extensões da MFEL. Experimentalmente, foi determinado que o raio da zona plastificada ao redor da trinca é aproximadamente igual à espessura da chapa. Mills considerou que a zona de plastificação é muito maior que a espessura, e modelou a zona plastificada em forma de uma tira na frente da ponta da trinca. O material é considerado elasto-plástico perfeito na ponta da tira. Este modelo considera que o efeito do escoamento aumenta o tamanho da trinca, na direção da zona escoada. $O$ incremento no comprimento da trinca $\left(\delta_{t}\right)$ pode ser calculado para uma placa infinita, submetida à tensão uniforme $\sigma$, por meio da eq.(2.17) 


$$
\delta_{t}=\left[(8 / \pi) /\left(\sigma_{y} / E\right)\right] \cdot a \cdot \ln \left(\sec \frac{\pi \cdot \sigma}{2 \cdot \sigma_{y}}\right)
$$

onde:

$\delta_{\mathrm{t}}$ - incremento no comprimento da trinca $(\mathrm{m})$;

$\sigma_{y^{-}}$limite de escoamento na ponta da trinca $(\mathrm{Pa})$;

E- módulo de elasticidade (Pa);

$\sigma$. tensão aplicada na placa $(\mathrm{Pa})$;

a- semicomprimento da trinca $(m)$.

\subsection{COMPORTAMENTO EM FADIGA DE MATERIAIS POLIMÉRICOS}

Define-se fadiga como o fenômeno ou processo de alteração estrutural permanente e localizado que ocorre em um material devido à aplicação de tensões e deformações cíclicas em um ou mais pontos que pode culminar no aparecimento de trincas ou na completa fratura do material após um número suficiente de ciclos (FUCHS, 1980).

A falha de um material polimérico devido ao fenômeno de fadiga acontece devido à aplicação de tensões cíclicas com valores abaixo dos requeridos para causar escoamento ou fratura quando a tensão aplicada aumenta continuamente. O efeito destas tensões cíclicas origina a iniciação de trincas microscópicas em centros de concentração de tensões ou sobre a superfície, e subsequentemente a propagação desta trinca levando a uma eventual falha do material (WARD; SWEENEY, 2004). Nos polímeros de uso estrutural, a falha pode ser definida não só em termos de fratura também devido á perda da rigidez (HERTZBERG; MANSON, 1980).

A vida a fadiga é definida como o número de ciclos de oscilação $(\mathrm{N})$, até que um corpo atinge a fratura é dado pelas tensões e deformações aplicadas. A vida a fadiga é uma das características mais importante do material e uma função das tensões aplicadas, freqüência, temperatura entre outros fatores (RIDDELL, 1974; NIELSEN, LANDEL, 1994). 
Para ocorrer o fenômeno de fadiga é necessária a existência de três fatores básicos, que são: tensões cíclicas; tensões de tração; deformações plásticas localizadas (FUCHS, 1980).

O processo de fadiga decorre da aplicação repetida de cargas, ao longo do período de uso da estrutura. A falha por fadiga freqüentemente ocorre de forma repentina sem indicação prévia em pontos localizados da estrutura, sendo que estes normalmente correspondem a áreas de elevadas tensões e deformações devido ao carregamento externo, locais onde ocorrem mudanças abruptas de geometria, presença de tensões residuais e imperfeições do material tais como poros e descontinuidades. Deve-se ressaltar que o processo de fadiga caracteriza-se também pela propagação de uma trinca até que esta atinja um comprimento tal que parte do material remanescente não possa mais suportar as tensões e deformações decorrentes do carregamento externo, ocorrendo falha por fratura frágil.

\subsubsection{Ensaios à fadiga em materiais poliméricos}

Os materiais poliméricos têm substituído os metais e outros materiais em muitas aplicações estruturais críticas, devido a isto os testes de fadiga têm-se tornado de muita importância, já que as máximas cargas cíclicas que o material pode suportar são somente uma fração de sua resistência (RIDDELL, 1974; HERTZBERG, MANSON, 1980; NIELSEN, LANDEL, 1994).

Ensaios de fadiga envolvem muitos parâmetros, tais como: amplitude das tensões e deformações aplicadas, tensão e deformação média, freqüência com que são aplicados os carregamentos, característica da curva das tensões e deformações aplicadas (senoidal, quadrada, etc), temperatura ambiente, temperatura do corpode-prova e geometria do espécime, os quais são de grande importância na hora de realizar os ensaios (ANDREWS, 1969; HERTZBERG, MANSON, 1980).

Os ensaios de fadiga mais convencionais dão uma pequena indicação da vida limite dos objetos submetidos a deformações cíclicas. Estes são especialmente importantes para os polímeros que são usados em estruturas submetidas à carga variável. 
A obtenção da curva S-N é o ensaio clássico de fadiga em materiais poliméricos, no qual as variações das tensões ou deformações são registradas versus o número de ciclos a que o material falha (numa escala logarítmica). Este tipo de curva tem sido amplamente usada por engenheiros e projetista que geralmente não conhecem os mecanismos de falha. Eles conhecendo a variação das tensões e a tensão média de serviço da peça ou estrutura, estando estas solicitações abaixo da assíntota horizontal da curva S-N do material a falha por fadiga não deve acontecer. Em outros casos a vida de serviço pode ser estimada mediante uma adequada análise estatística da curva S-N. A curva SN não distingue entre a iniciação da trinca e sua propagação catastrófica até a falha (HERTZBERG; MANSON, 1980).

A Figura 2.20 (RIDDELL, 1974) mostra as curvas de vida à fadiga S-N, para vários materiais poliméricos. A freqüência usada para os ensaios foi de $30 \mathrm{~Hz}$. A vida à fadiga, expressa como o número de ciclos $(\mathrm{N})$ antes que aconteça a falha, incrementa-se quando as tensões máximas por ciclo decrescem. Abaixo de alguns valores de tensão máxima, chamado limite de resistência à fadiga, o material pode ser submetido a um número de ciclos muito grande ou infinito sem atingir a falha. $O$ limite para a maioria dos polímeros, é de 20 a $40 \%$ da resistência a tração estática (NIELSEN; LANDEL, 1994).

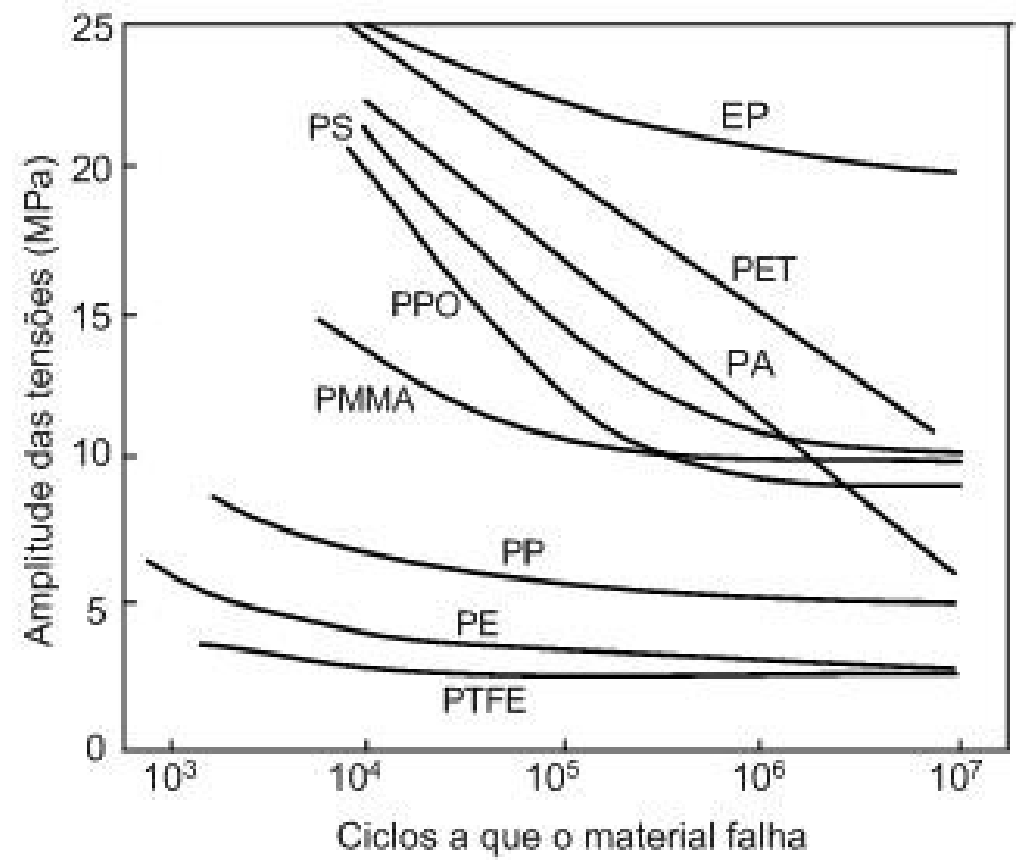

Figura 2.20 - Curva de vida a fadiga para alguns tipos de polímeros estruturais (RIDDELL, 1974) 
A fonte básica da trinca são os defeitos dos materiais, daí a grande dispersão estatística nos dados e o grande número de ensaios requeridos para a construção da curva S-N, particularmente o limite de resistência à fadiga.

Os materiais sempre contêm defeitos que desenvolvem trincas submicroscópicas se as tensões são maiores que um valor crítico. Durante os picos de carga de cada ciclo acontece um pequeno crescimento das trincas microscópicas até um ponto em que começam a propagar-se rapidamente ocasionando a falha.

As curvas de fadiga são somente o resultado de um ensaio de observação específico, e não a base do processo de crescimento da trinca, não se podendo usálas como parâmetro de predição. A mecânica da fratura examina a taxa do crescimento da trinca pré-existente em termos de tensões locais na ponta da mesma. Isto requer um entendimento ou uma estimativa (modelo) da morfologia e propriedades da zona localmente deformada à frente da ponta da trinca.

A taxa de crescimento da trinca por ciclos de carga estática é dada pela eq.(2.18) (HERTZBERG; MANSON, 1980).

$$
\frac{d a}{d N}=A \cdot \Delta K^{m}
$$

onde:

$\frac{d a}{d N}$ - taxa de crescimento da trinca por ciclos de carga $(\mathrm{m})$;

A e m- são constantes que caracterizam o material;

$\Delta \mathrm{K}$ - fator de intensidade de tensões $\left(\mathrm{Pa} \mathrm{m}^{1 / 2}\right)$.

A equação 2.18 é chamada a "Lei de Paris", e é aplicável a polímeros e metais. A e m são constantes características de um polímero ou sistema polimérico dado, mas A é dependente da freqüência, reflexo da natureza visco-elástica dos polímeros. Quando a dependência do tempo é forte, A é também uma função da relação das tensões máxima e mínima em cada ciclo. 
Em níveis moleculares, o crescimento da trinca é controlado por múltiplos processos de iniciação e propagação que podem acontecer num volume muito deformado e próximo à frente da ponta da trinca. Uma análise mais detalhada, na qual se considera o crescimento uniforme em cada ciclo, pode ser feita utilizando-se a eq.(2.19) (NIELSEN; LANDEL, 1994).

$$
\frac{d a}{d N}=\frac{\pi}{8} \cdot \frac{1}{\left(\sigma_{0}-\sigma_{c}\right)^{2}}\left[(1-R)^{2} \cdot K_{\max }^{2}-\sigma_{c} \cdot \delta_{c} \cdot E\right]
$$

onde:

$\sigma_{0}$ - tensão local na ponta da trinca $(\mathrm{Pa})$;

$\sigma_{\mathrm{c}}$ - tensão requerida para produzir o trincamento $(\mathrm{Pa})$;

$R$ - relação dos valores da intensidade de tensões;

$\mathrm{K}_{\max }-$ valor máximo da intensidade de tensões durante o ciclo de carga $\left(\mathrm{Pa} \mathrm{m}^{1 / 2}\right)$;

$\delta_{c^{-}}$deslocamento crítico da trinca $(\mathrm{m})$;

E- módulo de elasticidade $(\mathrm{Pa})$.

A taxa de crescimento da trinca é zero até que $\mathbf{K}$ exceda os valores críticos $\boldsymbol{\sigma}_{\mathbf{c}}, \boldsymbol{\delta}_{\mathbf{c}} \mathrm{e}$ E.

\subsubsection{Propagação da trinca em materiais poliméricos devido aos carregamentos cíclicos}

Sehanobish, Moet e Chudnovsky (1987) observaram que a taxa de propagação da trinca por fadiga no HDPE é uma função não monotônica da taxa de energia liberada, fenômeno previamente notado em outros polímero semicristalinos. Observações em microscópios revelaram uma zona ativa de fissuramentos precedendo a formação da trinca com uma etapa de aceleração inicial durante sua formação. Subseqüentemente uma desaceleração da trinca é associada com esta zona circular ativa. A falha final acontece por uma reaceleração de trinca precedido por um escoamento em grande escala por meio de uma zona de dano alongada 
acompanhada por grandes deformações (SEHANOBISH; MOET; CHUDNOVSKY, 1987).

O grafico da Figura 2.21 (KASAKEVICH; MOET; CHUDNOVSKY, 1990a) mostra a curva comprimento da trinca versus taxa de propagação de trinca por fadiga para HDPE. Pode-se apreciar as três etapas, a aceleração inicial seguida por uma desaceleração e posteriormente a reaceleração até a falha.

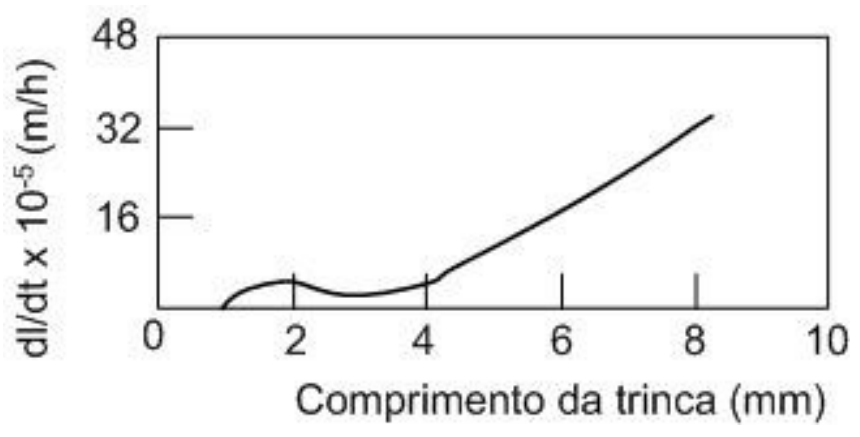

Figura 2.21 - Curva comprimento da trinca - taxa de propagação da trinca devido á fadiga para HDPE (KASAKEVICH; MOET; CHUDNOVSKY, 1990a)

Assim, eles concluiram que a propagação da trinca por fadiga envolve dois mecanismos: quase-frágil e dúctil. O primeiro domina a aceleração inicial já o segundo domina subseqüente a desaceleração não monotônica e seguinte aceleração da propagação da trinca até a falha final. Estes dois mecanismos, um de fissuramento e outro de escoamento em grande escala competem (SEHANOBISH; MOET; CHUDNOVSKY, 1987).

Kasakevich, Moet e Chudnovsky (1990b) fizeram uma análise comparativa da propagação da trinca no HDPE sob duas condições de carragamentos diferentes: fadiga e fluência. A análise foi centrada na semelhança dos mecanismos de falha por fadiga e por fluência do HDPE. A demostração destas semelhanças seria crucial para estabelecer a validade da fadiga como um ensaio acelerado de falha sob condições de fluência durante muito tempo. A teoria da camada trincada foi utilizada como uma ferramenta analítica na pesquisa. Eles estableceram semelhança da mecânica do processo de fratura do HDPE sob fluência e fadiga e concluiram que a fadiga podia ser usada como um meio de acelerar testes de fluência no HDPE. Para 
ambos casos fluência e fadiga no HDPE a análise da entalpia específica do dano foi da ordem de 1-2 cal g-1. Eles demonstraram que, dentro dos limites da análise real, a semelhança da mecânica da falha por fluência é preservada quando a fadiga é usada como um agente acelerador na propagação da trinca no HDPE. Durante a fadiga do HDPE a unidade básica de dano são as cavidades fibriladas (KASAKEVICH; MOET; CHUDNOVSKY, 1990b).

Meyer e Pruitt (2001) estudaram a influência combinada dos carregamentos cíclicos e as radiações- $\gamma$ sobre o polietileno de ultra-alto peso molecular (UHMWPE) empregado para substituir cartilagens articulares. Eles utilizaram UHMWPE extrudado para uso médico GUR 4150 e confeccionaram corpos-de-prova para ensaios de tração, segundo a norma ASTM D 638. Os corpos-de-prova foram usinados na direção paralela à linha de extrusão. A metade dos corpos foi esterilizada com raios- $\gamma$ em ambiente de nitrogênio, além de serem envelhecidos por quatro anos ao ar antes de serem ensaiados.

Os ensaios consistiram em submeter os diferentes corpos-de-prova a carregamentos cíclicos de tração uniaxial. Os testes feitos mostraram que com o incremento do número de ciclos de cargas e as deformações reais, resultou em um aumento das deformações plásticas e com isso decresceu linearmente a densidade do material, assim como também aumentou a formação de microporos e fissuras. Além disso, foi encontrado um incremento no alinhamento lamelar.

O estudo mostrou que os raios- $\gamma$ e o posterior envelhecimento tiveram um efeito fragilizante sobre o UHMWPE provocando microporos e fissuras que poderiam originar fraturas prematuras nas próteses

\subsubsection{Influência da temperatura sobre a vida a fadiga dos polímeros}

A vida à fadiga geralmente diminui com a temperatura. O efeito da temperatura sobre a vida à fadiga está relacionado com o fato de que geralmente a resistência dos polímeros decresce com o aumento da temperatura, e facilita-se o crescimento da trinca (NIELSEN; LANDEL, 1994). 
A vida à fadiga para polímeros rígidos é dada pela eq.(2.20) (NIELSEN; LANDEL, 1994).

$$
\log N=A+\frac{B}{T}
$$

onde:

$\mathrm{N}$ - vida a fadiga em número de ciclos;

A e B- constantes;

T- temperatura absoluta $(\mathrm{K})$.

Num ensaio de fadiga dinâmico, um material perfeitamente elástico se manterá na mesma temperatura do ambiente do ensaio, desde que a energia não seja dissipada pelo corpo-de-prova. No entanto, os polímeros são materiais visco-elásticos e mostram histerese mecânica para deformações moderadas e grandes. Assim, quando submetidos a carregamentos cíclicos e deformações inelásticas, a energia será dissipada como calor em cada ciclo. Isto resultará num aumento da temperatura do corpo-de-prova até que o calor gerado por ciclo seja igual ao calor dissipado como resultado da condução, da convecção e da radiação (KINLOCH; YOUNG, 1983).

O aumento da temperatura do corpo-de-prova depende de fatores tais como a temperatura do ambiente de ensaio, as dimensões do corpo-de-prova, freqüência de aplicação da carga e da amplitude das tensões aplicadas. Outros fatores que também influenciam são o atrito interno do material, sua condutividade térmica e seu calor específico. Com o aumento da freqüência, das máximas tensões e do atrito interno aumenta a temperatura do material ensaiado (KINLOCH; YOUNG, 1983).

O efeito da freqüência sobre a vida à fadiga é pequeno quando esta é baixa, mas a diminuição de vida à fadiga pode ser grande quando ocorre um incremento na temperatura do corpo-de-prova devido ao amortecimento. A temperatura do corpode-prova pode ser consideravelmente maior que a temperatura ambiente devido ao amortecimento. 
A energia dissipada no corpo-de-prova por segundo $\left(\xi_{\mathrm{d}}\right)$ é dada pela eq.(2.21) (NIELSEN; LANDEL, 1994).

$$
\xi_{d}=\pi \cdot f \cdot M^{\prime \prime} \cdot \varepsilon_{0}^{2}
$$

onde:

$\xi_{\mathrm{d}}$ - energia dissipada por segundo $(\mathrm{J} / \mathrm{s})$;

$f$ - freqüência $(\mathrm{Hz})$;

M"- perda na rigidez $(\mathrm{J})$;

$\varepsilon_{0^{-}}$deformação.

Para tensões e deformações no regime visco-elástico linear, num sistema adiabático a variação da temperatura é dada pela eq.(2.22).

$$
\Delta T=\frac{\xi_{d}}{\rho \cdot c_{p}}
$$

onde:

$\Delta \mathrm{T}$ - variação da temperatura $(\mathrm{K})$;

$\rho$ - densidade $\left(\mathrm{kg} / \mathrm{m}^{3}\right)$;

$\mathrm{C}_{\mathrm{p}}$ - calor específico $(\mathrm{J} / \mathrm{kg}-\mathrm{K})$.

Nos polímeros a diferença dos metais a falha térmica é o mecanismo de maior potencial de falha quando são feitos ensaios de fadiga mecânica. Neste caso a falha que acontece não é necessariamente por fratura do corpo-de-prova, ou seja, sua separação em peças (fadiga mecânica), mas pode acontecer devido a uma excessiva deformação plástica (fadiga térmica). O corpo-de-prova amolece tanto que falhará por sua baixa rigidez.

Além disso, o aumento da temperatura durante a fadiga dinâmica afeta as propriedades mecânicas, tais como: o módulo de elasticidade e a tensão de 
escoamento. De fato, o incremento local da temperatura pode causar embotamento na ponta da trinca, devido à diminuição na tensão de escoamento e melhora a resistência à fadiga (KINLOCH; YOUNG, 1983).

\subsection{DANO EM MATERIAIS POLIMÉRICOS}

Entende-se por dano o processo físico progressivo de deterioração que acontece num material antes da falha deste e que geralmente não é possível perceber, (KACHANOV, 1986; LEMAITRE, 1996). No sentido mecânico para materiais sólidos, o dano é a criação e o crescimento de micro trincas e micro-cavidades, as quais são descontinuidades num meio considerado como contínuo em grande escala. $\mathrm{Na}$ Engenharia, a mecânica do meio continuo introduz o Elemento Representativo de Volume (ERV), no qual todas as propriedades são representadas por variáveis homogeneizadas (LEMAITRE; DESMORAT, 2005). Desde o ponto de vista da Física, estas quantidades representam uma média de um certo volume. O EVR deve ser suficientemente pequeno para evitar atenuação de grandes gradientes, mas grande o suficiente par representar a média do micro-processo. Para fins experimentais, análises numéricas e práticas no caso de polímeros, considera-se a magnitude do EVR como $1 \mathrm{~mm}^{3}$ a escala meso mecânica (LEMAITRE, 1996).

A mecânica do dano é estudada por meio de variáveis mecânicas dos mecanismos envolvidos na deterioração do material, quando este é submetido a carregamentos. Em microescala, é a acumulação de micro-deformações na vizinhança de defeitos ou interfaces na ruptura da ligação, ambos danificando o material. Em mesoescala o EVR é o crescimento e coalescência de microtrincas ou micro-poros, os quais juntos dão inicio às trincas. Em macroescala é o crescimento da trinca (LEMAITRE, 1996).

Por muito tempo a fratura tem sido estudada como um processo relacionado a valores críticos de carga, tensão, deformação e tempo ou número de ciclos de carga. Trabalhos como os de: Palmgre (1924), Miner (1945) e Robinson (1952) foram pioneiros dos conceitos de variáveis relacionadas à deterioração progressiva antes da falha, mas 1958 é o ano considerado ponto de partida da mecânica do dano continuo, quando Kachanov publicou o primeiro trabalho no campo da variável $\psi$, chamada continuidade. Aproximadamente 50 anos após, $D=(1-\psi)$ recebeu o 
status de uma variável do estado interno no sentido termodinâmico $(0 \leqslant D \leqslant 1)$ " 0 " para o estado não danificado e "1" para a falha, de fato a falha acontece para $D<1$, por meio de um processo instável. Durante este tempo o conceito foi quase ignorado, até que no ano 1968 Rabotnov introduz o conceito de tensão efetiva. Nos anos 80, a teoria do dano tomou uma base muito mais rigorosa usando a termodinâmica e a micro-mecânica como ferramentas fundamentais (LEMAITRE, 1996).

Materiais tais como polímeros, compositos, metais, cerâmicas, rochas, concreto e madeiras, no entanto, têm estruturas físicas diferentes, qualitativamente, seus comportamentos mecânicos são similares. Todos mostram comportamento elástico, escoamento e alguma forma de plasticidade a deformação irreversível, anisotropia induzida pelas deformações, laços de histereses cíclicas, dano por carregamentos monotônicos ou por fadiga, e crescimento da trinca sob cargas estáticas ou dinâmicas. Ou seja, as propriedades mesoscópicas comuns podem ser explicadas por mecanismos de energia que são similares para todos estes materiais. Esta é a principal razão que permite explicar suficientemente com a mecânica do meio continuo e a termodinâmica dos processos irreversíveis, quais modelam o material sem detalhes referentes à complexidade de sua microestrutura física (LEMAITRE, 1996).

Todos os materiais são compostos por átomos que se juntam por ligações resultantes das interações de campos eletromagnéticos. A elasticidade é diretamente relacionada ao movimento relativo dos átomos. Quando há desligamento dos átomos é o inicio do processo de dano (LEMAITRE, 1996).

Nos polímeros, o dano acontece por ruptura de ligações que existem entre longas cadeias moleculares, este mecanismo cria deformações plásticas. A elasticidade é diretamente influenciada pelo dano, a diminuição do número de ligações atômicas é responsável pelo decréscimo da elasticidade com o aumento do dano. Este acoplamento, que acontece entre a deformação elástica e o dano do material é chamado estado de acoplamento (LEMAITRE, 1996).

A plasticidade é diretamente relacionada com o escorregamento. Nos polímeros acontece devido ao reordenamento das moléculas poliméricas. Isto pode induzir mudanças de volumes. Influência plástica do dano e deformação irreversível 
acontece porque a área de resistência diminui assim como o número de ligações. $\mathrm{O}$ dano não é diretamente influenciado pelo mecanismo de escorregamento, que não é um estado de acoplamento. O acoplamento indireto para um incremento da tensão efetiva só na cinética da equação constitutiva, este é chamado acoplamento cinético (LEMAITRE, 1996).

A elasticidade tem lugar a nível atômico. A plasticidade é dominada por escorregamentos a nível molecular. Dano e ruptura de ligações atômicas a mesoescala são a iniciação da trinca (LEMAITRE, 1996).

\subsubsection{Manifestações do dano}

O dano em microescala é governado por um mecanismo geral de ruptura de ligações atômicas. A meso escala pode manifestar-se de várias formas dependendo da natureza do material, tipo de carga e da temperatura, entre estas manifestações encontramos: dano frágil; dano dúctil; dano por fluência; dano por fadiga de baixo ciclo e devido a fadiga de alto ciclo (LEMAITRE, 1996).

O dano frágil acontece quando a trinca é iniciada sem grande deformação plástica. Para dar uma ordem da magnitude fala-se que a relação entre a deformação plástica e a deformação elástica é menor que a unidade. Isto significa que as forças de clivagem são menores que as forças que devem produzir o escorregamento, mas são maiores que as forças das ligações. O grau de localização é grande (LEMAITRE, 1996).

O dano dúctil, acontece simultaneamente com a deformação plástica. Resulta da nucleação de cavidades devido à separação das inclusões e o arranjo seguindo seu crescimento e sua coalescência através do fenômeno de instabilidade plástica. Como uma conseqüência, o grau de localização do dano dúctil é comparável ao da deformação plástica (LEMAITRE, 1996).

O dano por fluência ocorre quando o material é deformado com uma tensão constante, a deformação plástica envolve viscosidade. Quando a deformação é suficientemente grande acontece a ruptura das ligações atômicas o que origina o 
dano. Como para dano dúctil o gradiente de dano de fluência é similar para o gradiente de deformação viscoplástica (LEMAITRE, 1996).

O dano por fadiga de baixo ciclo ocorre quando o material é submetido a carregamentos cíclicos de grandes valores de tensão e deformação, desenvolvendo dano junto com deformação plástica após um período de incubação, procedendo à fase de nucleação e propagação das microtrincas. O grau de localização do dano é maior que para o dano dúctil e o de fluência. Devido aos grandes valores de tensão, a fadiga de baixo ciclo é caracterizada pelo pouco número de ciclos para a ruptura, menos de 10.000 ciclos (LEMAITRE, 1996).

No dano por fadiga de alto ciclo, o material é carregado com baixos valores de tensão, num meso nível a deformação plástica permanece pequena e ainda depreciável. No entanto, em alguns pontos num micro-nível a deformação plástica pode ser alta desenvolvendo-se microtrincas em alguns planos, freqüentemente na superfície do material. O número de ciclos para a falha é muito maior que para o dano de baixo ciclo, mais de 100.000 ciclos (LEMAITRE, 1996).

\subsubsection{Estimativa do dano}

À microescala o dano pode ser interpretado como a criação de micro superfícies de descontinuidades, ruptura de ligações atômicas e crescimento plástico de micro cavidades. A mesoescala, o número de ligações quebradas ou de micro cavidades pode ser aproximado em qualquer plano pela área de interseção de todas os defeitos com esse plano.

Considerando o corpo danificado e o EVR, como mostra a Figura 2.22 (LEMAITRE; DESMORA, 2005) o dano variável pode ser definido fisicamente pela densidade superficial de microtrincas e microcavidades que se interceptam com o plano de corte do EVR de seção transversal $(\delta S)$. Para o plano com normal $\vec{n}$ onde a densidade é máxima o valor de dano é dado pela eq.(2.23) (LEMAITRE; DESMORA, 2005).

$$
D_{(\vec{n})}=\frac{\delta S_{D}}{\delta S}
$$


onde:

$\delta S$ - área da interseção do plano com EVR $\left(\mathrm{m}^{2}\right)$;

$\delta S_{D^{-}}$área da interseção de todas as microtrincas o microcavidades com $\delta S\left(\mathrm{~m}^{2}\right)$.

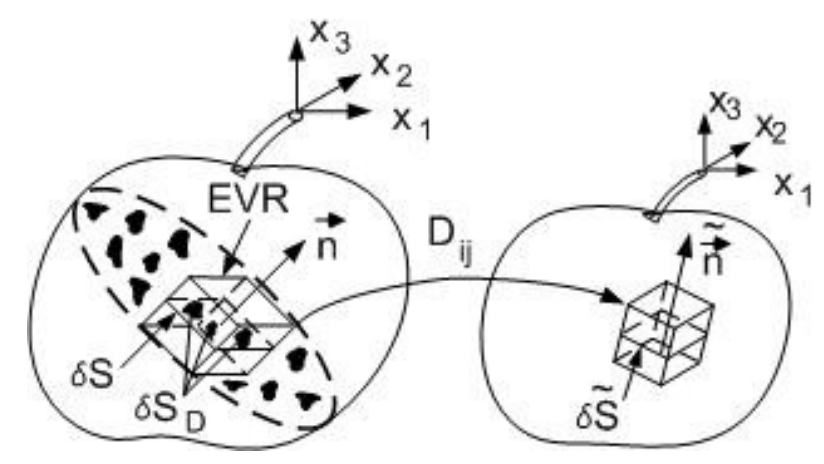

Figura 2.22 - Representação física e matemática do Dano (LEMAITRE; DESMORAT, 2005)

Se o dano é isotrópico, a variável escalar $D_{(\vec{n})}$ não depende da normal, então a variável será um escalar que é dado pela eq.(2.24), que pode ser usada para resolver problemas tridimensionais (LEMAITRE, DESMORA, 2005).

$$
D=\frac{\delta S_{D}}{\delta S}
$$

Considerando o caso unidimensional de dano homogêneo, leva a uma definição simples de dano como a densidade da superfície efetiva de micro-defeitos, este é dado pela eq. (2.25).

$$
D=\frac{S_{D}}{S}
$$

onde:

D- dano acumulado

$\mathrm{S}_{\mathrm{D}}$ áreas superficiais das microtrincas e microdefeitos $\left(\mathrm{m}^{2}\right)$;

$\mathrm{S}$ - área $\left(\mathrm{m}^{2}\right)$. 
Se o EVR é carregado com uma força $\vec{F}=\vec{n} \cdot F$, como mostra a Figura 2.23 (LEMAITRE, 1996), a tensão uniaxial é dada pela eq.(2.26).

$$
\sigma=\frac{F}{S}
$$

onde,

$\sigma$ - tensão uniaxial $(\mathrm{Pa})$;

F- carga aplicada $(\mathrm{N})$;

S- área da seção transversal do $\operatorname{EVR}\left(\mathrm{m}^{2}\right)$.

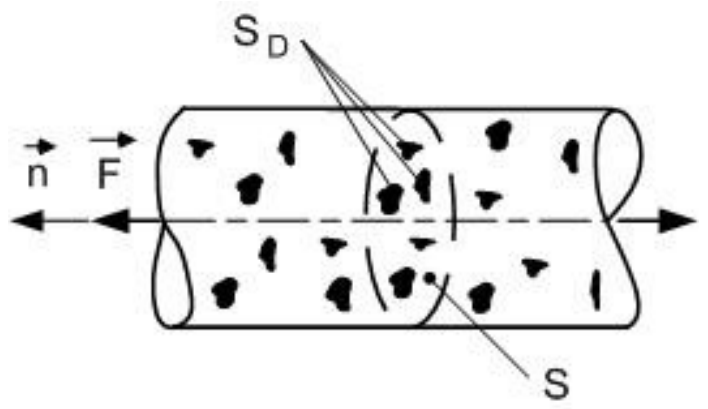

Figura 2.23 - Elemento de volume representativo danificado submetido à tração uniaxial (LEMAITRE, 1996)

Se ao aplicar a carga todos os defeitos são abertos de tal forma que as micro-forças atuam sobre as superfícies das microtrincas e microcavidades representado por $\mathrm{S}_{D}$, é conveniente introduzir o conceito de tensão efetiva $\sigma_{\text {ef, }}$ relacionada com a superfície que resiste efetivamente a carga $\left(S-S_{D}\right)$, então $\sigma_{\text {ef }}$ é dada pela eq.(2.27).

$$
\sigma_{e f}=\frac{F}{S-S_{D}}
$$


Introduzindo a variável dano, eq.(2.25) obtem-se:

$$
\begin{gathered}
\sigma_{e f}=\frac{F}{S\left(1-\frac{S_{D}}{S}\right)} \\
\text { ou } \\
\sigma_{e f}=\frac{\sigma}{1-D}
\end{gathered}
$$

Esta definição de tensão efetiva é para material sob tração. No caso de materiais sob compressão, se alguns defeitos fecham, o dano se mantém invariável, a superfície que resiste a carga efetiva é maior que $S-S_{D}$. Em particular, se todos os defeitos fecham, a tensão efetiva em compressão é igual à tensão convencional.

\subsubsection{Formas de medir o dano}

Segundo Lemaitre (1996), existem duas formas de medir o dano num material: uma de forma direta e outra de maneira não direta.

As medidas diretas consistem na avaliação da área total da trinca $\delta S_{D}$ sobre uma superfície determinada usando a eq.(2.24). Assumindo o fator de correção k para igualar a 1, isto pode ser feito por observação micrográfica. Este método é trabalhoso na prática. Se o dano consiste em trincas que não são perfeitamente homogêneas no EVR, não existe chance de obter uma trinca em qualquer interseção de plano. No entanto, o dano só pode ser avaliado por meio de linhas que indicam a interseção das microtrincas com o plano de observação. Um dano isotrópico equivalente pode ser obtido.

As medidas não diretas são baseadas na influência do dano sobre uma propriedade mecânica do material, por exemplo, a elasticidade (módulo de elasticidade do material) por meio do estado de acoplamento.

Este método requer a manufatura de corpos-de-prova para fazer o ensaio. O dano é assumido como uniforme e homogêneo na seção de trabalho do corpo-de-prova. 
Se $E_{e f}=E(1-D)$ é considerado módulo de elasticidade efetivo do material danificado, os valores de dano podem ser derivados das medições do $\mathbf{E}_{\text {ef }}$, providenciado que o módulo de elasticidade do material não danificado, E, seja conhecido.

$$
D=1-\frac{E_{e f}}{E}
$$

onde,

D- dano;

$E_{\text {ef- }}$ módulo de elasticidade efetivo (material danificado);

E- módulo de elasticidade do material não danificado.

Este método prático requer medições exatas de deformação. Sensores de deformação são comumente usados e o $\mathbf{E}_{\text {ef }}$ é medido com maior precisão durante o descarregamento. Esta técnica pode-se usar para qualquer tipo de dano contanto que o dano seja uniformemente distribuído no volume no qual a deformação é medida que é a principal limitação do método (LEMAITRE, 1996).

Existem outros muitos métodos de medir indiretamente o dano em materiais por meio da variação de suas propriedades tais como, microdureza, propagação das ondas ultra sônicas, densidade, resistência elétrica (queda da voltagem), etc (LEMAITRE, 1996).

\subsection{DEGRADAÇÃO DOS POLÍMEROS DEVIDO AO MEIO MARINHO}

Considera-se como degradação qualquer alteração sofrida por um material durante a sua vida, tanto na aparência como nas propriedades químicas ou mecânicas. A degradação dos materiais poliméricos frente aos agentes da natureza ocorre como resultado do ataque químico e físico pelo ambiente, normalmente através da combinação de uma série de agentes cujos mecanismos são muito variados (WHITE; TURNBULL, 1994). Estas mudanças químicas e físicas são irreversíveis e conduzem à falha prematura do material (VALADEZ; CERVANTES; VELEVA, 1999). 
Geralmente, a maioria das falhas que acontecem nos materiais poliméricos devido a processos de degradação podem ser atribuídas a três tipos de fontes (WHITE; TURNBULL, 1994):

- Degradação molecular causada durante o processamento, geralmente devido as elevadas temperaturas e frequentemente combinado com a oxidação atmosférica;

- Degradação em serviço causada pelo meio natural;

- Ataque de agentes quimicamente agressivos durante a vida de serviço.

O envelhecimento natural de qualquer polímero depende geralmente de vários parâmetros tais como, radiação ultravioleta, temperatura e umidade. Estes fatores determinam a vida de um produto feito de polímero em aplicações ao ar livre (SAMPERS, 2002; ROY et al., 2005).

Num meio quimicamente agressivo as moléculas poliméricas podem ser quebradas (cisão das cadeias), originar ligações cruzadas (cross-linking) ou sofrer reações de substituição. A substituição é menos comum e provoca pequenas mudanças nas propriedades do polímero. A cisão e as ligações cruzadas, ambas acontecem baixo condições do meio natural. A degradação molecular pode acontecer durante 0 processamento (WHITE; TURNBULL, 1994).

O polietileno é um material semicristalino cuja estrutura é composta majoritariamente por três regiões: uma região cristalina ordenada, uma região desordenada chamada de amorfa e uma região interfacial (MANDELKERN, ÁLAMO, 1990; VALADEZ, CERVANTES, VELEVA, 1999). As reações de degradação acontecem quase exclusivamente na fase amorfa do polímero porque esta absorve o oxigênio muito mais rapidamente que a fase cristalina (KOMITOV, KOTOV, STANCHEV, 1989; WHITE, TURNBULL, 1994). Além disto, a oxidação pode ocorrer preferencialmente na fronteira entre as fases amorfa e cristalina onde o dano será maior (SCHIERS, BIGGER, DELATYCKI, 1991; WHITE, TURNBULL, 1994).

Geralmente com a exposição ao intemperismo a superfície da maioria dos polímeros fica enrijecida, isto é atribuído à cisão. Em alguns casos a deterioração acontece antes do esperado e é explicado pela redução do peso molecular (WHITE, TURNBULL, 1994). 
As trincas se formam facilmente numa camada enrijecida, às vezes aparentemente sem a existência de uma força externa aplicada. Estas trincas podem atuar como concentradores de tensões, e facilitar a falha do material menos degradado na parte mais próxima ao centro da seção (SCHOOLENBERG, 1988).

No entanto, o caso do enrijecimento das superfícies poliméricas devido ao efeito do meio, a análise da fratura mecânica nestes casos é menos direta devido à variação das propriedades ao longo da profundidade do material. O módulo de elasticidade pode mudar como uma função da profundidade até a superfície, e se é o caso de uma deformação aplicada a densidade da energia de deformação também variará com a profundidade (WHITE; TURNBULL, 1994).

Karpuhin (1990) observou que a profundidade da trinca desenvolvida na superfície de um cabo insulado com polietileno foi igual à profundidade da oxidação calculada. Ele mostrou que o esforço de tração para a formação da trinca foi a tensão de contração na camada oxidada, correspondendo a uma deformação de contração de 1 a $2 \%$. Esta contração podendo ser causada pela cristalização química (KARPUHIN, 1990). No entanto, a profundidade da camada enrijecida não é necessariamente igual á profundidade das trincas superficiais (SCHOOLENBERG, 1988).

\subsubsection{Influência dos agentes ambientais na degradação dos polímeros}

A durabilidade dos materiais poliméricos é marcadamente influenciada pela degradação que sofrem devido a sua susceptibilidade às diferentes condições ambientais. (DAVIS; SIMS, 1983). Esta degradação é o resultado de agressões química ou física do meio, com reações fotoquímicas que envolvem radiação ultravioleta, fótons da luz e oxigênio atmosférico que levam à ruptura de cadeias poliméricas. Estas reações químicas podem ser aceleradas por fatores como altas temperaturas, causadas pelo aquecimento solar, tensões aplicadas externamente ou internas geradas durante o processo moldado, e variações de temperatura ou nos coeficientes de expansão térmica nos diferentes pontos da peça durante 0 processamento (WHITE; TURNBULL, 1994). 
2.7.1.1 Influência da radiação ultravioleta na degradação dos polímeros

A durabilidade dos materiais orgânicos, exposto a intemperismo, é determinada fundamentalmente pela radiação solar que incide sobre eles (SEARLE,1994). Enquanto outros fatores do meio contribuem a limitar a vida do material exposto, a energia do sol absorvida pelo material é principalmente responsável pelo efeito destrutivo do meio. A luz solar tem o maior potencial para quebrar as ligações químicas. Esta é um pré-requisito para as mudanças químicas que causam a degradação do material. Outros fatores do meio tais como calor, umidade e oxigênio geralmente promovem o envelhecimento devido a reações secundárias, seguindo as reações primárias de rompimento das ligações provocadas pela luz (VALADEZ, VELEVA; 2004).

Muitos polímeros são propensos à degradação causada pelas reações fotoquímicas envolvendo os fótons da radiação ultravioleta que leva à cisão das cadeias poliméricas. Estas reações químicas podem ser aceleradas pelo aumento da temperatura pelo efeito de aquecimento do material devido à radiação solar ou mesmo pela presença de tensões, tanto aplicadas sobre o mesmo, quanto residuais do processamento (WHITE; TURNBULL, 1994). A deterioração dos polímeros expostos à radiação ultravioleta é uma das principais desvantagens do emprego destes materiais para seu uso ao ar livre (VALADEZ; CERVANTES; VELEVA, 1999).

O processo de foto-oxidação pode ser iniciado por um radical de cadeia ou pela dissociação causada pela colisão de um fóton com suficiente energia com uma molécula polimérica ou como resultado de alguma impureza presente (WHITE; TURNBULL, 1994).

Os polietilenos comerciais são instáveis à luz devido a impurezas adventícias tais como resíduos de catalisador, instaurações e componentes de carbono. As instaurações e componentes de carbono são formados como resultado da degradação termomecânica que os polímeros experimenta durante seu processamento (SCOTT,1976; HINSKEN et al., 1991), embora, eles possam ser produzidos fotoquimicamente, por exposição ao oxigênio atmosférico a determinadas faixas de temperatura (GUILLET, 1978). 
Os polímeros são sensíveis a vários tipos de radiação como ultravioleta, raios gama, feixes eletrônico e neutrônico, iônicos entre outros (SUAREZ, MANO; 2001), (SUAREZ; MONTEIRO; MANO, 2002). Estes agentes externos normalmente afetam a superfície a níveis maiores que no interior do material, mas não obstante podem ter uma grande influência no desempenho global do material dependendo da aplicação que este vai ter. Os processos de envelhecimento originado pela exposição em condições de intemperismo é um dos processos mais significativos que conduzem à modificação da superfície do polímero, e tem suas implicações práticas (TAVARES et al., 2003).

Geralmente existem duas fontes de radiação ultravioleta usadas nos ensaios de envelhecimento artificial de materiais poliméricos, estas são as lâmpadas de arco de xenônio e as lâmpadas ou tubos fluorescentes. Ambas as fontes simulam razoavelmente o espectro solar. $\mathrm{O}$ arco de xenônio possue radiações ultravioleta com comprimento de onda menores que a radiação solar que devem ser removidas usando filtros. Este tipo de fonte também emite uma grande intensidade de radiação infravermelha, que também deve ser removida para evitar o superaquecimento da amostra (WHITE; TURNBULL, 1994).

Os tubos fluorescentes são mais baratos e não produzem o aquecimento indesejado. Estes tipos de tubos estão disponíveis com diferentes espetros de saída. Os do tipo UV-B os quais tem seu pico de radiação no comprimento de onda ao redor dos $313 \mathrm{~nm}$, sendo a saída muito forte ao longo dos comprimento de onda inferiores do espetro solar. Devido a isto pode acontecer uma forte aceleração causando reações indesejadas. Os tubos de tipo UV-A não apresentam estes problemas e o UVA-340 simula a radiação solar até $350 \mathrm{~nm}$. Os tubos fluorescentes emitem baixo nível de radiação visível e nenhuma radiação infravermelha. $O$ efeito de aquecimento é depreciável, havendo necessidade de uma fonte de calor adicional para manter a temperatura do meio de ensaio acima da ambiente (WHITE; TURNBULL, 1994). 


\subsubsection{Influência da temperatura na degradação dos polímeros}

A maioria dos ensaios de envelhecimento artificial são conduzidos em elevada temperatura, isto é feito com o objetivo de aumentar termicamente a velocidade das reações que acontecem. Este aumento da temperatura pode promover processos de degradação que não aconteceriam em temperatura ambiente (KOCKOTT, 1985).

A temperatura da superfície do polímero exposto a luz solar pode ser muito maior que a do ambiente circundante devido ao calor desenvolvido no material (RABONAVITCH, QUEENSBERRY, SUMMERS, 1983; ANDRADY et al., 1998; ROY et al., 2005). A superfície que é submetida diretamente à radiação solar fica mais aquecida que as outras superfícies, somado à baixa condutividade térmica dos polímeros, isto pode originar um gradiente de temperatura significante, o que provoca o desenvolvimento de tensões térmicas. Estas tensões podem originar esforços de tração e formação de trincas superficiais que levam à formação de macro trincas as que ocasionam a falha do componente (WHITE; TURNBULL, 1994).

O polietileno quando exposto ao calor e/ou radiação ultravioleta, desenvolve termo e/ou foto-oxidação. Estas reações conduzem à formação de uma variedade de óxidos dos quais alguns contém diferentes componentes de carbono. A degradação fotoquímica do polietileno é um resultado de uma competição de reações de formação de ligações cruzadas e cisão de cadeias poliméricas que conduzem a mudanças do peso molecular e diminuição da temperatura de fusão (HINSKEN et al., 1991; HAMID, AMIN, 1995; KHRAISHI, AL ROBAIDI, 1991; VALADEZ, CERVANTES, VELEVA, 1999).

Durante o processo de fabricação, quando a temperatura requerida para produzir o fluxo desejado para a operação, é freqüentemente maior que o suficiente para promover uma degradação significativa, especialmente na presença de oxigênio. Ás vezes as forças sobre o fluxo são suficientes para causar cisão mecânica nas cadeias poliméricas. A degradação térmica é importante devido a que o dano originado no polímero durante seu processamento a elevadas temperaturas pode levar a subseqüente deterioração adicional, sob condições de foto-oxidação. A degradação molecular que acontece durante a fabricação pode fazer o polímero 
mais vulnerável a danos durante sua subseqüente exposição ao meio natural (WHITE; TURNBULL, 1994).

\subsubsection{Influência do oxigênio na degradação dos polímeros}

A taxa de oxidação dos processos de envelhecimento é sensível à pressão do oxigênio na interfase gás-sólido (CLARK, MUNRO, 1984; WHITE, TURNBULL, 1994). O aumento da pressão do oxigênio pode acelerar algumas reações.

Temperaturas e tensões de cisalhamento afetam significativamente a cinética e os mecanismos de degradação do HDPE. A literatura reporta dois mecanismos de degradação predominantes que dependem da temperatura e das tensões de cisalhamento (E'LDAROV et al., 1996; PINHEIRO, CHINELATTO, CANEVAROLO, 2004, 2006): cisão de cadeias e ramificação das cadeias levando a um decrescimento ou crescimento do peso molecular. O processo de ramificação pode levar à formação das ligações cruzadas.

O oxigênio disponível no sistema e sua concentração têm um papel importante na degradação termo mecânica (HOLMSTRÖM, SÖRVIK, 1978; GUGUMUS, 2000). Durante o processamento do polímero, as macromoléculas sofrem cisão devido á ação da temperatura e das tensões de cisalhamento, formando macro radicais, se a concentração de oxigênio é baixa os macro radicais podem reagir com outros dando lugar a ramificações (RIDEAL, PADGET, 1976; HOLMSTRÖM, SÖRVIK, 1978). Por outro lado se a concentração de oxigênio é grande facilita sua reação com os macro radicais, dando origem à propagação da degradação por meio da formação de radicais livres e compostos instáveis que atacam as cadeias poliméricas (PINHEIRO, CHINELATTO, CANEVAROLO, 2004, 2006).

A origem do mecanismo de cisão de cadeias poliméricas ocorre devido ao ataque de oxigênio que dá lugar à formação de radicais. Estes radicais extraem os átomos de hidrogênio das cadeias causando o aumento da cisão das cadeias o que leva a uma diminuição do peso molecular. O mecanismo de ramificação das cadeias surge quando os macroradicais são adicionados, formado na etapa final moléculas com ligações cruzadas (RIDEAL, PADGET, 1976; HOLMSTRÖM, SÖRVIK, 1978; PINHEIRO, CHINELATTO, CANEVAROLO, 2004, 2006). 
2.7.1.4 Influência da umidade na degradação dos polímeros

Em alguns polímeros a hidrólise pode levar a cisão das cadeias poliméricas. Em contato com água ou umidade do ambiente alguns polímeros se incham devido que acontece, um processo de absorção, o que origina tensões residuais quando a água se distribui de forma não uniforme. Da mesma forma que durante a exposição inicial à umidade, quando o material é removido da umidade, rapidamente acontece um processo inverso (WHITE; TURNBULL, 1994).

Pegram e Andrady (1989), pesquisaram o comportamento de vários polímeros em ambiente marinho úmido e seco, eles envelheceram alguns tipos de termoplásticos e elastômero entre eles o LDPE, durante um ano, uns flutuando na água do mar e outros fora do mar ao ar. Para monitorar a degradação eles mediram as propriedades a tração do material segundo a ASTM D 638. Especificamente para o LDPE foi medido o limite de resistência do material e a deformação à fratura. Como resultado dos ensaios obtiveram que a taxa de degradação foi menor para as amostras que ficaram flutuando no mar que para as que foram exposta fora da água, ele atribuíram como causa principal disto ao efeito de esfriamento da água do mar, outra causa poderia ter sido o recobrimento biológico das superfícies das amostras que flutuavam no mar o que diminuiu a incidência da luz solar sobre o material.

\subsubsection{Ensaios de envelhecimento natural e artificial em polímeros}

Geralmente, o objetivo final de um ensaio de envelhecimento é predizer a vida de uma componente em condições similares às de serviço. O tipo de exposição mais apropriada é quando as condições do ambiente de ensaio são exatamente iguais as condições de serviço (WHITE; TURNBULL, 1994). Isto muitas vezes é difícil de conseguir, já seja pelo tipo de ambiente de serviço ou pela durabilidade do objeto estudado. Seria necessário esperar por anos para avaliar o comportamento de novos produtos durante seu processo de envelhecimento natural. Em contraste, testes de envelhecimento acelerados permitem obter estes resultados em semanas (SEARLE; SEARLE, 2004). Para componentes que demandam uma vida de 50 anos 
ou mais, os ensaios de envelhecimento natural são quase impossíveis pelo que é necessário acelerar as condições de serviço (WHITE; TURNBULL, 1994).

Os ensaios de envelhecimento natural avaliam as causas e efeitos que um determinado material, ou grupo de materiais, experimentam quando são expostos diretamente a um ambiente natural. Ensaios de envelhecimento acelerados ou artificial, são planejados para simular um ambiente natural num laboratório. Fazendo isto é possível correlacionar o resultado com as condições achadas no meio natural (WHITE; TURNBULL, 1994).

O principal objetivo dos ensaios de envelhecimento artificial é acelerar o processo de degradação para que uma predição razoável da vida da componente seja feita num período de tempo curto. Estes tipos de ensaios, feitos em laboratórios, são geralmente mais fáceis de executar. Mais a validade da predição da vida sob condições naturais de serviço a partir dos dados obtidos neste tipo de ensaio são questionáveis. A avaliação pode ser realizada de acordo com uma série de técnicas. Entretanto, deve-se levar em conta que independente da técnica empregada, a complexidade dos processos de degradação dos polímeros limita a modelagem da taxa de degradação a sistemas específicos, de forma que as predições não podem ser generalizadas (WHITE; TURNBULL, 1994).

Uma alternativa é tratar de relacionar a taxa de degradação do ambiente de ensaio com o ambiente de serviço, embora o nível de radiação ultravioleta, temperatura, umidade e oxigênio de ambos ambientes sejam diferentes. Estes agentes e suas interações devem ser considerados caso se deseje avaliar a durabilidade de um componente polimérico destinado ao uso externo (WHITE; TURNBULL, 1994).

\subsubsection{Métodos para caracterizar a degradação nos polímeros devido ao envelhecimento}

Uma das dificuldades com testes de envelhecimento acelerados é a escolha de parâmetros que podem ser usados para observar e estimar a magnitude da degradação. Observação visual e medida das propriedades mecânicas geralmente são os mais usados (KELEN, 1983). 
As propriedades microscópicas e mecânicas são usadas geralmente para monitorar mudanças na morfologia e na resistência mecânica dos materiais poliméricos antes e após de qualquer tipo de tratamento (ROSA et al. 2005). Para medir a degradação física de um material polimérico a deformação de ruptura é um parâmetro mais apropriado que a resistência à tração, desde que reflita a fragilidade e consequentemente a tendência do polímero a fragmentar-se (PEGRAM; ANDRADY, 1989). A tensão de escoamento e a perda na porcentagem de alongamento à fratura podem ser levadas em conta como indicadores diretos de degradação em materiais poliméricos (QURESHI, 1990; TAVARES et al., 2003; ROY et al., 2005).

Tavares et al. (2003) estudaram a degradação do polietileno de baixa densidade (LDPE) após submetido a dois métodos diferentes de envelhecimento artificial. Para determinar a variação das propriedades mecânicas no material usaram a técnica de nano indentação. Esta técnica usa uma ponta identadora que penetra na superfície da amostra, o deslocamento e a carga aplicada durante o processo de entalhe são controlados. Esta técnica tem uma alta resolução e pode ser usada para avaliar as propriedades mecânicas de superfícies e camadas finas em materiais poliméricos.

Durante o ensaio notaram que até as primeiras $200 \mathrm{~h}$ de envelhecimento a variação das propriedades nano mecânicas do material foram pequenas, restringiu-se a uma fina camada superficial do material não maior de $1 \mathrm{~mm}$. Eles observaram que os valores de dureza e módulo de elasticidade aumentaram, mais na superfície que no interior do material, ambos valores variaram de acordo com a profundidade. O perfil da variação das propriedades nanomecânicas ao longo da profundidade do material seguiu o mesmo padrão que a variação do índice de carbono. Isto indicou que as modificações mecânicas e químicas, provocadas pelo envelhecimento podem ser correlacionadas, e que a técnica de nanoindentação é uma ferramenta poderosa para caracterizar o perfil de degradação por envelhecimento em materiais poliméricos.

Finalmente apresentaram uma interpretação para o fissuramento da superfície envelhecida baseada no incremento diferencial do módulo de elasticidade nas diferentes profundidades e concluíram que as variações do módulo de elasticidade com profundidade foram suficientemente altas para promover trincas superficiais para um tempo de exposição de $400 \mathrm{~h}$. 
Valadez, Cervantes e Veleva (1999), estudaram a foto-oxidação do HDPE, eles irradiaram o polímero com radiação ultravioleta numa câmara de envelhecimento artificial. O estudo mostrou que em termos gerais o material degradou-se em três etapas seguindo o mecanismo da cadeia radical livre. Durante as primeiras $600 \mathrm{~h}$ de exposição do HDPE na câmara de envelhecimento, sua cristalinidade teve um crescimento exponencial, depois desse tempo esta foi estabilizada. $O$ incremento exponencial da cristalinidade poderia ser atribuído à oxidação preferencial da fase amorfa do HDPE, assim como à formação de novos cristalitos induzidos pelo fenômeno de cisão de cadeias poliméricas. Uma característica intrínseca destas novas pequenas regiões cristalinas foi sua temperatura de fusão menor (VALADEZ, CERVANTES, VELEVA, 1999).

Eles também observaram usando um microscópio eletrônico de varredura (MEV) que a radiação ultravioleta degradou a superfície do HDPE, e mostra finas microfissuras com padrões lineares e unidirecionais orientadas de forma perpendicular à direção de fluxo de extrusão. É bem conhecido que este processo mecânico promove regiões com concentração de tensões residuais. Provavelmente, isto apresenta as lamelas, dos emaranhamentos da fase amorfa do HDPE, quebradas (VALADEZ; CERVANTES; VELEVA, 1999).

Valadez e Veleva (2004), também fizeram ensaios de envelhecimento natural em HDPE, eles expuseram ao intemperismo amostras do mesmo material empregado no ensaio de envelhecimento feito por Valadez, Cervantes e Veleva (1999), em dois ambientes diferentes, um rural-urbano e outro litoral-marinho. $O$ ensaio teve duração de dois anos. Nas amostras foram analisadas as mudanças das propriedades físicas e químicas, com respeito ao comportamento térmico à absorção infravermelha e ao peso molecular. Os resultados mostraram que apesar das diferenças dos valores diários registrados de temperatura e umidade nos dois ambientes, a temperatura ambiental foi o fator fundamental que influencia a taxa de envelhecimento. As duas experiências permitiram comparar o mecanismo de degradação de HDPE, de forma natural e acelerada.

Quintela e Alves (2002) estudaram a influência dos agentes naturais externos tais como a radiação solar e a atmosfera marinha sobre a camada externa de HDPE de linhas flexíveis. Eles fizeram testes de envelhecimento natural e acelerado com o objetivo de avaliar possíveis alterações nas propriedades do material. Como corpos- 
de-prova utilizaram seções de risers flexível de diâmetro 63,5 mm. Estas foram expostas indistintamente à intempérie em uma atmosfera natural altamente corrosiva, e a envelhecimento acelerado em condições de laboratório numa câmara de intemperismo artificial um lote segundo a norma ASTM G 26 (radiação ultravioleta e água) e outro segundo a ASTM B 117 (névoa salina).

Depois de concluído o envelhecimento com as amostras de HDPE foram feitos corpos-de-prova, segundo a norma ASTM D 638 para ensaios de tração uniaxial. Os resultados dos ensaios de tração mostraram uma diminuição significativa na carga máxima suportada pelo HDPE, devido aos diferentes processos de envelhecimento a que foram submetidos. Além disso, durante a inspeção visual das amostras, constatou-se que a superfície do polímero encontrava-se com um aspecto bastante esbranquiçado, como resultado da radiação ultravioleta. Por meio da microscopia óptica constatou-se a presença de fissuras na superfície do material envelhecido.

Rosa et al. (2005), estudaram o envelhecimento do polipropileno isotático (iPP). Eles submeteram amostras de material a envelhecimento natural e artificial. Para medir a degradação que sofreu o material usaram varias técnicas, como microscopia óptica, microscopia eletrônica de varredura (MEV) e medições das propriedades mecânicas. Obtiveram como resultado a diminuição de $50 \%$ na deformação à fratura. Os resultados foram similares para as amostras submetidas aos dois tipos de envelhecimento. Finalmente concluíram que os três métodos empregados para medir o grau de degradação do material polimérico foram satisfatórios.

\subsection{ENSAIOS DE TRAÇÃO EM MATERIAIS POLIMÉRICOS}

Os testes de tração uniaxial são os ensaios mecânicos mais usados devido a seu baixo custo, rapidez e simplicidade com que podem ser feitos (SOUZA, 1988). Quando se fazem ensaios de tração em polímeros, como resultados diretos pode-se obter os valores de cargas aplicadas, e os alongamentos originados por estas, e com estes dados construir a curva tensão-deformação de engenharia do material a partir das eq.(2.31) e eq.(2.32) (BROWN, 1988). 


$$
\begin{aligned}
& \sigma=\frac{F}{S_{o}} \\
& \varepsilon=\frac{L-L_{o}}{L_{o}}
\end{aligned}
$$

onde:

$\sigma$ - tensão $(\mathrm{Pa})$;

F- carga aplicada $(\mathrm{N})$;

$\mathrm{S}_{\mathrm{o}}$ - área da seção transversal do corpo de prova não deformado $\left(\mathrm{m}^{2}\right)$;

$\varepsilon$ - deformação;

$\mathrm{L}$ - comprimento da base de referência final $(\mathrm{m})$;

$L_{0^{-}}$comprimento da base referência inicial $(m)$.

A partir da curva tensão-deformação é possível determinar o módulo de elasticidade do material $(E)$, o qual nos dá a medida da rigidez deste. Esta propriedade nos polímeros é determinada pelas forças de ligação entre os átomos. Determina-se por meio da eq.(2.34), a qual se obtém a partir da eq.(2.33), que descreve o comportamento linear elástico do material na primeira parte da curva de acordo com a "Lei de Hooke" (BROWN, 1988).

$$
\begin{aligned}
& \sigma=E \cdot \varepsilon \\
& E=\frac{F \cdot L_{o}}{S_{o} \cdot \Delta L}
\end{aligned}
$$

Pode-se definir como limite de escoamento à mínima tensão à qual a deformação permanente é produzida quando a tensão é subsequentemente removida. Em muitos casos o escoamento coincide com a carga máxima aplicada da curva forçaalongamento. O limite de escoamento também pode-se definir como a tensão real, quando é observada a carga máxima porque esta carga é alcançada com um pequeno alongamento do corpo-de-prova, sendo frequentemente adequado o uso da definição de engenharia de limite de escoamento como a carga máxima 
observada dividida pela área da seção transversal inicial do corpo-de-prova (WARD; SWEENEY, 2004). O limite de escoamento e é dada pela eq.(2.35).

$$
\sigma_{e}=\frac{F_{e}}{S_{o}}
$$

onde:

$\sigma_{\mathrm{e}}$ - limite de escoamento $(\mathrm{Pa})$;

$\mathrm{F}_{\mathrm{e}}$ - carga a que acontece o escoamento $(\mathrm{N})$.

Nos materiais poliméricos às vezes é muito difícil determinar com precisão o valor de limite de escoamento, já que o desvio da linearidade é sempre gradual e não há precisamente um ponto bem determinado, ou seja, é como uma zona de transição entre a zona de comportamento elástico e a de comportamento plástico.

Nos casos em que não é possível encontrar o limite de escoamento com precisão, adota-se, por convenção, o limite convencional $n$ de escoamento ou limite $n\left(\sigma_{n}\right)$ dado pela equação (2.36).

$$
\sigma_{n}=\frac{F_{n}}{S_{o}}
$$

onde:

$\sigma_{\mathrm{n}}$ - limite convencional $\mathrm{n}(\mathrm{Pa})$;

$F_{n}$ - carga em que se observa uma deformação de $n \%$ do material $(N)$.

Na prática, n pode ter o valor de $0,2 \%$ no caso mais geral (ROYLANCE, 1996).

O limite elástico e o limite de proporcionalidade nos mostram o final da zona de comportamento elástico do material. Eles podem ser determinados mediante carregamentos e descarregamentos sucessivos dos corpos-de-prova, até que seja obtida uma carga onde se observe, com boa precisão, a deformação permanente para o limite elástico, ou uma tensão onde a deformação deixe de ser proporcional a 
ela para o limite de proporcionalidade. Este processo é muito trabalhoso e a qualidade dos resultados depende em grande parte da medida da precisão dos dispositivos de medição e da máquina de ensaio usada. Os limites elástico e de proporcionalidade podem-se determinar também por métodos gráficos com a desvantagem de que são menos precisos (SOUZA, 1982).

Depois de superar o limite de escoamento, o material começa a comportar-se plasticamente e atinge o limite de resistência $\left(\sigma_{r}\right)$, que é a tensão máxima atingida durante o ensaio. Na realidade, a tensão que o material sofre ao atingir a carga máxima é maior que a tensão de ruptura calculada, devido à diminuição da área, que não é levada em conta na equação.

No caso de materiais dúcteis para projetos é mais usado o limite de escoamento ou limite n. Para materiais frágeis o limite de resistência é um critério válido para projetos, já que o limite de escoamento é muito difícil de se medir, e a diminuição da área da seção transversal é desprezível por causa da pequena zona de comportamento plástico que estes materiais apresentam.

O limite de resistência do material é determinado utilizando a eq.(2.37).

$$
\sigma_{r}=\frac{F_{r}}{S_{o}}
$$

onde:

$\sigma_{\mathrm{r}}$ - limite de resistência do material $(\mathrm{Pa})$;

$\mathrm{Fr}_{\mathrm{r}}$ carga de ruptura $(\mathrm{N})$.

No ensaio, após ser atingido o limite de resistência, começa a ruptura do material, caracterizada pelo fenômeno da estricção, ou seja a diminuição da secção transversal do corpo-de-prova, numa região determinada do mesmo. Onde se dá a ruptura, e com ela o final do ensaio. Nesta fase final a deformação torna-se não uniforme, e a força deixa de agir unicamente na direção normal à secção transversal do corpo-de-prova.

Outras propriedades do material que se podem determinar pelo ensaio de tração são o coeficiente de Poisson (v), o alongamento total $(A)$ e a estricção $(\varphi)$. 
Chama-se de coeficiente de Poisson, à propriedade que nos dá a rigidez do material na direção perpendicular à direção da carga de tração aplicada no ensaio. Para seu cálculo aplica-se a eq.(2.38).

$$
v=-\frac{\varepsilon_{T}}{\varepsilon_{L}}
$$

onde:

$v$ - coeficiente de Poisson;

$\varepsilon_{T}$ - deformação transversal;

$\varepsilon_{L}$ - deformação longitudinal.

A área abaixo da parte elástica da curva tensão versus deformação nos dá o valor da resiliência do material, que nada mais é do que a capacidade do material de absorver energia quando é deformado elasticamente, ou seja, dentro da zona elástica e liberá-la quando descarrega. Esta propriedade é medida pelo módulo de resiliência $\left(U_{R}\right)$ que é a energia de deformação por unidade de volume necessária para tensionar o material da origem até a tensão do limite de proporcionalidade.

Para determinar $\mathbf{U}_{\mathbf{R}}$, uma vez que a carga é aplicada gradualmente, o trabalho exercido para tensionar até atingir o limite de proporcionalidade é igual à tensão média multiplicada pela deformação $\varepsilon_{p}$, causada, segundo a eq.(2.40) e eq.(2.41) (ROYLANCE, 1996).

$$
\begin{aligned}
U_{R} & =\int_{0}^{\varepsilon_{p}} \sigma d \varepsilon \\
U_{R} & =\frac{\sigma_{p}^{2}}{2 E}
\end{aligned}
$$

onde:

$\mathrm{U}_{\mathrm{R}^{-}}$resiliência $\left(\mathrm{J} / \mathrm{m}^{3}\right)$;

$\sigma_{p^{-}}$limite de proporcionalidade $(\mathrm{Pa})$;

$\varepsilon_{p}$ - deformação no limite de proporcionalidade. 
Agora, então, se agregamos as áreas abaixo as curva das zonas elásticas e as plásticas obtém-se o valor da tenacidade, que é a capacidade que tem um material de absorver energia até sua ruptura. Ela é medida através do módulo de tenacidade $\left(\cup_{T}\right)$, que é a quantidade de energia absorvida por unidade de volume que o material pode resistir até atingir a fratura, é calculada pela a eq.(2.42) e eq.(2.43) (SOUZA, 1982).

$$
\begin{aligned}
& U_{T}=\int_{0}^{\varepsilon f} \sigma d \varepsilon \\
& U_{T}=\left(\frac{\sigma_{e}+\sigma_{r}}{2}\right) \varepsilon_{f}
\end{aligned}
$$

onde:

$\mathrm{U}_{\mathrm{T}}$ - tenacidade $\left(\mathrm{J} / \mathrm{m}^{3}\right)$;

$\sigma_{\mathrm{r}^{-}}$limite de resistência do material $(\mathrm{Pa})$;

$\varepsilon_{f^{-}}$deformação até a fratura.

\subsection{ESTADO DE TENSÕES MULTIAXIAIS E CRITÉRIOS DE ESCOAMENTO}

Um elemento estrutural na prática raramente está submetido a um estado tensional uniaxial, estados multiaxiais de deformações são difíceis de evitar. Na realidade, na maioria das vezes as estruturas estão submetidas a estados tensionais multiaxiais seja bi ou triaxiais. Nestes estados acontecem os mesmos fenômenos que no estado uniaxial tais como uma zona elástica, limite de escoamento, uma zona plástica, limite de resistência etc (SOUZA, 1982; SMITH; PASCOE, 1983). No entanto é necessário conhecer como ocorre a iniciação e crescimento da trinca sob condições de tensões multiaxiais já que estes mudam (SMITH; PASCOE, 1983).

Em uma viga carregada longitudinalmente sob uma tensão de tração uniaxial acontece uma contração lateral como mostra a Figura 2.24. Esta contração da origem a um estado deformacional tri-axial, com a deformação longitudinal $\left(\varepsilon_{\mathrm{L}}\right)$ observa-se duas deformação transversais $\left(-\varepsilon_{T}\right)$, no qual o coeficiente de Poisson (v) é a relação entre as deformações longitudinais e transversais (eq. 2.38), v varia 
entre os valores de 0,1 (alguns concretos) e 0,5 (elastômeros) (POPOV, 1978; FUCHS, STEPHENS, 1980).

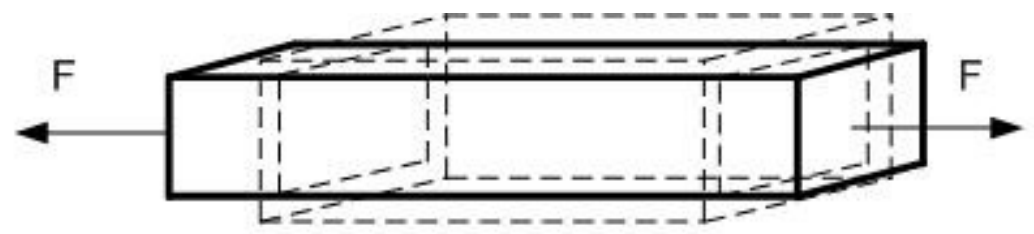

(a)

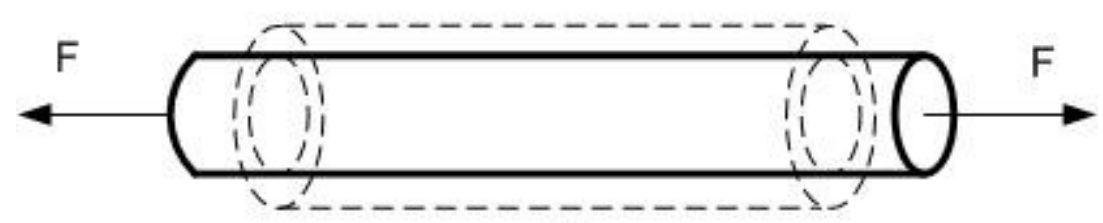

(b)

Figura 2.24 - Alongamento axial e contração lateral de duas barras carregadas à tração longitudinal: a, seção retangular; b, seção circular (as deformações foram exageradas)

Existem varias teorias que permitem estimar os limites de escoamento e de resistência de elementos estruturais submetidos a estados multiaxiais de tensões. Estas teorias ou critérios são baseadas nas propriedades mecânicas obtidas a partir de ensaios uniaxiais (SOUZA, 1982). As teorias baseadas no limite de escoamento são as mais confirmadas na prática, entre elas encontram-se: Teoria da máxima tensão de cisalhamento (Tresca); Teoria da máxima energia de distorção (Von Mises-Hencky); Teoria da máxima tensão normal (Rankine) entre outras.

No caso dos polímeros estruturais os quais são considerados materiais dúcteis, a Teoria da máxima energia de distorção ou Critério de Von Mises é a mais empregada e difundida, pois é a que mais se aproxima aos resultados experimentais (SOUZA, 1982; ROYLANCE, 1996). Este critério de escoamento é baseado em conceitos de energia. Nesta teoria a energia elástica total é dividida em duas partes, uma associada com as mudanças volumétricas do material, e outra causando a distorção de cisalhamento. Igualando a energia de distorção de cisalhamento no ponto de escoamento à tração uniaxial, com aquela sob tensão multiaxial, é estabelecido o critério de escoamento para tensão multiaxial (POPOV, 1978). 
O escoamento em um determinado ponto de um corpo submetido a um estado multiaxial de tensões ocorre quando a tensão equivalente de Von Mises, se iguala ao limite de resistência mecânico a escoamento obtido através do ensaio de tração convencional. A teoria da máxima energia de distorção é definida matematicamente pela eq.(2.44).

$$
\sigma_{e q}^{2}=\frac{1}{2}\left[\left(\sigma_{1}-\sigma_{2}\right)^{2}+\left(\sigma_{2}-\sigma_{3}\right)^{2}+\left(\sigma_{3}-\sigma_{1}\right)^{2}\right]=\sigma_{e}^{2}
$$

para um estado plano de tensões $\left(\sigma_{3}=0\right)$,

$$
\sigma_{e q}^{2}=\sigma_{1}^{2}-\sigma_{1} \cdot \sigma_{2}+\sigma_{2}^{2}=\sigma_{e}^{2}
$$

onde:

$\sigma_{\text {eq }}$ - tensão equivalente de Von Mises (Pa);

$\sigma_{1}, \sigma_{2}, \sigma_{3}-$ tensões principais $(\mathrm{Pa})$;

$\sigma_{\mathrm{e}}$ - limite de escoamentos (Pa).

A Figura 2.25 (HIBBELER, 2003) mostra a representação gráfica da Teoria da máxima energia de distorção para um estado plano de tensões $\left(\sigma_{3}=0\right)$. Qualquer tensão no interior da elipse indica que o material se comporta elasticamente. Os pontos da elipse indicam que o material esta em escoamento.

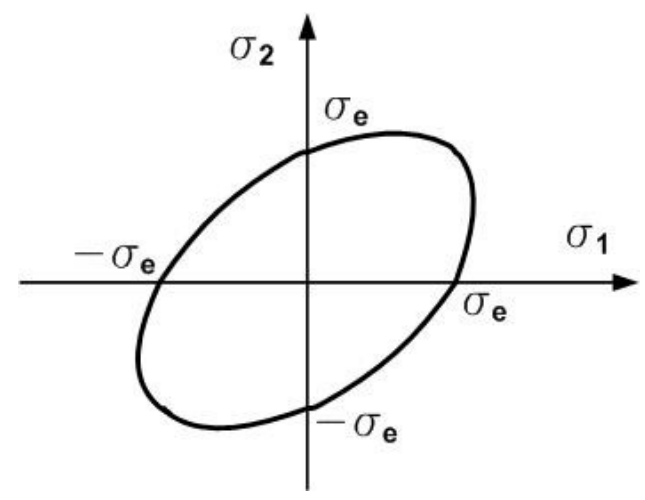

Figura 2.25 - Representação gráfica do critério de escoamento baseado na máxima energia de distorção (HIBBELER, 2003) 


\section{MÉTODO PARA ESTABELECER UM CRITÉRIO DE FALHA DA CAMADA POLIMÉRICA EXTERNA DO CABO UMBILICAL}

\subsection{HOMOLOGAÇÃO DE CABOS UMBILICAIS}

Os cabos umbilicais após projetados e fabricados passam por um processo de homologação antes de serem instalados nos Sistemas de Produção Flutuantes (SPF). No Brasil este processo é feito seguindo a metodologia fornecida pela norma API 17E. Esta norma estabelece os requisitos de projeto, manufatura e testes para o cabo umbilical e dois de seus componentes, cabos elétricos e mangueiras hidráulicas.

Entre os testes exigidos no processo de homologação dos cabos umbilicais segundo a norma API 17E encontram-se:

- Nos cabos elétricos: revisão visual e dimensional, resistência elétrica do cabo, resistência elétrica do isolamento, indutância, impedância e capacitância do cabo, característica de atenuação etc.

- Nas mangueiras hidráulicas: revisão visual e dimensional, mudança de comprimento quando pressurizadas, pressão de arrebentamento, flexão em frio, expansão volumétrica, pressurização cíclica, permeabilidade a líquidos e gases etc.

- No cabo umbilical: ensaios de tração, rigidez à flexão, compressão radial, fadiga, resistência elétrica dos cabos durante a realização dos diferentes testes.

Neste processo de homologação não leva em conta a falha da camada polimérica externa do cabo, o que permitiria a penetração da água do mar no cabo umbilical. Segundo estudos feitos, a penetração da água do mar no cabo pode originar uma redução da vida de serviço deste de mais de 25 anos (vida de projeto) para 2 anos ou menos devido à fadiga sob corrosão das armaduras de tração em um ambiente úmido e agressivo como o marinho (UKOOA, 2001; TAYLOR, JOOSTEN, SMITH, 2002). 
Daí a importância de paralelamente com os diferentes testes a que são submetidos os cabos e alguns de seus componentes durante o processo de homologação seja incluído um critério de falha da camada polimérica externa do cabo, devido á grande importância desta na durabilidade do umbilical.

O objetivo desta parte do trabalho foi estabelecer um critério da falha da camada polimérica externa do cabo umbilical.

\subsection{CRITÉRIO DE FALHA DA CAMADA POLIMÉRICA EXTERNA DE CABOS UMBILICAIS}

As propriedades dos materiais poliméricos, usados em estruturas de engenharia, modificam-se quando são submetidos a condições mecânicas e ambientais desfavoráveis devido às mudanças em sua microestrutura. $\mathrm{Na}$ maioria dos casos estas mudanças afetam negativamente as propriedades mecânicas do material.

Polímeros semicristalinos, como o polietileno de alta densidade, são materiais amplamente usados como isolante em cabos de alta voltagem devido a suas propriedades dielétricas e seu baixo custo.

Quando são usados na camada externa dos cabos umbilicais, o polímero fica submetido a carregamentos cíclicos e a uma combinação de fatores ambientais agressivos tais como radiações ultravioleta, oxigênio, variações de temperatura e ambientes salinos tanto secos como úmidos. Como resultado o material está propenso à formação de poros e fissuras superficiais, cavitações internas, cisão de cadeias poliméricas e formação de ligações cruzadas. Todo isto permitirá que a água e oxigênio do meio penetrem no material da camada polimérica passando ao interior do cabo, diminuindo a durabilidade deste devido ao fenômeno de fadiga com corrosão das armaduras de tração do umbilical (UKOOA, 2001; TAYLOR, JOOSTEN, SMITH, 2002; TAVARES et al., 2003; CÁRDENAS, MACHADO, GONÇALVES, 2007).

Devido ao exposto anteriormente, o critério de falha proposto baseia-se na perda da impermeabilidade da camada polimérica externa do cabo, materializado isto na 
quantidade de água absorvida por esta após de ser submetida a uma quantidade determinada de carregamentos cíclicos.

\subsection{MÉTODO PROPOSTO}

A metodologia proposta para verificar a falha da camada polimérica externa do cabo umbilical consta de seis etapas as quais apresentam-se a seguir.

\subsubsection{Primeira etapa - Fadiga}

A primeira etapa da metodologia consiste em realizar um ensaio de fadiga à tração uniaxial no polímero da camada externa do cabo. O objetivo deste teste é simular, com um ensaio de fadiga à tração uniaxial de polímero, as solicitações mecânicas a que é submetida a camada polimérica externa do cabo no ensaio de fadiga feito segundo a norma API 17E e, assim, conseguir um dano similar em ambos os ensaios.

No ensaio de fadiga à tração uniaxial os carregamentos aplicados são estabelecidos pela mesma deformação cíclica ocorrida no ensaio de fadiga feito, segundo a norma API 17E, no cabo umbilical.

Para determinar as deformações cíclicas a que é submetida a camada polimérica externa do cabo umbilical durante o ensaio de fadiga feito segundo a norma API 17E, consideram-se: as deformações residuais devido ao processo de fabricação do cabo; as deformações devido à tração inicial imposta ao cabo e as deformações devido à flexão.

\subsubsection{Ensaio de fadiga no cabo umbilical segundo a norma API 17E}

Para a realização do ensaio de fadiga no cabo umbilical emprega-se como guia de referência o esquema da Figura I-2 do Appendix I- Fatigue Testing (API 17E), onde 
mostra-se esquematicamente a disposição do cabo ao redor de uma polia oscilante, Figura 3.1.

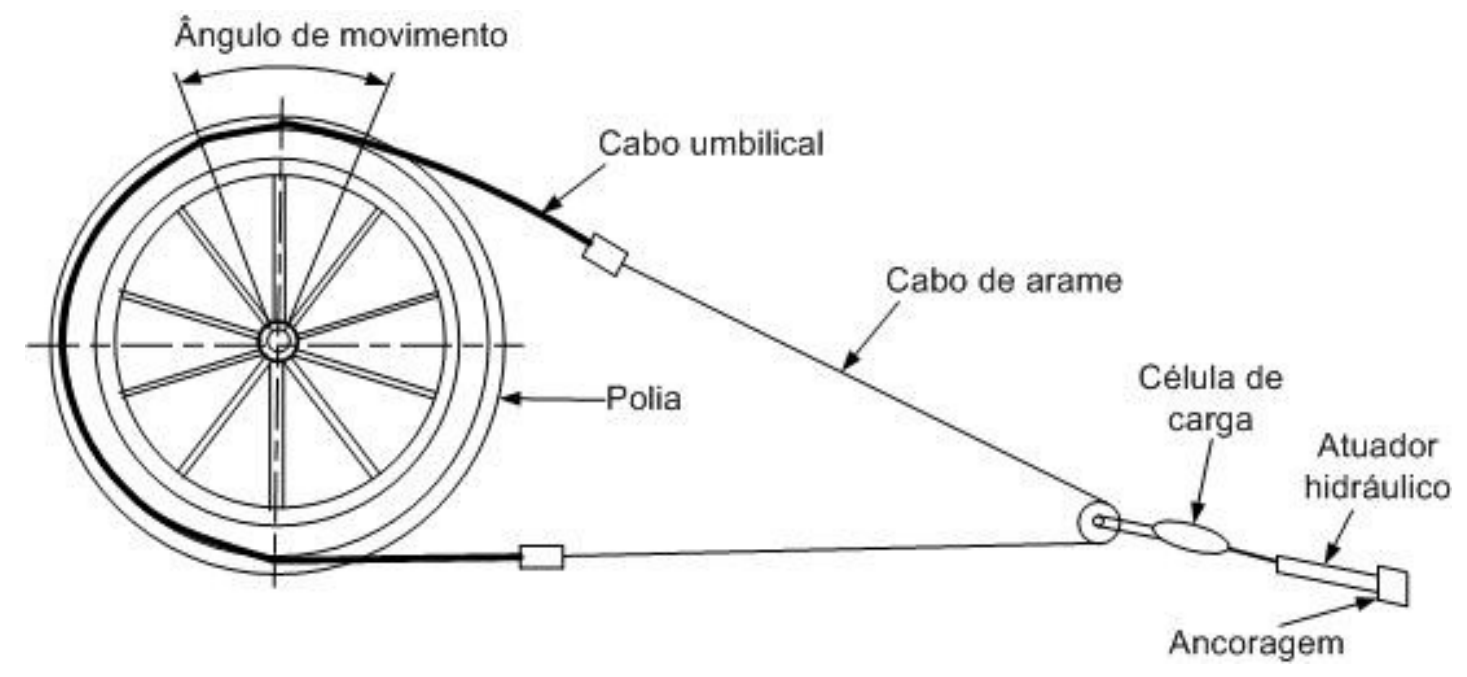

Figura 3.1 - Esquema típico para um ensaio de fadiga em cabos umbilicais segundo a norma API 17E (API 17E)

Com o ensaio de fadiga do cabo umbilical segundo norma API 17E trata-se de simular os diversos e complexos carregamentos, tais como: tração, flexão, torção etc, a que estão submetidos os cabos umbilicais durante sua instalação e serviço nas operações offshore.

Estes ensaios são realizados numa bancada especialmente projetada e construída para tal, a qual se mostra na Figura 3.2 (LÉPORE, 2003). Esta foi concebida a partir de uma roda (polia) de 3,5 m de diâmetro e um sistema capaz de tracionar o corpo-de-prova (cabo umbilical) com uma carga de $2.000 \mathrm{kN}$.

Como corpo-de-prova para o ensaio de fadiga é empregado um segmento de cabo umbilical de 13,5 m de comprimento, Figura 3.3 (CÁRDENAS, 2002), sendo que nas suas extremidades são montadas conexões do tipo flange. 


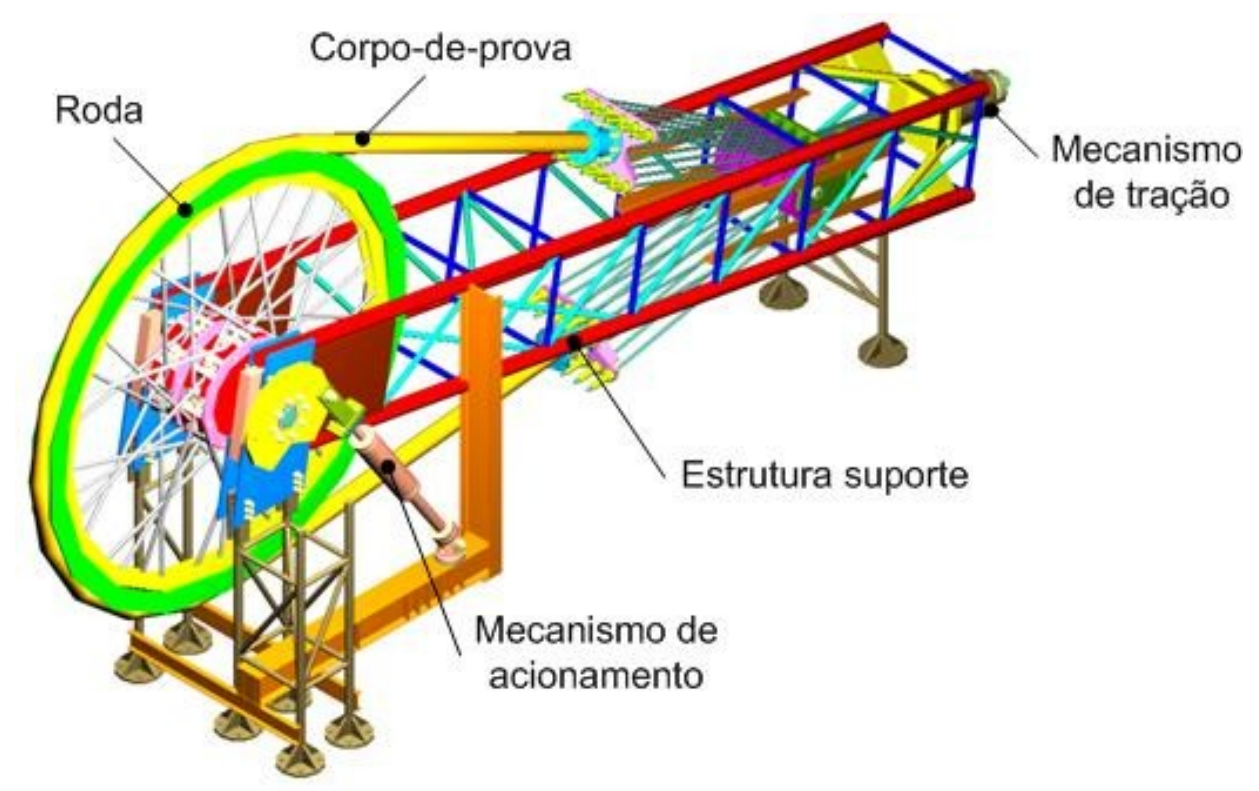

Figura 3.2 - Arranjo de ensaio de fadiga mecânica no cabo umbilical segundo a API 17E (LEPORE, 2003)

Figura 3.3 - Corpo-de-prova para ensaio de fadiga segundo norma API 17E (CÁRDENAS, 2002)

Durante o ensaio de fadiga o corpo-de-prova é submetido a um carregamento de tração de $600 \mathrm{kN}$. Em seguida, mantendo-se essa carga, impõe-se um movimento alternativo na polia, fazendo com que ocorram mudanças de curvatura no cabo umbilical, originando, assim, tensões e deformações cíclicas em suas diferentes camadas. O cabo, em cada ciclo, flexiona um comprimento de 1,8 m. A duração do ensaio é de 30.000 ciclos, e o período de cada ciclo é estabelecido entre 5 e 10 segundos. 
No Anexo A, mostram-se algumas fotos do arranjo experimental para ensaios de fadiga segundo a norma API 17E.

\subsubsection{Deformações residuais}

Os cabos umbilicais, devido à sua complexa geometria estrutural, à diversidade dos materiais que o compõem e aos complexos processos empregados na sua fabricação, após serem fabricados e antes de entrar em serviço estão sob um complexo campo tenso-deformacional. A estrutura interna do cabo e principalmente as armaduras de tração exercem esforços sob a camada polimérica externa a qual é extrudada sobre estas armaduras.

A determinação do campo de deformações residuais foi feita através do método da extensômetria elétrica, utilizando um extensômetro do tipo roseta retangular de três elementos (ALMEIDA, 1996).

Para a determinação experimental das deformações na camada polimérica externa deve usar-se uma seção de cabo de comprimento não menor que três vezes o período dos tendões (arames da armadura de tração) para evitar o efeito dos extremos que podem mascarar os verdadeiros valores das deformações residuais.

Para o ensaio de desconfinamento adotou-se um rigoroso procedimento para instrumentar o corpo-de-prova. O procedimento contou com as seguintes etapas.

Primeiramente são tomadas as dimensões do corpo-de-prova. No ponto médio do seu comprimento, é preparada a superfície onde será colado o extensômetro elétrico. Esta preparação consiste no melhoramento desta superfície. Lixa-se esta com papel de esmeril fino e limpa-se com uma gaze e álcool para retirar as impurezas, como gordura e poeira, com o objetivo de conseguir uma melhor aderência do extensômetro. Em seguida, com uma caneta, é marcado o lugar onde será colado o extensômetro. Emprega-se o extensômetro do tipo roseta retangular de três elementos com o objetivo de medir simultaneamente a deformação em três eixos coordenados (ALMEIDA, 1996). O primeiro componente do extensômetro é orientado na direção axial do cabo para medir a deformação longitudinal, os outros dois componentes são orientados um no sentido transversal, para medir a 
deformação circunferêncial e outro a $45^{\circ}$ dos outros dois eixos, para medir a deformação nesta direção.

Para a colagem do extensômetro usou-se o adesivo recomendado pelo fabricante do sensor segundo o tipo de material que será testado e as características do ensaio. $\mathrm{Na}$ realização da colagem é colocado o adesivo na superfície inferior do extensômetro e, com ajuda de uma fita adesiva, este é posicionado na zona que tinha sido marcada anteriormente. Com uma borracha é exercida uma leve pressão por dois minutos sobre o extensômetro. Em seguida, são verificadas as resistências elétricas do extensômetro comprovando-se que mantém as características dadas pelo fabricante. O tempo de cura é no mínimo de $24 \mathrm{~h}$ para conseguir uma boa aderência. Posteriormente, proceder-se á soldagem dos cabos de cobre nos terminais do extensômetro para ligar este ao Sistema de Aquisição de Dados (SAD). Já com o arranjo pronto para o experimento, é feita a calibração do SAD. Esta consiste em deixar os três canais a que estão ligados os componentes do extensômetro com deformação zero. Na Figura 3.4 (CÁRDENAS; GONÇALVES; SUÑÉ; VALIN, 2006) mostra-se esquematicamente o arranjo experimental.

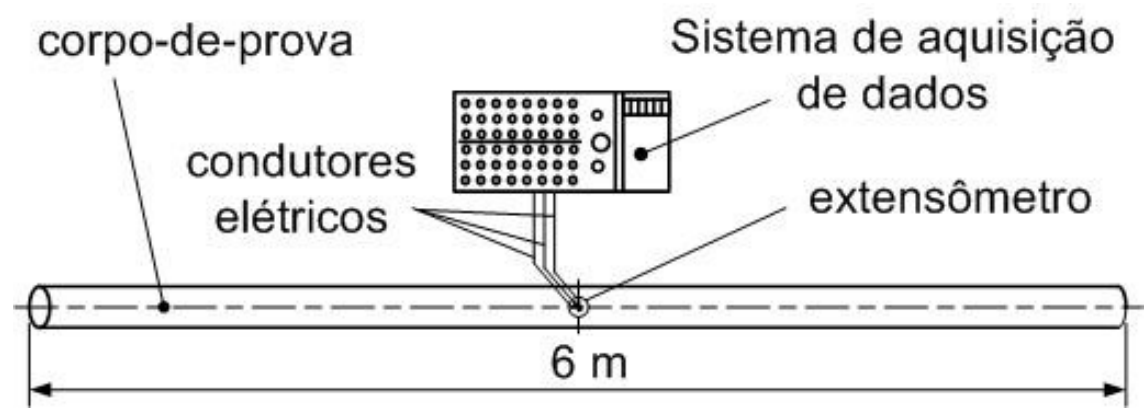

Figura 3.4 - Arranjo para ensaio de desconfinamento (CÁRDENAS; GONÇALVES; SUÑÉ; VALIN, 2006)

Após instrumentado o cabo umbilical, com o extensômetro de resistência elétrica e calibrado o SAD proceder-se-á operação de desconfinamento da região da camada polimérica externa onde foi colado o extensômetro.

O desconfinamento da região da camada na qual foi colado o extensômetro visa determinar qual é a variação das deformações após separar a parte instrumentada 
da camada externa do cabo e, assim, conhecer o estado de deformação a que está submetido esta camada devido ao processo de fabricação e à estrutura interna do cabo.

Com ajuda de uma serra manual e um estilete é retirada a zona da camada externa do cabo onde foi colado o extensômetro, tendo o cuidado de que, neste processo, não se danifique o elemento sensor, o que poderia afetar os resultados experimentais. Após retirada a zona instrumentada do cabo umbilical, como ilustra a Figura 3.5, são registradas as medidas de deformação dos três componentes do extensômetro.

Durante o ensaio são monitorados e registrados os valores das temperaturas ambiente e do corpo-de-prova na região onde foi colado o extensômetro.

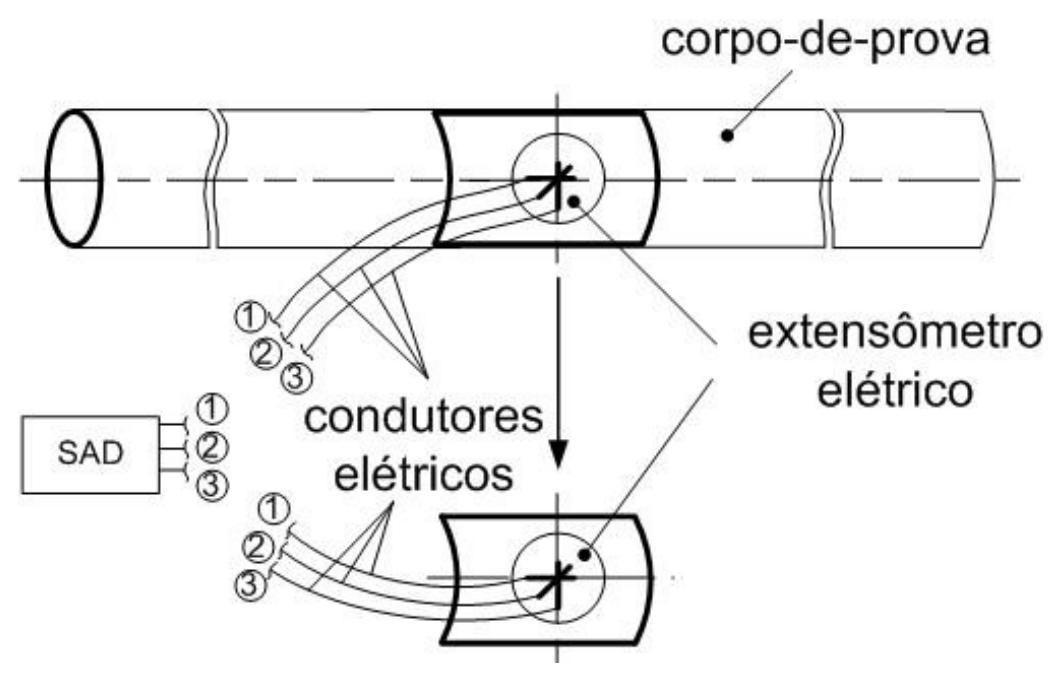

Figura 3.5 - Esquema da região do corpo-de-prova instrumentada antes e após do desconfinamento

Para o cálculo das deformações principais são usados os resultados obtidos no ensaio de desconfinamento e as equações fornecidas por (DALLY; RILEY, 1978).

As deformações principais são calculadas a partir das eq.(3.1) e eq.(3.2). 


$$
\begin{aligned}
& \varepsilon_{1}=\frac{\varepsilon_{A}+\varepsilon_{C}}{2}+\frac{\sqrt{\left(\varepsilon_{A}-\varepsilon_{C}\right)^{2}+\left(2 \cdot \varepsilon_{B}-\varepsilon_{A}-\varepsilon_{C}\right)^{2}}}{2} \\
& \varepsilon_{2}=\frac{\varepsilon_{A}+\varepsilon_{C}}{2}-\frac{\sqrt{\left(\varepsilon_{A}-\varepsilon_{C}\right)^{2}+\left(2 \cdot \varepsilon_{B}-\varepsilon_{A}-\varepsilon_{C}\right)^{2}}}{2}
\end{aligned}
$$

onde:

$\varepsilon_{1}$ - deformação máxima principal $(\mu \mathrm{m} / \mathrm{m})$;

$\varepsilon_{\mathrm{A}}$ - deformação longitudinal $(\mu \mathrm{m} / \mathrm{m})$;

$\varepsilon_{\mathrm{c}}$ - deformação circunferêncial $(\mu \mathrm{m} / \mathrm{m})$;

$\varepsilon_{B}$ - deformação a $45^{\circ}(\mu \mathrm{m} / \mathrm{m})$;

$\varepsilon_{2}$ - deformação mínima principal $(\mu \mathrm{m} / \mathrm{m})$.

Para determinar o ângulo entre o eixo longitudinal do cabo e o eixo da deformação máxima principal, será usada a eq.(3.3) (DALLY; RILEY, 1978).

$$
(\tan 2 \phi)=\frac{2 \varepsilon_{B}+\varepsilon_{A}-\varepsilon_{C}}{\varepsilon_{A}-\varepsilon_{C}}
$$

onde:

$\theta$ - ângulo entre o eixo longitudinal do cabo e o eixo da deformação máxima principal $\left({ }^{\circ}\right)$;

$\varepsilon_{B}$ - deformação a $45^{\circ}(\mu \mathrm{m} / \mathrm{m})$;

$\varepsilon_{\mathrm{A}}$ - deformação longitudinal $(\mu \mathrm{m} / \mathrm{m})$;

$\varepsilon_{c}$ - deformação circunferêncial $(\mu \mathrm{m} / \mathrm{m})$.

3.3.1.3 Deformação na camada polimérica externa do cabo umbilical devido à tração inicial

Para determinar a deformação a que é submetida a camada polimérica externa do cabo umbilical durante, a tração inicial de $600 \mathrm{kN}$ no ensaio de fadiga feito segundo 
a norma API 17E, será feito um ensaio de tração no cabo umbilical. Este teste é feito na bancada onde foi realizado o ensaio de fadiga do cabo umbilical segundo a norma API 17E, Figura 3.2.

Para a realização do ensaio de tração no cabo umbilical é usado como corpo-deprova uma seção de umbilical com comprimento de $13,5 \mathrm{~m}$, o mesmo usado no ensaio de fadiga segundo a API 17E, Figura 3.3. O procedimento para a preparação do espécime será o mesmo utilizado no ensaio de fadiga segundo API 17E, item 3.3.1.1.

Uma vez preparado o corpo-de-prova este é colocado e fixado na bancada de ensaio. Concluída esta operação, o espécime é instrumentado através da colagem de duas pastilhas metálicas cilíndricas na parte reta do cabo que fica submetida somente a carregamento de tração. Estas pastilhas metálicas servem como pontos de referência base para apoiar os ponteiros do extensômetro mecânico que é usado como sensor de deformação. Na Figura B1 do Apêndice B, mostra-se uma foto de um corpo-de-prova instrumentado com as duas pastilhas metálicas.

Para auxiliar o posicionamento das pastilhas durante a colagem será utilizado como gabarito uma base de $50 \mathrm{~mm}$ a qual é um dos acessórios do extensômetro. $\mathrm{Na}$ Figura B2 do Apêndice B, mostra-se as fotos do extensômetro mecânico (a), e da base (b) usada como gabarito no ensaio de tração do cabo umbilical.

O ensaio de tração do cabo umbilical consiste em submeter o cabo a uma carga de tração que é a mesma carga estática aplicada no ensaio de fadiga segundo a API 17E. Prevendo que ao se aplicar um carregamento de tração ocorre uma acomodação das diferentes camadas e componentes estruturais do corpo-de-prova, a aplicação da carga será feita por incrementos não maiores de 20 \% da carga total, até chegar ao valor de carregamento final desejado.

Após aplicada a carga total é feita a medição do deslocamento na camada polimérica externa do cabo usando um extensômetro mecânico. Como resultado do ensaio de tração obtém-se o valor de deslocamento da camada polimérica externa. Levando em conta que a base de medida usada é de $50 \mathrm{~mm}$ e sabendo que os corpos-de-prova a serem submetidos a fadiga à tração uniaxial têm base de medida de $50 \mathrm{~mm}$, o deslocamento estimado será o mesmo a usar no ensaio de fadiga à tração uniaxial da camada externa devido à tração inicial do cabo 
3.3.1.4 Deformação na camada polimérica externa do cabo umbilical devido à flexão

A determinação da deformação devido à flexão é calculada considerando a variação geométrica do ponto de interesse assumindo o cabo como uma viga submetida a flexão pura através das equações dadas por Pissarenko, lakovlev e Matveiev (1985). $\mathrm{Na}$ Figura 3.6 (PISSARENKO; IAKOVLEV; MATVEIEV, 1985) ilustra-se esquematicamente a geometria de um segmento de viga em flexão pura.

Quando uma viga é submetida à flexão, a deformação de uma certa fibra situada a uma distância (y) do eixo neutro, no caso da flexão pura, pode ser determinado o arco de comprimento $a_{1} b_{1}$, a partir da eq.(3.6) (PISSARENKO; IAKOVLEV; MATVEIEV, 1985).

$$
\begin{gathered}
\varepsilon=\frac{L-L_{0}}{L_{0}}=\frac{a_{1} b_{1}-d z}{d z}=\frac{(\rho+y) d \theta-\rho d \theta}{d z} \\
\varepsilon=y \frac{d \theta}{d z} \\
\varepsilon=\frac{y}{\rho}
\end{gathered}
$$

onde:

$\varepsilon$ - deformação;

$\mathrm{L}$ - comprimento da base de referência final $(\mathrm{m})$;

$\mathrm{L}_{0}$ - comprimento da base de referência inicial $(\mathrm{m})$;

$a_{1} b_{1}$ - comprimento do arco $(m)$;

dz- comprimento do segmento de viga analisada $(m)$;

$\rho$ - raio de curvatura $(m)$;

$y$ - distancia do ponto analisado ao eixo $(\mathrm{m})$;

$d \theta$ - ângulo formado durante a flexão entre os extremos do segmento de viga analisado $\left({ }^{\circ}\right)$. 

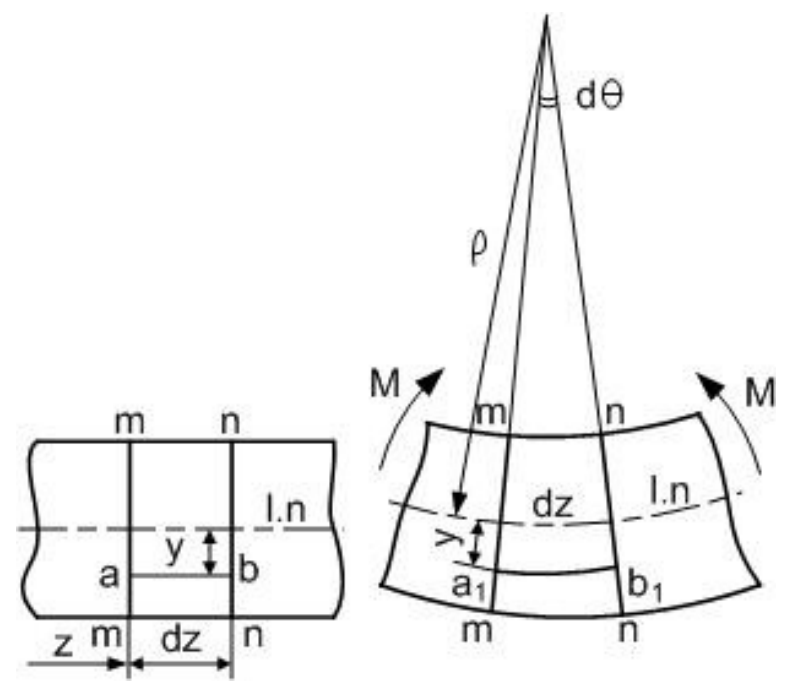

Figura 3.6 - Esquema de viga submetida a flexão pura (PISSARENKO; IAKOVLEV; MATVEIEV, 1985)

O valor da deformação é obtido substituindo os valores conhecidos de y e $\boldsymbol{\rho}$ na eq.(3.6), com este valor de deformação $(\varepsilon)$, obtido e com o comprimento da base de referência de $50 \mathrm{~mm}$, esta última magnitude tomada da norma ASTM D 638 para um corpo-de-prova de ensaio de tração uniaxial.

3.3.1.5 Ensaio de fadiga à tração uniaxial no material da camada polimérica externa do cabo

O objetivo deste ensaio de fadiga à tração uniaxial é simular, as solicitações mecânicas a que a camada polimérica externa do cabo umbilical são submetidas quando ensaiadas à fadiga segundo a norma API 17E, provocando, assim, um dano similar ao originado pelo ensaio feito segundo a norma API 17E.

Os corpos-de-prova empregados no ensaio de fadiga à tração uniaxial serão de acordo com o formato apresentado na Figura 3.7, segundo a norma ASTM D 638. 


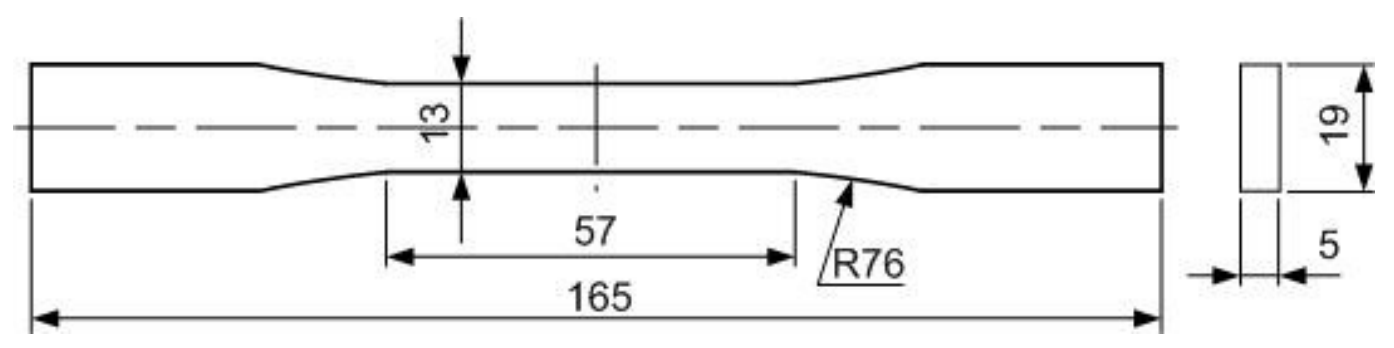

Figura 3.7 - Corpo-de-prova empregado nos ensaios de fadiga à tração uniaxial, dimensões em mm (ASTM D 638)

Escolheu-se este tipo de corpo-de-prova com o fim de, após submetermos a ensaio de fadiga à tração uniaxial, realizar com eles ensaios de absorção de água e observação no microscópio.

Também serão feitos ensaios de tração segundo a norma ASTM D 638, com o fim de comparar os resultados destes ensaios com os obtidos nos ensaios de tração feitos com as amostras da camada polimérica externa tirada de um cabo que não foi utilizado.

Para elaborar os corpos-de-prova para os ensaios de fadiga à tração uniaxial, primeiramente, são retiradas do cabo umbilical, sem uso, amostras da camada polimérica externa. Este processo é feito cuidadosamente com ferramentas manuais (serra manual, estilete, etc) para que o aumento da temperatura durante a operação de corte não afete as propriedades originais do material.

Após retiradas as amostras do material a ser ensaiadas, e com a ajuda de um gabarito, são traçados os perfis dos espécimes que são cortados com uma serra manual e, em seguida, com uma esmeriladora e com papel de lixa fino, são dadas as dimensões desejadas e é feito o acabamento final. As dimensões finais dos corpos-de-prova devem ficar dentro das tolerâncias admitidas pela norma ASTM D 638. Todas as superfícies usinadas dos corpos-de-prova devem ficar livres de defeitos, ranhuras e imperfeições.

São elaborados cinco corpos-de-prova com o formato da Figura 2.7, um para ensaio de absorção de água, um para as observações no microscópio e três para ser ensaiados a tração, após concluído o ensaio de fadiga à tração uniaxial. 
$\mathrm{Na}$ execução dos ensaios de fadiga à tração uniaxial a máquina empregada é do tipo atuador servo hidráulico. Na Figura 3.8 mostra-se esquematicamente o arranjo experimental usado na realização do ensaio de fadiga à tração uniaxial na camada polimérica externa do cabo umbilical.

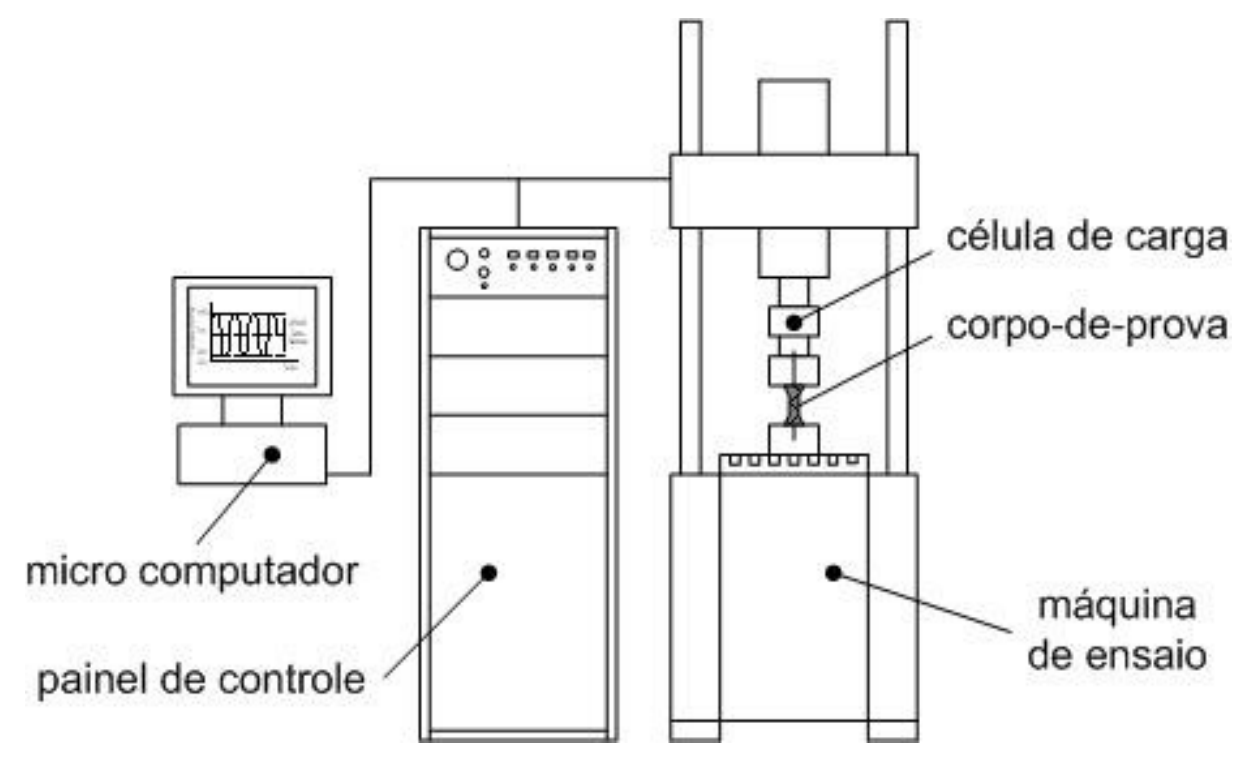

Figura 3.8 - Esquema do arranjo usado para o ensaio de fadiga à tração uniaxial

Neste ensaio tanto os carregamentos como os deslocamentos a que serão submetidos os corpos-de-prova podem ser controlados e monitorados pelos diferentes acessórios da máquina de ensaio.

O ensaio de fadiga à tração uniaxial consistirá em submeter o corpo-de-prova elaborado a partir da camada externa do cabo a deformações cíclicas similares as que é submetida a camada polimérica externa da parte superior do cabo umbilical durante o ensaio de fadiga feito segundo a norma API 17E.

Para determinar os deslocamentos a que vai estar submetido o corpo-de-prova no ensaio de fadiga à tração uniaxial assume-se como comprimento da base de referência $50 \mathrm{~mm}$, que é o valor dado como comprimento de referência na norma ASTM D 638 para o tipo de corpo-de-prova empregado. 
Os valores de deslocamento a que será submetido o material da camada polimérica externa durante o ensaio de fadiga à tração uniaxial serão calculados usando a eq.(3.7) (SOUZA, 1982).

$$
\Delta L=\varepsilon \cdot L
$$

onde:

$\Delta \mathrm{L}$ - deslocamento $(\mathrm{m})$;

$\varepsilon$ - deformação;

L- comprimento da base de referência $(m)$.

$\mathrm{Na}$ execução do ensaio de fadiga, inicialmente é aplicado ao espécime um deslocamento com a magnitude correspondente à somatória das deformações devido ao processo de fabricação $\left(\varepsilon_{F}\right)$ e à tração inicial $\left(\varepsilon_{T}\right)$ a que é submetido o cabo durante o ensaio de fadiga realizado segundo a norma API 17E. A amplitude da oscilação para o ensaio de fadiga à tração uniaxial é obtida da deformação devido à curvatura $\left(\varepsilon_{c}\right)$ durante a flexão, que sofre a parte superior da camada polimérica externa do cabo.

Na Figura 3.9 ilustra-se o gráfico dos ciclos de fadiga (deformação-tempo) que serão impostos aos corpos-de-prova durante o ensaio de fadiga à tração uniaxial.

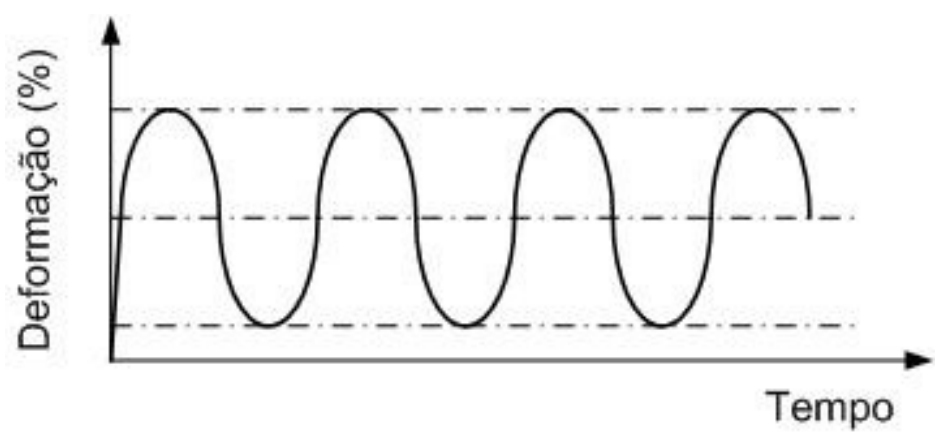

Figura 3.9 - Gráfico dos ciclos de fadiga a serem impostos ao polímero no ensaio de fadiga à tração uniaxial 
No ensaio de fadiga à tração uniaxial, a quantidade de carregamentos cíclicos aplicados será a mesma que no ensaio de fadiga feito segundo a API 17E. A freqüência dos carregamentos aplicados será $0,5 \mathrm{~Hz}$, maior que a usada no ensaio de fadiga segundo a API 17E (entre 0,1 e 0,2 Hz) e menor que a freqüência de 30 $\mathrm{Hz}$ utilizada por Riddell (1974) na obtenção das curvas S-N de diferentes materiais poliméricos, entre eles o polietileno, material amplamente usado na fabricação das camadas externas de cabos umbilicais.

Serão realizados cinco testes de fadiga à tração uniaxial para obter os espécimes que serão posteriormente ensaiados a absorção (um espécime), observação no microscópio (um) e ensaiados a tração (três).

Durante a realização do ensaio de fadiga à tração uniaxial no local no qual será feito o teste a temperatura deve ser mantida a $23 \pm 2{ }^{\circ} \mathrm{C}$ e a umidade relativa deve ser $50 \pm 5 \%$.

\subsubsection{Segunda etapa - Envelhecimento}

Os cabos umbilicais, após serem instalados nos Sistemas Flutuantes de Produção (SFP), durante sua vida de serviço encontram-se submetidos a diferentes condições do meio ao longo de seu comprimento, como ilustra a Figura 3.10 (CÁRDENAS; MACHADO, GONÇALVES, 2007).

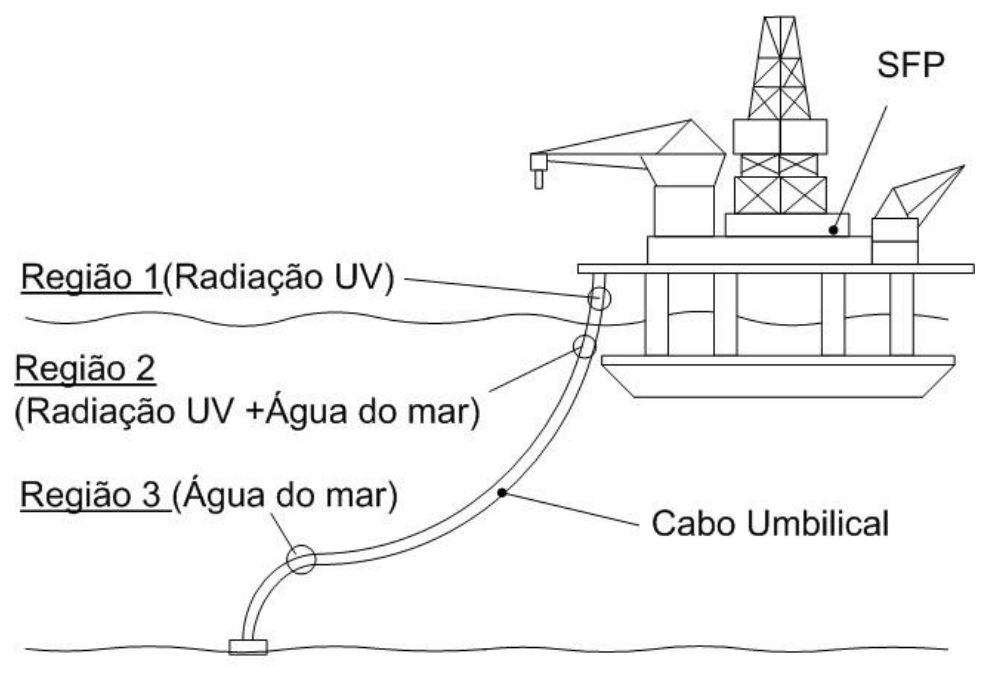

Fundo marinho

Figura 3.10 - Condições ambientais a que está submetido o cabo durante sua vida de serviço nos SFP (CÁRDENAS; MACHADO, GONÇALVES, 2007) 
A região $1^{1}$ do cabo, a camada externa está submetida à radiação solar. Já na região $2^{* *}$, o cabo sofre a influência da radiação solar e da água marinha simultaneamente. Por último, a região $3^{* * *}$, fica afetada principalmente pela água do mar.

Além disso, os cabos encontram-se submetidos às correntes marinhas, que provocam deslocamentos laterais das plataformas e movimentação das linhas ao longo do comprimento dos cabos. Isso ocasiona uma combinação de esforços de tração, flexão, torção e pressão externa. Tais esforços, combinados com a água salgada, radiação ultravioleta e outros agentes do meio, podem levar a uma falha precoce da camada polimérica externa e com isso comprometer a durabilidade do cabo umbilical (WHITE, TURNBULL, 1994; CÁRDENAS, GONÇALVES, 2003; CÁRDENAS; MACHADO, GONÇALVES, 2007).

Este ensaio tem como objetivo estudar o efeito da radiação ultravioleta, da água do mar e dos carregamentos cíclicos combinados nas propriedades mecânicas da camada polimérica externa do cabo umbilical.

A radiação solar que atinge as camadas mais exteriores da atmosfera terrestre possui espectro contínuo entre 0,7 e $3.000 \mathrm{~nm}$. Ao passar pelas diversas camadas da atmosfera, somente uma parte deste espectro atinge a superfície terrestre, notadamente acima de 290-300 nm. Só uns $6 \%$ da radiação incidente na superfície terrestre encontra-se dentro da faixa do ultravioleta, sendo esta pequena porção responsável pelos processos foto degradantes sofridos pelas ligações químicas dos materiais poliméricos (GUGUMUS, 1990).

Para conseguir um efeito similar à radiação solar à intempérie recomenda-se usar lâmpadas fluorescentes que emitam uma radiação com comprimento de onda entre 300 e 400 nm (ASTM D 4329; ASTM G 154; WHITE, TURNBULL, 1994).

Dois tipos de espécimes, são submetidos ao envelhecimento os que foram submetidos anteriormente à fadiga (item 3.3.1.5) e outros que serão feitos com amostras tomadas da camada polimérica externa do cabo sem uso.

Os espécimes usados no ensaio de envelhecimento são do tipo placa e de formato segundo a norma ASTM 638, Figura 3.7. Os do tipo placa serão observados no microscópio antes e após o envelhecimento. Com os de formato da Figura 3.7 serão

\footnotetext{
${ }^{1 *}$ Região 1 do cabo fica entre o SFP e a superfície marinha; ${ }^{* *}$ Região 2, está submersa, próxima à superfície marinha; ${ }^{* * \star}$ Região 3 , está submersa, a profundidade maiores e próxima ao fundo do mar.
} 
feitos ensaios de tração segundo a norma ASTM 638, com o fim de comparar os resultados destes ensaios com os obtidos nos ensaios de tração feitos com as amostras retiradas do cabo sem uso.

O procedimento seguido para a preparação dos corpos-de-prova para ensaio de tração é o mesmo empregado no item 3.3.1.5. Serão confeccionados nove corposde-prova para ensaios de tração, a partir da amostra do material retirado do cabo sem uso e nove do material que foi submetido á fadiga.

Para as observações no microscópio serão feitos seis espécimes do tipo placa, três do material tirado do cabo sem uso e três do material que foi submetido à fadiga. As dimensões dos corpos-de-prova são $18 \mathrm{~mm}$ de comprimento e $13 \mathrm{~mm}$ largura, a espessura é a mesma da camada externa do cabo.

A fim de simular as condições a que a camada polimérica externa do cabo está submetida durante seu serviço são criados três ambientes em condições de laboratório para submeter o material a um envelhecimento acelerado.

O primeiro ambiente (Região 1), Figura 3.10, é aquele que fica fora do mar, sob radiação ultravioleta. Para conseguir um efeito similar à radiação solar são usadas lâmpadas fluorescentes que emitem uma radiação com comprimento de onda na faixa de 300 a $400 \mathrm{~nm}$. O ensaio será feito segundo as normas ASTM D 4329 e ASTM G 154.

Para a simulação da segunda zona (Região 2), Figura 3.10, é criado um segundo ambiente. Com este objetivo emprega-se uma manta térmica e uma cuba de cristal. Os corpos-de-prova serão colocados dentro da cuba de cristal que conterá água do mar artificial, preparada segundo a norma ASTM D 1141, até um nível que cubra os corpos-de-prova. A temperatura da água estará controlada pela manta térmica. Simultaneamente, os corpos-de-prova são irradiados com radiação ultravioleta durante o tempo que dure o ensaio.

Para simular o terceiro ambiente (Região 3), Figura 3.10, emprega-se a mesma metodologia do ambiente anterior, Região 2, com a diferença que os corpos-deprova não são irradiados, ficando isolados em um local escuro. Na Figura 3.11 ilustram-se esquematicamente os arranjos experimentais para o ensaio de envelhecimento da camada externa do cabo umbilical. 


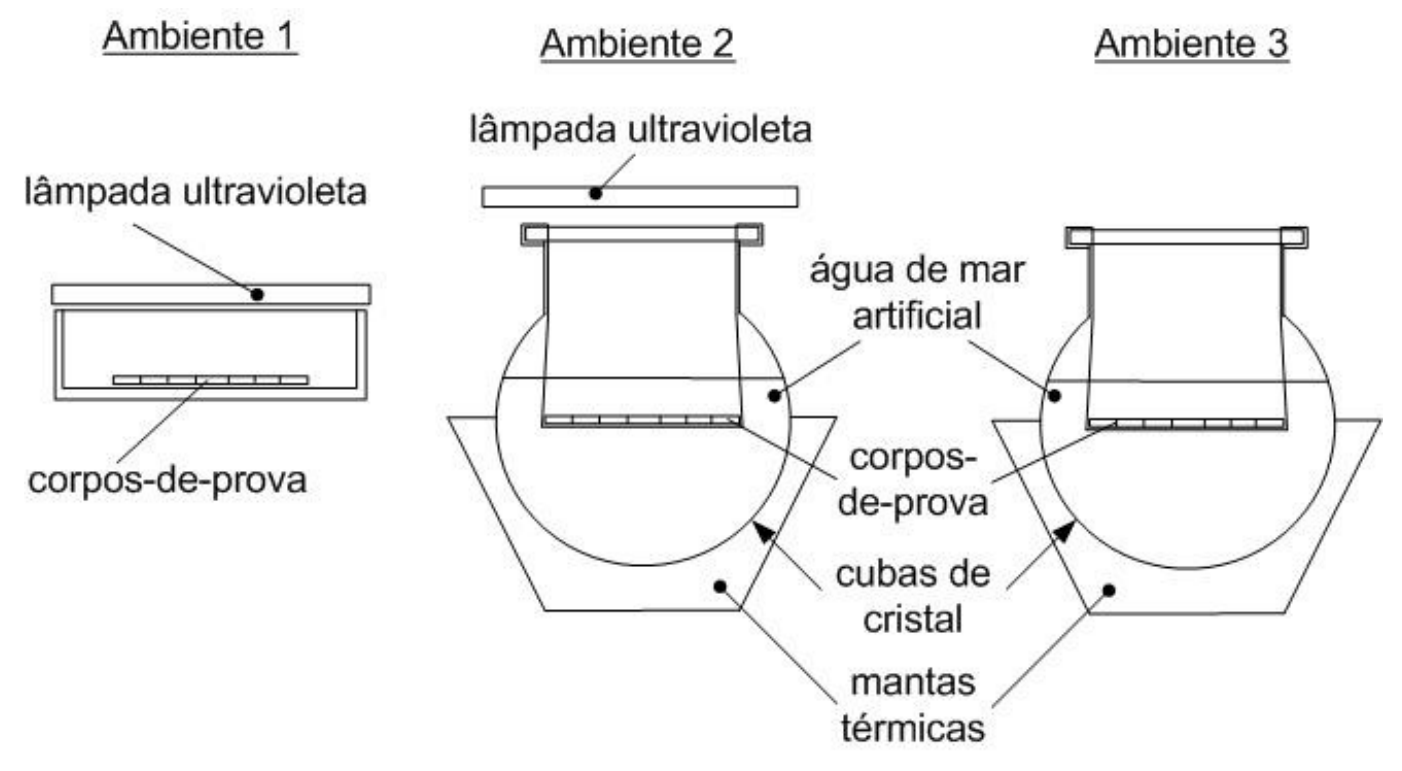

Figura 3.11 - Esquema do arranjo de ensaio de envelhecimento

Os ensaios terão uma duração de $500 \mathrm{~h}$ e durante toda sua realização a temperatura dos três ambientes devem ser controladas e mantidas em $35 \pm 1^{\circ} \mathrm{C}$.

Em cada ambiente são envelhecidos seis corpos-de-prova para ensaios de tração, três do material tirado do cabo sem uso e três do material que foi submetido à fadiga. Além disso, serão envelhecidos seis espécimes tipo placa para serem observados no microscópio, três do material tirado do cabo sem uso e três dos que tinham sido carregados ciclicamente.

\subsubsection{Terceira etapa - Ensaios de tração}

Com o fim de verificar a variação das propriedades mecânicas da camada polimérica externa do cabo umbilical, provocado pelos carregamentos cíclicos durante o ensaio de fadiga à tração uniaxial, e os agentes do meio marinho (radiação ultravioleta e água do mar) durante o ensaio de envelhecimento, serão feitos ensaios de tração nas amostras da camada polimérica externa do cabo umbilical. 
A metodologia seguida para a realização dos ensaios de tração é a que estabelece a norma ASTM D 638. Este método de ensaio permite determinar as propriedades de tração em materiais poliméricos.

Os corpos-de-prova a serem empregados no ensaio de tração serão do tipo I segundo a norma ASTM D 638, Figura 3.7. Escolheu-se este tipo de espécime, pois, além de ser o recomendado pela norma ASTM D 638, já foram anteriormente usados como corpos-de-prova no teste de fadiga à tração uniaxial (item 3.3.1.5) e no ensaio de envelhecimento (item 3.3.2). Assim, a partir dos resultados obtidos poderão ser comparados os resultados destes ensaios com os obtidos nos ensaios de tração feitos com as amostras do material, da camada externa do cabo sem uso.

Finalmente serão comparados os resultados de todos os ensaios de tração feitos durante o trabalho e será analisada a influência dos carregamentos cíclicos e os agentes do meio marinho sobre as propriedades da camada polimérica externa do cabo.

O procedimento seguido para a preparação dos corpos-de-prova é o fornecido pela norma ASTM D 638, o mesmo empregado no item 3.3.1.5.

Os corpos-de-prova que serão ensaiados a tração são os mesmos que foram ensaiados a fadiga à tração uniaxial e ao envelhecimento. Além disso, serão ensaiados a tração espécimes elaborados da camada externa do cabo sem uso.

Os ensaios consistem em submeter os corpos-de-prova, Figura 3.7, a um esforço de tração ao longo de seu comprimento que tende a esticá-lo originando uma deformação do material na direção da força aplicada.

Como resultado direto dos ensaios de tração são obtidos os valores de cargas aplicadas e os deslocamentos originados no material da camada polimérica externa do cabo, e a partir destes usando as eq.(2.31) e eq.(2.32), são construídas as curvas tensão-deformação de engenharia dos materiais ensaiados.

Devido a que os resultados dos ensaios de tração serão comparados, todos os testes serão feitos com a mesma velocidade, preferivelmente $50 \mathrm{~mm} / \mathrm{min}$, que é uma velocidade media entre as três que recomenda a norma ASTM D 638. Durante a realização do ensaio de tração a temperatura deve ser de $23 \pm 2{ }^{\circ} \mathrm{C}$ e a umidade relativa de $50 \pm 5 \%$ valores estes recomendados pela norma ASTM D 638 . 
Neste ensaio, tanto as deformações como os esforços são medidos por dispositivos acoplados na própria máquina.

Logo com todas as curvas tensão-deformação das amostras da camada externa do cabo, ensaiadas e não ensaiadas, a partir da comparação destas, será analisado o grau de deterioração (DANO ACUMULADO) que sofreu a camada polimérica externa do cabo devido aos carregamentos cíclicos e ao processo de envelhecimento a que foram submetidas.

\subsubsection{Quarta etapa - Microscopia}

O objetivo desta etapa é observar a influência dos carregamentos cíclicos, a radiação ultravioleta e a água marinha na microestrutura da superfície da camada polimérica externa do cabo umbilical. Com este fim, as amostras da camada externa que são submetidas a carregamentos cíclicos e retirada do cabo sem uso, envelhecidas e não envelhecidas são observadas usando a microscopia.

Os corpos-de-prova a serem observados na microscopia são do tipo placa, o corte deles é feito com um estilete.

As dimensões dos espécimes são de $5 \mathrm{~mm}$ de largura e $5 \mathrm{~mm}$ de comprimento, a espessura é a mesma da camada polimérica externa do cabo.

São elaborados dois lotes de oito corpos-de-prova cada um. Oito para observações na superfície externa da camada e oito para observações ao longo da espessura da camada.

O primeiro lote é elaborado com o material da camada do cabo sem uso: um não envelhecido, um envelhecido com radiação ultravioleta, um envelhecido com água salgada, e um envelhecido com radiação ultravioleta e água salgada simultaneamente. O segundo lote é elaborado com o material da camada que foi submetida a carregamentos cíclicos: um não envelhecido; um envelhecido com radiação ultravioleta; um envelhecido com água salgada, e um envelhecido com radiação ultravioleta e água salgada simultaneamente. 
As observações são feitas em cada amostra: na superfície externa da camada e ao longo da espessura da camada. Para fazer as observações recomenda-se usar um microscópio que possa atingir um aumento mínimo de 1000x.

Como resultados desta etapa serão obtidas as micrografias das superfícies e ao longo da espessura das amostras. Estas serão analisadas e se verificará a deterioração da camada externa do cabo, materializado esta com o surgimento de trincas e poros superficiais no material, provocados pelos carregamentos cíclicos e o envelhecimento nos diferentes ambientes. Também poderá apreciar-se a orientação lamelar originada pelos carregamentos cíclicos.

As diferentes micrografias dos materiais ensaiados a fadiga e envelhecido serão comparadas com a micrografia do material retirado do cabo sem uso.

\subsubsection{Quinta etapa - Absorção de água}

Os polímeros termoplásticos são amplamente usados como isolante em cabos de alta voltagem devido a suas boas propriedades dielétricas e seu baixo custo. Quando ele é usado na camada externa de cabos umbilicais fica exposto a uma combinação de fatores ambientais agressivos como radiações ultravioletas e variações da temperatura em um ambiente úmido e salino.

Além disso, o cabo fica sob carregamentos cíclicos originados pela correnteza marinha. Como resultado, é normal a ocorrência de reações de oxidação, formação de ligações cruzadas e de cisão das cadeias poliméricas, com o desenvolvimento de poros e trincas superficiais que permitem a penetração da água salgada nas profundezas da camada polimérica até o ponto que pode transpassar esta e chegar até armaduras de tração comprometendo seriamente a durabilidade do cabo umbilical.

Esta etapa da metodologia tem dois objetivos; o primeiro determinar a proporção de água absorvida pela camada externa do cabo quando imerso no líquido, e, o segundo, ver a relação que existe entre a quantidade de carregamentos cíclicos a que é submetida o material da camada externa e a quantidade de água que esta 
absorve. O ensaio será feito seguindo a metodologia fornecida pela norma ASTM D 570 (tecnicamente equivalente à norma ISO 62).

Os corpos-de-prova para os ensaios de absorção de água, são elaborados com amostras tomadas das camadas poliméricas externas do cabo umbilical sem uso, e dos espécimes que foram submetidos anteriormente a ensaio à fadiga à tração uniaxial no item 3.5.1.5.

A geometria dos espécimes empregados é do tipo placa com $13 \mathrm{~mm}$ de largura e 18 mm de comprimento, a espessura é a mesma da camada polimérica externa do cabo umbilical.

A operação de corte dos corpos-de-prova é realizada com uma serra manual, o acabamento das superfícies originadas pelo corte é feito com papel de lixa fina. As operações de corte e lixamento serão realizadas de forma cuidadosa e lenta o bastante para que o material não sofra um aquecimento considerável que mude suas propriedades originais. As superfícies originadas pela operação de corte ficaram livres de poros e fissuras. Na Figura 3.12 mostram-se um esquema para a elaboração dos corpos-de-prova feitos a partir do material que tinha sido submetido à fadiga à tração uniaxial.

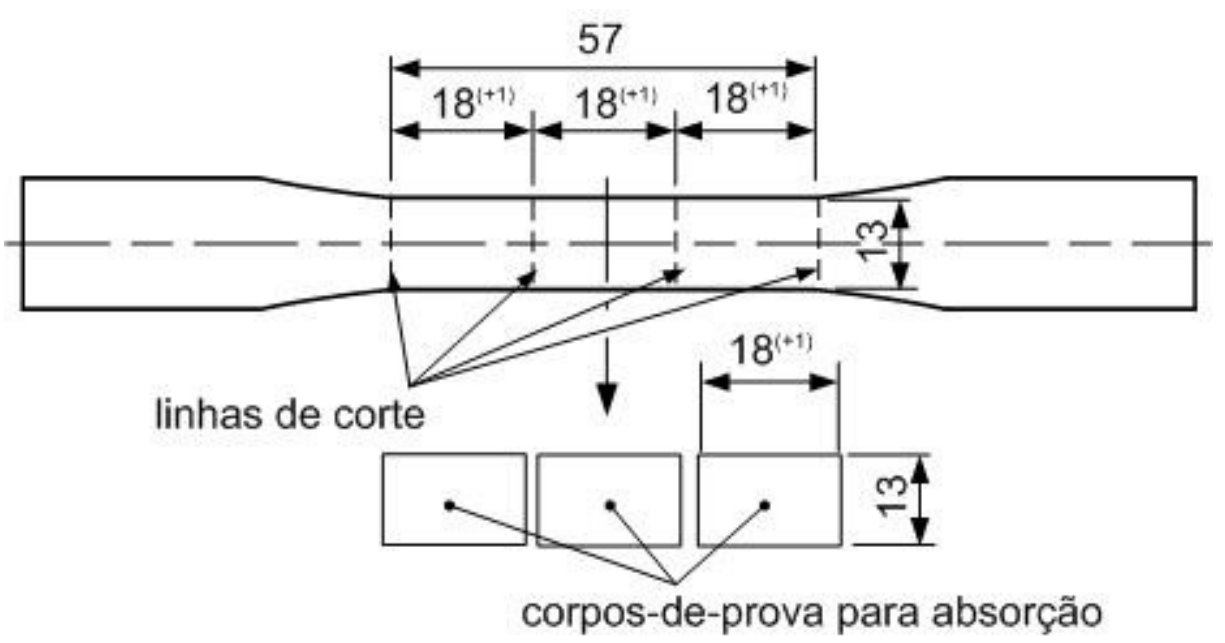

Figura 3.12 - Esquema guia para elaboração dos espécimes, do material submetido a fadiga à tração uniaxial, usados no ensaio de absorção 
São confeccionados seis corpos-de-prova, três da camada externa do cabo sem uso e três do material que fora submetido a fadiga à tração uniaxial.

Serão ensaiadas a absorção várias amostras diferentes da camada polimérica externa do cabo, com o intuito de comparar os resultados, antes da imersão os espécimes são submetidos a um processo de dessecagem (recomendado pela norma ASTM D 570) por um período de $24 \mathrm{~h}$ a uma temperatura de $50 \pm 3^{\circ} \mathrm{C}$ numa câmara térmica. Posteriormente, os espécimes são resfriados e imediatamente pesados numa balança analítica com uma precisão mínima de 0,1 mg.

Os corpos-de-prova, já dessecados, são colocados dentro da cuba de cristal que contem água destilada, até um nível que cubra os espécimes, por um período de 24 h. A temperatura da água deve-se manter em $23 \pm 1^{\circ} \mathrm{C}$ durante o ensaio.

Na Figura 3.13, mostra-se um esquema do arranjo experimental para o ensaio de absorção de água no material da camada polimérica externa do cabo umbilical.

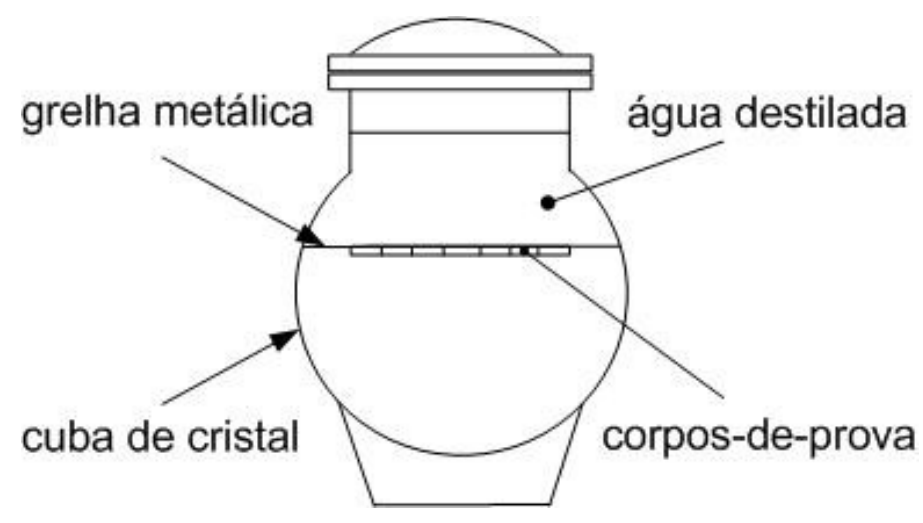

Figura 3.13 - Arranjo experimental usado no ensaio de absorção de água

Ao término das $24 \mathrm{~h}$, os corpos-de-prova são tirados da água. Em seguida com um pano, são secas as superfície de cada espécime e imediatamente são pesados na balança analítica com uma precisão mínima de 0,1 mg.

Após ter os pesos das diferentes amostras da camada polimérica externa, antes e depois da imersão, será estimada a proporção de água absorvida pelas amostras da camada sem uso e fadigada à tração uniaxial. A proporção de água absorvida será 
estimada utilizando o cálculo do incremento percentual da massa eq.(3.12) a qual é obtida substituindo a eq. (3.11) na eq.(3.10).

$$
\begin{aligned}
& I_{m}=\frac{m_{u}-m_{s}}{m_{s}} \cdot 100 \\
& m=\frac{p}{g} \\
& I_{m}=\frac{p_{u}-p_{s}}{p_{s}} \cdot 100
\end{aligned}
$$

onde:

Im- incremento da massa (\%);

$\mathrm{m}_{\mathrm{u}}$ - massa do material após da absorção $(\mathrm{g})$;

$\mathrm{m}_{\mathrm{s}}$ - massa do material antes da absorção $(\mathrm{g})$;

p- peso do material $(\mathrm{g})$;

g- aceleração da força de gravidade $\mathrm{m} / \mathrm{s}^{2}$;

$\mathrm{p}_{\mathrm{u}}$ - peso do material após da absorção (g);

$\mathrm{p}_{\mathrm{s}}$ - peso do material antes da absorção $(\mathrm{g})$.

Os resultados obtidos de incremento de massa devido à absorção de água para cada amostra da camada polimérica, ensaiada a absorção, nos dará uma medida do grau de deterioração da camada externa do cabo devido aos carregamentos cíclicos.

\subsubsection{Sexta etapa - Estimativa do dano}

Os materiais usados na engenharia quando submetidos a condições mecânicas e ambientais desfavoráveis sofrem mudanças na sua microestrutura. Estas mudanças acumuladas que afetam negativamente as propriedades mecânicas de um determinado material podem-se definir como dano acumulado (KACHANOV, 1986). 
O dano, em microescala pode ser interpretado como a criação de micro descontinuidades na superfície, ruptura de ligações atômicas e crescimento plástico de microcavidades. Este tipo de deterioração acontece no material antes da falha e geralmente não é perceptível a olho nú (LEMAITRE, 1996).

Nos polímeros, o dano acontece por ruptura das ligações que existem entre longas cadeias moleculares. Este mecanismo cria deformações plásticas, quando o desligamento acontece, é o inicio do processo de dano (LEMAITRE, 1996), (LEMAITRE; DESMORAT, 2005).

Esta etapa do método tem o objetivo de quantificar o dano provocado na camada polimérica externa do cabo devido aos carregamentos cíclicos. O dano é estimado a partir das quantidades de água absorvida pelas camadas, sem uso e a que foi submetida a fadiga à tração uniaxial, no ensaio de absorção feito anteriormente no item 3.5.5.

Para fazer a estimativa do dano provocado pelos carregamentos cíclicos sobre a microestrutura da camada polimérica externa do cabo, são usados os dados obtidos no ensaio de absorção feito segundo a ASTM D 570, no item 5.5.6. O dano é calculado a partir do incremento percentual da massa $\left(I_{m}\right)$ das amostras poliméricas após a imersão, durante $24 \mathrm{~h}$, em água destilada. A quantidade de água absorvida está relacionada com o grau de deterioração da microestrutura da camada polimérica externa do cabo umbilical. Para determinar o dano é usada a eq.(3.13).

$$
D=1-\frac{I_{m S U}}{I_{m D}}
$$

onde:

D- dano acumulado;

$I_{\mathrm{msu}}$ - incremento da massa do material tirado do cabo sem uso (g); $\mathrm{I}_{\mathrm{mD}}$ incremento da massa do material danificado $(\mathrm{g})$.

Após do cálculo do dano, e com todos os outros resultados obtidos nas diferentes etapas da metodologia proposta (ensaios de tração e microscopia eletrônica de varredura), será dado um parecer sobre o comportamento satisfatório ou não da camada polimérica externa do cabo umbilical analisado. 


\section{VALIDAÇÃO EXPERIMENTAL DO CRITÉRIO DE FALHA DA CAMADA POLIMÉRICA EXTERNA DO CABO UMBILICAL}

Nesta parte do trabalho busca-se validar experimental o método proposto no Capítulo 3.

\subsection{MATERIAIS E MÉTODOS}

O cabo umbilical, objeto de estudo, é empregado em uso estático e dinâmico até profundidades de $1.500 \mathrm{~m}$. Tem capacidade para transmitir entre 12 e $20 \mathrm{kV}$ de energia elétrica. Na Figura 4.1 (CÁRDENAS; GONÇALVES, 2004), mostra-se a seção transversal do cabo a qual é composta basicamente de uma superposição de camadas plásticas e metálicas de caráter estrutural.

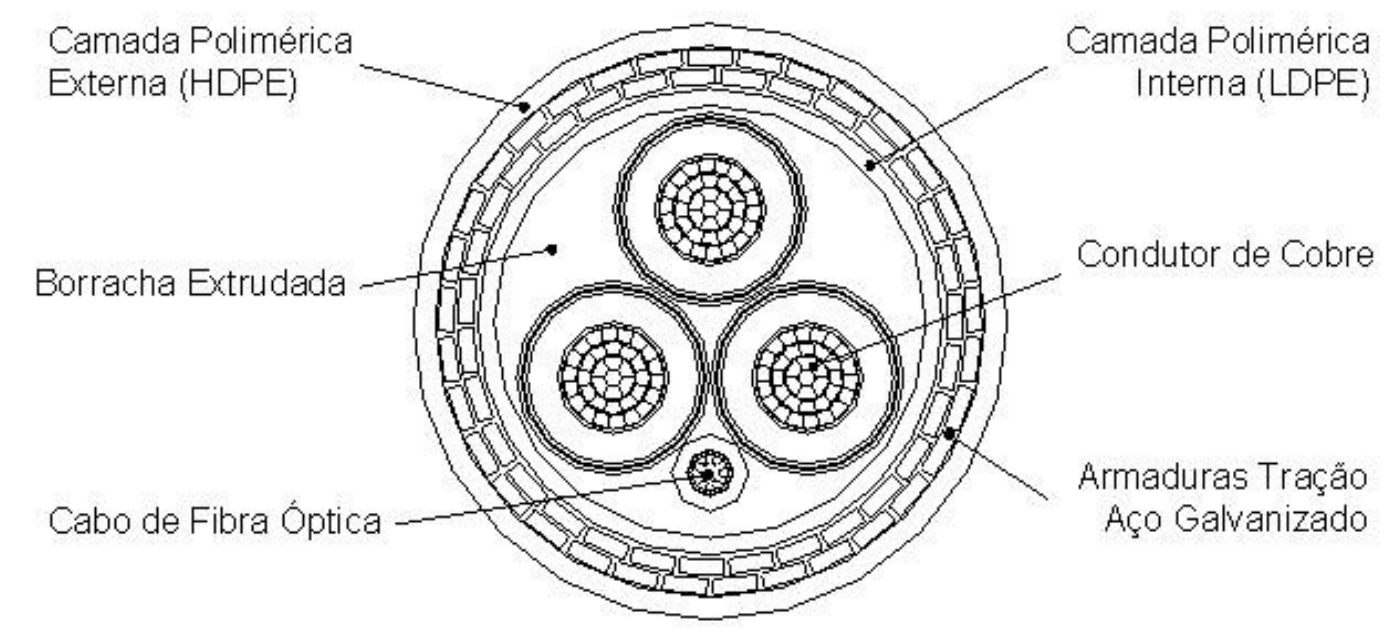

Figura 4.1 - Seção transversal do cabo umbilical (CÁRDENAS; GONÇALVES, 2004)

O cabo tem diâmetro externo de 108,5 mm e seu núcleo funcional está composto por três cabos de cobre os quais tem como função conduzir energia elétrica e, um cabo de fibra óptica, responsável pela transmissão de sinais. A camada polimérica 
externa do cabo tem $5 \mathrm{~mm}$ de espessura e é feita de polietileno de alta densidade (HDPE), extrudada sobre as armadura de tração externa de aço galvanizado.

O HDPE é um polímero tenaz e coriáceo, com aparência untuosa, amplamente usado na confecção de isolamentos flexíveis para cabos elétricos (BLASS, 1988).

A estrutura química do HDPE esta formada por ligações primarias fortes, C-C e C-H, as quais são do tipo covalente. Este tipo de ligação consiste no compartilhamento pelos átomos de dois elétrons, normalmente envolvem distâncias curtas e elevado nível energético. As ligações covalentes vão ter uma grande influência na rigidez e na estabilidade térmica, química e fotoquímica do polímero (LIN; ARGON, 1994).

Ao mesmo tempo as cadeias moleculares principais estão unidas por ligações secundarias fracas, chamadas forças de Van der Waals. Este tipo de ligação permitem os movimentos individuais entre os segmentos das cadeias moleculares. As ligações secundárias vão determinar a maioria das propriedades físicas, tais como, cristalinidade, solubilidade, temperatura de fusão, deformação e escoamento. Quanto mais fortes estas ligações, maior será a atração entre as cadeias moleculares, com isso aumentará a resistência ao fluxo de uma cadeia sobre outra e a sua separação (LIN, ARGON, 1994; CANEVAROLO, 2002).

\subsection{ENSAIO DE FADIGA À TRAÇÃO UNIAXIAL NO HDPE DA CAMADA POLIMÉRICA EXTERNA DO CABO UMBILICAL}

O ensaio de fadiga no cabo umbilical, feito segundo a API 17E, é um ensaio custoso e muito trabalhoso devido ao emprego de um corpo-de-prova de grandes dimensões (13,5 m de comprimento) e à complexidade da bancada de teste. Para a realização do ensaio é imprescindível pessoal especializado tanto para a montagem do corpode-prova quanto para a realização do ensaio. Além disso, o gasto de energia e o tempo de duração do teste são grandes.

Com o ensaio de fadiga à tração uniaxial objetivou-se provocar um dano similar, na camada polimérica externa do cabo umbilical, ao criado pelo ensaio de fadiga feito segundo a norma API 17E e avaliar a influência dos carregamentos cíclicos sobre as 
propriedades do HDPE, material que compõe a camada externa dos cabos umbilicais.

Para determinar os ciclos de tensões a que esteve submetida a camada polimérica do cabo umbilical durante o ensaio de fadiga segundo a norma API 17E, levou-se em conta as deformações devido ao: processo de fabricação $\left(\varepsilon_{F}\right)$, tração inicial do cabo $\left(\varepsilon_{T}\right)$; curvatura provocada pela flexão do umbilical $\left(\varepsilon_{\mathrm{C}}\right)$. Para determinar estas deformações foi seguida a metodologia proposta no item 3.3.1.

\subsubsection{Determinação experimental da deformação residual a que está submetida a camada externa devido ao processo de fabricação}

Este ensaio foi feito com o objetivo geral de determinar experimental e analiticamente as deformações a que está submetida a camada polimérica externa de um cabo submarino eletro óptico devido aos processos de fabricação e sua estrutura interna. Primeiramente, mediante o método da extensômetria elétrica, foi determinado experimentalmente o campo de deformações residuais na camada polimérica externa do cabo submarino. Em seguida usando os valores das deformações residuais obtidas experimentalmente, determinaram-se analiticamente as deformações principais a que estava submetida a camada polimérica externa do cabo umbilical.

Os cabos umbilicais, devido à sua complexa geometria estrutural, à diversidade dos materiais que o compõem e aos complexos processos empregados na sua fabricação, após serem elaborados e antes de entrar em serviço veêm-se submetidos a um complexo campo deformacional. A estrutura interna do cabo e principalmente as armaduras de tração exercem esforços sob a camada polimérica externa a qual é extrudada sobre estas armaduras.

Geralmente, para definir o campo deformacional num corpo-de-prova precisa-se medir três deformações num ponto. Consegue-se isto com extensômetro elétrico do tipo roseta retangular de três elementos (ALMEIDA, 1996). Para a determinação experimental das deformações na camada polimérica externa do cabo empregou-se, como corpo-de-prova, uma seção de cabo de 6 m de comprimento, Figura 4.2. 


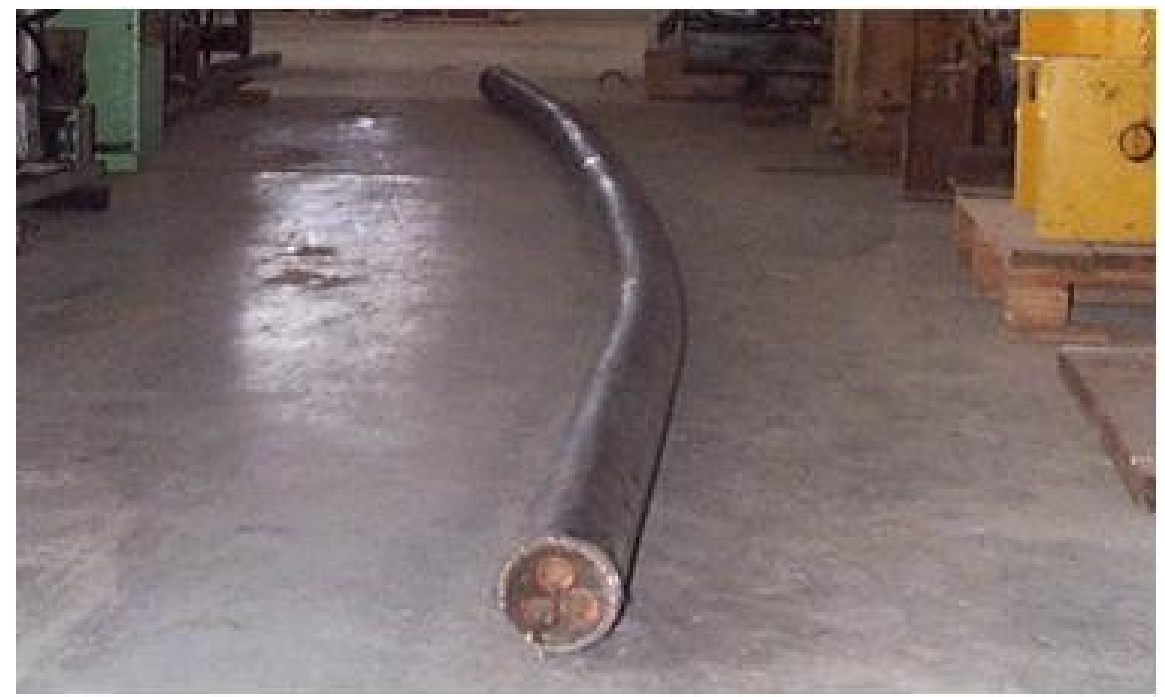

Figura 4.2 - Foto do corpo-de-prova usado no ensaio de desconfinamento

Primeiramente, foram tomadas as dimensões do corpo-de-prova. No ponto médio do comprimento deste procedeu-se à preparação da superfície onde seria colado o extensômetro elétrico. Esta preparação consistiu no melhoramento desta superfície. Lixou-se esta com papel de esmeril fino e limpou-se com uma gaze e álcool para retirar as impurezas como gordura e poeira, com o objetivo de conseguir uma melhor aderência. Em seguida, com uma caneta, marcou-se o lugar onde seria colado o extensômetro. O extensômetro empregado foi do tipo roseta retangular de três elementos KGF-5-120-C1-11 (KYOWA), Figura 4.3.

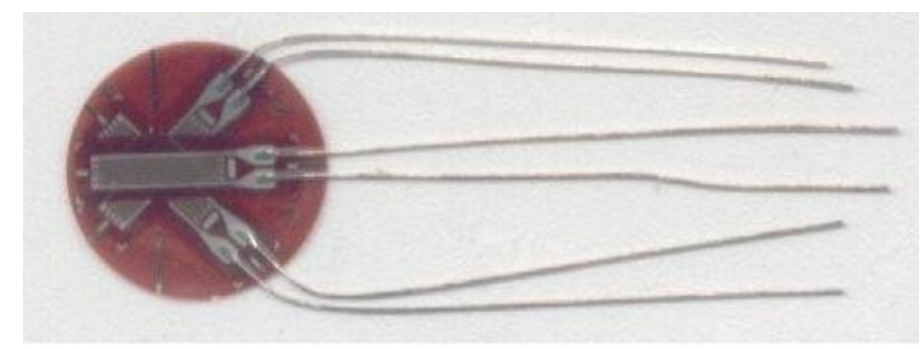

Figura 4.3 - Foto do extensômetro empregado no ensaio de desconfinamento 
Usou-se este tipo de extensômetro com o objetivo de medir simultaneamente a deformação em três eixos coordenados. O primeiro componente do extensômetro foi orientado na direção axial do cabo para medir a deformação longitudinal, os outros dois componentes ficaram orientados no sentido transversal, para medir a deformação circunferêncial e a $45^{\circ}$ dos outros dois eixos para medir a deformação neste sentido.

Para a colagem do extensômetro empregou-se adesivo do tipo CC-33A, recomendado pelo fabricante do extensômetro. Na realização desta operação colocou-se o adesivo na superfície inferior do extensômetro e, com ajuda de uma fita adesiva, este foi posicionado na zona que tinha sido marcada. Com uma borracha foi exercida uma pressão por dois minutos sobre o extensômetro. Em seguida, foram verificadas as resistências elétricas do extensômetro comprovando-se que mantinham as características dadas pelo fabricante. O tempo de cura foi de $24 \mathrm{~h}$ para conseguir uma boa aderência. Posteriormente, passou-se a soldar cabos de cobre nas terminais do extensômetro para ligar este com o Sistema de Aquisição de Dados (SAD), fabricado pela KYOWA.

Já com o arranjo pronto para o experimento, procedeu-se a calibração do SAD. Esta foi feita manualmente e individual os três canais onde foram ligados os componentes do extensômetro. Na Figura 3.4 mostrou-se esquematicamente como foi configurado o arranjo experimental.

O experimento consistiu na instrumentação com um extensômetro elétrico de uma região da camada polimérica externa do cabo umbilical. Com isto perseguiu-se determinar qual seria a variação nas deformações após se separar a parte instrumentada da camada externa do cabo e, assim, conhecer o estado deformacional a que está submetido o HDPE, que compõe esta camada do cabo devido ao processo de fabricação e à estrutura interna do cabo.

Com ajuda de uma serra manual e um estilete foi retirada a zona da camada externa do cabo onde tinha sido colado o extensômetro, tendo o cuidado de que, neste processo, não se danificar o elemento sensor e afetar os resultados experimentais. Após de retirada a zona instrumentada do cabo umbilical, como ilustra a Figura 4.4, foram registradas as medidas de deformação dos três componentes do extensômetro. 

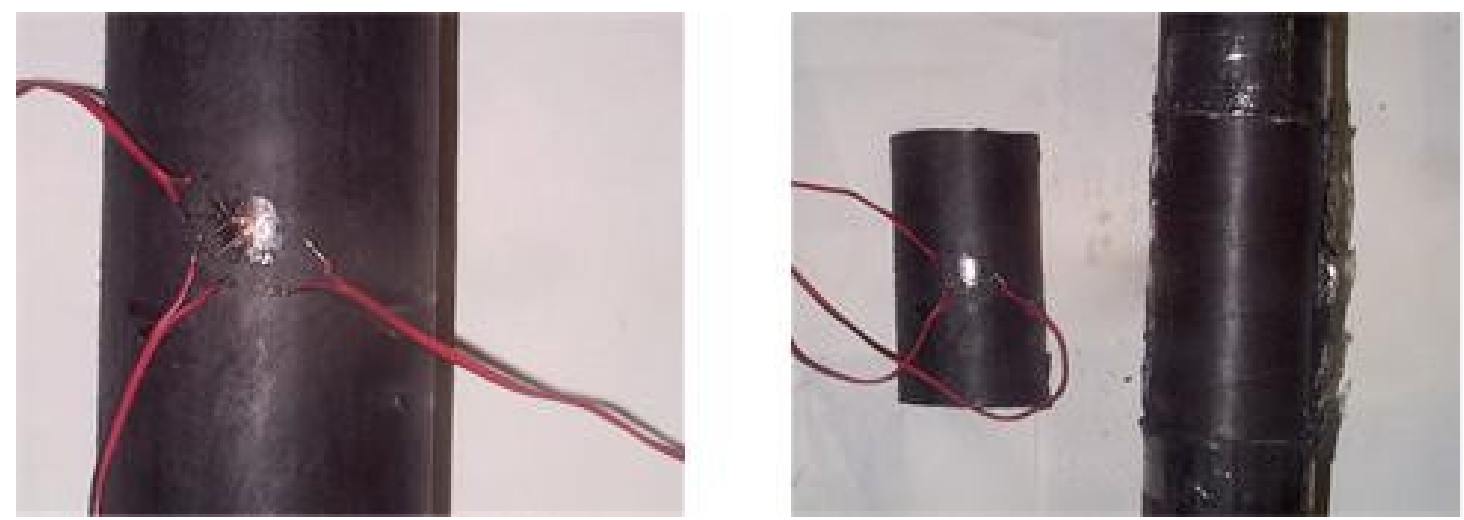

Figura 4.4 - Foto da região do corpo-de-prova instrumentada antes e após de retirada a seção da camada externa do cabo

$\mathrm{Na}$ Figura 4.5 ilustram-se as curvas de sinais temporais obtidas durante 0 experimento e na Tabela 4.1 podem-se observar os valores de deformação obtidos durante o experimento.

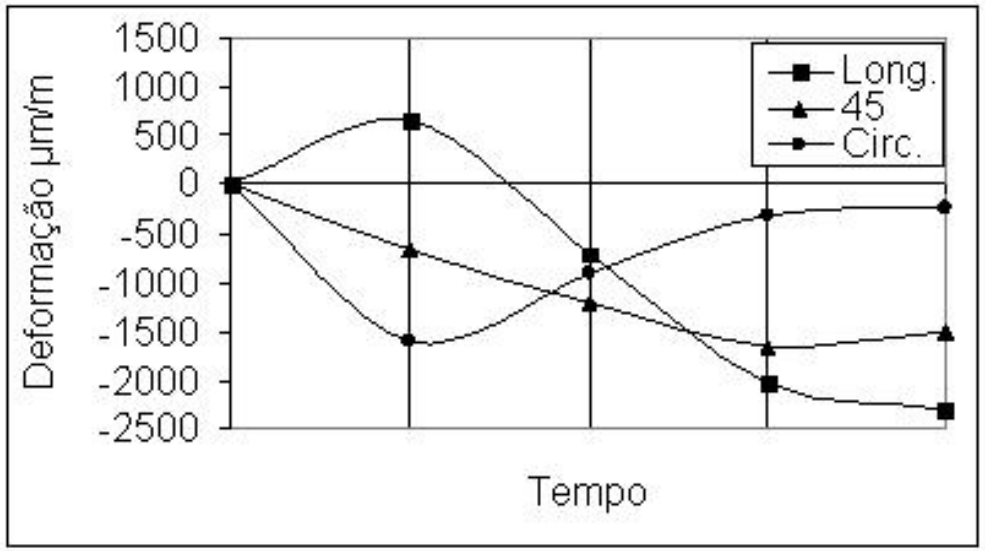

Figura 4.5 - Curvas deformação-tempo obtidas durante o desconfinamento

Tabela 4.1 - Valores das deformações obtidas durante o desconfinamento

\begin{tabular}{|c|c|c|c|}
\hline \multirow{2}{*}{$\begin{array}{l}\text { Seqüência } \\
\text { dos cortes }\end{array}$} & \multicolumn{3}{|c|}{ Deformação $(\mu \mathrm{m} / \mathrm{m})$} \\
\hline & Longitudinal & Circunferêncial & $45^{\circ}$ \\
\hline 0 (Inicial) & 0 & 0 & 0 \\
\hline 1 (Longitudinal) & -645 & 1.595 & 660 \\
\hline 2 (Longitudinal) & 700 & 920 & 1.200 \\
\hline 3 (Transversal) & 2.030 & 315 & 1.660 \\
\hline 4 (Livre) & 2.300 & 245 & 1.509 \\
\hline
\end{tabular}


Durante o ensaio foram monitoradas as temperaturas ambiente e do corpo-de-prova na zona onde foi colado o extensômetro sendo as mesmas de $22 \pm 1$ e $23 \pm 1^{\circ} \mathrm{C}$ respectivamente, a umidade relativa do ar manteve-se em 53\%.

Para o cálculo das deformações principais usaram-se os valores de deformações residuais obtidos durante o ensaio de desconfinamento. Substituindo os valores experimentais obtidos [ $\varepsilon_{A}=2.300 \mu \mathrm{m} / \mathrm{m}$ (deformação longitudinal), $\varepsilon_{B}=1.509 \mu \mathrm{m} / \mathrm{m}$ (deformação $45^{\circ}$ ), $\varepsilon_{C}=245 \mu \mathrm{m} / \mathrm{m}$ (deformação circunferêncial)] nas equações eq.(3.1) e eq.(3.2), obtiveram-se os valores da deformação máxima principal de $2.327 \mu \mathrm{m} / \mathrm{m}$ e da deformação mínima principal de $218,1 \mu \mathrm{m} / \mathrm{m}$.

Também foi determinado o ângulo entre o eixo do cabo e o eixo da deformação máxima principal, a partir da eq.(3.3), o valor do ângulo foi de $6,47^{\circ}$.

Após análise dos resultados do ensaio de desconfinamento, estes mostraram claramente que a camada polimérica externa do cabo umbilical está submetida a um estado tensional de tração. Este provocado pelo processo de elaboração da camada, que é extrudada a quente sobre a armadura de tração do cabo pelo que ao concluir o processo de fabricação e diminuir a temperatura o material fica em estado de tração tratando de recuperar sua forma inicial, ação que é impedida pela armadura de tração externa e a estrutura interna do cabo. Comprovou-se este fato ao ver a variação na deformação que aconteceu depois de retirar a amostra da camada externa do cabo onde estava colado o extensômetro tipo roseta retangular de três elementos.

Os três componentes do extensômetro registraram deformações negativas, ou seja, de contração. O componente número um do extensômetro, que estava orientada no sentido do eixo axial para medir a deformação longitudinal da camada polimérica foi a que registrou uma maior variação de $2.300 \mu \mathrm{m} / \mathrm{m}$, isto devido, principalmente, a que o eixo de orientação deste componente coincide com o sentido principal da extrusão.

Já no componente número dois do extensômetro, que estava orientado no sentido transversal do cabo, para medir a deformação circunferêncial, o valor da variação desta foi de $245 \mu \mathrm{m} / \mathrm{m}$ muito menor que a deformação longitudinal. No terceiro componente do extensômetro orientado a $45^{\circ}$ entre os dois eixos anteriores, o valor 
da deformação (contração) foi de $1.509 \mu \mathrm{m} / \mathrm{m}$ um valor intermediário entre os dois anteriores.

Os valores das deformações principais calculados foram a deformação máxima principal a qual foi de $2.327 \mu \mathrm{m} / \mathrm{m}$ e a mínima principal de $218,1 \mu \mathrm{m} / \mathrm{m}$.

A direção da deformação máxima principal foi em um ângulo de $6,47^{\circ} \mathrm{com}$ respeito ao eixo longitudinal do cabo. Esta deviação angular da deformação máxima principal originada pelo ângulo de assentamento dos tendões da armadura de tração externa, sobre a qual a camada polimérica externa é extrudada. No Apêndice C são calculadas as tensões residuais a que esta submetida a camada polimérica externa do cabo umbilical.

\subsubsection{Deformação no HDPE da camada externa do cabo umbilical devido à tração inicial}

Para medir a deformação a que foi submetida a camada polimérica externa do cabo umbilical durante, a tração inicial de $600 \mathrm{kN}$ no ensaio de fadiga feito segundo a norma API 17E, levou-se a cabo um ensaio de tração no cabo umbilical. Este ensaio foi feito na bancada onde foi realizado o ensaio de fadiga do cabo umbilical segundo a norma API 17E, Figura 3.2.

Para a realização do ensaio de tração no cabo umbilical empregou-se como corpode-prova uma seção de umbilical de comprimento $13,5 \mathrm{~m}$, Figura 3.3. O procedimento para a preparação do espécime foi o mesmo empregado no ensaio de fadiga segundo API 17E, item 3.3.1.1.

Uma vez preparado o corpo-de-prova procedeu-se a sua montagem e fixação na bancada de ensaio. Concluída esta operação realizou-se a instrumentação do espécime, esta consistiu na colagem de duas pastilhas metálicas cilíndricas na parte reta do cabo que fica submetida somente a carregamento de tração. Estas pastilhas metálicas serviriam como pontos de referência base para apoiar os ponteiros do extensômetro mecânico que seria usado como instrumento de medição. Na Figura B1 do Apêndice $B$, mostra-se uma foto do corpo-de-prova instrumentado com as duas pastilhas metálicas. 
Para auxiliar o posicionamento das pastilhas durante a colagem usou-se como gabarito uma base de $100 \mathrm{~mm}$ a qual é um dos acessórios do extensômetro. O extensômetro mecânico usado foi do tipo Tensotast-Huggenberger 85350. Na Figura B2 do Apêndice B, mostram-se as fotos do extensômetro mecânico (a) e da base (b) usada como gabarito no ensaio de tração do cabo umbilical.

O ensaio de tração do cabo umbilical consistiu em submeter o cabo a uma carga de 600 kN. Sabendo de antemão que ao aplicar um carregamento de tração aconteceria uma acomodação das diferentes camadas e componentes estruturais do corpo-de-prova, a aplicação da carga foi feita por incrementos de $100 \mathrm{kN}$ até chegar ao valor total desejado, sendo assim a carga aplicada em seis passos.

Após de aplicada a carga total procedeu-se à medição do deslocamento na camada polimérica externa do cabo usando o extensômetro mecânico do tipo TensotastHuggenberger 85350.

O valor de deslocamento da camada polimérica externa, obtido durante o ensaio de tração do cabo umbilical, foi de $0,099 \mathrm{~mm}$. Levando em conta que a base de medida usada foi de $100 \mathrm{~mm}$ e sabendo que os corpos-de-prova a serem submetidos à fadiga convencional, Figura 3.7, têm comprimento de referencia de $50 \mathrm{~mm}$, foi assumido como deslocamento a usar no ensaio de fadiga à tração uniaxial, devido à tração inicial, um valor de 0,049 mm a metade do deslocamento obtido no ensaio de tração.

\subsubsection{Deformação devido à flexão}

Para determinar a deformação devido à flexão assumiu-se o cabo como uma viga submetida a flexão pura e calculou-se a deformação geométrica substituindo os valores da distância do ponto analisado ao eixo (y) de $52,5 \mathrm{~mm}$ e do raio de curvatura do cabo $(\rho)$ durante a flexão no ensaio de fadiga feito segundo a API 17E de $1.822,8 \mathrm{~mm}$.

O valor da deformação obtido foi de 0,0288 , o que equivale a um deslocamento de $1,44 \mathrm{~mm}$ se tomamos como comprimento da base de referência uma magnitude de 
$50 \mathrm{~mm}$, este ultimo valor tomado da norma ASTM D 638 para o tipo de corpo-deprova, Figura 3.7, que será ensaiado a fadiga à tração uniaxial.

\subsubsection{Preparação dos corpos-de-prova para o ensaio de fadiga à tração uniaxial}

Os corpos-de-prova empregados no ensaio de fadiga à tração uniaxial foram os que estabelece a norma ASTM D 638, Figura 3.7. Escolheu-se este tipo de espécime com o fim de, após de submetido os corpos-de-prova a ensaio de fadiga à tração uniaxial, fazer um ensaio de absorção de água segundo a norma ASTM D 570, usando a região de trabalho deste espécime como mostra a Figura 3.12, e assim verificar a permeabilidade do HDPE da camada externa do cabo após de submetida a carregamentos cíclicos.

Além disso, os corpos-de-prova ensaiados à fadiga à tração uniaxial também serão ensaiados a tração, segundo a norma ASTM D 638, para comparar os resultados destes testes com os obtidos nos ensaios de tração feitos com as amostras de HDPE retiradas do cabo sem uso. O procedimento seguido para a preparação dos corpos-de-prova foi o mesmo empregado no item 3.3.1.5.

\subsubsection{Arranjo experimental usado no ensaio de fadiga à tração uniaxial do HDPE}

$\mathrm{Na}$ execução dos ensaios de fadiga à tração uniaxial a máquina empregada foi do tipo atuador servo hidráulico, modelo DARTEC. Neste ensaio tanto os carregamentos como os deslocamentos a que foram submetidos os corpos-de-prova foram controlados e monitorados pelos diferentes acessórios da máquina de ensaio. $\mathrm{Na}$ Figura 4.6 mostra-se uma foto do arranjo experimental usado para a realização do ensaio de fadiga à tração uniaxial no HDPE. 

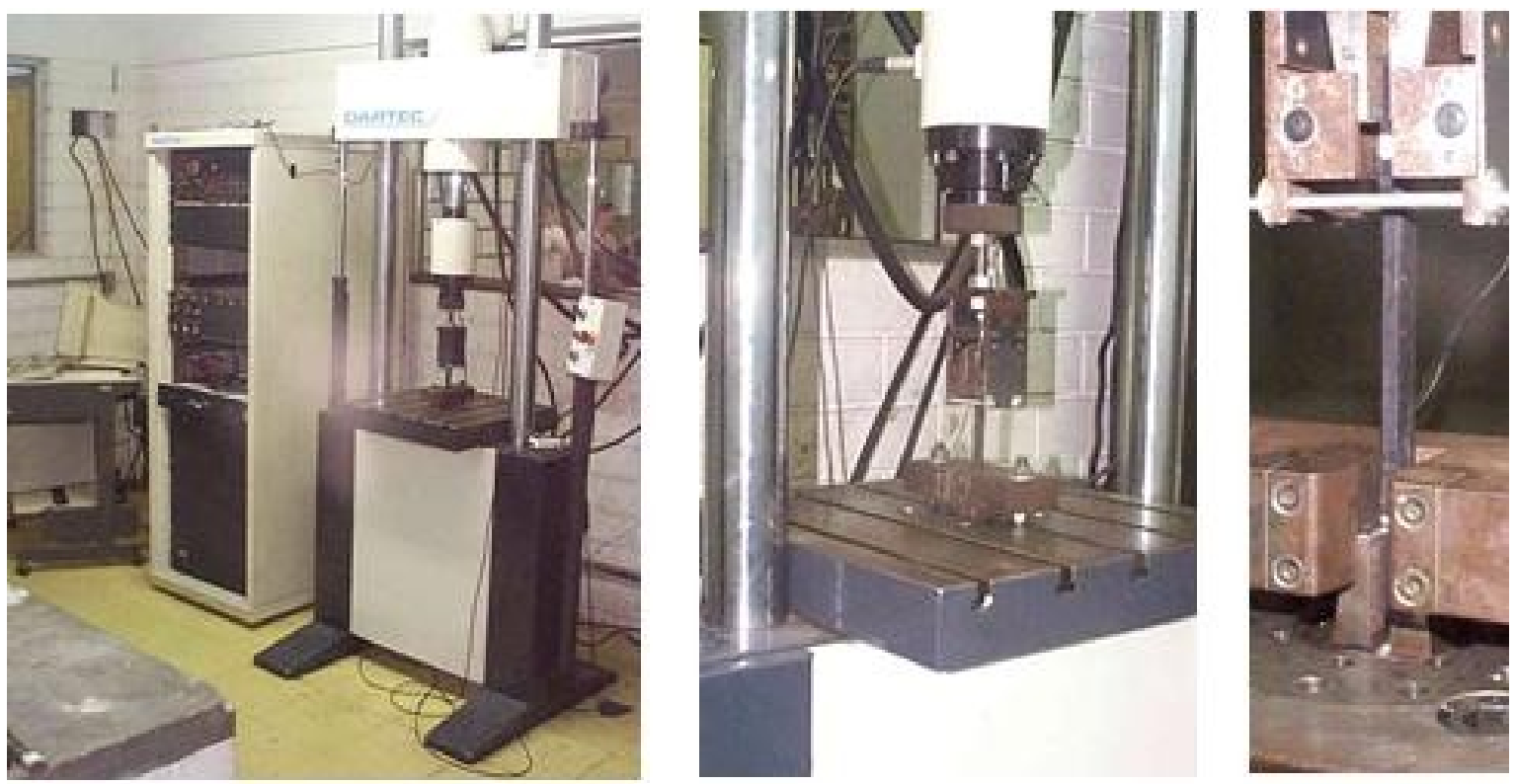

Figura 4.6 - Fotos do arranjo experimental usado para o ensaio de fadiga à tração uniaxial do HDPE

\subsubsection{Execução do ensaio de fadiga à tração uniaxial do HDPE da camada externa do cabo}

O ensaio de fadiga à tração uniaxial consistiu em submeter o corpo-de-prova feito de HDPE a deformações cíclicas similares as que foram submetidas a região superior da camada polimérica externa do cabo umbilical durante o ensaio de fadiga feito segundo a norma API 17E.

Para a determinação do deslocamento a que foi submetido o corpo-de-prova no ensaio de fadiga à tração uniaxial assumiu-se como comprimento da base de referência $50 \mathrm{~mm}$, que é o valor de referência dado na norma ASTM D 638 para o tipo de corpo-de-prova empregado.

Os valores de deslocamentos a que foram submetidos o HDPE durante o ensaio de fadiga à tração uniaxial foram calculados usando a eq.(3.7).

$\mathrm{Na}$ execução do ensaio de fadiga, inicialmente foi aplicado ao espécime um deslocamento de $0,16 \mathrm{~mm}$, correspondendo este à somatória das deformações 
devido ao processo de fabricação e à tração inicial a que foi submetido o cabo durante o ensaio de fadiga realizado segundo a API 17E.

A variação da oscilação para o ensaio de fadiga à tração uniaxial foi obtida a partir da curvatura que acontece no cabo devido à flexão. O valor do deslocamento aplicado foi de $1,44 \mathrm{~mm}$.

Na Figura 4.7 ilustra-se o gráfico dos ciclos de fadiga (deformação-tempo) impostos aos corpos-de-prova fabricados a partir das amostras de HDPE retiradas do cabo sem uso.

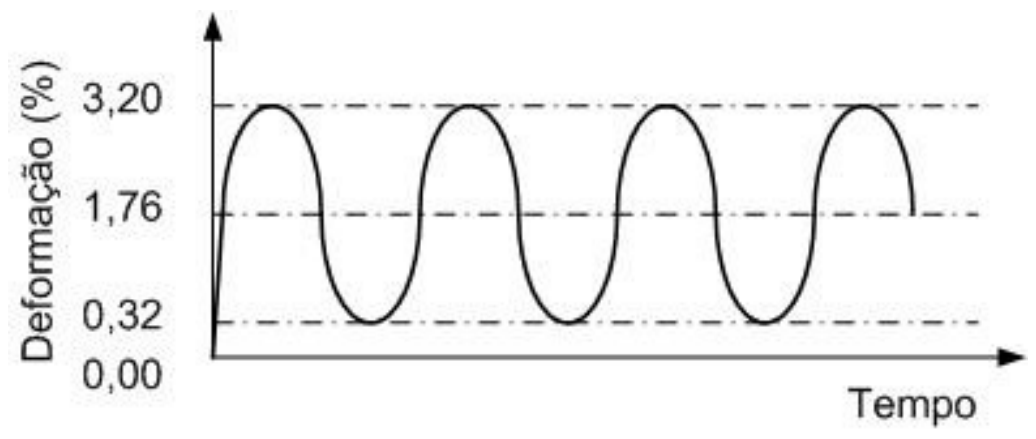

Figura 4.7 - Gráfico dos ciclos de fadiga impostos ao HDPE no ensaio de fadiga à tração uniaxial

$\mathrm{Na}$ Tabela 4.2 mostram-se os valores de deslocamento e a deformação correspondente a que foi submetido o HDPE durante o ensaio de fadiga à tração uniaxial.

Tabela 4.2 - Valores de deslocamento e a deformação correspondente aplicados durante o ensaio de fadiga à tração uniaxial

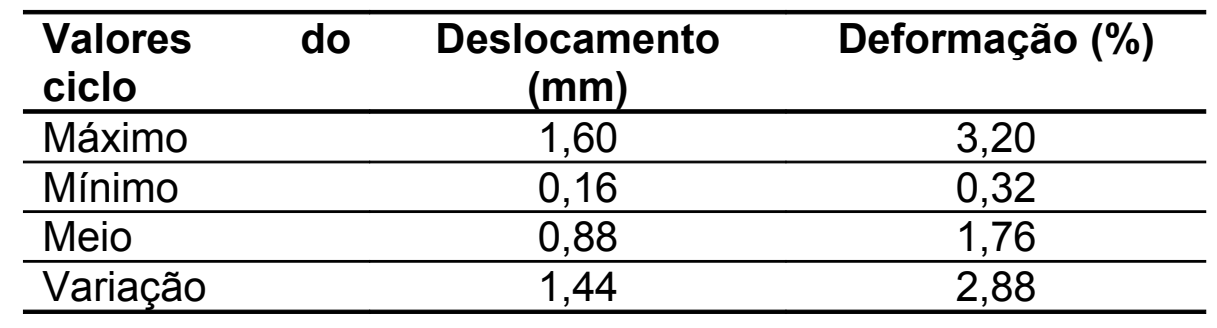


Foram feitos três series diferentes de ensaios de fadiga à tração uniaxial com o HDPE do cabo. Na primeira serie, o número de carregamentos cíclicos aplicados foi de 30.000 , a mesma quantidade a que fui submetido o cabo umbilical no ensaio de fadiga feito segundo a API 17E. Na segunda serie o número de carregamentos cíclicos aplicados foi de 10.000 e na terceira a quantidade ciclos aplicados foi de 100.000 .

No total, foram obtidos sete corpos-de-prova ensaiados a fadiga à tração uniaxial, três submetidos a 10.000 ciclos (um espécime para ser ensaiado a absorção e dois a tração), três submetidos a 30.000 ciclos (um para absorção e dois a tração) e um submetido a 100.000 ciclos para ensaiar a absorção. Em todos os ensaios a freqüência dos carregamentos cíclicos aplicados foi de $0,5 \mathrm{~Hz}$.

Durante o período em que foram feitos os ensaios de fadiga à tração uniaxial no local onde foram realizados os testes a temperatura foi mantida entre 22 e $23^{\circ} \mathrm{C}$ e a umidade relativa foi de $54 \%$.

\subsection{ENSAIO DE ENVELHECIMENTO ARTIFICIAL NO HDPE DA CAMADA POLIMÉRICA EXTERNA DO CABO UMBILICAL}

Este ensaio teve como objetivo estudar o efeito da radiação ultravioleta, da água do mar e dos carregamentos cíclicos combinados nas propriedades mecânicas da camada polimérica externa do cabo umbilical.

A radiação solar que atinge as camadas mais exteriores da atmosfera terrestre possui espectro contínuo entre 0,7 e $3.000 \mathrm{~nm}$. Esta, ao passar pelas diversas camadas da atmosfera, somente uma parte deste espectro atinge a superfície terrestre, notadamente acima de 290-300 nm. Só um 6\% da radiação incidente na superfície terrestre encontra-se dentro da faixa do ultravioleta, sendo esta pequena porção responsável pelos processos foto degradantes sofridos pelas ligações químicas dos materiais poliméricos (GUGUMUS, 1990).

Para conseguir um efeito similar à radiação solar à intempérie recomenda-se usar lâmpadas fluorescentes que emitam uma radiação com comprimento de onda entre 300 e 400 nm (ASTM D 4329; ASTM G 154; WHITE, TURNBULL, 1994). 


\subsubsection{Elaboração dos corpos-de-prova para ensaio de envelhecimento}

Os corpos-de-prova que foram submetidos ao envelhecimento foram elaborados com amostras de HDPE tomadas das camadas poliméricas externas de duas seções do cabo umbilical. Uma sem uso e outra que tinha sido ensaiada à fadiga segundo a norma API 17E.

Para a confecção dos corpos-de-prova de envelhecimento foi tomada como padrão a geometria dada na norma ASTM D 638, Figura 3.7. Foram confeccionados dezoito corpos-de-prova para ensaios de tração, nove a partir da amostra do HDPE retiradas do cabo sem uso e nove da seção que foi submetida ao ensaio de fadiga segundo a norma API 17E. Além disso, foram elaborados espécimes tipo placa para ensaios de dureza Tipo D segundo a norma ASTM D 2240 e observações num microscópio eletrônico de varredura (MEV).

\subsubsection{Execução do ensaio de envelhecimento artificial do HDPE da camada externa do cabo}

A fim de simular as condições a que o HDPE, da camada externa do cabo, está submetido durante sua vida de serviço foram criados três ambientes em condições de laboratório para submeter o material a um envelhecimento acelerado.

O primeiro ambiente (Região 1), Figura 3.10, é aquele que fica fora do mar, sob radiação ultravioleta. Para conseguir um efeito similar à radiação solar usaram-se lâmpadas fluorescentes da marca PHILIPS tipo 09N que emitem uma radiação com comprimento de onda na faixa de 320 a $390 \mathrm{~nm}$. O ensaio foi feito segundo as normas ASTM D 4329 e ASTM G 154.

Para a simulação da segunda zona (Região 2), Figura 3.10, foi criado um segundo ambiente. Com este objetivo usou-se uma manta térmica e uma cuba de cristal. Os corpos-de-prova foram colocados dentro da cuba de cristal na qual foi colocada água do mar artificial, preparada segundo a norma ASTM D 1141, até um nível que cobria os corpos-de-prova. A temperatura da água foi controlada usando uma manta 
térmica. Simultaneamente, os corpos-de-prova foram irradiados com radiação ultravioleta durante o tempo que durou o ensaio.

Para simular o terceiro ambiente (Região 3), Figura 3.10, usou-se a mesma metodologia do ambiente anterior, Região 2, com a diferença que os corpos-deprova não foram irradiados, ficando isolados em um local escuro. Nas Figura $4.8 \mathrm{e}$ D1 (Apêndice D) são mostradas fotos dos três ambientes criados para o ensaio de envelhecimento artificial.

Todos os ensaios tiveram duração de $500 \mathrm{~h}$ e durante toda sua realização a temperatura dos três ambientes foram controladas e mantidas a $(35 \pm 1)^{\circ} \mathrm{C}$.
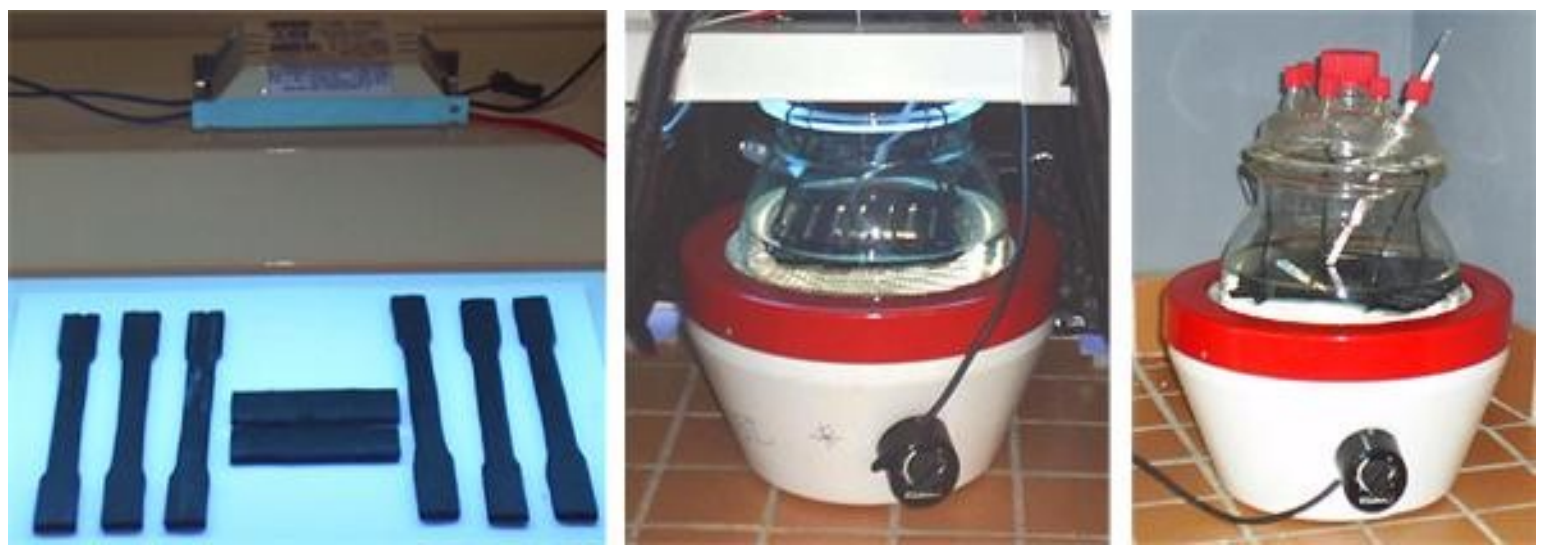

Figura 4.8 - Fotos dos três ambientes para ensaio de envelhecimento

Em cada ambiente foram envelhecidos seis corpos-de-prova para ensaios de tração, três do material retirado do cabo sem uso e três do material que tinha sido carregado ciclicamente segundo a API 17E. Além disso, foram envelhecidas amostras de HDPE retiradas do cabo sem uso e carregados ciclicamente para fazer ensaios de dureza e observações em MEV.

Após concluído o processo de envelhecimento, os corpos-de-prova foram submetidos a ensaios mecânicos de tração, segundo a norma ASTM D 638, ensaio de dureza Tipo D segundo a norma ASTM D 2240 e à observação em MEV para ver o efeito do envelhecimento e dos carregamentos cíclicos nas propriedades e na microestrutura do HDPE. 


\subsubsection{Execução dos ensaios de Dureza Tipo D}

Os ensaios de dureza basearam-se na norma ASTM D 2240. Foram ensaiadas oito amostras de HDPE, das quais seis tinham sido submetidas a processo de envelhecimento artificial e duas não sofreram nenhum tipo de envelhecimento. Os corpos-de-prova ensaiados foram do tipo placa com espessura de $5 \mathrm{~mm}$ (a mesma da camada polimérica externa), largura de $20 \mathrm{~mm}$ e comprimento de $75 \mathrm{~mm}$. Estes foram pré-condicionados por 40 horas à temperatura $23 \pm 2{ }^{\circ} \mathrm{C}$ e umidade relativa de $55 \pm 5 \%$.

Durante o ensaio, fizeram-se cinco determinações para cada corpo-de-prova. $\mathrm{Na}$ execução dos ensaios o equipamento empregado foi um durômetro Tipo D (Digital)DU-010.

\subsubsection{Resultados dos ensaios de Dureza}

Os valores de dureza oscilaram entre um valor máximo D/64 e um valor mínimo $\mathrm{D} / 60$. Após de analisar estes resultados chega-se à conclusão que o material não sofreu grandes variações na sua dureza. Este ensaio não foi conclusivo para mostrar o efeito degradantes dos carregamentos cíclicos e os fatores ambientais (radiação ultravioleta e água salgada) sobre o HDPE da camada externa do cabo umbilical.

Na Tabela 4.3 são apresentados os resultados dos ensaios de dureza tipo D feitos, segundo a norma ASTM D 2240, nas diferentes amostras do HDPE.

Tabela 4.3 - Resultados dos ensaios de Dureza Tipo D no HDPE

\begin{tabular}{|l|c|c|c|c|}
\hline \multirow{2}{*}{ No. de CP } & \multicolumn{4}{|c|}{ Dureza Tipo D } \\
\cline { 2 - 5 } & Máxima & Mínimo & Média $\left({ }^{*}\right)$ & Desv. Padrão $\left.{ }^{*}\right)$ \\
\hline 1 & $\mathrm{D} / 64 / 1$ & $\mathrm{D} / 62 / 1$ & $\mathrm{D} / 63 / 1$ & 0,89 \\
\hline 2 & $\mathrm{D} / 62 / 1$ & $\mathrm{D} / 62 / 1$ & $\mathrm{D} / 62 / 1$ & 0,00 \\
\hline 3 & $\mathrm{D} / 63 / 1$ & $\mathrm{D} / 61 / 1$ & $\mathrm{D} / 62 / 1$ & 0,71 \\
\hline 4 & $\mathrm{D} / 63 / 1$ & $\mathrm{D} / 61 / 1$ & $\mathrm{D} / 62 / 1$ & 0,89 \\
\hline 5 & $\mathrm{D} / 60 / 1$ & $\mathrm{D} / 60 / 1$ & $\mathrm{D} / 60 / 1$ & 0,00 \\
\hline 6 & $\mathrm{D} / 64 / 1$ & $\mathrm{D} / 63 / 1$ & $\mathrm{D} / 64 / 1$ & 0,55 \\
\hline 7 & $\mathrm{D} / 64 / 1$ & $\mathrm{D} / 63 / 1$ & $\mathrm{D} / 64 / 1$ & 0,55 \\
\hline 8 & $\mathrm{D} / 62 / 1$ & $\mathrm{D} / 61 / 1$ & $\mathrm{D} / 62 / 1$ & 0,45 \\
\hline
\end{tabular}

$\left.{ }^{*}\right)$ para 5 determinações 
HDPE retido do cabo sem uso: 1, não envelhecido; 3 , envelhecido com radiação ultravioleta; 5, envelhecido com água salgada; 7, envelhecido com radiação ultravioleta e água salgada simultaneamente.

HDPE que foi submetido a carregamentos cíclicos: 2, não envelhecido; 4, envelhecido com radiação ultravioleta; 6, envelhecido com água salgada; 8, envelhecido com radiação ultravioleta e água salgada simultaneamente.

\subsubsection{Microscopia eletrônica de varredura}

Para se observar a influência dos carregamentos cíclicos, a radiação ultravioleta e água salgada na microestrutura do HDPE, amostras do polímero retirado do cabo sem uso e que tinham sido submetidas a carregamentos cíclicos, envelhecidas e não envelhecidas foram observadas usando um MEV.

Os corpos-de-prova usados na microscopia eletrônica de varredura foram tipo placa, estes foram cortados com um estilete. Suas dimensões foram $5 \mathrm{~mm}$ de largura, $5 \mathrm{~mm}$ de comprimento e $5 \mathrm{~mm}$ de espessura (a mesma da camada polimérica externa do cabo).

Foram preparados dois lotes de oito corpos-de-prova cada um. Um lote foi elaborado com o HDPE retirado do cabo sem uso e outro do material que tinha sido submetido a carregamentos cíclicos.

Cada um dos lotes tinha quatro espécimes para observações na superfície externa da camada e quatro para observações ao longo da espessura da camada. Dos quatro espécimes um era não envelhecido, um envelhecido com radiação ultravioleta, um envelhecido com água salgada, um envelhecido com radiação ultravioleta e água salgada simultaneamente.

As dezesseis amostras de material foram observadas usando um microscópio eletrônico de varredura (STEREOSCAN 440, LEO), o aumento utilizado foi de 1000x. Todas as amostras foram recobertas com ouro para permitir a observação, já que esses materiais não são condutores elétricos.

Nas observações feitas ao longo da espessura da camada não foram detectadas evidências de degradação, já nas observações feitas nas superfícies externas das 
amostras foi claramente perceptível a deterioração da microestrutura do material causada pelos carregamentos cíclicos, a radiação ultravioleta e a água salgada.

$\mathrm{Na}$ análise das micrografias eletrônicas de varredura da superfície da camada das duas amostras de HDPE não envelhecidas observou-se uma leve orientação lamelar no material que tinha sido submetido a carregamentos cíclicos.

Na Figura 4.9 mostram-se as micrografias eletrônicas de varredura da superfície do HDPE das duas amostras que não foram envelhecidas: a, material que foi retirado do cabo sem uso; b, material que foi submetido a carregamentos cíclicos.
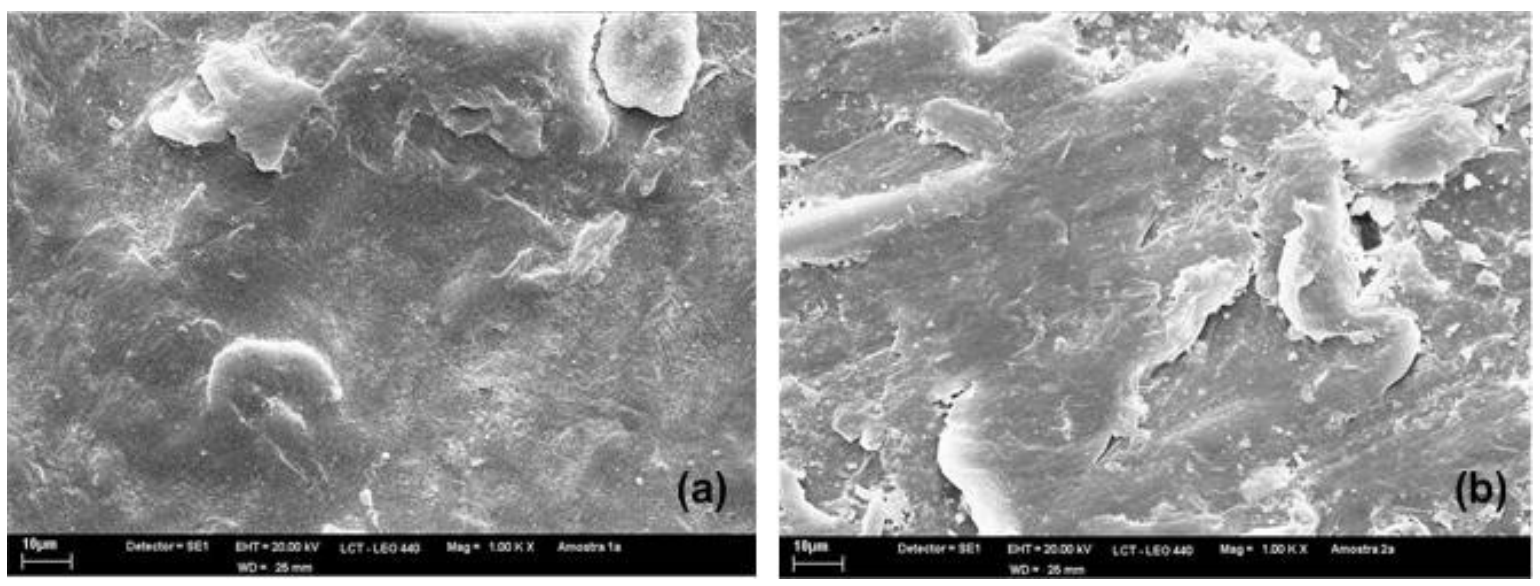

Figura 4.9 - Micrografias eletrônicas de varredura das superfícies do HDPE não envelhecido: a, material retirado do cabo sem uso; b, material que foi submetido a carregamentos cíclicos.

$\mathrm{Na}$ análise das micrografias eletrônicas de varredura da superfície do HDPE, dos corpos de prova que tinham sido submetidos a carregamentos cíclicos e envelhecidos nos diferentes ambientes, constatou-se que o efeito do envelhecimento com radiação ultravioleta e água salgada separadamente não foi muito perceptível, já no caso da radiação ultravioleta e a água salgada atuando simultaneamente o efeito degradante foi maior principalmente no material que foi submetido carregamentos cíclicos, onde observaram-se o surgimento de trincas na superfície do material.

Na Figura 4.10 mostram-se imagens das micrografias eletrônicas de varredura das superfícies do HDPE que tinham sido submetidas a carregamentos cíclicos e logo foi envelhecido nos diferentes ambientes. 

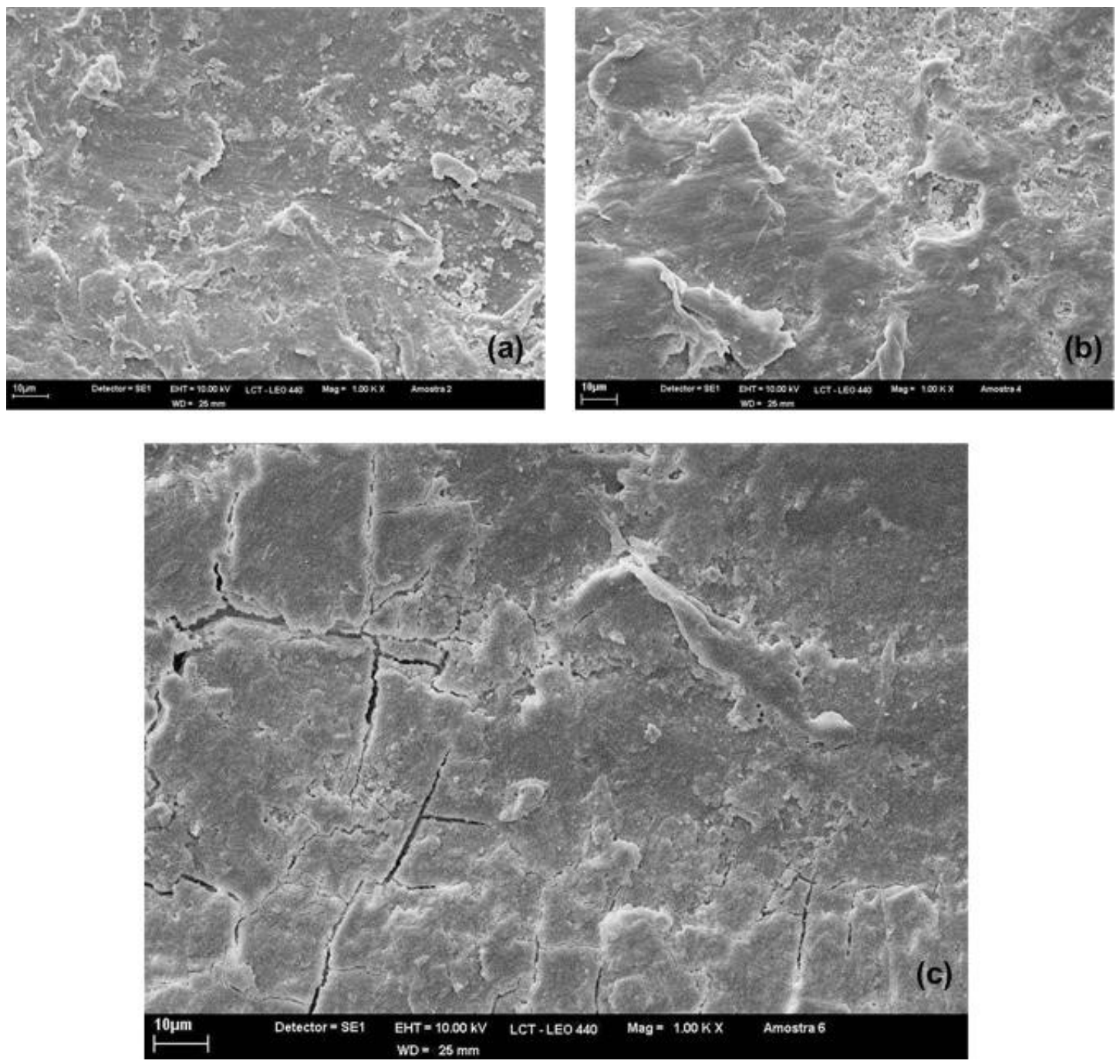

Figura 4.10 - Micrografias eletrônicas de varredura das superfícies do HDPE que foram submetidos a carregamentos cíclicos e envelhecido:

a, envelhecido com radiação ultravioleta; b, envelhecido com água salgada; c, envelhecido com radiação ultravioleta e água salgada simultaneamente.

O HDPE que foi submetido à fadiga quando exposto a radiação ultravioleta, desenvolve um processo de foto-oxidação. Este processo de degradação fotoquímica é resultado de um conjunto de reações de formação de ligações cruzadas e cisões de cadeias poliméricas que conduzem a mudanças da massa molecular e diminuição da temperatura de fusão (HINSKEN et al., 1991; HAMID, AMIN, 1995; KHRAISHI, AL ROBAIDI, 1991; VALADEZ, CERVANTES, VELEVA, 1999).

Durante a foto-oxidação do HDPE, originada pela exposição a radiação ultravioleta a cristalinidade do polímero mostra um crescimento exponencial atribuído isto à 
oxidação preferencial de sua fase amorfa, assim como à formação de novos cristalitos induzidos pelo fenômeno de cisão de cadeias poliméricas (VALADEZ, CERVANTES, VELEVA, 1999; VALADEZ, VELEVA, 2004). Devido ao incremento da cristalinidade acontece um aumento diferencial do módulo de elasticidade nas diferentes profundidades do material. Os valores do módulo de elasticidade variaram de acordo com a profundidade, sendo maiores na superfície do que no interior do material. Esta variação do módulo de elasticidade com a profundidade pode ser suficientemente alta para promover trincas na superfície do polímero (TAVARES et al., 2003).

\subsection{ENSAIOS DE TRAÇÃO DO HDPE DA CAMADA POLIMÉRICA EXTERNA DO CABO}

Com o fim de verificar a variação das propriedades mecânicas do HDPE da camada externa do cabo umbilical ensaiadas a fadiga à tração uniaxial e envelhecidas foram feitos ensaios de tração nas amostras obtidas. Também foram ensaiadas a tração amostras do HDPE retiradas do cabo sem uso. As curvas tensão-deformação obtidas nestes ensaios serão comparadas com as curva tensão-deformação do HDPE de uma camada polimérica externa, tirada de um umbilical, que tinha sido submetido a um ensaio de fadiga de 30.000 ciclos segundo a norma API 17E, no processo de homologação do cabo.

\subsubsection{Preparação dos corpos-de-prova para o ensaio de tração}

Os corpos-de-prova usados nos ensaio de tração foram o que estabelece a norma ASTM D 638, Figura 3.7. Foi escolhido este tipo de corpo-de-prova já que é o preferível quando o polímero a ser testado, o HDPE, é considerado um polímero semi-cristalino (LIN; ARGON, 1994), e sua espessura é maior que $1 \mathrm{~mm}$ e menor que $7 \mathrm{~mm}$. O procedimento seguido para a preparação dos corpos-de-prova foi o fornecido no item 3.3.1.5. 


\subsubsection{Execução de ensaio de tração instrumentado}

Com o fim de determinar o módulo de elasticidade $(E)$ e o coeficiente de Poisson (v) do HDPE da camada externa do cabo foi feito um ensaio de tração instrumentado. Neste ensaio o espécime foi instrumentado com um extensômetro de resistência elétrica, e a carga foi aplicada só para obter valores de deslocamento na zona elástica da curva tensão-deformação do polímero, e com estes dados de tensão e deformação calcular os valores de v e E.

O corpo-de-prova usado no ensaio foi o apresentado na Figura 3.7. O procedimento seguido para a preparação do espécime foi o que fornecido no item 3.3.1.5.

Concluída a elaboração do corpo-de-prova, procedeu-se à preparação da superfície onde seria colado o extensômetro (zona de trabalho do corpo-de-prova). Os procedimentos de preparação da superfície do espécime e colagem do extensômetro são similares aos feitos para o ensaio de desconfinamento no item 4.2.1. O extensômetro de resistência elétrica e o adesivo usados são dos mesmos tipos empregados no ensaio de desconfinamento, item 4.2.1.

Após colado o extensômetro, como ilustra a Figura 4.11, e curado o adesivo, verificou-se as resistências elétricas do extensômetro comprovando-se que mantinham as características dadas pelo fabricante. Logo se procedeu a soldar condutores elétricos nas terminais do extensômetro para ligar este com o SAD (KYOWA).

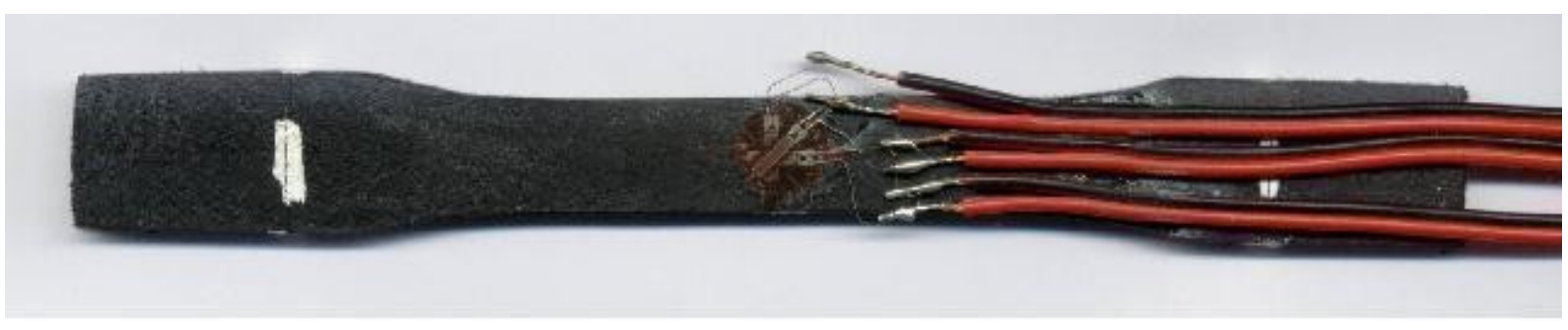

Figura 4.11 - Fotos do corpo-de-prova de tração instrumentado 
Seguidamente, procedeu-se à colocação e fixação do corpo-de-prova já instrumentado nas garras da máquina de ensaio. Durante a colocação e a fixação do corpo-de-prova teve-se o cuidado que o eixo médio do espécime, linha traçada ao longo de seu comprimento, coincidisse com o eixo mecânico da maquina de ensaios (pontos centrais das mordaças), já que qualquer erro de alinhamento poderia alterar o valor das propriedades mecânicas a se medir (BROWN, 1988).

As mordaças ficaram bem apertadas ao corpo-de-prova para evitar escorregamento do mesmo durante o ensaio, que poderia ocasionar erros nos dados obtidos ou ruptura do corpo-de-prova fora da zona de trabalho (pescoço). Na execução dos ensaios a máquina de tração empregada foi do tipo servo hidráulica, modelo UT5TA7.

Após fixar o espécime na maquina de ensaio, procedeu-se ao ligamento dos condutores soldados ao extensômetro com o Sistema de Aquisição de Dados (SAD). Com o arranjo para ensaio pronto procedeu-se à calibração do SAD. Esta foi feita manual e individualmente para os três canais onde foram ligados os componentes do extensômetro. Na Figura 4.12 mostra-se o arranjo de ensaio de tração instrumentado.

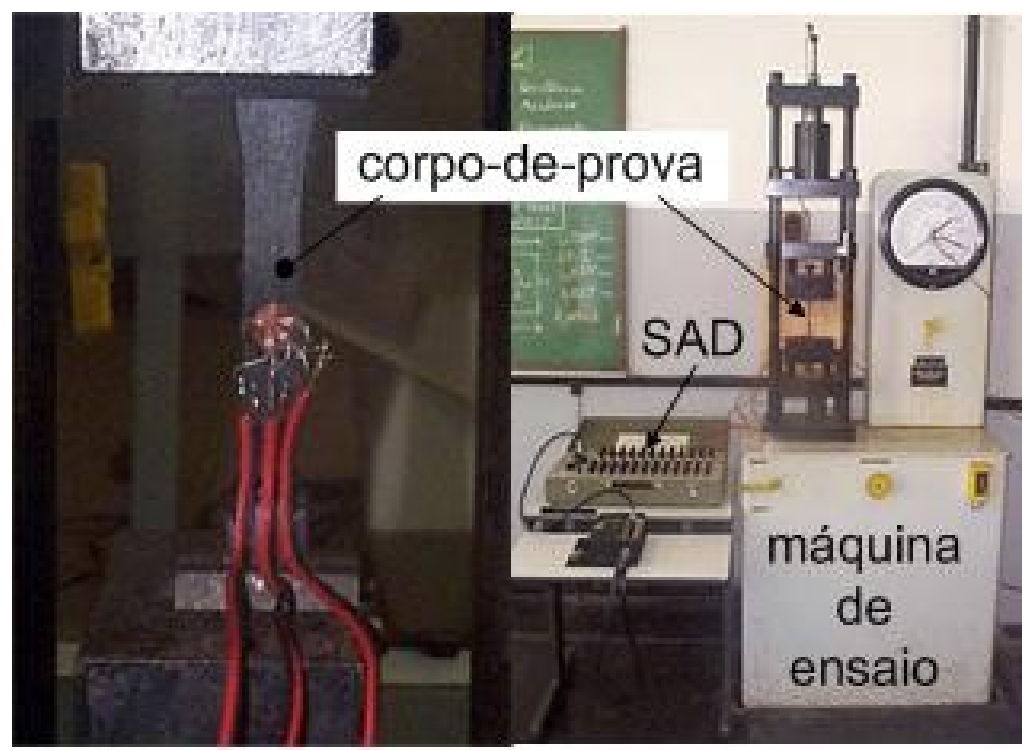

Figura 4.12 - Arranjo para ensaio de tração instrumentado 
O ensaio de tração consistiu em se submeter o corpo-de-prova a quatro cargas de tração diferentes $(100 \mathrm{~N}, 200 \mathrm{~N}, 300 \mathrm{~N}, 400 \mathrm{~N})$ todas dentro da zona de comportamento elástico do material, para registrar os deslocamentos que estas originariam. Com os resultados obtidos usando as eq.(2.31) e eq.(2.32) foram estimadas as tensões e deformações, e com estas a partir das eq.(2.34) e eq.(2.38) foram calculados os valores de E e $v$ do HDPE que compõe a camada externa do cabo umbilical.

Neste experimento, as cargas foram medidas por um dispositivo acoplado na própria máquina de ensaio, e as deformações com um extensômetro elétrico, tipo roseta retangular de três elementos, com o qual se conseguiu medir, ao mesmo tempo, as deformações longitudinais, transversais e num eixo a $45^{\circ}$ dos dois anteriores.

Como resultado do ensaio obteve-se que o HDPE que compõe a camada polimérica externa do cabo tem um modulo de elasticidade de 708,78 MPa e um coeficiente de Poisson de 0,48. Na Figura 4.13 mostram-se as curvas deformação-força e tensãodeformação para o corpo-de-prova ensaiado.
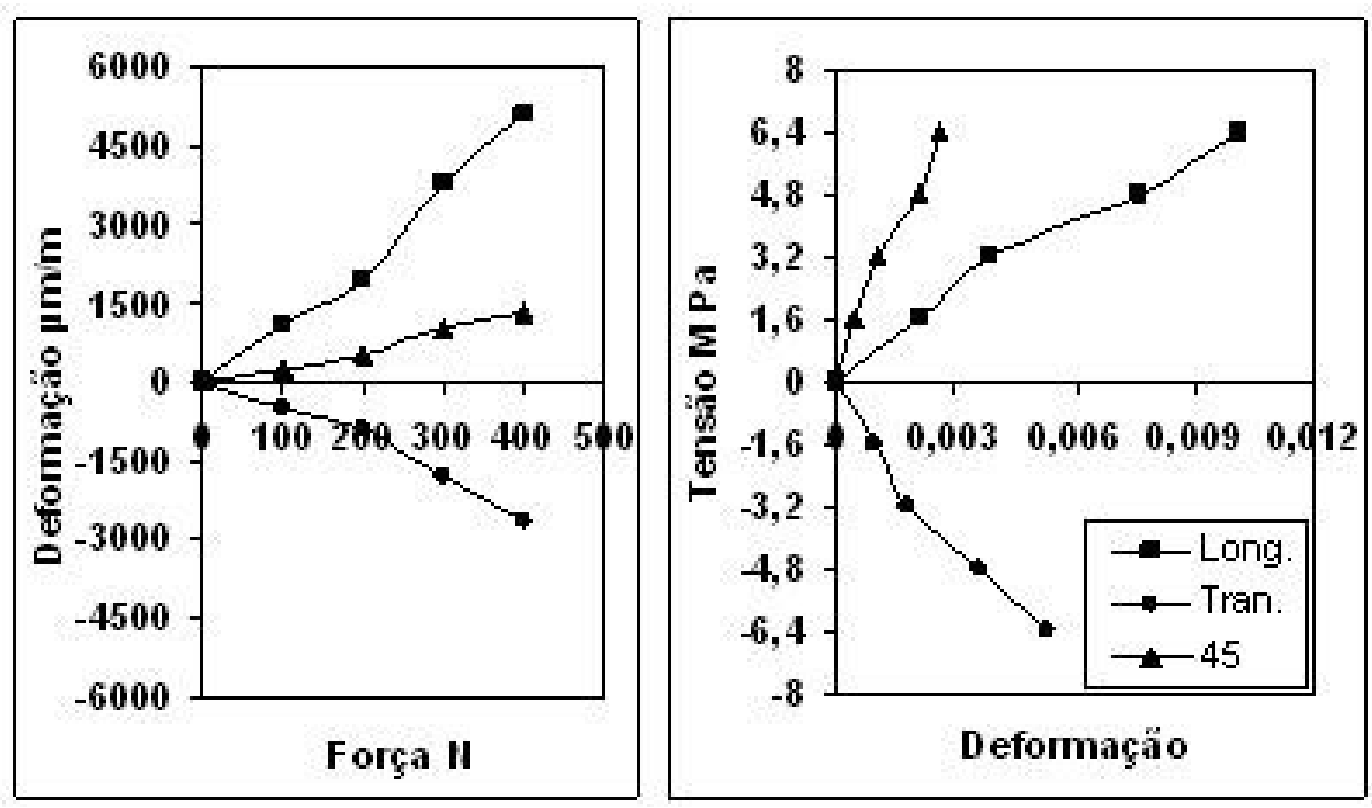

Figura 4.13 - Curvas deformação-força e tensão-deformação para o corpo-de-prova ensaiado a tração 
Na Tabela 4.4 podem-se observar os valores de deformações, tensões, módulos de Elasticidade e coeficientes de Poisson obtidos durante o ensaio de tração para os diferentes valores de carregamento.

Tabela 4.4 - Valores $\varepsilon, \sigma, v$ e E obtidos no ensaio de tração instrumentado

\begin{tabular}{|c|c|c|c|c|c|c|}
\hline \multirow{2}{*}{$\begin{array}{c}\text { Força } \\
(\mathrm{N})\end{array}$} & \multicolumn{3}{|c|}{ Deformação $(\mu \mathrm{m} / \mathrm{m})$} & \multirow{2}{*}{$\begin{array}{c}\text { Tensão } \\
\text { (MPa) }\end{array}$} & \multirow[t]{2}{*}{$v$} & \multirow{2}{*}{$\begin{array}{c}\mathrm{E} \\
(\mathrm{MPa}) \\
\end{array}$} \\
\hline & Longitudinal & Transversal & $45^{\circ}$ & & & \\
\hline 100 & 1060 & -487 & 222 & 1,60 & 0,46 & 752,39 \\
\hline 200 & 1940 & -912 & 520 & 3,19 & 0,47 & 822,20 \\
\hline 300 & 3790 & -1800 & 1042 & 4,79 & 0,47 & 631,30 \\
\hline 400 & 5070 & -2640 & 1310 & 6,38 & 0,52 & 629,22 \\
\hline
\end{tabular}

Durante a realização do ensaio a temperatura no local foi de $23^{\circ} \mathrm{C}$ e a umidade relativa de $52 \%$, valores permissíveis pela norma ASTM D 638.

\subsubsection{Execução dos ensaios de tração convencionais no HDPE da camada externa}

A metodologia seguida para a realização dos ensaios de tração é a que estabelece a norma ASTM D 638. O procedimento para a realização dos ensaios de tração foi descrito no item 3.3.3.

O ensaio de tração nas amostras de HDPE consistiu em submeter o corpo-de-prova, Figura 3.7, a um esforço de tração ao longo de seu comprimento que tende a esticálo originando uma deformação do material na direção da força aplicada.

Como resultado direto dos ensaios de tração são obtidos os valores de cargas aplicadas e os deslocamentos originados no material da camada polimérica externa do cabo, e a partir destes usando as eq.(2.31) e eq.(2.32), será construídas as curvas tensão-deformação de engenharia dos materiais ensaiados.

Devido a que os resultados dos ensaios serão comparados, todos os testes são feitos com a mesma velocidade, $50 \mathrm{~mm} / \mathrm{min}$, que é uma velocidade média entre as três que recomenda a norma ASTM 638. Durante a realização dos ensaios a temperatura foi mantida de $23 \pm 2^{\circ} \mathrm{C}$ e a umidade relativa de $50 \pm 5 \%$, valores estes toleráveis pela norma ASTM D 638. 
4.4.3.1 Resultados dos ensaios de tração no HDPE tirado da camada externa do cabo sem uso

Na Figura 4.14, mostra-se a curva tensão-deformação obtida para um dos corposde-prova elaborados a partir da amostra de HDPE retirada do cabo sem uso.

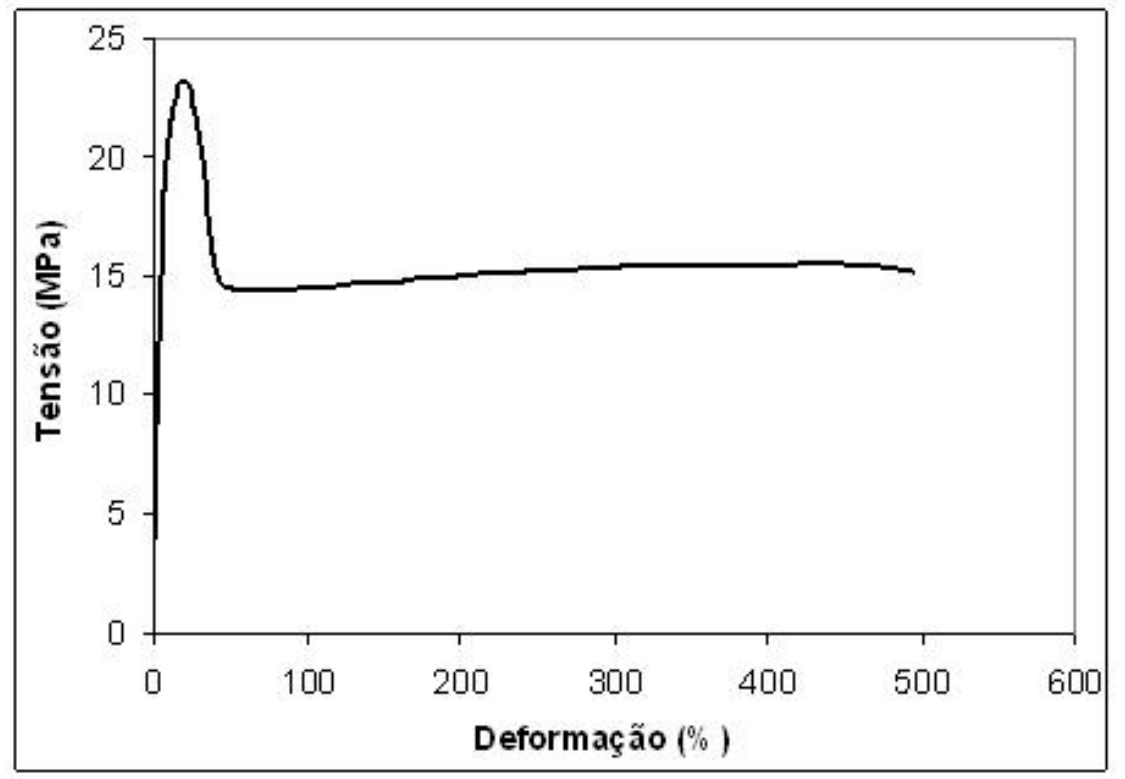

Figura 4.14 - Curva tensão-deformação do HDPE retirado do cabo sem uso

Na Tabela 4.5 mostram-se os valores de tensão e deformação representativos do ensaio.

Tabela 4.5 - Valores de tensão e deformação representativos obtidos no ensaio do HDPE retirado do cabo sem uso

\begin{tabular}{lrc}
\hline Propriedades Mecânicas & & Valores \\
\hline Limite de escoamento & $(\mathrm{M} \mathrm{Pa})$ & 17,96 \\
\hline Deformação de escoamento & $(\%)$ & 6,62 \\
\hline Tensão máxima & $(\mathrm{M} \mathrm{Pa})$ & 23,21 \\
\hline Deformação quando a tensão é máxima & $(\%)$ & 20,62 \\
\hline Tensão de ruptura & $(\mathrm{M} \mathrm{Pa})$ & 15,17 \\
\hline Deformação de ruptura & $(\%)$ & 495,22 \\
\hline
\end{tabular}


4.4.3.2 Resultados dos ensaios de tração no HDPE da camada externa do cabo ensaiada à fadiga segundo a norma API 17E

Para este ensaio as amostras foram retiradas da zona da parte superior do cabo onde este esteve submetido a carregamentos cíclicos combinadas de tração e flexão durante o ensaio de fadiga feito segundo a norma API 17E, o cabo foi submetido a 30.000 ciclos de carga (CÁRDENAS; GONÇALVES, 2003).

Na Figura 4.15 mostra-se uma das curvas tensão-deformação obtidas da amostra de HDPE, retirada da seção de cabo ensaiada previamente à fadiga de 30.000 ciclos segundo a norma API 17E.

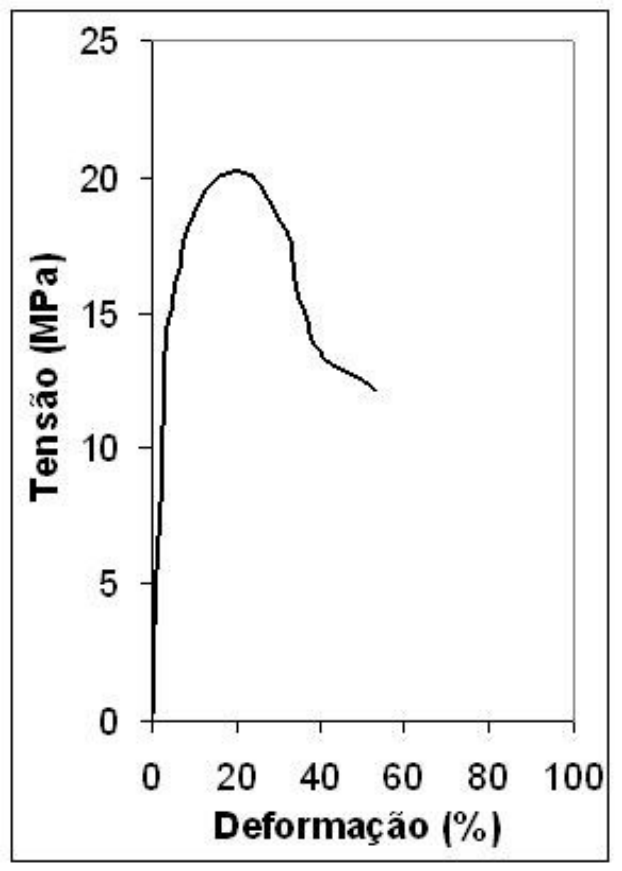

Figura 4.15 - Curva tensão-deformação do HDPE submetido a carregamentos cíclicos segundo API 17E (CÁRDENAS; GONÇALVES, 2003)

Na Tabela 4.6 são apresentados os valores de tensão e deformação representativos do ensaio (CÁRDENAS; GONÇALVES, 2003). 
Tabela 4.6 - Valores de tensão e deformação representativos do ensaio de tração feito ao HDPE que foi submetido à fadiga segundo a norma API 17E

\begin{tabular}{lrc}
\hline Propriedades Mecânicas & & Valores \\
\hline Limite de escoamento & $(\mathrm{MPa})$ & 16,07 \\
\hline Deformação de escoamento & $(\%)$ & 5,83 \\
\hline Tensão máxima & $(\mathrm{MPa})$ & 20,22 \\
\hline Deformação quando a tensão é máxima & $(\%)$ & 20,00 \\
\hline Tensão ruptura & $(\mathrm{MPa})$ & 12,19 \\
\hline Deformação de ruptura & $(\%)$ & 53,33 \\
\hline
\end{tabular}

4.4.3.3 Resultados dos ensaios de tração no HDPE da camada externa do cabo que foi submetida a fadiga à tração uniaxial

Foram ensaiados a tração quatro corpos-de-prova que tinham sido submetidos a fadiga à tração uniaxial. Dois a 30.000 e dois a 10.000 ciclos de carga.

Na Figura 4.16 mostra-se duas das curvas tensão-deformação obtidas nos ensaios de tração dos espécimes que tinham sido submetidos a fadiga à tração uniaxial antes de ser ensaiados à tração.
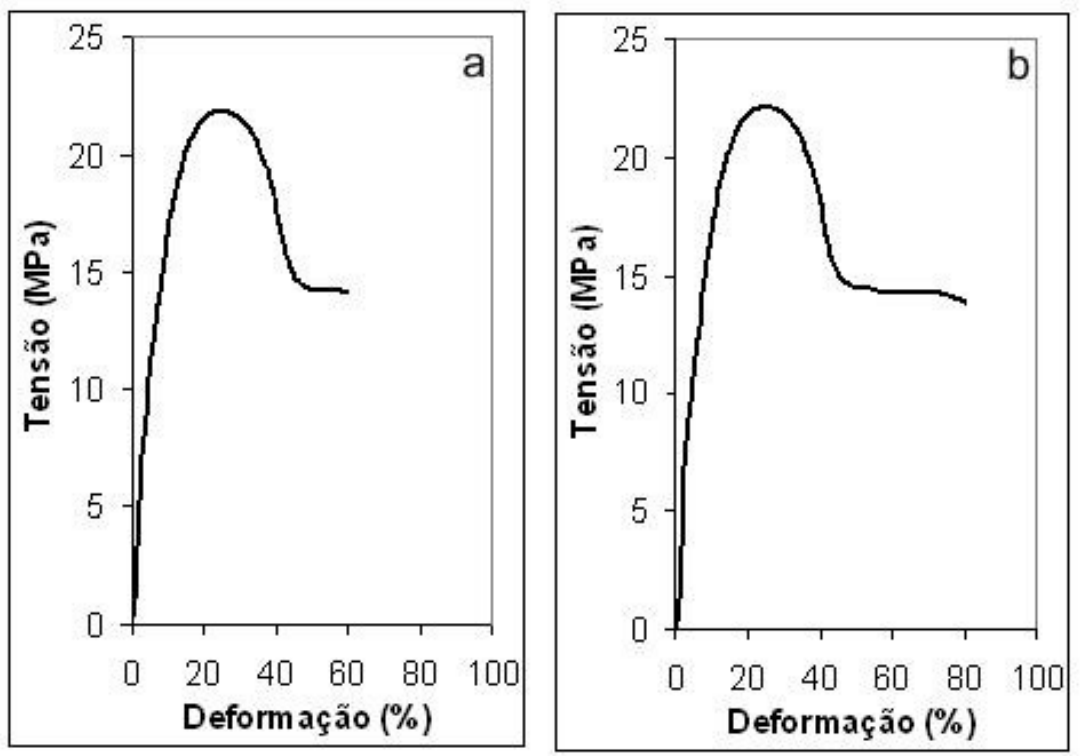

Figura 4.16 - Curvas tensão-deformação do HDPE que tinha sido submetido a fadiga à tração uniaxial: a, 30.000 ciclos ; b, 10.000 ciclos 
Na Tabela 4.7 apresentam-se os valores de tensões e deformações representativos obtidos para dois dos ensaios de tração feitos nos corpos-de-prova, os quais tinham sido submetidos a 30.000 e 10.000 ciclos de carga nos ensaios de fadiga à tração uniaxial.

Tabela 4.7 - Valores das tensões e deformações representativos obtidos nos ensaio de tração do HDPE que foi submetido a fadiga à tração uniaxial

\begin{tabular}{lrcc}
\hline Propriedades Mecânicas & \multicolumn{2}{c}{$\begin{array}{c}\text { Número de ciclos } \\
\text { aplicados }\end{array}$} \\
\cline { 3 - 4 } & & 30.000 & 10.000 \\
\hline Limite de Escoamento & $(\mathrm{MPa})$ & 15,35 & 15,42 \\
\hline Deformação de escoamento & $(\%)$ & 8,64 & 8,51 \\
\hline Tensão máxima & $(\mathrm{MPa})$ & 21,86 & 22,17 \\
\hline Deformação quando a tensão é máxima & $(\%)$ & 23,52 & 23,85 \\
\hline Tensão de ruptura & $(\mathrm{MPa})$ & 14,13 & 13,14 \\
\hline Deformação de ruptura & $(\%)$ & 59,71 & 98,49 \\
\hline
\end{tabular}

4.4.3.4 Análise dos resultados dos ensaios de tração do HDPE que tinha sido submetido a fadiga à tração uniaxial

Os resultados deste estudo mostraram claramente que as deformações cíclicas a que foi submetido o HDPE que compõe a camada externa do cabo umbilical tiveram grande influência nas propriedades mecânicas deste. Percebeu-se isto depois de analisar e comparar os resultados obtidos nos ensaios de tração dos corpos-deprova feitos com as amostras de material polimérico, que foram submetidas a carregamentos cíclicos previamente e outra que não sofreram nenhum tipo de carregamento.

Comparando as curvas tensão-deformação obtidas nos ensaios de tração dos corpos-de-prova confeccionados com as amostras de material da camada externa do cabo, pôde-se observar que o comportamento para todas é similar na primeira parte da curva até atingir a tensão de escoamento.

No entanto, quando o material começou a escoar no corpo-de-prova feito com a amostra de polímero que não tinha sido submetido a carregamentos cíclicos antes do ensaio de tração, a tensão decresceu bruscamente até um valor de 13,34 MPa e uma deformação média de $57 \%$. A partir desse instante iniciou-se um 
estrangulamento não uniforme na zona de trabalho do corpo-de-prova originado por uma reorientação nas cadeias poliméricas e apreciando-se um platô na curva tensão deformação, ou seja, mantendo-se uma tensão quase constante nesta parte da curva com tendência a um pequeno aumento, pelo fenômeno de reorientação das cadeias poliméricas, até o final do ensaio onde o valor de tensão de 15,17 MPa com uma deformação de $495,22 \%$.

Para os corpos-de-prova, confeccionados com HDPE e submetido à fadiga à tração uniaxial, antes de ser ensaiado à tração, no instante depois de ter atingido a tensão de escoamento, nota-se um decréscimo brusco da tensão e ao mesmo tempo um estrangulamento não uniforme da zona de trabalho do corpo-de-prova até a ruptura deste. Isto é devido ao processo de formação de micro cavidades instra e trans esferulíticas e à cisão de cadeias poliméricas provocado pelos carregamentos cíclicos a que foi submetido o HDPE (ANDREWS, WALKER, 1971; KAUSCH, 1978; BRETZ, HERTZBERG, MANSON, 1981; KASAKEVICH, MOET, CHUDNOVSKY, 1990).

Todos estes defeitos provocados pelos carregamentos cíclicos funcionam como concentradores de tensões, provocando uma acentuada diminuição na tenacidade do material da camada externa do cabo umbilical (MEYER, PRUITT, 2001; CÁRDENAS, MACHADO, GONÇALVES, 2007).

Na Figura 4.17 pode-se observar uma superposição das curvas tensão-deformação para alguns dos corpos-de-prova de HDPE ensaiados à tração: retirado do cabo sem uso, submetido a 30.000 ciclos de carga segundo a norma API 17E, submetido a 30.000 e 10.000 ciclos durante a fadiga à tração uniaxial. Comparando as curvas tensão-deformação percebe-se uma diminuição da tenacidade do HDPE com o aumento do número de ciclos de carga aplicados durante os ensaios de fadiga. 


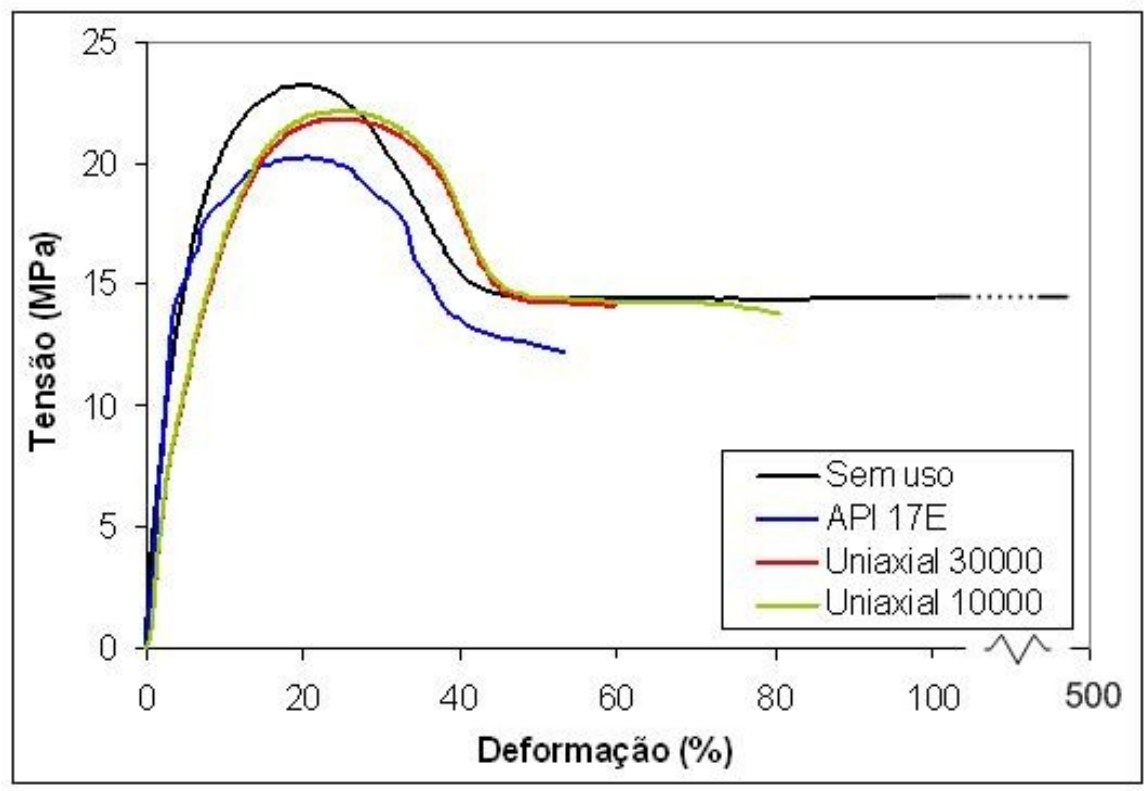

Figura 4.17 - Curvas tensão-deformação para o HDPE retirado do cabo sem uso, submetido a fadiga à tração uniaxial e segundo a norma API 17E

$\mathrm{Na}$ Tabela 4.8 pode-se observar os valores de tensões e deformações representativos dos ensaios de tração feitos nos corpos-de-prova fabricados com HDPE retirado do cabo sem uso, submetido a 30.000 ciclos de carga segundo a norma API 17E, submetido a 30.000 e 10.000 ciclos de carga durante os ensaios de fadiga à tração uniaxial.

Tabela 4.8 - Valores das tensões e deformações representativos obtidos nos ensaios de tração dos corpos-de-prova feitos de HDPE retirado do cabo sem uso e submetidos a carregamentos cíclicos

\begin{tabular}{|c|c|c|c|c|}
\hline \multirow[b]{2}{*}{ Propriedades Mecânicas } & \multirow[b]{2}{*}{$\begin{array}{c}\text { Sem } \\
\text { uso }\end{array}$} & \multicolumn{3}{|c|}{ Fadigado } \\
\hline & & $\begin{array}{l}30.000 \\
\text { API17E }\end{array}$ & $\begin{array}{l}30.000 \\
\text { uniaxial }\end{array}$ & $\begin{array}{l}10.000 \\
\text { uniaxial }\end{array}$ \\
\hline Limite de escoamento & 17,96 & 16,07 & 15,35 & 15,42 \\
\hline Deformação de escoamento (\%) & 6,92 & 5,83 & 8,64 & 8,51 \\
\hline Tensão máxima $\quad(\mathrm{MPa})$ & 23,21 & 20,22 & 21,86 & 22,17 \\
\hline Deformação a tensão é máxima (\%) & 20,62 & 20,00 & 23,52 & $23 ., 85$ \\
\hline Tensão de ruptura $\quad$ (MPa) & 15,17 & 12,19 & 14,13 & 13,14 \\
\hline Deformação de ruptura & 495,22 & 53,33 & 59,71 & 98,49 \\
\hline
\end{tabular}


Ao analisar os valores das tensões máximas mostrados na Figura 4.17 e na Tabela 4.8, para as amostras de HDPE retirado do cabo que foi submetido à fadiga segundo a API 17E e para a amostra que foi ensaiada à fadiga a tração uniaxial, verifica-se uma pequena variação de 7,5 \%. Sendo maior a tensão máxima no ensaio de fadiga à tração uniaxial, provocado isto pela diferença de estados tensionais a que é submetido o HDPE em cada um dos ensaios de fadiga.

No ensaio de fadiga do cabo feito segundo a norma API 17E, quando o umbilical é carregado ciclicamente acontece um deslocamento axial simultaneamente com uma contração no diâmetro exterior da seção transversal do cabo. Na camada polimérica externa do umbilical, que pela sua geometria comporta-se como uma casca fina, origina-se um estado tensional biaxial. Surgem duas componentes de tensões, uma no sentido longitudinal $\left(\sigma_{1}\right)$, causada pelo deslocamento do cabo e outra no sentido transversal $\left(\sigma_{2}\right)$, originada pela contração do diâmetro do umbilical.

No ensaio de fadiga do HDPE à tração uniaxial aparece apenas uma componente da tensão $\left(\sigma_{1}\right)$ no sentido longitudinal do corpo-de-prova testado.

Ao aplicar a "Teoria da máxima energia de distorção" (iten 2.8) e estimar a tensão equivalente de Von Mises ( $\left.\sigma_{\text {eq }}\right)$ utilizando a eq.(2.45) para os dois estados tensionais, biaxial $\left(\sigma_{3}=0\right)$ e uniaxial $\left(\sigma_{2}=\sigma_{3}=0\right)$, verifica-se que a $\sigma_{\text {eq }}$ é maior no HDPE que se encontra no cabo que é submetido à fadiga segundo a API 17E. Constata-se que esta amostra de material sofre uma maior perda de resistência mecânica como ilustra a Figura 4.17.

4.4.3.5 Resultados dos ensaios de tração no HDPE da camada externa do cabo que foi envelhecido

Foram ensaiados a tração os dezoito corpos-de-prova que tinham sido envelhecidos anteriormente nos diferentes ambientes, nove que tinham sido elaborados a partir da amostra do HDPE como recebida e nove da amostra que foi submetida ao ensaio de fadiga segundo a norma API 17E. 
Na Figura 4.18, são apresentadas as curvas tensão-deformação para quatro dos doze corpos-de-prova feitos com a amostra do HDPE como recebida: a, não envelhecido; b, envelhecido com radiação ultravioleta; c, envelhecido com água salgada; d, envelhecido com radiação ultravioleta e água salgada simultaneamente.
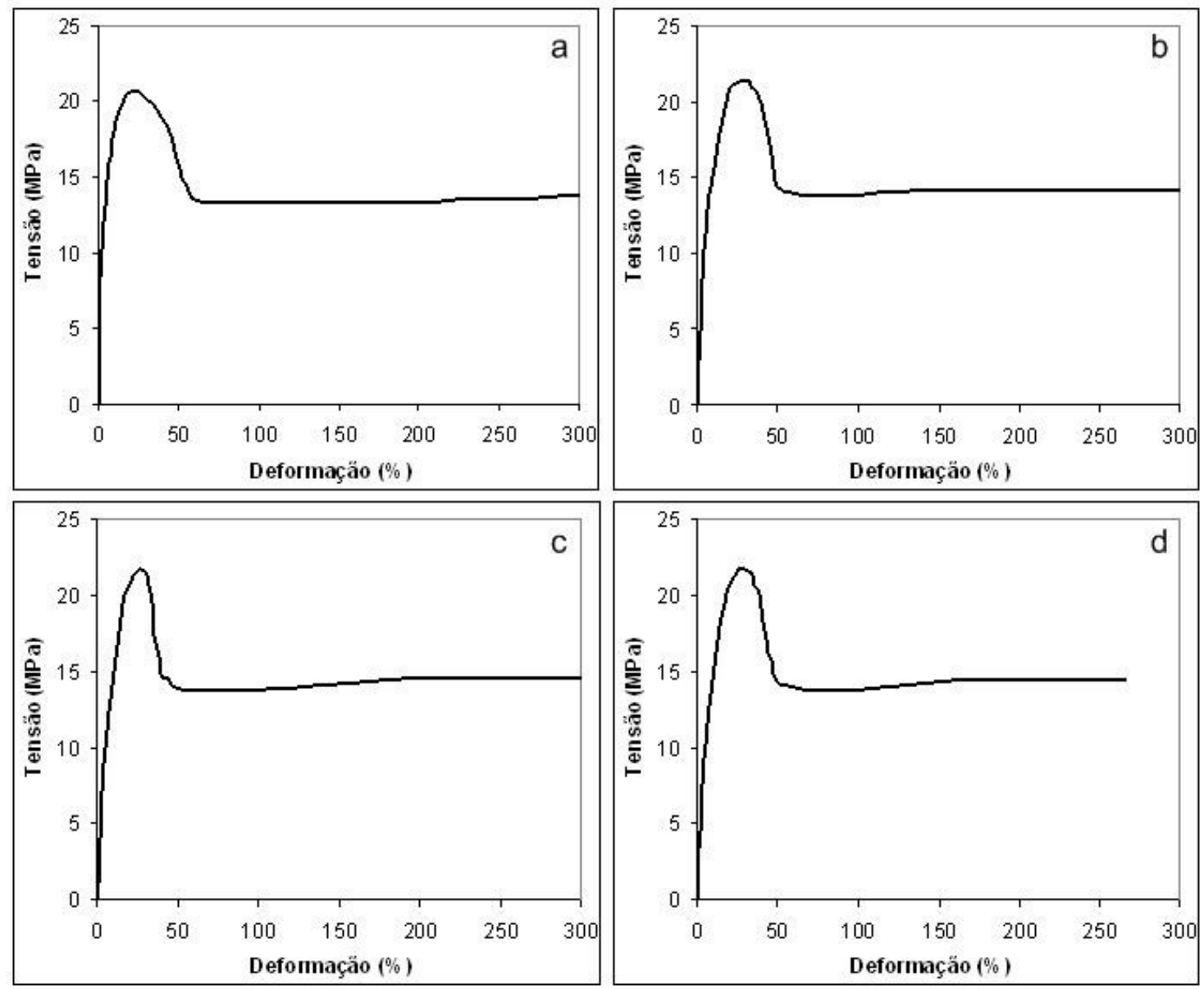

Figura 4.18 - Curva tensão-deformação para o HDPE retirado do cabo sem uso e envelhecidos: a, não envelhecido; b, envelhecido com radiação ultravioleta; c, envelhecido com água salgada; d, envelhecido com radiação ultravioleta e água salgada simultaneamente

$\mathrm{Na}$ Tabela 4.9 são apresentados os valores de tensões e deformações representativas dos ensaios de tração feitos nos corpos-de-prova fabricados das amostras de HDPE retirado do cabo sem uso e que foram envelhecidos. 
Tabela 4.9 - Valores das tensões e deformações representativos obtidos nos ensaios de tração para o HDPE envelhecido e não envelhecido, que não foi submetido a carregamentos cíclicos

\begin{tabular}{|c|c|c|c|c|}
\hline Propriedades Mecânicas & $\begin{array}{c}\text { Não } \\
\text { envelhecida }\end{array}$ & $U^{2}$ & $\mathrm{AS}^{2}$ & $\begin{array}{l}U^{U V^{1} e} \\
A^{2}{ }^{2}\end{array}$ \\
\hline Limite de escoamento & 16,31 & 16,22 & 15,87 & 16,10 \\
\hline Deformação de escoamento (\%) & 7,50 & 11,07 & 11,67 & 11,53 \\
\hline Tensão máxima $\quad(\mathrm{M} \mathrm{Pa})$ & 20.66 & 21,38 & 21,69 & 21,74 \\
\hline Deformação a tensão máxima (\%) & 22,50 & 26,67 & 26,33 & 26,00 \\
\hline $\begin{array}{ll}\text { Tensão de ruptura } & (\mathrm{MPa})\end{array}$ & 13,80 & 14,15 & 14,55 & 14,49 \\
\hline Deformação de ruptura & 300,0 & 300,0 & 300,0 & 266,6 \\
\hline
\end{tabular}

$\mathrm{Na}$ Tabela 4.10 pode-se observar os valores de tensões e deformações representativos dos ensaios de tração feitos nos corpos-de-prova fabricados das amostras de HDPE e que foi submetido a carregamentos cíclicos e envelhecimento.

Tabela 4.10 - Valores das tensões e deformações representativos obtidas nos ensaios para os corpos-de-prova feitos de HDPE que foram submetidos à fadiga mecânica segundo a API 17E e envelhecimento

\begin{tabular}{|c|c|c|c|c|}
\hline Propriedades Mecânicas & $\begin{array}{l}\text { Não } \\
\text { envelhecida }\end{array}$ & $\mathrm{UV}^{1}$ & $\mathrm{AS}^{2}$ & $\begin{array}{l}U^{1} \mathrm{e} \\
\mathrm{AS}^{2}\end{array}$ \\
\hline Limite de escoamento & 16,07 & 15,71 & 16,48 & 16,03 \\
\hline Deformação de escoamento (\%) & 5,83 & 8,33 & 11,67 & 8,87 \\
\hline Tensão máxima $\quad(\mathrm{M} \mathrm{Pa})$ & 20,09 & 21,86 & 22,87 & 21,42 \\
\hline Deformação a tensão máxima (\%) & 23,33 & 20,83 & 26,67 & 20,83 \\
\hline Tensão de ruptura $\quad$ (MPa) & 12,19 & 13,43 & 14,01 & 13,11 \\
\hline Deformação de ruptura & 53,33 & 51,67 & 66,67 & 48,33 \\
\hline
\end{tabular}

$\mathrm{Na}$ Figura 4.19 mostram-se as curvas tensão-deformação para quatro dos doze corpos-de-prova feitos com as amostras de HDPE que foram submetidas a carregamentos cíclicos antes dos ensaios de tração.

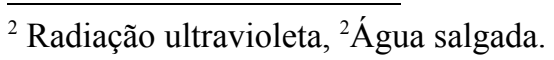




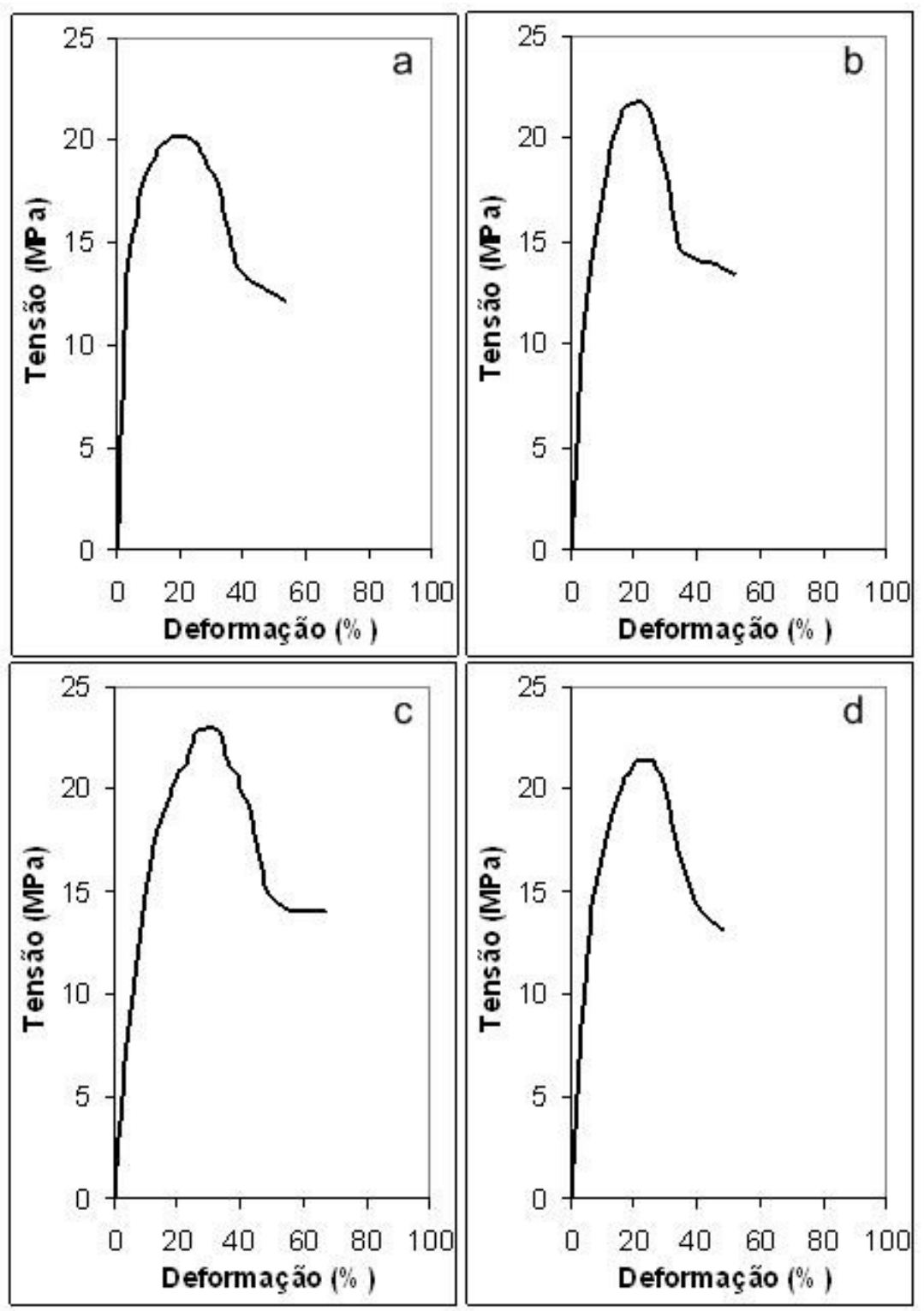

Figura 4.19 - Curva tensão-deformação para o HDPE que foi submetido a carregamentos cíclicos e envelhecidos: a, não envelhecido; b, envelhecido com radiação ultravioleta; c, envelhecido com água salgada; $d$, envelhecido com radiação ultravioleta e água salgada simultaneamente

4.4.3.6 Análise dos resultados dos ensaios de tração do HDPE que tinha sido envelhecido artificialmente

Os resultados dos ensaios de tração das amostras que foram envelhecidas mostraram que os carregamentos cíclicos foi o agente mais danoso tanto para as propriedades mecânicas como para a microestrutura do HDPE, assim como, que 
quando estes são combinados com agentes do meio, como radiação ultravioleta e água salgada os efeitos degradantes são incrementados.

$\mathrm{Na}$ Figura 4.20, são apresentadas as curvas tensão-deformação representativas para quatro dos corpos-de-prova feitos com a amostra do HDPE retirado do cabo sem uso e que foram envelhecidos nos diferentes ambientes: $a$, não envelhecido; b, envelhecido com radiação ultravioleta; c, envelhecido com água salgada; d, envelhecido com radiação ultravioleta e água salgada simultaneamente.

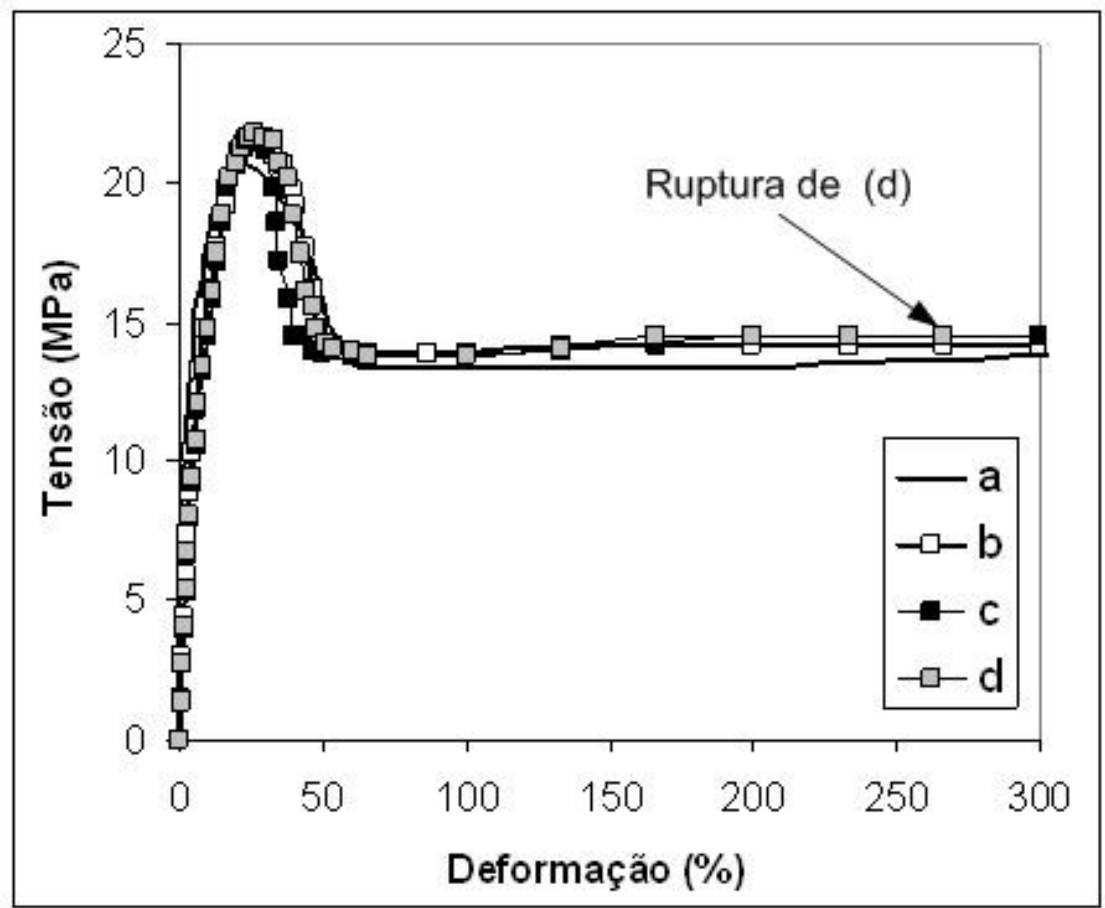

Figura 4.20 - Sobreposição das curvas tensão-deformação para o HDPE retirado do cabo sem uso e envelhecido: a, não envelhecido; b, envelhecido com radiação ultravioleta; c, envelhecido com água salgada; $d$, envelhecido com radiação ultravioleta e água salgada simultaneamente

Observou-se que quando o material começou a escoar, a tensão decresceu bruscamente até um valor médio de $14 \mathrm{MPa}$ e uma deformação média de $60 \%$. A partir desse instante iniciou-se um estrangulamento não uniforme na zona de trabalho do corpo-de-prova (pescoço) originado por uma reorientação nas cadeias poliméricas e apreciando-se um platô na curva tensão deformação, ou seja, mantendo-se uma tensão quase constante nesta parte da curva com tendência a um pequeno aumento, pelo fenômeno de reorientação das cadeias poliméricas, até o final do ensaio onde o valor de tensão média foi de 14,5 MPa com uma deformação de $300 \%$. 
O comportamento de todos os corpos-de-prova elaborados com a amostra de material da camada externa, HDPE, retirada cabo sem uso foram similares, exceto os corpos-de-prova que foram envelhecidas com radiação ultravioleta e água salgada simultaneamente, Figura $4.20 \mathrm{~d}$, onde a ruptura do corpo-de-prova aconteceu com uma deformação menor de $300 \%$.

Na Figura 4.21 mostram-se as curvas tensão-deformação para quatro dos corposde-prova feitos com a amostra de HDPE que foi submetido a carregamentos cíclicos antes dos ensaios de tração: a, não envelhecido; b, envelhecido com radiação ultravioleta; c, envelhecido com água salgada; d, envelhecido com radiação ultravioleta e água salgada simultaneamente. Pôde-se observar que o comportamento na primeira parte da curva até atingir o ponto de escoamento é similar as curvas da Figura 4.20. Já no instante posterior ao escoamento notou-se um decréscimo abrupto na tensão junto a um estrangulamento não uniforme na zona de trabalho dos corpos-de-prova (pescoço) até a ruptura destes, sendo a tensão e a deformação médias no momento da ruptura respectivamente de $13,36 \mathrm{MPa}$ e $61,08 \%$.

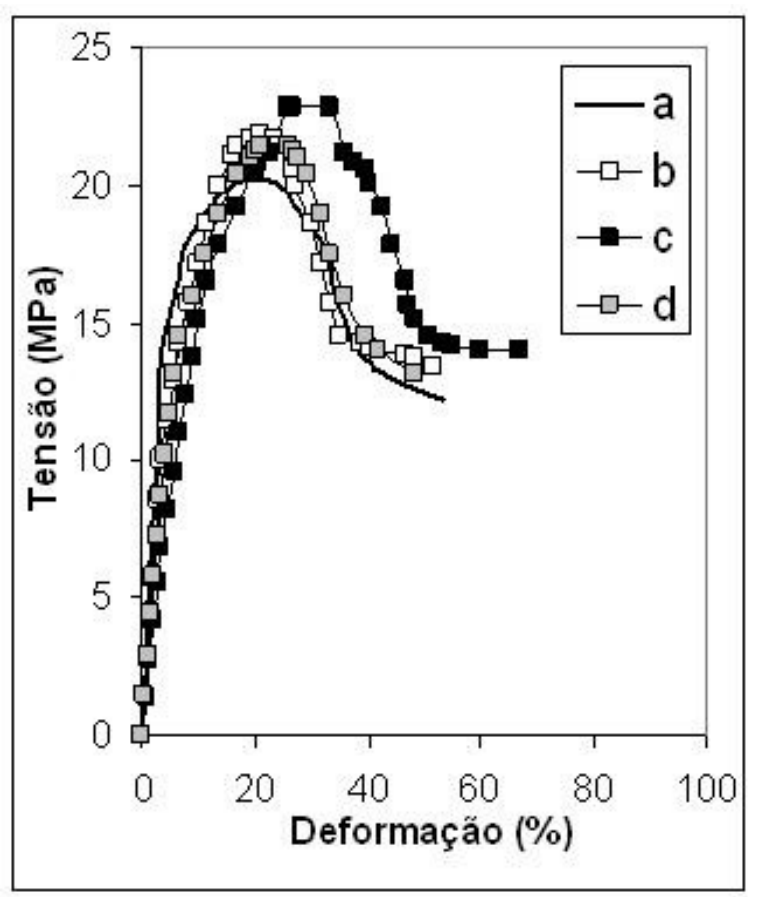

Figura 4.21 - Sobreposição das curvas tensão-deformação para o HDPE que foi submetido à fadiga e envelhecido 
Os resultados deste estudo mostraram claramente que os carregamentos cíclicos e o processo de envelhecimento a que foram submetidas as amostras de HDPE da camada externa do cabo umbilical tiveram grande influência na suas propriedades mecânicas. Percebeu-se isto depois de analisar e comparar as curvas tensãodeformação obtidas nos ensaios de tração dos corpos-de-prova feitos com as amostras de HDPE fadigado e envelhecido, e as curvas do HDPE retirado do cabo sem uso.

\subsection{ENSAIO DE ABSORÇÃO DE ÁGUA NO HDPE DA CAMADA POLIMÉRICA EXTERNA DO CABO UMBILICAL}

O HDPE é um polímero amplamente usado como isolante em cabos de alta voltagem devido a suas boas propriedades dielétricas e seu baixo custo. Quando ele é usado na camada externa de cabos umbilicais fica exposto a uma combinação de fatores ambientais agressivos como radiação ultravioleta e variações de temperatura em um ambiente úmido e salino. Além disso, o cabo fica sob carregamentos ciclos originados pela correnteza marinha. Como resultado, é normal a ocorrência de reações de oxidação, formação de ligações cruzadas e de cisão das cadeias poliméricas, com o desenvolvimento de poros e trincas superficiais que permitem a penetração da água salgada nas profundezas da camada polimérica até o ponto que pode transpassar esta e chegar até armaduras de tração comprometendo seriamente a durabilidade do cabo umbilical.

Este ensaio teve dois objetivos o primeiro, determinar a proporção de água absorvida pelo HDPE da camada externa do cabo quando imerso no líquido, e, o segundo, ver a influência dos carregamentos cíclicos sobre a variação da absorção de água na camada polimérica externa dos cabos umbilicais.

Para a realização do ensaio seguiu-se a metodologia fornecida pela norma ASTM D 570 (tecnicamente equivalente à norma ISO 62).

Os corpos-de-prova que foram submetidos a ensaios de absorção foram elaborados com diferentes amostras de HDPE tomadas da camada polimérica externas do mesmo cabo umbilical, uma do cabo sem uso, uma do cabo que tinham sido ensaiada à fadiga segundo a norma API 17E com 30.000 ciclos de carga e outras 
três que tinham sido submetidas à fadiga uniaxial à tração de $30.000,10.000 \mathrm{e}$ 100.000 ciclos de carga.

Os corpos-de-prova empregados foram do tipo placa com $13 \mathrm{~mm}$ de largura e 18 $\mathrm{mm}$ de comprimento, a espessura foi a mesma da camada polimérico externa do cabo $5 \mathrm{~mm}$. Estes foram cortados com uma serra manual, o acabamento das superfícies originadas pelo corte foi feito com papel de lixa fina. As operações de corte e lixado foram realizadas de forma cuidadosa e lenta o bastante para que o material não sofresse um aquecimento considerável que mudaria suas propriedades originais.

Foram confeccionados 15 corpos-de-prova, três a partir da amostra de HDPE retiradas do cabo sem uso, três da amostra tirada da seção de cabo que foi submetida a 30.000 ciclos de carga segundo a norma API 17E. Os outros nove espécimes foram feitos com as amostras do HDPE que tinham sido submetidos a fadiga à tração uniaxial. Deles, três tinham sido submetidos a 30.000 ciclos, três a 10.000 ciclos e três a 100.000 ciclos.

Como seriam ensaiadas a absorção varias amostras de HDPE, com o intuito de comparar os resultados, antes da imersão, os espécimes foram submetidos a um processo de dessecagem (recomendado pela norma ASTM D 570) por um período de $24 \mathrm{~h}$ a uma temperatura de $50^{\circ} \mathrm{C}$ numa câmara térmica. Posteriormente, os espécimes foram resfriados e imediatamente pesados numa balança analítica (Ohaus AP250D) capaz de medir com uma precisão de 0,1 mg.

Os espécimes já dessecados foram imersos completamente numa cuba de cristal que continha água destilada (segundo a norma ASTM D 570) por um período de 24 h. A temperatura da água manteve-se em $23^{\circ} \mathrm{C}$ durante o período de imersão.

Ao término das $24 \mathrm{~h}$, os corpos-de-prova foram tirados da água. Em seguida com um pano, foram secas as superfície de cada espécime e imediatamente foram pesados na balança analítica (Ohaus AP250D).

Após ter os pesos das diferentes amostras de HDPE, antes e depois da imersão, procedeu-se a estimar a proporção de água absorvida. Conseguiu-se isto mediante o cálculo do incremento percentual da massa a partir da eq.(3.12). 
$\mathrm{Na}$ Figura 4.22, mostra-se duas foto do arranjo experimental usado no ensaio de absorção de água no HDPE: a, cuba de cristal com água destilada e corpos-deprova; $b$, corpos-de-prova imersos na água.
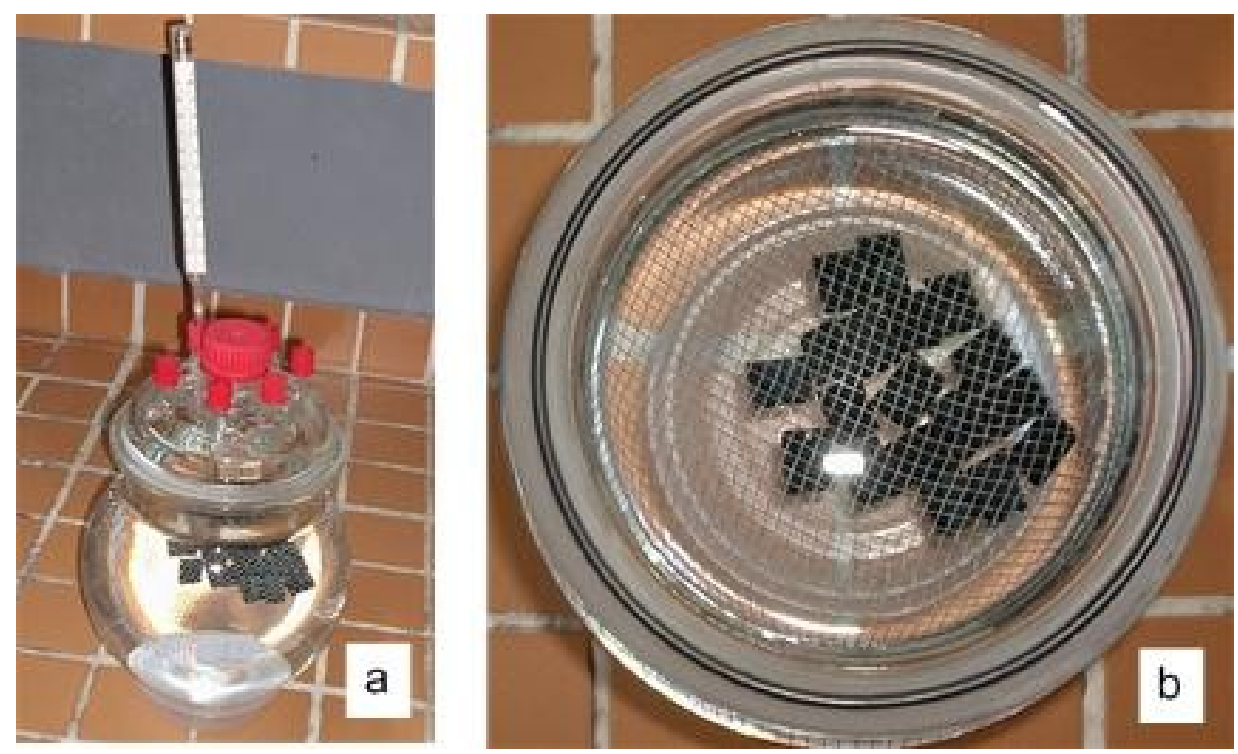

Figura 4.22 - Fotos do arranjo usado no ensaio de absorção de água: a, cuba de cristal com água destilada e corpos-de-prova; b, corpos-de-prova imersos na água

\subsubsection{Resultados do ensaio de absorção de água no HDPE}

$\mathrm{Na}$ Tabela 4.11 são apresentados os resultados obtidos no ensaio de absorção de água no HDPE feito segundo a norma ASTM D 570 e na Figura 4.23 pode-se apreciar a relação existente entre o número de carregamentos cíclicos aplicados ao HDPE e a quantidade de água absorvida por este.

Após analisar os resultados dos ensaios de absorção pode-se apreciar que com o aumento dos carregamentos cíclicos aumenta o volume de água absorvida pelo HDPE que compõe a camada externa do cabo umbilical. Isto devido ao fenômeno que acontece nos polímeros semi-cristalinos quando são submetidos a carregamentos cíclicos. O dano acontece pela deformação do esferulito, seguido por uma transformação do esferulito em fibrilhas que são subsequentemente alongadas (KAMBOUR, 1973; BOWDEN, YOUNG, 1974; PERKINS, PORTER, 1977). 
Tabela 4.11 - Resultados dos ensaios de absorção de água no HDPE

\begin{tabular}{|c|c|c|c|c|c|c|}
\hline \multicolumn{2}{|c|}{ Tipo de amostra } & No. & $\begin{array}{c}\text { Peso } \\
\text { Seco }(g)\end{array}$ & $\begin{array}{l}\text { Peso Úmido } \\
\text { (g) }\end{array}$ & $\begin{array}{c}\text { Variação da } \\
\text { massa (\%) }\end{array}$ & $\begin{array}{l}\text { Desvio } \\
\text { Padrão }\end{array}$ \\
\hline \multirow{4}{*}{\multicolumn{2}{|c|}{$\begin{array}{l}\text { Retirada do cabo } \\
\text { sem uso }\end{array}$}} & 1 & 1,3078 & 1,3083 & 0,0382 & \\
\hline & & 2 & 1,2424 & 1,2428 & 0,0322 & \\
\hline & & 3 & 1,3551 & 1,3557 & 0,0443 & \\
\hline & & média & & & 0,0382 & 0,006 \\
\hline \multirow{4}{*}{\multicolumn{2}{|c|}{$\begin{array}{l}\text { Fadiga API 17E } \\
\text { (30.000 ciclos) }\end{array}$}} & 7 & 1,0788 & 1,0796 & 0,0742 & \\
\hline & & 8 & 0,9941 & 0,9950 & 0,0905 & \\
\hline & & 9 & 0,9551 & 0,9562 & 0,1152 & \\
\hline & & média & & & 0,0933 & 0,021 \\
\hline \multirow{12}{*}{$\begin{array}{c}\text { Fadiga } \\
\text { tração } \\
\text { uniaxial }\end{array}$} & \multirow{4}{*}{$\begin{array}{l}10.000 \\
\text { ciclos }\end{array}$} & 10 & 1,2201 & 1,2206 & 0,0410 & \\
\hline & & 11 & 1,0123 & 1,0127 & 0,0395 & \\
\hline & & 12 & 1,0933 & 1,0938 & 0,0457 & \\
\hline & & média & & & 0,0421 & 0,003 \\
\hline & \multirow{4}{*}{$\begin{array}{l}30.000 \\
\text { ciclos }\end{array}$} & 13 & 1,1545 & 1,1556 & 0,0953 & \\
\hline & & 14 & 1,2903 & 1,2915 & 0,0930 & \\
\hline & & 15 & 1,2897 & 1,2916 & 0,1473 & \\
\hline & & média & & & 0,1119 & 0,031 \\
\hline & \multirow{4}{*}{$\begin{array}{l}100000 \\
\text { ciclos }\end{array}$} & 16 & 1,2446 & 1,2466 & 0,1607 & \\
\hline & & 17 & 1,1668 & 1,1680 & 0,1028 & \\
\hline & & 18 & 1,2530 & 1,2550 & 0,1596 & \\
\hline & & média & & & 0,1411 & 0,033 \\
\hline
\end{tabular}

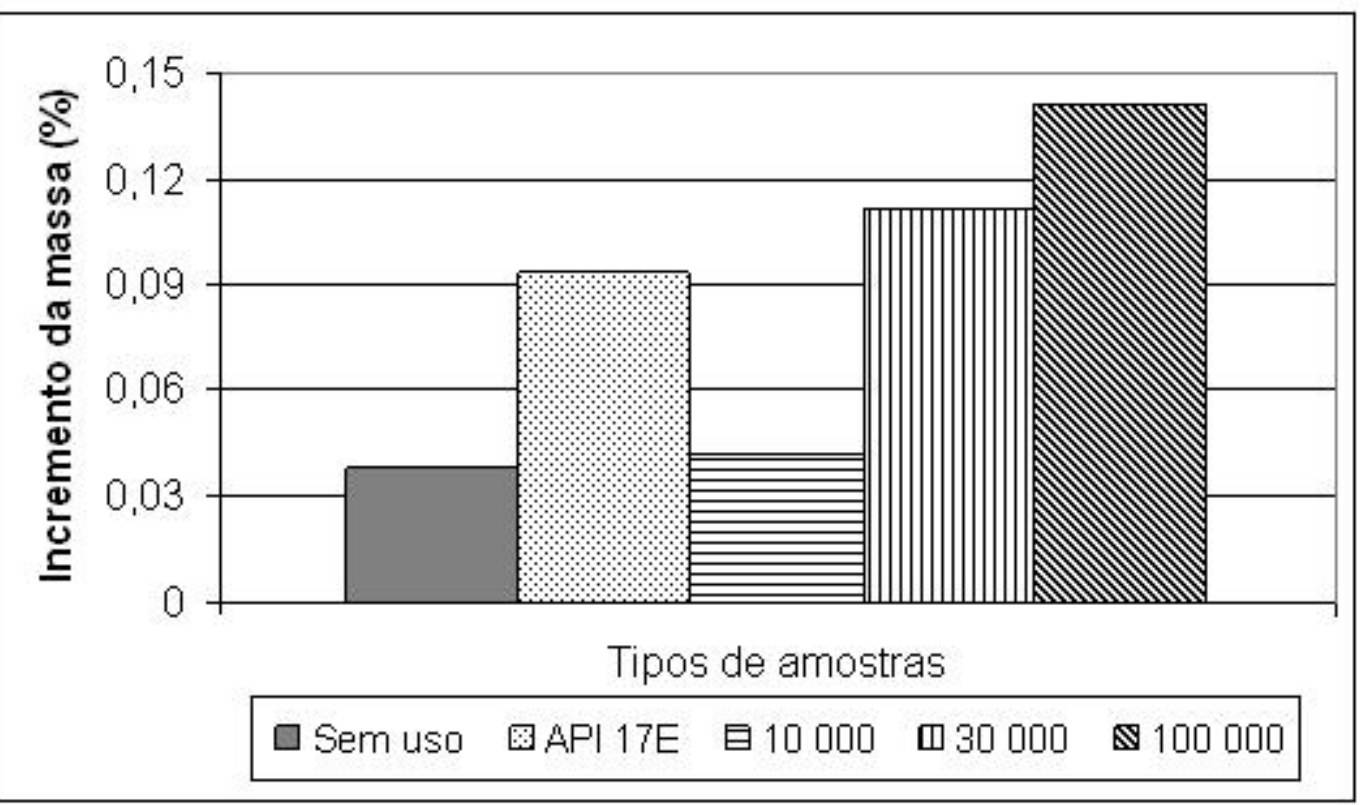

Figura 4.23 - Gráfico de colunas, número de carregamentos cíclicos aplicados versus incremento da massa do HDPE 
O dano inicial acontece por cavitação nas regiões interlamelares no interior do esferulito, primeiramente no plano equatorial perpendicular ao eixo das tensões aplicadas (KAUSCH, 1978; BRETZ, HERTZBERG, MANSON, 1981 KASAKEVICH, MOET; CHUDNOVSKY, 1990). A grande facilidade com que a água penetra nestas cavidades indica que estas devem estar interconectadas (CANEVAROLO, 2002).

O volume de água absorvida aumenta 2,4 vezes no HDPE que foi submetido a 30.000 ciclos de carga no ensaio de fadiga segundo a norma API 17E, com relação ao HDPE retirado do cabo sem uso. Para o HDPE que foi submetido a 30.000 ciclos de fadiga à tração uniaxial o volume de água absorvido aumenta 2,9 vezes. Esta diferença na absorção de água é originada pelos diferentes estados tensionais provocados no material da camada polimérica externa do umbilical durante os dois tipos de testes de fadiga feitos.

Durante a execução do ensaio de fadiga do cabo umbilical segundo a norma API 17E, quando o umbilical é submetido a carregamentos cíclicos $(F)$ seu comprimento aumenta e o diâmetro exterior da sua seção transversal diminui, provocando um estado de tensões biaxiais na camada polimérica externa do cabo que devido a sua geometria comporta-se como uma casca fina como mostra a Figura 4.24a. Durante os carregamentos cíclicos no estado de tensões biaxiais, baixo a condição $\lambda=-1$ $\left(\lambda=\sigma_{2} / \sigma_{1}, \sigma_{1}>0, \sigma_{2}<0\right)$ os micro defeitos e micro cavidades do HDPE ao mesmo tempo em que são abertas pelas tensões longitudinais de tração $\left(\sigma_{1}\right)$, também são fechadas pelas tensões transversais de compressão $\left(\sigma_{2}\right)$ provocada pela diminuição do diâmetro da seção transversal do umbilical.

Algo diferente acontece no ensaio de fadiga à tração uniaxial do HDPE, no qual o polímero fica submetido a um estado tensional uniaxial de tração, sob a condição $\lambda=0\left(\sigma_{1}>0, \sigma_{2}=0\right)$, como mostra a Figura 4.24b. Neste caso, quando o polímero é submetido à fadiga a tração uniaxial os micro defeitos e micro cavidades se abrem com os carregamentos cíclicos uniaxiais. 


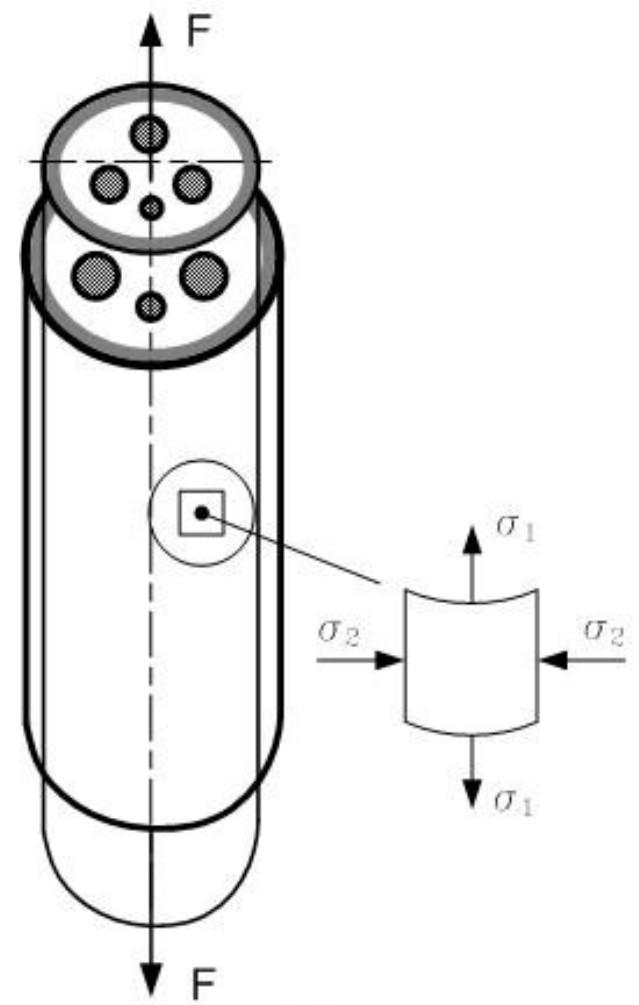

(a)

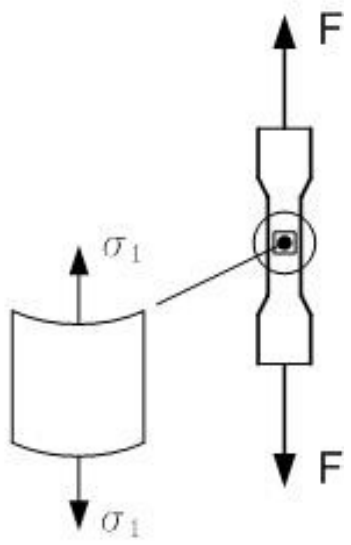

(b)

Figura 4.24 - Representação esquemática dos estados tensionais a que é submetida a camada polimérica externa do cabo umbilical nos ensaios de fadiga: a, segundo norma API 17E; b, tração uniaxial.

Analisando os resultados dos ensaios de absorção de água pode-se perceber que o polímero usado para elaborar a camada externa do cabo pode por em risco sua vida de projeto devido à perda da impermeabilidade do HDPE que permitiria a penetração da água do mar no cabo.

\subsection{ESTIMATIVA DO DANO PROVOCADO PELOS CARREGAMENTOS CÍCLICOS NO HDPE DA CAMADA POLIMÉRICA EXTERNA DO CABO UMBILICAL}

Para fazer a estimativa do dano provocado pelos carregamentos cíclicos sobre a microestrutura do HDPE que compõe a camada externa do cabo, serão usados os dados obtidos no ensaio de absorção feito segundo a ASTM D 570, Tabela 4.11. O dano será calculado a partir do incremento percentual da massa $\left(I_{m}\right)$ das amostras de HDPE após a imersão. A quantidade de água absorvida nos dará o grau de 
deterioração da microestrutura da camada polimérica externa do cabo umbilical. Para determinar o dano será usada a eq.(3.13).

Substituindo os valores de incremento da massa do HDPE retirado do cabo sem uso $\left(I_{m s u}\right)$ e incremento da massa do material danificado $\left(I_{m D}\right)$ na eq.(3.13) são obtidos os danos provocados pelos carregamentos cíclicos no HDPE da camada externa do cabo umbilical. Na Tabela 4.12 apresenta-se os valores de danos obtidos.

Tabela 4.12 - Valores de dano provocado pelos carregamentos cíclicos no HDPE da camada externa do cabo umbilical

\begin{tabular}{llc}
\hline Tipo de amostra & & Dano acumulado \\
\hline Fadiga API 17E & 30.000 ciclos & 0,59 \\
\hline \multirow{2}{*}{$\begin{array}{l}\text { Fadiga à tração } \\
\text { uniaxial }\end{array}$} & 10.000 ciclos & 0,09 \\
\cline { 2 - 3 } & 30.000 ciclos & 0,66 \\
\cline { 2 - 3 } & 100.000 ciclos & 0,73 \\
\hline
\end{tabular}

$\mathrm{Na}$ Figura 4.25, são apresentados graficamente os valores de dano provocados pelos carregamentos cíclicos nos ensaios de fadiga realizados.

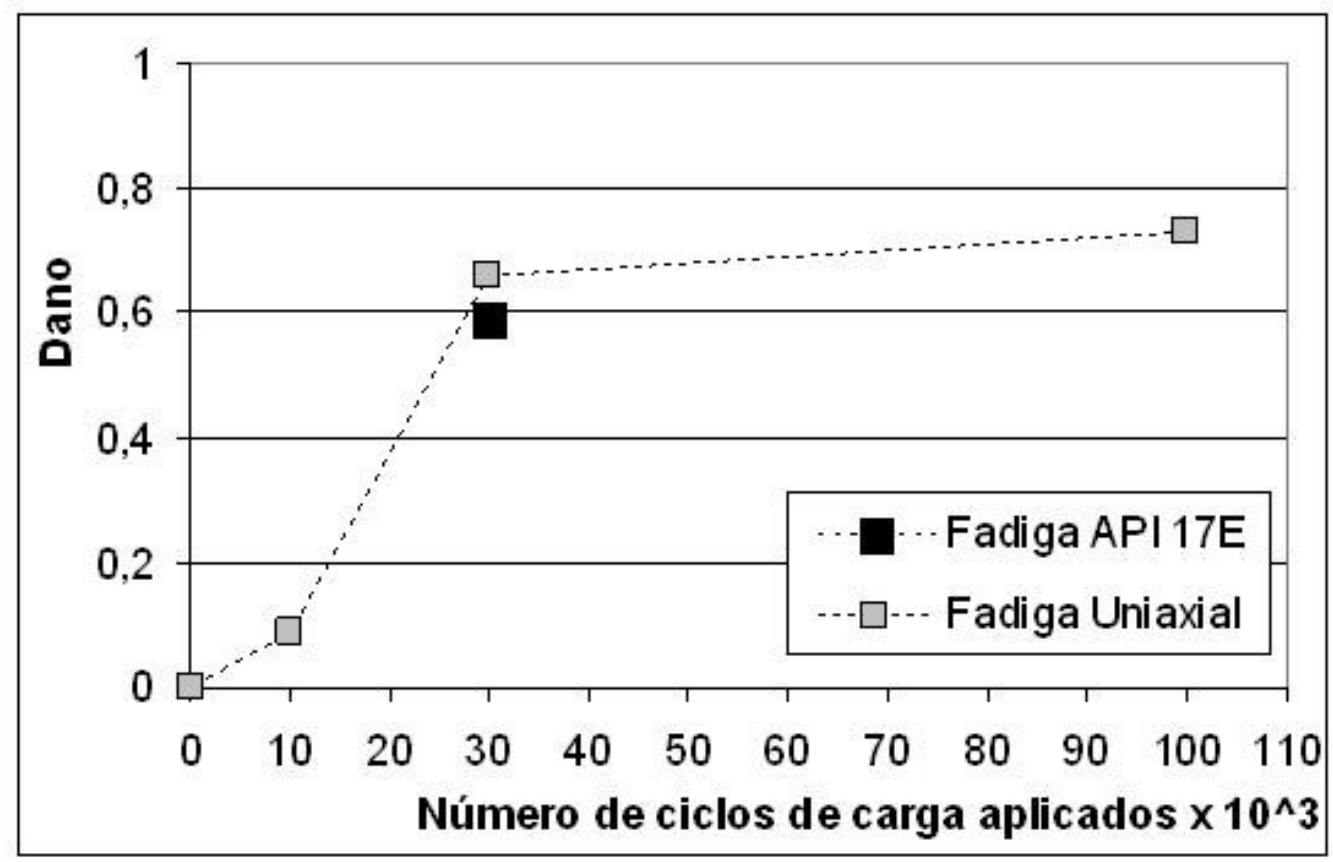

Figura 4.25 - Representação gráfica dos valores de dano provocados pelos carregamentos cíclicos nos ensaios de fadiga realizados 
Comparando os valores de dano obtidos para as diferentes amostras de HDPE que foram ensaiados à fadiga segundo a norma API 17E e à fadiga uniaxial a tração, aprecia-se que com o aumento do número de ciclos aplicado ao polímero, aumenta o dano na microestrutura do material e que este dano não tem um comportamento linear. Até os 10.000 ciclos aplicados o dano é bem leve $(D=0,09)$, já entre 10.000 e 30.000 ciclos aplicados percebe-se um brusco incremento de $\mathbf{D}$ até atingir um valor de 0,59 para o ensaio feito segundo a API 17E é de 0,66 para o polímero submetido à fadiga a tração uniaxial. Esta diferença de valores de $\mathbf{D}$ provocada pela diferença de estados tensionais biaxiais e uniaxiais originadas pelas diferentes condições dos ensaios de fadiga explicados no item 4.5.1. A partir dos 30.000 e até os 100.000 ciclos de carga aplicados no polímero o valor do dano aumenta pouco até atingir um valor de 0,73 .

Após do cálculo do dano, e com todos os outros resultados obtidos nas diferentes etapas da metodologia proposta, pode-se afirmar que a camada polimérica externa do cabo umbilical estudado sofreu um grande nível de degradação, provocado isto pelos carregamentos cíclicos e o envelhecimento a que foram submetidos. Comprovou-se isto durantes os testes de absorção de água, tração e microscopia eletrônica de varredura. 


\section{CONCLUSÕES E RECOMENDAÇÕES}

\subsection{Conclusões}

Após desenvolvimento deste estudo as seguintes conclusões podem ser inferidas.

i) A partir de um ensaio de absorção de água e utilizando como variável de controle a massa, pode-se quantificar o dano provocado pelos carregamentos cíclicos na microestrutura de um material polimérico.

ii) A falha da camada polimérica externa do cabo não acontece pela fratura devido à fadiga mecânica e sim pela perda da impermeabilidade desta, provocada pelos carregamentos cíclicos e o meio marinho.

iii) O método proposto garante que o polímero usado na elaboração da camada polimérica externa do cabo umbilical colabore com a integridade estrutural deste, não permitindo a penetração da água no cabo.

iv) Com o ensaio de fadiga à tração uniaxial do polímero que compõe a camada externa do umbilical é possível criar um dano similar ao originado na camada polimérica externa do cabo ensaiado a fadiga segundo a norma API 17E.

v) Dos agentes degradantes do ambiente oceânico no qual trabalha o cabo umbilical (carregamentos cíclicos, radiação ultravioleta e água salgada) os carregamentos cíclicos são os que mais dano causam nas propriedades da camada polimérica externa, e quando todos atuam simultaneamente os efeitos degradantes são amplificados.

vi) Além dos ensaios de absorção de água e de tração, as observações no microscópio auxiliam a caracterização do dano provocado na microestrutura superficial da camada polimérica externa do cabo, pelos carregamentos cíclicos e o meio marinho.

vii)Ensaios de dureza convencional não são adequados para caracterizar a degradação da camada polimérica externa dos cabos umbilicais provocada pelos carregamentos cíclicos e o meio marinho. 
Os resultados obtidos neste trabalho tornaram possível aprofundar os conhecimentos sobre a influência da fadiga mecânica e do meio marinho sobre as propriedades dos polímeros que compõe a camada externa dos cabos umbilicais, possibilitando avaliar a confiabilidade destes materiais para uso em estruturas oceânicas. 


\subsection{Recomendações}

Neste estudo foi estabelecido um critério de falha da camada polimérica externa dos cabos umbilicais, nele comprovou-se a influência dos carregamentos cíclicos e os diferentes agentes do meio marinho sob as propriedades e a microestrutura superficial do polímero que compõe a camada externa do cabo umbilical. Para próximos trabalhos recomenda-se:

i) Fazer ensaio de fadiga uniaxial à tração do material da camada polimérica externa do cabo simultaneamente com o ensaio de envelhecimento do material.

ii) No ensaio de envelhecimento incluindo o contato do oxigênio com o polímero da camada externa do cabo, poderia conseguir-se isto adicionando um agitador ao dispositivo experimental para simular a movimentação das ondas marinhas.

iii) Realização de ensaio de envelhecimento e de absorção de água sob pressão compatível à utilização do cabo.

iv) Estudar o fenômeno de difusão da água através da espessura da camada polimérica dos cabos umbilicais antes e após dos carregamentos cíclicos.

v) Usando o Método dos Elementos Finitos determinar as tensões e deformações longitudinais e circunferências durante a tração e flexão do cabo no ensaio de fadiga feito segundo a norma API 17E, e comparar estes com os valores de tensão e deformação aplicados ao polímero durante o ensaio de fadiga à tração uniaxial. 


\section{REFERÊNCIAS BIBLIOGRÁFICAS}

ALMEIDA, P. A. O. Introdução à extensômetria elétrica de resistência. São Paulo: EPUSP, 1996. 18 p. Apostila para disciplina de pós-graduação do Departamento de engenharia de estruturas e fundações, PEF - 5003 - Análise Experimental de Tensões.

ALVES, T. M. J.; COSTA, L. C. S. Resistência residual de linhas flexíveis com defeitos naturais. Rio de Janeiro, Bol. Téc. PETROBRAS, v. 44, n. 14, p. 60-74, 2001.

ANDERSON, T. L., Fracture mechanic: fundamentals and applications. Boca Raton: 2 ed. CRC Press LLC. 1995. 688 p.

ANDRADY, A. L.; HAMID, S. H.; HU, X.; TORIKAI, A. Effects of increased solar ultraviolet radiation on materials. J. Photoch. Photob. B: Bio. v. 46. p.96-103. 1998.

ANDREWS, E. H. Testing of polymers. New York: Wiley Interscience. 1969. 237 p.

ANDREWS, E. H.; REED, P. E. Molecular fracture in polymers. Advan. Polym. Scien. v. 27, p. 1-66, 1978.

ANDREWS, E. H.; WALKER, B. J. Fatigue fracture in polyethylene. Proceedings of the Royal Society of London. Series A, Mathem. Phys. Scien. v. 325, n. 1560, p. 57-79, 1971.

ARGON, A. S., The role of heterogeneities in fracture. Philadelphia, ASTM STP 1020, p. 127-128, 1989.

BARENBLATT, G. I., The mathematical theory of equilibrium cracks in brittle fracture. Advan. App. Mech., v. 7, p. 55-129, 1962.

BLASS, A. Processamento de polímeros. Florianópolis: Santa Catarina: ed. UFSC, 1988. 313 p.

BOWDEN, P. B.; YOUNG, R. J. Deformation mechanisms in crystalline polymers. J. Mater. Sci. v. 9, n. 12, p. 2034-2051, 1974.

BRETZ, P. E., HERTZBERG. R. W., MANSON, J. A. Mechanisms of fatigue damage and fracture in semi-crystalline polymers. Polymer, v. 22, p. 1272-1278, 1981.

BROWN, R. P. Handbook of plastic test methods. London: 3 ed. Logman Scientific \& Technical, 1988. $442 \mathrm{p}$.

BUREAU, M. N.; DICKSON, J. I.; DENAULT, J. Comparison of fatigue propagation behavior of polystyrene and 95/5/polyethylene blends. J. Mater. Scien., v. 33, n. 6, p. 1591-1606, 1998. 
BUREAU, M. N.; DICKSON, J. I.; DENAULT, J. Fatigue propagation behavior of polystyrene/polyethylene blends. J. Mater. Scien., v. 33, n. 6, p.1405-1419, 1998.

CALLISTER, W. D. Materials science and engineering: An introduction. New York: John Wiley \& Sons, 1997. $852 \mathrm{p}$.

CANEVAROLO Jr, S. V. Ciência dos polímeros: um texto básico para tecnólogos e engenheiros. São Paulo: Artliber Editora, 2002. 183 p.

CÁRDENAS, N. O., GONÇALVES, E. Influência das Cargas Cíclicas no Comportamento Mecânico das Camadas Poliméricas dos Cabos Submarinos. IV Encuentro de Ingeniería de Materiales (Materiales 2002), Ciudad de la Habana, Cuba, 2002

CÁRDENAS, N. O. Análise da influência dos carregamentos cíclicos sobre o comportamento mecânico das camadas poliméricas de cabos submarinos eletro ópticos. 2002. 108 p. Dissertação (Mestrado) - Escola Politécnica, Universidade de São Paulo, São Paulo, 2002.

CÁRDENAS, N. O., GONÇALVES, E. Análise do Comportamento Mecânico das Camadas Poliméricas de Cabos Submarinos Após de Submetidos à Fadiga. Boletim Técnico da Escola Politécnica da USP, Departamento de Engenharia Mecatrônica e de Sistemas Mecânicos, BT/PMR/0306, São Paulo, 2002.

CÁRDENAS, N. O., GONÇALVES, E. Mechanical behavior analysis of the high density polyethylene after been submitted to cyclic loading, 17th. International Congress of Mechanical Engineering COBEM 2003. São Paulo, 2003.

CÁRDENAS, N. O., GONÇALVES, E. Influência das deformações cíclicas no comportamento mecânico das camadas poliméricas dos cabos submarinos. III Congresso Nacional de Engenharia Mecânica (CONEM 2004), Belém, 2004.

CÁRDENAS, N. O.; GONÇALVES, E.; SUÑÉ, D. C.; VALIN, J. L. R. Caracterização do estado tenso-deformacional da camada polimérica externa de um cabo umbilical. XIII Convención Científica de Ingeniería y Arquitectura, Ciudad de La Habana, Cuba. p. 29. 2006.

CÁRDENAS, N. O.; MACHADO, I. F.; GONÇALVES, E. Cyclic loading and marine environment effects on the properties of HDPE umbilical cables. J. Mater. Sci. v. 42. n. 16, p. 6935-6941, 2007.

CASALE, A.; PORTER. R. S. Polymer stress reactions, v. 1: Introduction. New York. Academic Press. 1978. 118 p.

CASTELEIN, G.; COULON, G.; G'SELL, C. Polymers under mechanical stress: Deformation of the nanostructure of isostatic polypropylene revealed by scanning force microscopy. Polym. Eng. Sci., v. 37, n.10, p.1694-1701, 1997. 
CLARK, D. T.; MUNRO, H. S. Some surface aspects of the photo-oxidation of polystyrene films as revealed by ESCA: Part II-Irradiations in air, Polym. Degrad. Stab., v. 9, n. 2, p. 63-71, 1984.

DALLY, J. W.; RILEY, F. W. Experimental stress analysis. New York: 2ed. McGrawHill book Company. 1978. $571 \mathrm{p}$.

DAVIS, A.; SIMS, D. Weathering of polymers. 1ed. London. Applied Science Publishers Ltd. 1983. 294p.

DEVRIES, K. L., ROYLANCE, D. K., WILLIAMS, M. L. An experimental investigation of some models of polymer fracture. Int. J. Fract. Mech. v.7, n. 2, p. 197-202, 1971.

DOAK, K. W. et. al. Encyclopedia of polymer science and engineering. New York: John-Wiley \& Sons, v. 6, 1986.

DUGDALE, D. S., Yielding in steel sheets containing slits. J. Mec. Phisic. Solids. v. 8, n. 2, p. 100-104, 1960.

E'LDAROV, E. G.; MAMEDOV, F. V., GOLD'BERG, V. M.; ZAIKOV, G. E. A kinetic model of polymer degradation during extrusion. Polym. Degrad. Stab. v. 9, p. 271, 1996.

FAULKNER, D. L. Effects of high oxygen pressure and temperature on the aging of polypropylene. Polym. Eng. Scien. v. 22, n. 8, p.466-471, 1982.

FELD, G. et al. Mechanical behaviour of the metallic elements of submarine cables as a function of cable loading. Eng. Struct. v. 17, n. 4, p. 240-253, 1995.

FLORY, P. J. Principles of polymer chemistry. New York: Cornell Univers. Press, Ithaca, 1953. $688 \mathrm{p}$.

FUCHS, H. O.; STEPHENS, R. I. Metal fatigue in engineering. New York: John Wiley \& Sons, 1980. $318 \mathrm{p}$.

FUKU, T. et al. Fatigue properties and analysis of flexible risers. $24^{\text {th }}$ Offshore Technology Conference, Houston, p. 35-44, 1992.

GRIFFITH, A. A. The phenomena of rupture and flow in solids. Phil. Trans. Roy. Soc. v. 221 , p. $163-198,1920$.

GUGUMUS, F. Light stabilizers. In: GÄCHTER, R; MÜLLER, H. (Ed.). Plastics additives handbook. Munique: Hanser, p. 129-270,1990.

GUGUMUS, F. Physico-chemical aspects of polyethylene processing in na open mixer 5. Kinetics of hydroperoxide formation. Polym. Degrad. Stab. v.68, p. 327, 2000. 
GUILLET, J. Stabilization and degradation of polymers. ACS Advances in Chemistry Series 169. Washington DC: ACS, 1978.

GUILLET J. Degradable polymers principles \& applications. London: Chapman \& Hall; 1995. 500 p.

HAMID, S. H.; AMIN, M. B. Lifetime prediction of polymers .J. Appl. Polym. Scien. v. 55, n. 10, p. 1385-1394, 1995.

HARPER, CH. A. Handbook of plastics, elastomers, and composites. New York: 2.ed. Mc Graw-Hill, Inc, 1992. 848 p.

HERTZBERG, R. W.; MANSON, J. A. Fatigue of engineering plastic. New York: 1.ed. Academic Press, 1980. 295 p.

HIBBELER, R. C. Mechanics of materials. New Jersey: 1.ed. Prentice Hall, 2003. $848 p$.

HILTON, P. D. Plastic intensity factors for cracked plates subjected to biaxial loading. Int. J. Fract. n. 9, p. 149-156, 1973.

HINSKEN, H.; MOSS, S.; PAUQUET, J.; ZWEIFEL, H. Degradation of polyolefins during melt processing. Polym. Degrad. Stab. v. 34. n 1-3, p. 279-293,1991.

HOLMSTRÖM, A.; SÖRVIK, E. M. Thermooxidative degradation of polyethylene. I and II. Structural changes occurring in low density polyethylene, high density polyethylene and tetratetracontane heated in air. J. Polym. Scien. Chem. v. 16, p. 2555, 1978.

IRWIN, G. R. Structural aspects of brittle fracture. Appl. Mater. Res. v. 3, p.65-81, 1964.

ISHI, K. et al. Flexible riser technology for deep water. Applications. $27^{\text {th }}$ Offshore Technology Conference, Houston, p. 327-334, 1995.

KACHANOV, L. M. Introduction to continuum damage mechanics. Dordrecht. Martinus Nijhoff Publishers. 1986. 135 p.

KAMBOUR, R. P, A review of crazing and fracture in thermoplastics, Macromol. Rev. v. 7, n. 1, 1973.

KASAKEVICH, M. L.; MOET, A.; CHUDNOVSKY, A. Comparative crack layer analysis of fatigue and creep crack propagation in high density polyethylene. Polymer, v. 31, p. 435-439, 1990.

KASAKEVICH, M. L.; MOET, A.; CHUDNOVSKY, A. A crack layer approach to fatigue crack propagation in high density polyethylene J. Appl. Pol. Scien. v. 39, p. 395-413, 1990. 
KAUSCH, H. H. Polymer fracture. Polymers Properties and Aplications. v. 2, New York: Springer Verlag. 1978. 332 p.

KELEN,T. Methods of studying polymer degradation. New York: 1.ed. Nostrand Reinhold Company.1983.

KINLOCH, A. J.; YOUNG, R. J. Fracture behavior of polymers. London: ed. Chapman \& Hall, 1983. 496p.

KOCKOTT, D. Adjustment and control of weathering conditions in accelerated tests of polymer materials for better correlation. Angew. Makrom. Chem. v. 137, p. 1-13, 1985.

KOMITOV. P., KOTOV. G., STANCHEV, S. Ageing of LDPE: Structural changes Polymer Degradation and Stability. Pol. Deg. Stab. v. 24. p. 303-312, 1989.

KHRAISHI, N.; A. AL-ROBAIDI, A. Effect of weathering on UV-stabilized low density polyethylene films (LDPE) for a multilayer greenhouse cover. Polym. Degrad. Stab. v. 32, p. 105-114. 1991.

KURTZ, S. et al.. The yielding, plastic flow, and fracture behavior of ultra-high molecular weight polyethylene used in total joint replacements. Biomaterials, $v 19, p$ 1998-2003, 1998.

LEGALLAIS, L. et al. A new generation of umbilical house: field drilling and development system. Proceedings, Annual Offshore Technology Conference, Houston, v. 4, p. 115-123, 1993.

LEMAITRE, J. A course on damage mechanics. Berlin: 2.ed Springer; 1996. 228 p.

LEMAITRE, J.; DESMORAT, R. Engineering Damage Mechanics. Netherlands: ed. Springer, 2005. $380 \mathrm{p}$.

LÉPORE, P. F. Implantação de um procedimento de projeto estrutural e homologação de umbilicais. 2003. 200 p. Tese (Doutorado) - Escola Politécnica, Universidade de São Paulo, São Paulo, 2003.

LÉPORE, P. F.; BUELTA, M. A. M. Fatigue testing, experimental and numeric studies of electro-optical flexible pipes (Umbilicals). Materials Research, p. 1-19, 2007.

LIN, L.; ARGON, A. S. Review structure and plastic deformation of polyethylene. J. Mater. Scien. v. 29, p. 294-323, 1994.

LIU, K.; PIGGOTT, R. Fracture failure processes in polymers In: Mechanical tests and results. Polym. Eng. Scien. v.38, n.1, p.60-68, 1998.

MANDELKERN L, ALAMO RG, KENNEDY MA. Macromolecules. v. 23, p.472. 1990.

MANO, E. B. Introdução a polímeros. São Paulo: Edgard Blucher, 1985. 111p. 
MANO, E. B. Polímeros como materiais de engenharia. São Paulo: ed. Edgard Blucher, 1991. 197 p.

MASCIA, L. Thermoplastic: Materials engineering. London: 2ed. Elsevier, 1989. $550 p$.

MASSA, F.; PIQUES, R.; LAURENT, A rapid crack propagation in polyethylene pipe: combined effect of strain rate and temperature on fracture toughness. J. Mater. Scien, v.32, n.24, p.6583-6587, 1997.

MEYER, R. W.; PRUITT, L. A. The effect of cyclic true strain on the morphology, structure, and relaxation behavior of ultra high molecular weight polyethylene. Polymers, v.42, p. 5293-5306, 2001.

MILLS, M. J. Dugdale yielding zones in cracked sheets of glassy polymers. Eng. Fract. Mec. E.U.A, v.6, n.6, p. 537-549, 1974.

NIELSEN, L. Mechanical properties of polymers. New York: ed. Van Nostrand Reinhold, 1962. 274 p.

NIELSEN, L.; LANDEL, R. F. Mechanical properties of polymers and composites. New York: 2.ed. M. Dekker, 1994. 557 p.

OXBOROUGH, R. J.; BOWDEN, P. B.; A general critical strain criterion for crazing in amorphous glassy polymers. Philos. Magaz. v. 28, p. 547-559, 1973.

PATEL, M. H.; SEYED, F. B. Review of flexible riser modelling and analysis techniques. Eng. Struct. v. 17, n. 4, p. 293-304, 1995.

PEGORETTI, A.; MARCHI, A.; RICCO, T. Determination of the fracture toughness of thermoformed polypropylene cups by the essential work method. Polym. Eng. Scien. v.37, n.6, p. 1045-1052, 1997.

PEGRAM, J. E.; ANDRADY. A. L. Outdoor weathering of selected polymeric materials under marine exposure conditions. Polym. Degrad. Stab. v. 26, p. 333345,1989 .

PERKINS, W. G.; PORTER, R. S. Solid-state deformation of polyethylene and nylon and its effects on their structure and morphology. J. Mater. Scien., v. 12, n. 12, p. 2355-2388, 1977.

PETROBRAS, 2006. <http://www.petrobras.com.br>. Acesso em: 12 dez. 2006.

PINHEIRO, L. A.; CHINELATTO, M. A.; CANEVAROLO, S. V. Evaluation of Philips and Zieglere-Natta high-density polyethylene degradation during processing in an internal mixer using the chain scission and branching distribution function analysis. Polym. Degrad. Stab. v. 91. p. 2324, 2006. 
PINHEIRO, L. A.; CHINELATTO, M. A.; CANEVAROLO, S. V. The role of chain scission and chain branching in high density polyethylene during thermo-mechanical degradation. Polym. Degrad. Stab. v. 86, p. 445, 2004.

PIRELLI CABOS. Submarine Electrical and Optical Power Umbilical. Data Sheet. São Paulo, 2000. 8p.

PIRELLI CABOS 2004. <http://www.pirelli.com.br> Acesso em: 3 out. 2004.

PISSARENKO, G. S.; IAKOVLEV, A. P.; MATVEIEV, V.V. Prontuário de resistência de materiais. Moscou: 2.ed. Mir, 1985. 682 p.

POPOV, E. P. Introdução à mecânica dos sólidos. São Paulo: Edgard Blucher, 1978. $534 \mathrm{p}$.

QUINTELA, J.P.; ALVES, T. M. J. Corrosão atmosférica em linhas flexíveis causadas por danos na camada plástica externa. Bol. Téc. PETROBRAS, Rio de Janeiro, v.45, n. 1, p. 6-15, 2002.

QURESHI. F. S.; AMIN, M. B. MAADHAH, A. G.; HAMID, S. H. Weather induced degradation of linear low density polyethylene: mechanical properties. J. Polym. Eng. v. 9, p. 67-84, 1990.

RABONAVITCH, E. B.; QUEENSBERRY, J. G.; SUMMERS, J. W. Predicting heat build up due to suns energy. J. Vinyl. Technol. v. 5, p. 110, 1983.

RAYMOND, S. Polymers for engineering applications. Washington: ed. ASM International, 1991. 198 p.

RASHEED, H.; TASSOULA, L. Strength evaluation of composite risers. $27^{\text {th }}$ Offshore Technology Conference, Houston, p. 215-222, 1995.

RICETTI, E. M.; BITTENCOURT, J. N. Introdução aos conceitos básicos da mecânica da fratura elasto-plástica. Boletim Técnico da EPUSP, 1998.

RIDEAL, G. R.; PADGET, J. C. The thermal-mechanical degradation of high density polyethylene. J. Polym. Scien: Polym. Symp. v. 57, p. 1, 1976.

RIDDELL, M. N. A guide to better testing of plastics. Plast. Eng. v. 30, n. 4, p.71-78, 1974.

ROSA, D.S.; ANGELINI, J. M. G.; AGNELLI, J. A. M.; MEI, L. H. I. The use of optical microscopy to follow the degradation of isotactic polypropylene (iPP) subjected to natural and accelerated ageing. Polym. Test. v. 24, n. 8, p. 1022-1026, 2005.

ROYLANCE, D. Mechanics of materials. New York: ed. John Wiley \& Sons, Inc. 1996. 315 p.

ROY, P.K. et al. Effect of benzil and cobalt stearate on the aging of low-density polyethylene films. Polym. Degrad. Stab. v. 90, p. 577-585, 2005. 
SAEVIK, S.; BERGE, S. Fatigue testing and theoretical studies of two 4 in flexible pipes. Eng. Struc. v. 17, n. 4, p. 276-292, 1995.

SAMPERS. J. Importance of weathering factors other than UV radiation and temperature in outdoor exposure. Polym. Degrad. Stab. v. 76. p. 455, 2002.

SCHIERS, J., BIGGER, S. W., DELATYCKI; O., J. Poly. Sci., Polim. Phys. ED, v 29, p. $795,1991$.

SCHIOZER, D. J. Pesquisa na área de petróleo no Brasil. ABCM engenharia. v. 10, n. 1, p. 4-6, 2005.

SCHNABEL W. Polymer degradation. Principles and practical applications. New York: Hanser International, 1981.

SCHOOLENBERG, G. E. A fracture mechanics approach to the effects of UVdegradation on polypropylene. J.Mat. Scien. v. 23, n. 5. p. 1580-1590, 1988.

SCOTT, G. Ultraviolet light induced reactions. Polymers ACS Symposium Series 25. Washington DC: ACS, 1976.

SEHANOBISH, K.; MOET, A.; CHUDNOVSKY, A. Crack layer analysis of nonmonotonic fatigue crack propagation in high density polyethylene. Polymer, v. 28, p. 1315-1320, 1987.

SEARLE, N. D. Accelerated and outdoor durability testing of organic materials, ASTM STP 1202. Philadelphia: p. 52, 1994.

SEARLE, N. Z.; SEARLE, R. C. Hirt, Bibliography on ultraviolet degradation and stabilization of plastics, Pol. Engin. Scien. v. 1, n. 2, p. 32-54, 2004.

SIH, G. C. Handbook of stress intensity factors for researchers and engineers. Bethlehem: Lehigh Univ., 1973.

SMITH, E. W.; PASCOE. K. J. The behaviour of fatigue cracks subject to applied biaxial stress: a review of experimental evidence. Fat. Eng. Mater. Struct., v. 6, n. 3, p. 201-224, 1983.

SOUZA, S. A. Ensaios mecânicos de materiais metálicos. 5ed. São Paulo: Edgar Blucher, 1982. 286p.

SOUZA, A. P. F.; ET. AL. Colapso de dutos flexíveis sob pressão externa. Anais, 17으 Congresso Nacional de transportes maritimos e construção naval. SOBENA, CD ROM, 1998. 8 p.

SPARK, C. P. et al. Composite riser tubes: Defect tolerance assessment and nondestructive testing. $24^{\text {th }}$ Offshore Technology Conference, Houston, p. 191-198, 1992. 
SUAREZ, J. C. M.; MANO, E. B. Characterization of degradation on gammairradiated recycled polyethylene blends by scanning electron microscopy. Pol. Degrad. Stab, v. 72, p. 217-221, 2001.

SUAREZ, J. C. M.; MONTEIRO, E. E. C.; MANO, E. B. Study of the effect of gamma irradiation on polyolefins-low-density polyethylene. Pol. Degrad. Stab, v. 75, p. 143151, 2002.

SUH, N. P.; TURNER, P. L. Elements of the behavior of solid. Washington, D. C: McGraw-Hill, 1985. 615p.

SUÑÉ, D. C.; GONÇALVES, E.; CÁRDENAS, N. O.; VALIN, J. L. R. Caracterização mecânica e metalográfica das armaduras de tração de um cabo umbilical. XIII Convención Científica de Ingeniería y Arquitectura, Ciudad de La Habana, Cuba, p.30. 2006.

TAVARES, A. C.; GULMINE, J. V.; LEPIENSKI. C. M.; AKCELRUD, L. The effect of accelerated aging on the surface mechanical properties of polyethylene. Polym. Degrad. Stab. v. 81. p. 367-373. 2003.

TAYLOR, T. S.; JOOSTEN, M. W.; SMITH, F. Technical solutions applied for the treatment of damaged dynamic risers. In: Proceedings of 21st International conference on offshore mechanics and artic engineering, Oslo, OMAE 02, 2002. Disponível em: <www.zentech.co.uk> Acesso em: 12 ago. 2004.

TIMOSHENKO, S. P.; GOODIER, J. N. Theory of elasticity. New York: 3 ed. McGraw-Hill, 1970. 567 p.

TOBOLSKY, A. V. Properties and structures of polymers. New York: John Wiley \& Sons, 1960. $331 \mathrm{p}$.

TORRES, F. L. Análise estrutural de linhas flexíveis pelo método de elementos finitos. 1996. 68 p. Dissertação (Mestrado) - Escola Politécnica, Universidade de São Paulo, São Paulo, 1996.

TROINA ET AL. An experimental investigation on the bending behavior of flexible pipes, In: Proceedings of $22^{\text {nd }}$. International conference on offshore mechanics and artic engineering, Cancun, OMAE 03, 2003.

UNICAMP-DPE, 2004 (DEPARTAMENTO DE ENGENHARIA DE PETRÓLEO), Disponível em:<www.dep.fem.unicamp.br/boletim/BE13> Acesso em: 12 nov. 2006.

UKOOA WORK GROUP. State of the art flexible riser integrity issues. Study Report feito por Ukooa para MCS International. 2001.

VALADEZ-GONZALEZ, A.; CERVANTES, J. M.; VELEVA, L. Mineral filler influence on the photo-oxidation of high density polyethylene: I. Accelerated UV chamber exposure test. Polym. Degrad. Stabil. v. 3, n. 63. p. 253-260. 1999. 
VALADEZ-GONZALEZ, A.; VELEVA, L. Mineral filler influence on the photo-oxidation mechanism degradation of high density polyethylene. Part II: natural exposure test. Polym. Degrad. Stabil. v. 83, p. 139-148. 2004.

VAN VLACK, L. H. Princípios de ciência e tecnologia dos materiais. 4ed. Rio de Janeiro, Elsevier Editora Ltda, 1984. 567 p.

WARD, I. M.; SWEENEY, J. A introduction to the mechanical properties of solid polymers. 2ed. London. John Wiley \& Sons Ltda. 2004, 382p.

WESTERGAARD, H. M. Bearing pressures and cracks. J. Appl. Mech., Trans. ASME 6 A49-A53, 1939.

WHITE, J. R.; TURNBULL. A. Weathering of polymers: mechanisms of degradation and stabilization, testing strategies and modelling. J. Mater. Scien, v. 29, p. 584-613, 1994.

WITZ, J. A.; TAN, Z. On the axial-torsional structural behaviour of flexible pipes, umbilicals and marine cables. Mar. Struct.,v. 5, p. 205-227, 1992.

WITZ, J. A.; TAN, Z. On the flexural structural behaviour of flexible pipes, umbilicals and marine cables. Mar. Struct. v. 5, p. 229-249, 1992.

WITZ, J. A.; TAN, Z. Rotary bending of marine cables and umbilicals. Eng Struct. v. 17, n. 4 , p. 267-275, 1995.

WYATT, O. H.; HUGHES, D. D. Metals, ceramics and polymers: An introduction to the structure and properties of engineering materials. London: Cambridge University Press, 1974. 640p.

ZHURKHOV, S. N.; THOMASHEVSKII, E. E., Physical basis of yield and fracture. Conf. Ser. 1. Inst. Phys. Physical Soc. Oxford, 1966.

API 17E-98, Specification for sub sea production control umbilicals.

ASTM D 570-98. Standard Test Method for Water Absorption of Plastics.

ASTM D 638-03. Standard Test Method for Tensile Properties of Plastics.

ASTM D 1141-98. Standard Practice for the Preparation of Substitute Ocean Water.

ASTM D 2240-03. Standard Test Method for Rubber Property - Durometer Hardness.

ASTM D 4329-99. Standard Practice for Fluorescent Ultraviolet Exposure of Plastics.

ASTM G 154-00a. Standard practice for operating fluorescent light apparatus for ultraviolet exposure of nonmetallic materials.

ISO 62:1999, Plastics-Determination of Water Absorption 
ISO 10423:2003, Petroleum and natural gas industrie-Drilling and production equipment - Wellhead and Christmas Tree equipment.

ISO 13705:2006, Petroleum, petrochemical and natural gas industries - Fired heaters for general refinery service. 


\section{APÊNDICES}




\section{APÊNDICE A}

BANCADA PARA DE ENSAIOS DE FADIGA DOS CABOS UMBILICAIS SEGUNDO A NORMA API 17E
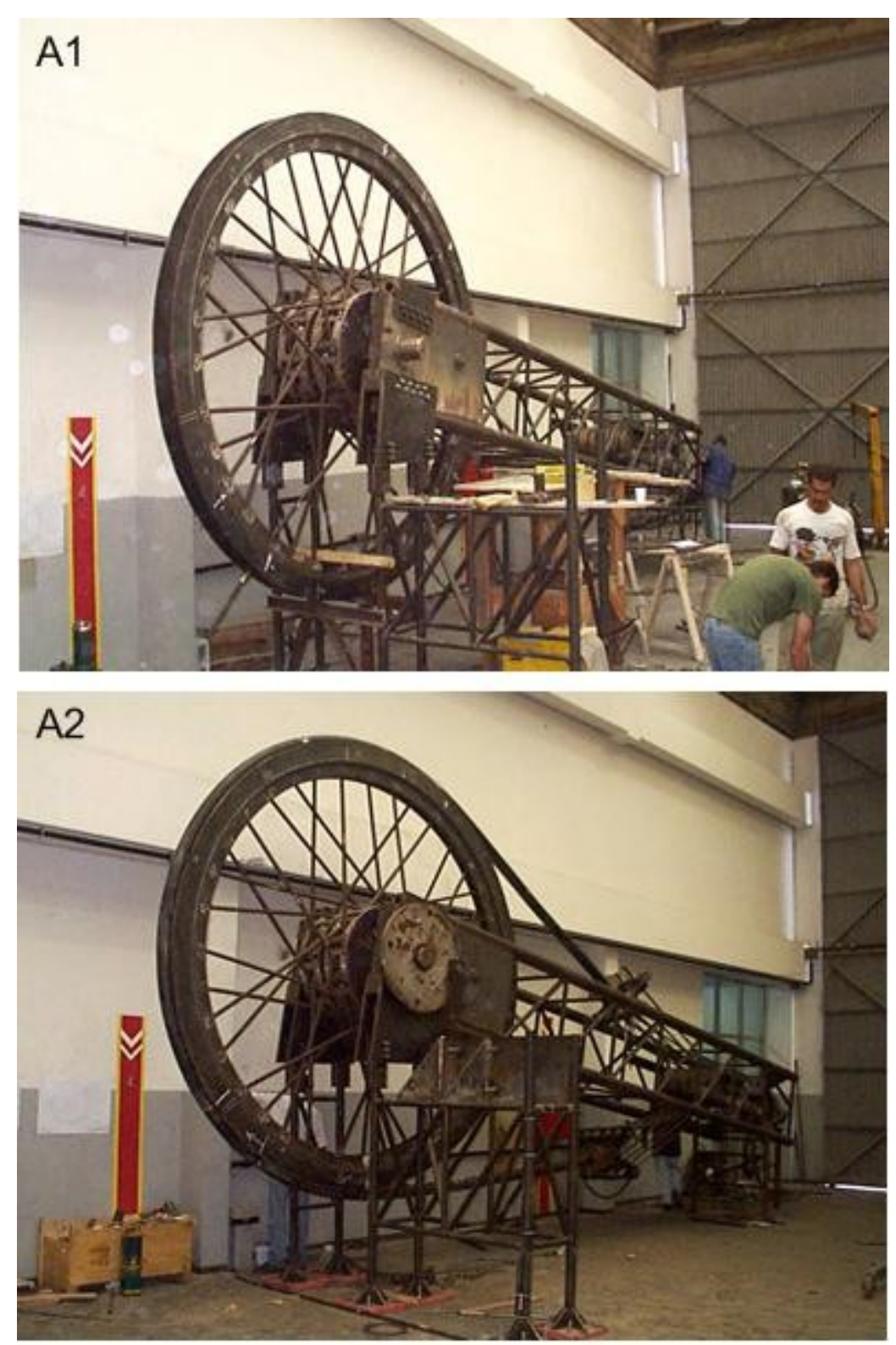

Figura A1 - Foto da bancada de ensaio à fadiga do cabo segundo API17E (CÁRDENAS, 2002).

Figura A2 - Foto da bancada de ensaio com corpo de prova montado (LÉPORE, 2003). 

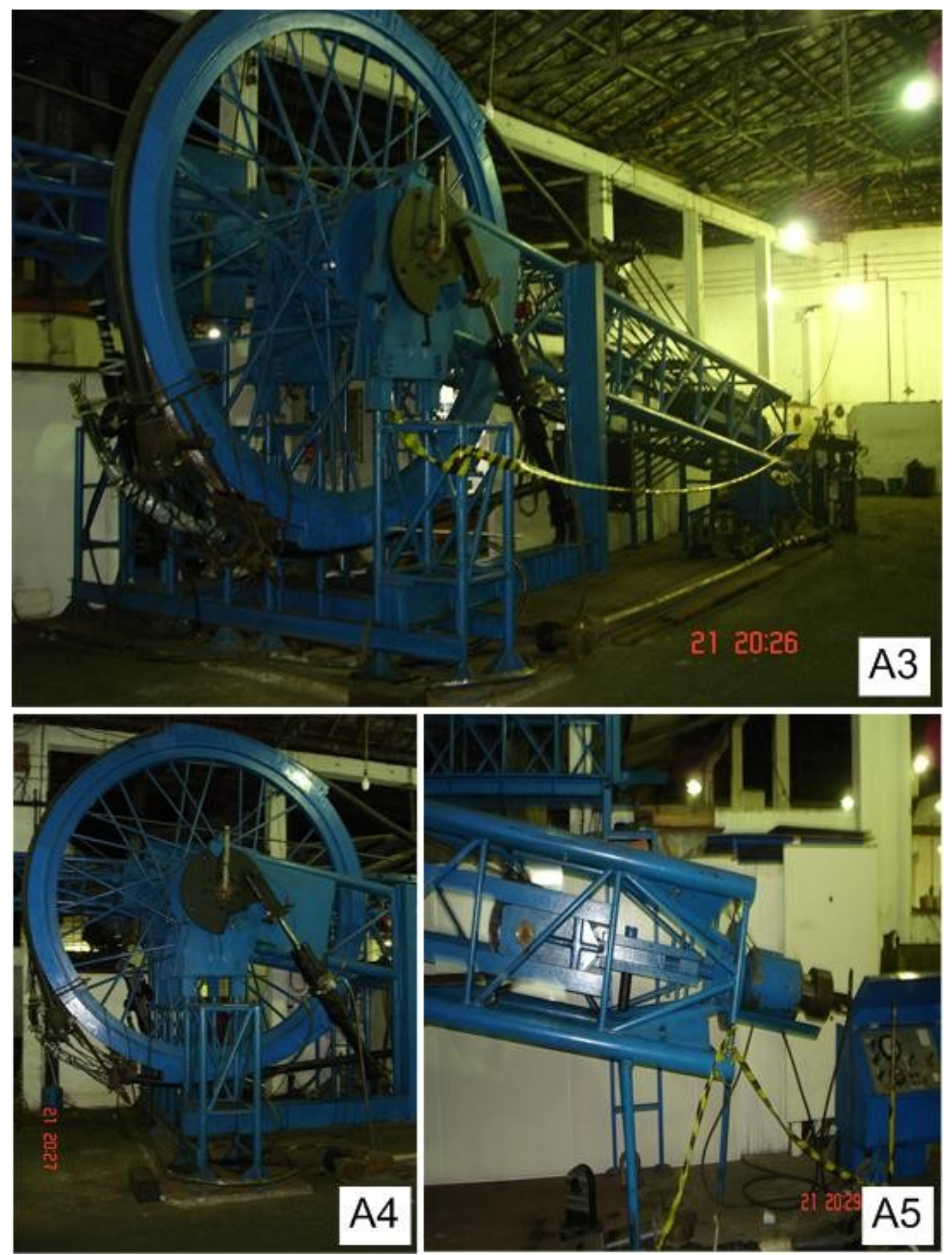

Figura A3 - Ensaio á fadiga do cabo segundo a norma API 17E em andamento.

Figura A4 - Módulos Roda e Acionamento da bancada de ensaio.

Figura A5 - Módulo de tração da bancada de ensaio. 


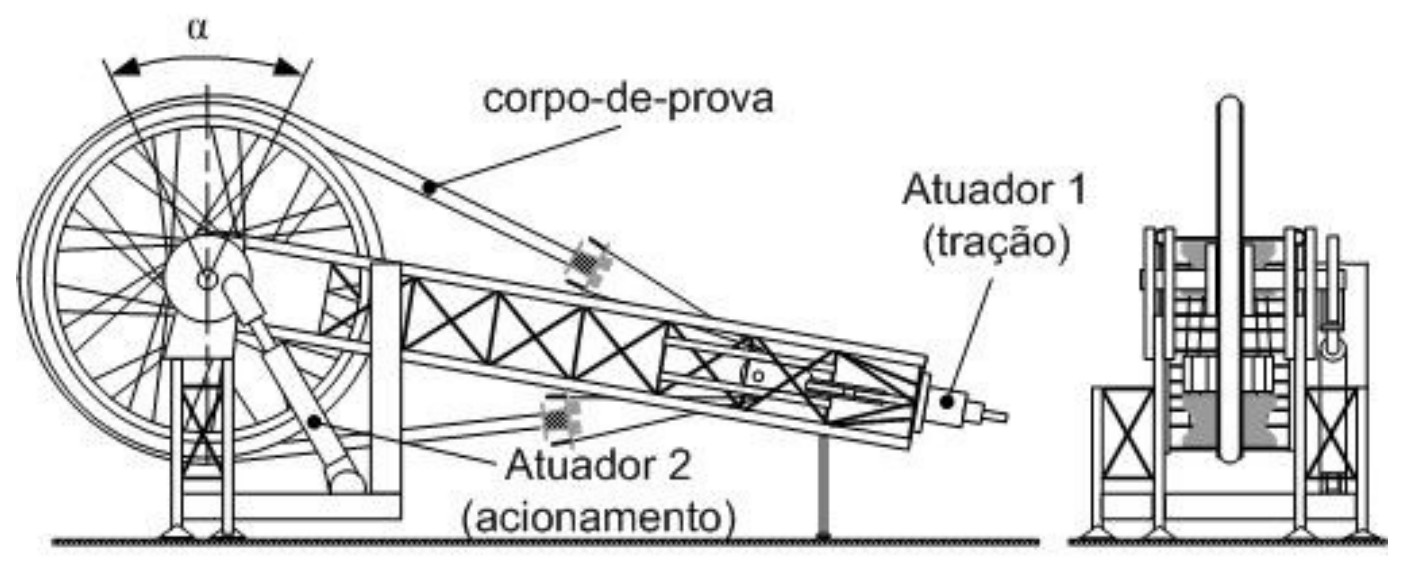

Figura A6 - Esquema da bancada para ensaio de fadiga segundo a norma API 17E

Tabela A1 - Características técnicas da bancada de ensaio de fadiga fabricada segundo a norma API 17E

\begin{tabular}{|l|r|}
\hline Capacidade de carga do Atuador 1 & $2.000 \mathrm{kN}$ \\
\hline Capacidade de carga do Atuador 2 & $180 \mathrm{kN}$ \\
\hline Curso máximo do atuador 2 & $0,5 \mathrm{~m}$ \\
\hline Raio da roda & $1,8 \mathrm{~m}$ \\
\hline Ângulo de movimento alternado $(\alpha)$ & $60^{\circ}$ \\
\hline Comprimento da bancada & $12 \mathrm{~m}$ \\
\hline Altura da bancada & $4 \mathrm{~m}$ \\
\hline Largura da bancada & $1,5 \mathrm{~m}$ \\
\hline Peso da bancada & $6.000 \mathrm{~kg}$ \\
\hline
\end{tabular}




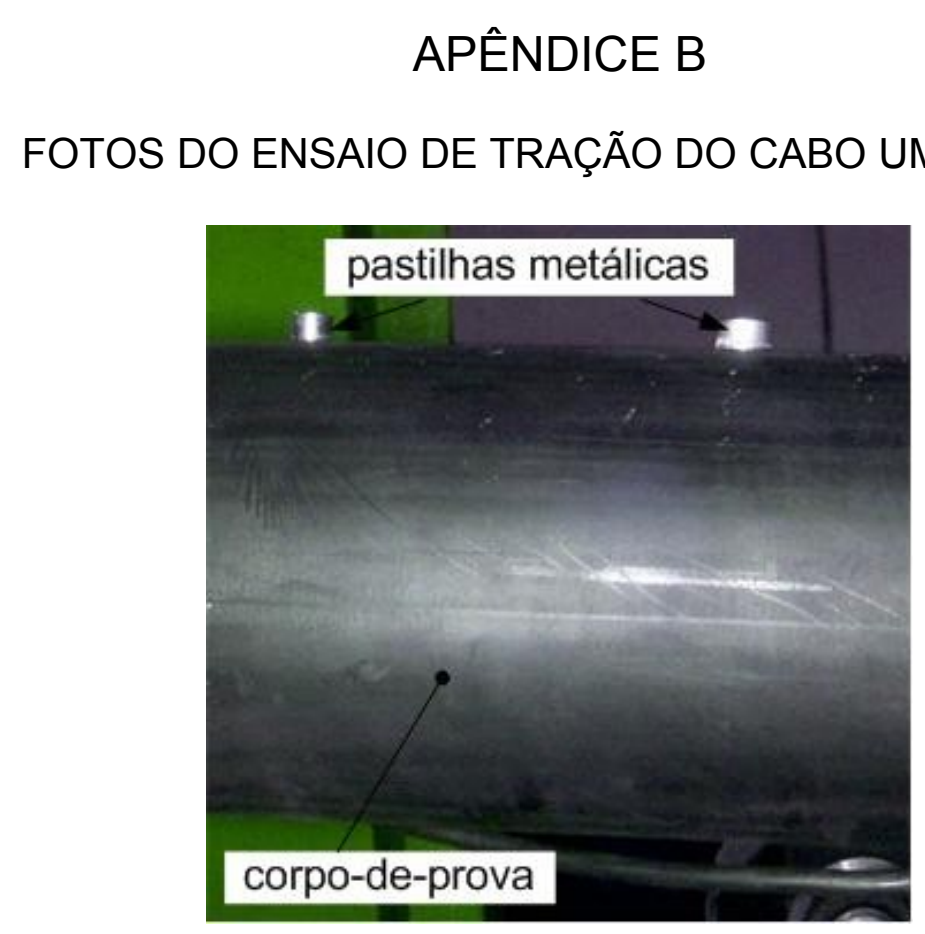

Figura B1 - Foto do corpo de prova instrumentado para ensaio de tração do cabo umbilical

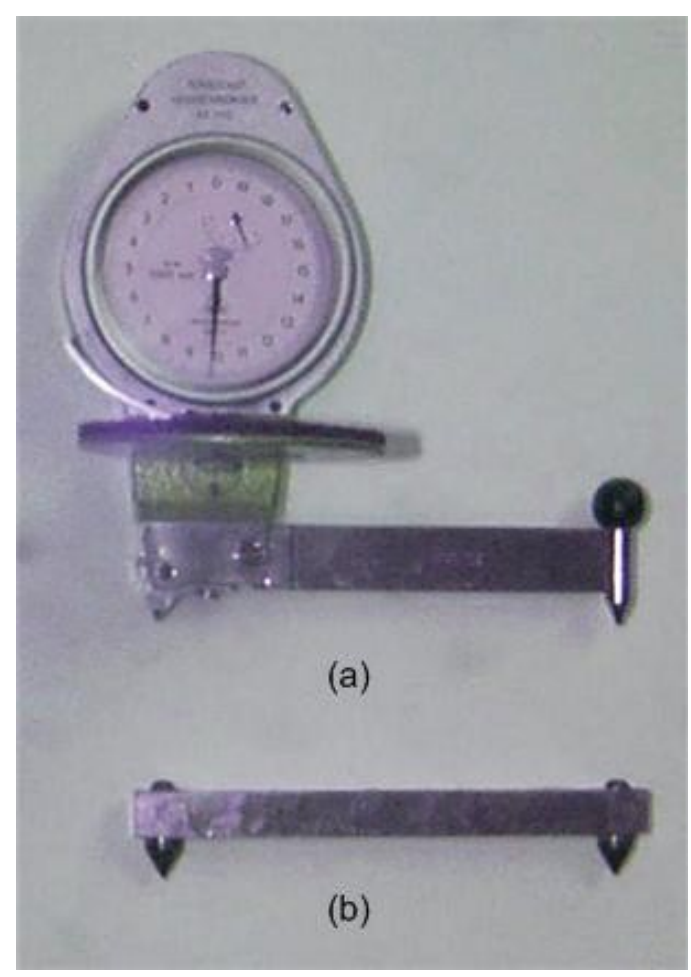

Figura B2 - Fotos do extensômetro mecânico e da base usados para medir a deformação durante o ensaio de tração do cabo umbilical 


\section{APÊNDICE C \\ DETERMINAÇÃO DAS TENSÕES RESIDUAIS A QUE ESTÁ SUBMETIDA A CAMADA EXTERNA DO CABO UMBILICAL}

Para o cálculo das tensões residuais principais usaram-se os resultados dos itens 4.2.1 e 4.4.2. Substituindo os dados obtidos experimentalmente nos ensaios desconfinamento e de tração instrumentado $\left[\varepsilon_{A}=2.300 \mu \mathrm{m} / \mathrm{m}\right.$ (deformação longitudinal), $\quad \varepsilon_{B}=1.509 \mu \mathrm{m} / \mathrm{m}$ (deformação $45^{\circ}$ ), $\quad \varepsilon_{C}=245 \mu \mathrm{m} / \mathrm{m}$ (deformação circunferencial), $v=0,48$ e $E=708,78 \mathrm{MPa}$ ] nas eq.(C.1) e eq.(C.2) (DALLY; RILEY, 1978) se obtém os valores das tensões residuais principais.

$$
\begin{gathered}
\sigma_{1}=E\left[\frac{\varepsilon_{A}+\varepsilon_{C}}{2(1-v)}+\frac{1}{2(1+v)} \cdot \sqrt{\left(\varepsilon_{A}-\varepsilon_{C}\right)^{2}+\left(2 \varepsilon_{B}-\varepsilon_{A}-\varepsilon_{C}\right)^{2}}\right] \\
\sigma_{1}=2,239 \cdot 10^{6} P a \\
\sigma_{2}=E\left[\frac{\varepsilon_{A}+\varepsilon_{C}}{2(1-v)}-\frac{1}{2(1+v)} \cdot \sqrt{\left(\varepsilon_{A}-\varepsilon_{C}\right)^{2}+\left(2 \varepsilon_{B}-\varepsilon_{A}-\varepsilon_{C}\right)^{2}}\right] \\
\sigma_{2}=1,230 \cdot 10^{6} P a
\end{gathered}
$$

Os valores das tensões residuais principais calculados foram a tensão residual máxima principal de 2,239 MPa, e a tensão residual mínima principal de 1,23 MPa. 


\section{APÊNDICE D}

\section{FOTOS DO ARRANJO PARA ENSAIOS DE ENVELHECIMENTO}
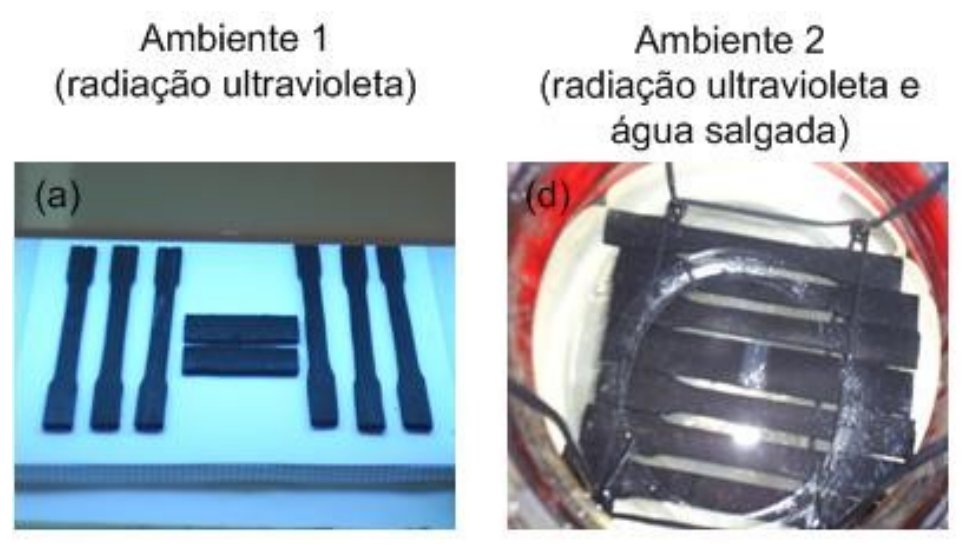

Ambiente 3

(água salgada)
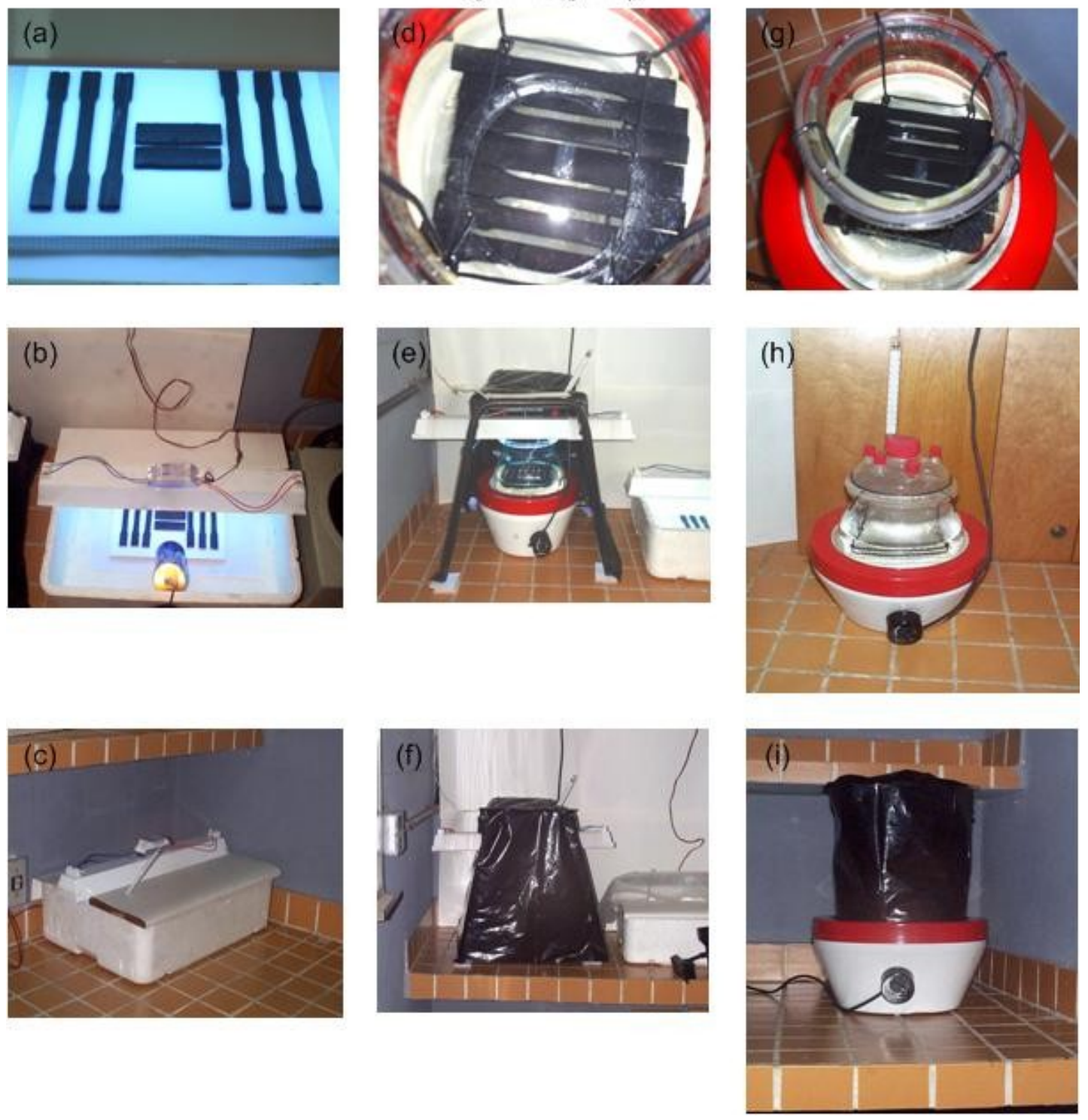

Figura D1 - Arranjo para ensaios de envelhecimento: (a) (b) e (c), mostra os corposde-prova no primeiro ambiente; (d), (e) e (f), mostra o segundo ambiente; (g), (h) e (i), mostra o terceiro ambiente 


\section{APÊNDICE E}

FOTO DE ALGUNS DOS ESPÉCIMES APÓS DE ENSAIADOS À TRAÇÃO

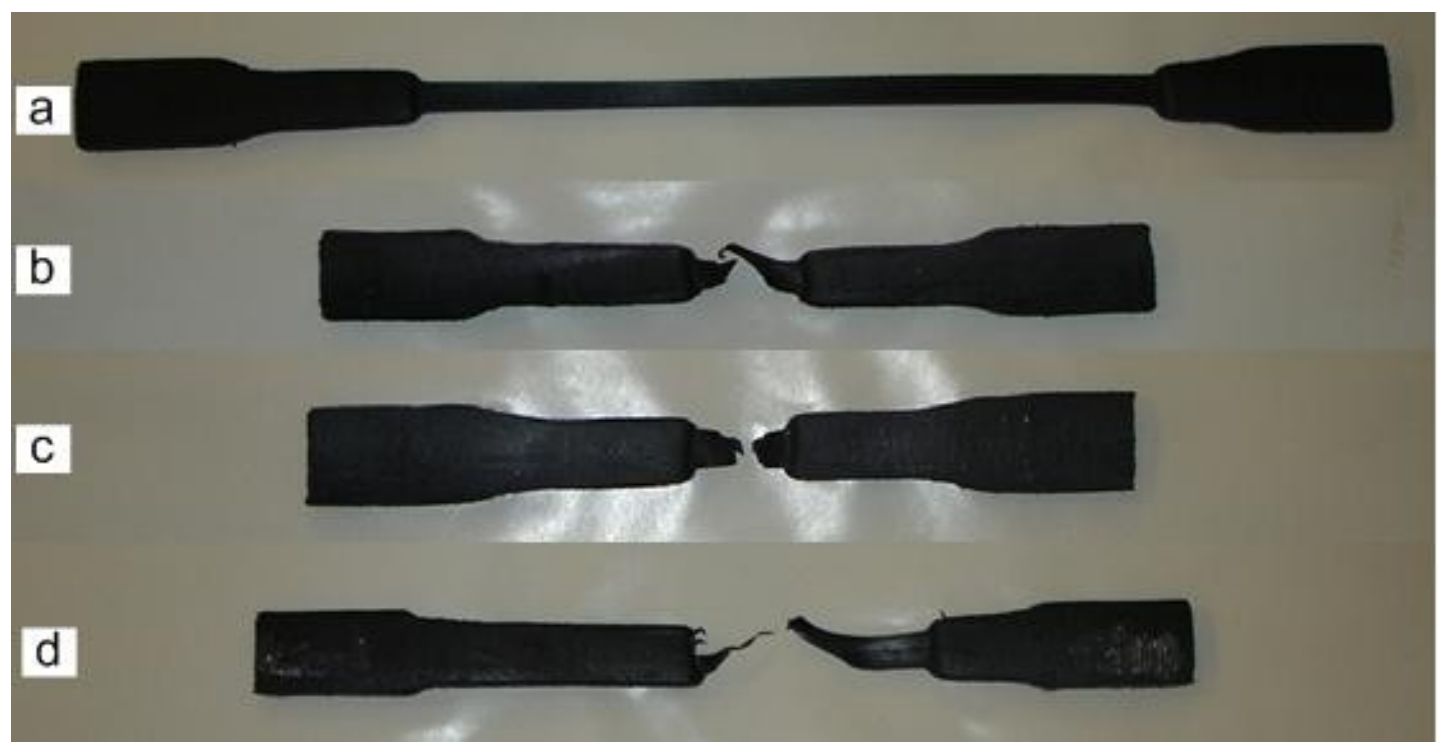

a- Corpo de prova elaborado com amostra da camada externa do cabo sem uso.

b- Corpo de prova elaborado com amostra da camada externa do cabo que foi submetido a 30.000 ciclos de carregamentos segundo a norma API 17E.

c- Corpo de prova que foi submetido a 30.000 ciclos de carga uniaxial.

d- Corpo de prova que foi submetido a 10.000 ciclos de carga uniaxial. 